

\section{INVESTIGACIONES EN EDUCACIÓN SUPERIOR Implicaciones y desafíos del estudiante universitario}


Esta obra fue dictaminada por pares académicos a través del método a doble ciego.

\section{INVESTIGACIONES EN EDUCACIÓN SUPERIOR \\ Implicaciones y desafíos del estudiante universitario}

1era. edición, octubre 2021

ISBN 978-607-8694-16-7

DOI 10.29410/QTP.21.14

D.R. (C) 2021. Qartuppi, S. de R.L. de C.V.

Villa Turca 17, Villas del Mediterráneo

Hermosillo, Son. 83220 México

http://www.qartuppi.com

Edición: Qartuppi, S. de R.L. de C.V.

Diseño: Catalina Guiffo Cardona

Fotografía de portada: Jazper Ong, Scop.io 


\section{Contenido}

$7 \quad$ Acerca de los coordinadores

$8 \quad$ Acerca de los evaluadores

9 Presentación

María Luisa Avalos Latorre

12 Capítulo 1

Caracterización de los hábitos alimentarios

en estudiantes de medicina

Andrea Itzel Santillán León y María Paulina Vázquez López

27 Capítulo 2

Caracterización de la actividad física de estudiantes universitarios

Erik Emmanuel Zúñiga Flores, Isaac Emmanuel Jauregui Rodríguez

y Daniel Alejandro López Hidalgo

$45 \quad$ Capítulo 3

Conducta prosocial y rendimiento académico

en estudiantes universitarios

María Luisa Avalos Latorre, Roberto Oropeza Tena, José Carlos Ramírez Cruz y Nancy Patricia Valencia Silva 
60 Capítulo 4

Estrés académico, características sociodemográficas y escolares en estudiantes de medicina

Ana Laura Rodríguez Hernández, Brandon Ruiz Espinoza

y Daniela Berenice Sandoval Campos

75 Capítulo 5

Consumo de alcohol, depresión y ansiedad en jóvenes universitarios

Ana Luisa Alejandre Alcantar, Jennifer Daana Ávila Cervantes, Javier González Guzmán, Estefania Ochoa Montañez $y$ Roberto Oropeza Tena

92 Capítulo 6

Identificación de hábitos de consumo y su relación con la autoestima en estudiantes universitarios

Arlet Estephani Hernandez Mendez, Nataly Consuelo Pérez Valdovinos, Mariana Paulina Alcantar Zavala, Yuri Guadalupe Zenteno Rios, Michelle Yelena González Sánchez y Roberto Oropeza Tena

110 Capítulo 7

Conocimientos y actitudes hacia el autoexamen de mama de mujeres universitarias

Alexa Fernanda Leal Fregoso, Sergio Antonio Vázquez Claro, Martin Ricardo Gutiérrez Jiménez y Diana Carolina Ramírez Ruvalcaba 
128 Capítulo 8

Estilo de vida en estudiantes universitarios

Alicia Abundis Gutiérrez, Joel Omar González Cantero

$y$ Víctor Hugo González Becerra

145 Capítulo 9

Evaluación de la práctica profesional en psicología de la salud en San Luis Potosí, desde la experiencia de psicólogos en formación Karina Guadalupe Noyola Luna, Alejandro Chávez Rodríguez, Dulce María Galarza Tejada y Silvia Larisa Méndez Martínez

171 Capítulo 10

Disponibilidad tecnológica, proceso de enseñanza e impacto psicológico en universitarios durante el confinamiento por COVID-19

María Luisa Avalos Latorre, Nayeli Amairani Mendoza Ramírez, Miguel Ángel Sosa Ibarra, Alejandro Chávez Rodríguez y Neyda Ma. Mendoza Ruvalcaba 


\section{Acerca de los coordinadores}

\section{María Luisa Avalos Latorre}

Licenciada en Psicología, Maestra en Ciencias del Comportamiento Opción Análisis de la Conducta, Doctora en Psicología. Posdoctorado Universidad Michoacana de San Nicolás de Hidalgo. Profesora investigadora titular en el Centro Universitario de Tonalá de la Universidad de Guadalajara. Miembro del Sistema Nacional de Investigadores (nivel I). Perfil prodep. Co-coordinadora de la Red Nacional de Procesos Psicosociales, Clínica y Salud del Sistema Nacional de Investigadores en Psicología. Coordinadora de la Red de Cuerpos Académicos Educación, Salud y Sociedad Sustentable.

\section{Roberto Oropeza Tena}

Licenciado en Musicología por la Escuela de Liturgia, Música y Arte "Cardenal Miranda”. Licenciado en Psicología, Maestro en Análisis de la Conducta y Doctor en Psicología (Área de la Salud). Profesor investigador titular "B” en la Facultad de Psicología de la Universidad Michoacana de San Nicolás de Hidalgo. Miembro del Sistema Nacional de Investigadores (nivel I). Perfil Prodep. Director General de Uaricha, Revista de Psicología. Profesor de Asignatura en la licenciatura de Música y Tecnologías Artísticas de la Escuela Nacional de Estudios Superiores (campus Morelia) de la Universidad Nacional Autónoma de México (UNAM).

\section{Marcela Janette Colunga González}

Licenciada en Psicología, estudiante de la Maestría en Ciencias de la Salud en el Trabajo de la Universidad de Guadalajara. Tema de investigación: estrés laboral y salud mental en docentes universitarios. 


\section{Acerca de los evaluadores}

\section{Cecilia Colunga Rodríguez}

Licenciada en Psicología por la Universidad de Guadalajara, Maestra y Doctora en Ciencias de la Salud Pública por la Universidad de Guadalajara. Miembro del Sistema Nacional de Investigadores (nivel I) desde 2007. Perfil deseable PRODEP. Investigadora en el Hospital de Pediatría del Centro Médico Nacional de Occidente del Instituto Mexicano del Seguro Social. Profesora investigadora del Departamento de Salud Pública del Centro Universitario de Ciencias de la Salud (cucs), Universidad de Guadalajara. Fue Coordinadora del Doctorado Interinstitucional en Psicología del 2008 al 2016. Profesora y excoordinadora de investigación en la Escuela Normal Superior de Jalisco. Miembro del Colegio de Profesionales de la Psicología del Estado de Jalisco. Miembro de la Academia Jalisciense de Ciencias y del Sistema Mexicano de Investigación en Psicología. Premio al Mejor Promedio de su generación en la licenciatura. Premio Jalisco de Psicología 2008 y Premio Mexicano de Psicología 2012. Línea de investigación: Factores psicosociales en enfermedades crónicas.

\section{Mario Ángel González}

Maestría en Ciencias de la Educación con línea terminal en Pedagogía. Doctor en Psicología por la Universidad de Guadalajara. Posdoctorado Universidad Autónoma de Aguascalientes, exbecado conacyt. Profesor investigador del Centro Universitario de Tonalá de la Universidad de Guadalajara. Catedrático en la Escuela Normal Superior de Jalisco. Responsable del Cuerpo Académico Consolidado UDG-CA 958 "Procesos Educativos, Salud y Trabajo". Presidente de la Asociación de Investigadores para el Desarrollo Humano Sustentable A.C., Miembro del Sistema Nacional de Investigadores y del Sistema Mexicano de Investigadores en Psicología. Presidente de la Red de Cuerpos Académicos e Investigadores para el Desarrollo Humano Sustentable. Estancias de investigación en la Universidad de Tokio en Japón, en la Facultad de Ciencias Psicológicas de la Universidad Central del Ecuador y en la Universidad HEC de Montreal, Canadá. 


\title{
Presentación
}

\author{
María Luisa Avalos Latorre
}

Investigaciones en educación superior: implicaciones y desafíos del estudiante universitario es producto de la suma de esfuerzos de investigadores de reconocido prestigio nacional y del trabajo en conjunto con sus alumnos, quienes a través de sus investigaciones explican algunas realidades del estudiante universitario. Asimismo, participaron expertos en el área de la investigación, de la psicología y de la educación como revisores de la obra con el fin de asegurar la calidad y validez de la información.

A través de los diez capítulos que conforman la obra, el lector tendrá la oportunidad de ampliar su conocimiento acerca de las condiciones y circunstancias en el que el estudiante universitario realiza sus estudios profesionales.

Estos estudiantes se enfrentan a grandes retos, ya que una vez que ingresan al contexto universitario deben cambiar su estilo de vida para adaptarse a las exigencias escolares. Dichas exigencias pueden conllevar adversidades y riesgos importantes tanto para su salud como para desempeñarse adecuadamente en sus estudios.

En el primer capítulo, "Caracterización de los hábitos alimentarios en estudiantes de medicina", los autores realizan una investigación cuantitativa y evalúan a 150 jóvenes a través de un cuestionario y de la toma de medidas antropométricas; en sus resultados, la accesibilidad a los alimentos es un factor importante para las elecciones que realizan.

En el segundo capítulo, "Caracterización de la actividad física de estudiantes universitarios", los autores analizaron las actividades físicas que llevan a cabo estudiantes de diferentes carreras de una universidad pública. Emplearon una metodología cuantitativa para evaluar a 138 jóvenes a través de un cuestionario y la toma de medidas antropométricas. Entre sus hallazgos, encontraron que los alumnos con mayor nivel de actividad física presentaron un índice mayor de IMC y que entre más avanzan en sus estudios, menos actividad física realizan.

El tercer capítulo titulado "Conducta prosocial y rendimiento académico en estudiantes universitarios" es producto de actividades colaborativas de investigadores de distintas 
instituciones, quienes emplearon una metodología cuantitativa para analizar las diferencias y la relación entre la conducta prosocial y el rendimiento académico en 328 jóvenes universitarios, a través de la aplicación de un cuestionario. Los autores observaron que el involucramiento de los estudiantes en actividades prosociales beneficia al rendimiento académico.

En el cuarto capítulo, "Estrés académico, características sociodemográficas y escolares en estudiantes de medicina”, los autores presentan los resultados de la evaluación realizada a 300 estudiantes, a través del Inventario sisco del Estrés Académico. Los resultados muestran, entre otras cosas, que los primeros años de la carrera pueden resultar más abrumadores para el alumno, aunado a que las mujeres estudiantes universitarias son más vulnerables a este padecimiento.

En el quinto capítulo titulado "Consumo de alcohol, depresión y ansiedad en jóvenes universitarios", se presentan los resultados de una investigación cuantitativa, en la cual se evaluaron a 200 estudiantes universitarios, a través del Cuestionario CAGE para el consumo de alcohol, la Escala de Depresión de Zung y la Escala de Ansiedad de Hamilton. Los autores observaron que poco más de una tercera parte de los estudiantes de esta muestra tiene un consumo peligroso del alcohol, siendo los hombres estudiantes universitarios los de mayor consumo.

El sexto capítulo titulado "Identificación de hábitos de consumo y su relación con la autoestima en estudiantes universitarios" muestra los resultados de un estudio llevado a cabo mediante un diseño transversal, de tipo descriptivo y correlacional, en el cual se evaluaron a 200 estudiantes de psicología, quienes respondieron la Escala de Hábitos y Conductas de Consumo, así como la Escala de Autoestima de Rosenberg. Los autores concluyeron que la mayoría de los universitarios mostraron hábitos concretos para planificar sus compras y plantean la necesidad de ejecutar acciones sobre educación económica.

En el séptimo capítulo titulado "Conocimientos y actitudes hacia el autoexamen de mama de mujeres universitarias" se muestran los resultados de un estudio cuantitativo, en el que participaron 130 estudiantes mujeres universitarias, a quienes se les aplicó el Cuestionario de Conocimiento sobre Autoexploración Mamaria. Los autores observaron que las participantes estudiantes universitarias cuentan con un conocimiento parcial del cáncer de mama y la técnica de autoexploración, y al igual que otras poblaciones, 
también se evidencian actitudes que obstaculizan la búsqueda y aceptación de estos términos o conceptos.

El octavo capítulo titulado "Estilo de vida en estudiantes universitarios" es un estudio realizado por tres investigadores quienes evaluaron, a través del cuestionario FANTASTIC, a 169 estudiantes universitarios de primer y segundo semestre, e identificaron un patrón claro de relación del estilo de vida con la composición corporal, el ejercicio activo y la nutrición, aunque también el estrés se hizo presente en la población estudiada.

En el noveno capítulo titulado "Evaluación de la práctica profesional en psicología de la salud en San Luis Potosí, desde la experiencia de psicólogos en formación" se presentan los resultados de un estudio con un enfoque cualitativo, en el que participaron 19 psicólogos en formación, quienes a través de la técnica de entrevista semiestructurada y grupos focales indicaron que los espacios de prácticas se pueden mejorar para que los interesados en la práctica de la psicología de la salud cuenten con mejores oportunidades y un mejor aprovechamiento en el aprendizaje de la psicología, que aporta valioso apoyo a la salud pública.

Finalmente, el décimo capítulo titulado "Disponibilidad tecnológica, proceso de enseñanza e impacto psicológico en universitarios durante el confinamiento por COviD-19", presenta los resultados de un estudio cuantitativo, transversal y analítico, en el cual se analizan dichas variables en 636 estudiantes universitarios, a través de una ficha de datos y una lista de cotejo sobre impacto psicológico del covid-19 (ad-hoc), los cuales se respondieron en línea durante el 1 de junio al 25 de julio de 2020, dos meses y medio después de la suspensión de actividades escolares presenciales en México. Los autores observaron que la carga académica, el semestre escolar y la percepción de dificultad de las actividades escolares afectan el bienestar psicológico de los estudiantes universitarios.

Esperamos que los hallazgos y recomendaciones aquí vertidas sean suficientes para motivar los estudios sobre esta población y que abone no solo al conocimiento del tema sino a la generación de próximas investigaciones que favorezcan una adecuada calidad de vida de los alumnos, al cuidado de su integridad y a una trayectoria escolar placentera y enriquecedora. 


\title{
CAPÍTULO 1
}

\section{Caracterización de los hábitos alimentarios en estudiantes de medicina}

\author{
Andrea Itzel Santillán León \\ y María Paulina Vázquez López
}

La alimentación es un elemento muy importante para una buena salud, en ella influyen la calidad de los alimentos, la cantidad que se consume y los hábitos alimentarios. De acuerdo con la Organización de las Naciones Unidas para la Alimentación y la Agricultura (FAO, s.f.), los hábitos alimentarios sanos son un "conjunto de costumbres que condicionan la forma como los individuos o grupos seleccionan, preparan y consumen los alimentos, influidos por la disponibilidad de estos, el nivel de educación alimentaria y acceso a los mismos" (p.130).

Por otro lado, los hábitos alimentarios malos son aquellos en los que no hay un consumo de alimentos adecuados, no se cumple con los requerimientos necesarios para el buen funcionamiento del cuerpo y todas las necesidades fisiológicas, se da una ingesta excesiva de alimentos ricos en grasas y, aun cuando no dejan de ser alimento, no son lo suficientemente nutritivos (Pereira \& Salas, 2017). Toda esta variabilidad en el consumo de los alimentos puede llevar a distintos trastornos con afecciones en la salud, uno de ellos es "la malnutrición considerada por déficit o por exceso, [que] afecta a una gran parte de la población y está condicionada a factores sociales, económicos y políticos que influyen en la disponibilidad, consumo y aprovechamiento biológico de los alimentos" (Vargas et al., 2010, p.117).

Según la oms (2016b), la combinación de comida rápida y gaseosa, que se presenta de manera frecuente, aumenta el riesgo de enfermedades como la obesidad y el sobrepeso en niños y jóvenes que pueden conllevar a otras enfermedades crónicas como la diabetes. Al respecto, de acuerdo con el Informe mundial sobre la diabetes (oms, 2016c), 


\section{CAPÍTULO 1}

422 millones de adultos en todo el mundo tenían diabetes en 2014, frente a los 108 millones de 1980. La prevalencia mundial (normalizada por edades) de la diabetes casi se ha duplicado desde ese año, pues ha pasado del $4.7 \%$ al $8.5 \%$ en la población adulta. En México, las cifras de sobrepeso y obesidad, según el Instituto Nacional de Salud Pública (INSP, 2017), muestran que casi 4 de cada 10 adolescentes presenta sobrepeso u obesidad, logrando un aumento de $36.3 \%$, mientras que en 2012 esta cifra era de $34.9 \%$.

Los jóvenes son un sector de la población muy vulnerable a desarrollar trastornos de alimentación, ya que la mayoría de ellos llevan una dieta excesivamente rica en azúcares añadidas, esto además de causarles trastornos de salud, también influye en el ámbito psicológico, ya que están expuestos ante los criterios sociales de belleza y aceptación, y a esto se le suma la poca o nula actividad física que realizan (Méndez et al., 2008).

Dadas las implicaciones que los hábitos de alimentación inadecuados conllevan en población joven, resulta importante llevar a cabo investigaciones en este sector de la población. El grueso poblacional de jóvenes se ubica en la etapa universitaria, ya que suele abarcar desde los 17 hasta los 25 años de edad; por esta razón, se debe considerar al estudiante universitario. La adaptación al ambiente universitario "representa un conjunto de situaciones altamente estresantes porque el individuo puede experimentar [...] transitoriamente, una falta de control sobre el nuevo ambiente" (Fisher, 1984 como se citó en Nieves et al., 2013, p.101). "La población universitaria se considera un colectivo especialmente vulnerable desde el punto de vista nutricional ya que comienza a responsabilizarse de su alimentación y atraviesa un período crítico en la consolidación de hábitos y conductas alimentarias" (Sánchez \& Aguilar, 2015, p.449).

El estilo de vida de los estudiantes se ve modificado con la inminencia del periodo de exámenes, incrementándose el consumo de cafeína, tabaco, sustancias psicoactivas como excitantes, incluso ingestión de tranquilizantes lo que, con el tiempo, puede llevar a la aparición de trastornos de salud. (Phinder-Puente et al., 2014, p.140)

Además, resulta conveniente abordar diferencialmente a esta población de acuerdo a la carrera que cursa, dada la diversidad de disciplinas/carreras a las que puede optar un estudiante universitario, y que, dicho sea de paso, están impregnadas de diversas 


\section{CAPÍTULO 1}

didácticas y metodologías de enseñanza-aprendizaje. El estudiante de medicina, en particular, se enfrenta a problemas financieros, abuso estudiantil, exceso de tareas, entre otras (Torres et al., 2016), por lo que suele experimentar cambios desfavorables en sus estilos de vida, sobre todo de alimentación, lo que puede provocar efectos significativos en la salud. Se considera que, en estos estudiantes, uno de los factores que más influye en el ámbito de la alimentación es la poca disponibilidad de tiempo para poder realizar sus comidas adecuadas, dentro de las horas que se debe y cuidando la calidad de sus alimentos, ya que por la demanda horaria de la carrera su estancia en la universidad es por tiempos muy prolongados, a esto se le añade la constante enmienda de tareas y materiales por estudiar, haciendo para el alumno una carga inmensa de trabajo, que le ocasiona trastornos de ansiedad, estrés y descuido de su alimentación (Duarte et al., 2015).

Investigaciones en torno al tema se han llevado a cabo, destaca la realizada por Rivera (2006), quien observó que la alimentación depende de factores económicos, publicitarios, ambientales, culturales y sociales. Por su parte, Contreras et al. (2013) afirman que los estudiantes eligen sus alimentos por la necesidad de satisfacer el hambre, de acuerdo con sus preferencias y a su economía, sin tomar en cuenta su aporte nutricional; coincidiendo con Duarte et al. (2015), también destacan la relevancia de dichas variables y observan que el tiempo del que disponen los jóvenes juega también un papel importante. Asimismo, Rosales et al. (2015) afirmaron que entre más tiempo pasan fuera de casa y están en la escuela, el consumo de alimentos nutritivos se reduce.

Existen otras investigaciones en las que se demuestra que las comidas rápidas y altas en grasas son las mayormente consumidas por los universitarios, sobre todo en semestres avanzados (Becerra et al., 2015; Torres et al., 2016), es decir, conforme avanzan en la carrera, empeoran sus hábitos alimentarios. Dada la importancia del tema y los pocos estudios al respecto en el contexto mexicano, el objetivo de nuestra investigación fue describir las características de los hábitos alimentarios en estudiantes de la carrera de medicina de una universidad pública. 


\section{CAPÍTULO 1}

\section{Método}

\section{Participantes}

Participaron voluntariamente 150 estudiantes de la carrera de Medicina, adscritos a una universidad pública, de ambos turnos y de ambos sexos, que cursaban el primero, tercero o quinto semestre; la edad promedio fue de 20.6 años $(\mathrm{DT}=2.2)$. Se excluyeron de la investigación a aquellos estudiantes que afirmaron consumir algún suplemento alimenticio, que estuvieran llevando a cabo una dieta especializada o que tenían diagnóstico de alguna enfermedad que los obligaba a llevar un régimen de dieta estricto.

\section{Instrumentos}

Se utilizó una ficha de datos, cuyo objetivo fue obtener información sociodemográfica, escolar y antropométrica tales como edad, semestre que cursaba y turno, también se registró la talla y peso, esto con la finalidad de obtener su índice de masa corporal (IMC), la cual es definida por la oms (2016a), como un indicador simple de la relación entre el peso y la talla que se utiliza frecuentemente para identificar el sobrepeso y la obesidad en los adultos. Se calcula dividiendo el peso de una persona en kilos por el cuadrado de su talla en metros.

También se empleó la Encuesta Nacional de Salud y Nutrición Medio Camino 2016 (INSP, 2017), que tiene como objetivo indagar sobre los alimentos consumidos durante la semana anterior a la aplicación de la encuesta y así determinar la frecuencia en que se consume cada grupo de alimento y sus porciones. El cuestionario está estructurado por 130 preguntas con siete opciones de respuesta en una escala que va de "Nunca" a "Siempre", además se incluye un apartado en donde se especifica la porción ingerida de cada alimento, cuya escala para responderlo es: "muy chica", "chica", "mediana", "grande", "muy grande" y "estándar"; finalmente, deben responder la frecuencia con la que se consumió cada alimento en los días mencionados, que va desde 1 a 6 veces. El tiempo promedio para responder la encuesta es de 60 minutos, es de tipo autoaplicable y se responde individualmente. Es un instrumento validado con un alfa de Cronbach de 0.87. La escala se divide en 17 subescalas que son las siguientes: Productos lácteos, Carnes, Cereales y tubérculos, Pescados y mariscos, Misceláneas, Frutas, Embutidos y huevo, Productos de maíz, Sopas, Verduras, Dulces y postres, Bebidas, Cremas y pastas, Comida rápida, Leguminosas, Botanas y Tortillas. 


\section{Equipo}

Para obtener las medidas antropométricas se utilizó una balanza más monitor de grasa corporal con porcentaje de agua corporal (Tanita Corporation ${ }^{\circledR}$ ) de 150 kilogramos de capacidad de peso, un estadiómetro portátil de alta precisión de hasta una talla de 205 centímetros marca SECA $213^{\circledR}$.

\section{Diseño y procedimiento}

Se trató de un estudio cuantitativo, transversal y descriptivo para determinar la frecuencia del consumo de alimentos en estudiantes de la carrera de medicina. La toma de datos se llevó a cabo dentro de los salones de clase, donde primero se les explicó a los participantes el propósito de la investigación, posteriormente, se les dio a conocer los términos del consentimiento informado, dejándoles claro que solo participarían si así lo deseaban; los estudiantes que estuvieron de acuerdo firmaron el consentimiento. Una vez firmado se les dio las instrucciones para responder la Encuesta Nacional de Salud y Nutrición Medio Camino y, una vez que quedaron claras, se procedió a responderla. Conforme concluyeron, se les tomaron las medidas de peso y talla.

\section{Consideraciones éticas}

La investigación se ajustó a los principios éticos de Helsinki (Asociación Médica Mundial, 2001), a los criterios del Reglamento de la Ley General de Salud en Materia de Investigación para la Salud (2014). Se tomó como consideración la ética, el anonimato y la confidencialidad de los participantes.

\section{Resultados}

De los 150 participantes, el 61\% fueron hombres y el resto mujeres. El 52\% asistía a la escuela en el turno matutino y el resto en el turno vespertino. Respecto a la distribución de la muestra por el semestre cursado, el 39\% eran de primer semestre, el 37\% de tercero y el $24 \%$ cursaban el quinto semestre. Referente a los resultados antropométricos, la estatura promedio fue de 1.7 metros ( $\operatorname{mín}=1.49$, máx $=2$, DT $=0.1)$, mientras que el peso promedio fue de 66.6 kilogramos ( $\operatorname{mín}=40$, máx $=130, \mathrm{DT}=15)$, el valor por IMC promedio fue de $23.5(\mathrm{DT}=4.6)$. 
Al comparar el estado por IMC de acuerdo con el género, observamos que casi la mitad de los varones se encontraron por arriba del IMC normal (tabla 1). Al comparar el estado por IMC de acuerdo al semestre cursado, observamos un incremento en la proporción de alumnos con sobrepeso y obesidad conforme avanzan los semestres (tabla 2). Finalmente, al comprar el estado de IMC por el turno escolar, observamos que el 37.5\% de los estudiantes del matutino están por arriba del valor normal, en contraposición con el 29.5\% de los estudiantes del vespertino (tabla 3).

\section{Tabla 1}

Tabla de contingencia de acuerdo con el sexo y al estado por IMC

\begin{tabular}{lccccc} 
& Peso bajo & Normal & Sobrepeso & Obesidad & Total \\
\hline Masculino & 3 & 32 & 20 & 4 & 59 \\
& $5.1 \%$ & $54.2 \%$ & $33.9 \%$ & $6.8 \%$ & $100.0 \%$ \\
Femenino & 10 & 54 & 19 & 7 & 90 \\
& $11.1 \%$ & $60.0 \%$ & $21.1 \%$ & $7.8 \%$ & $100.0 \%$ \\
Total & 13 & 86 & 39 & 11 & 149 \\
& $8.7 \%$ & $57.7 \%$ & $26.2 \%$ & $7.4 \%$ & $100.0 \%$ \\
\hline
\end{tabular}

\section{Tabla 2}

Tabla de contingencia de acuerdo con el semestre cursado y al estado por IMC

\begin{tabular}{lccccc} 
& Peso bajo & Normal & Sobrepeso & Obesidad & Total \\
Primero & 5 & 36 & 12 & 4 & 57 \\
& $8.8 \%$ & $63.2 \%$ & $21.1 \%$ & $7.0 \%$ & $100.0 \%$ \\
Tercero & 4 & 31 & 17 & 3 & 55 \\
& $7.3 \%$ & $56.4 \%$ & $30.9 \%$ & $5.5 \%$ & $100.0 \%$ \\
Quinto & 4 & 19 & 10 & 4 & 37 \\
& $10.8 \%$ & $51.4 \%$ & $27.0 \%$ & $10.8 \%$ & $100.0 \%$ \\
Total & 13 & 86 & 39 & 11 & 149 \\
& $8.7 \%$ & $57.7 \%$ & $26.2 \%$ & $7.4 \%$ & $100.0 \%$ \\
\hline
\end{tabular}


CAPÍTULO 1

\section{Tabla 3}

Tabla de contingencia de acuerdo al turno escolar y al estado por IMC

\begin{tabular}{lccccc} 
& Peso bajo & Normal & Sobrepeso & Obesidad & Total \\
Vespertino & 8 & 47 & 17 & 6 & 78 \\
& $10.3 \%$ & $60.3 \%$ & $21.8 \%$ & $7.7 \%$ & $100.0 \%$ \\
Matutino & 5 & 40 & 22 & 5 & 72 \\
& $6.9 \%$ & $55.6 \%$ & $30.6 \%$ & $6.9 \%$ & $100.0 \%$ \\
Total & 13 & 87 & 39 & 11 & 150 \\
& $8.7 \%$ & $58.0 \%$ & $26.0 \%$ & $7.3 \%$ & $100.0 \%$ \\
\hline
\end{tabular}

$\mathrm{Al}$ analizar la frecuencia de alimentos que consumen los universitarios y al compararlo entre hombres y mujeres, observamos que la mayoría de los hombres consumen prácticamente todos los días de la semana leche (55.9\%), en comparación con el 39.6\% de las mujeres. En ambos casos, la mitad del tiempo la prefieren con algún tipo de saborizante. Las mujeres consumen más frecuentemente quesos (59\% panela, 57.6\% quesos madurados), aproximadamente tres días a la semana, el $49.1 \%$ de los hombres come terciado queso panela y el $48.2 \%$ quesos madurados. El yogurt natural o con frutas es consumido entre 1 y 4 días a la semana por el 53\% y 53.6\% de las mujeres, el caso de los hombres, más del 50\% no consume este alimento. Aunado a ello, el 49.4\% de las mujeres consumen terciado yogurt para beber. Respecto a otros productos lácteos tales como el Danonino o Yakult, su consumo es nulo en la mayoría de los universitarios.

Respecto al grupo de frutas, en la figura 1 observamos la frecuencia de consumo en hombres y en mujeres; se aprecia que las mujeres consumen más frecuentemente frutas que los hombres. Los hombres comen con mayor frecuencia plátano, manzana, pera y fresas, mientras que las mujeres consumen manzana, pera, fresa, uvas, durazno, naranja y mandarina. 


\section{Figura 1}

Frecuencia de consumo de fruta en hombres y mujeres

\section{Hombres}

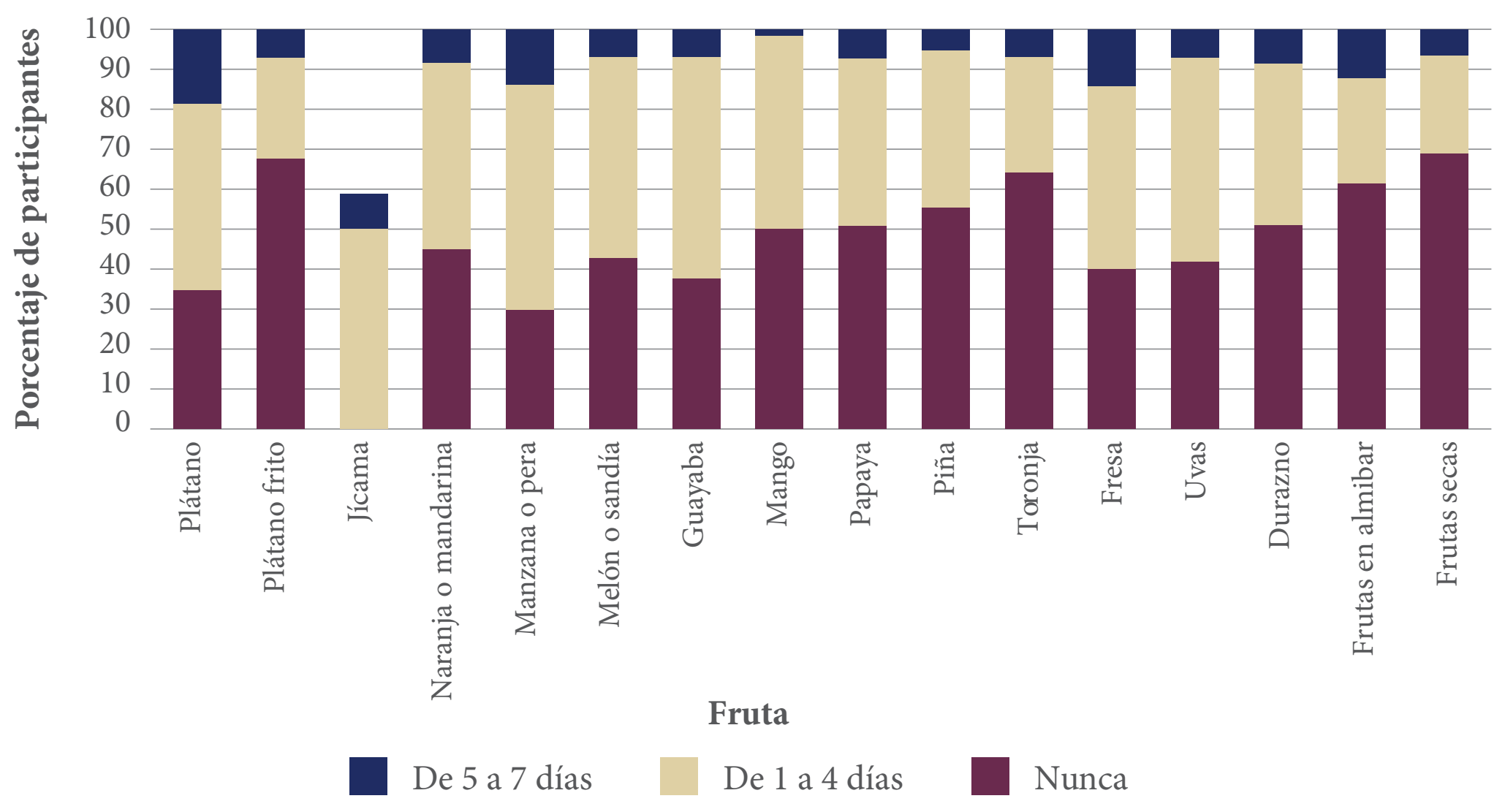

Mujeres

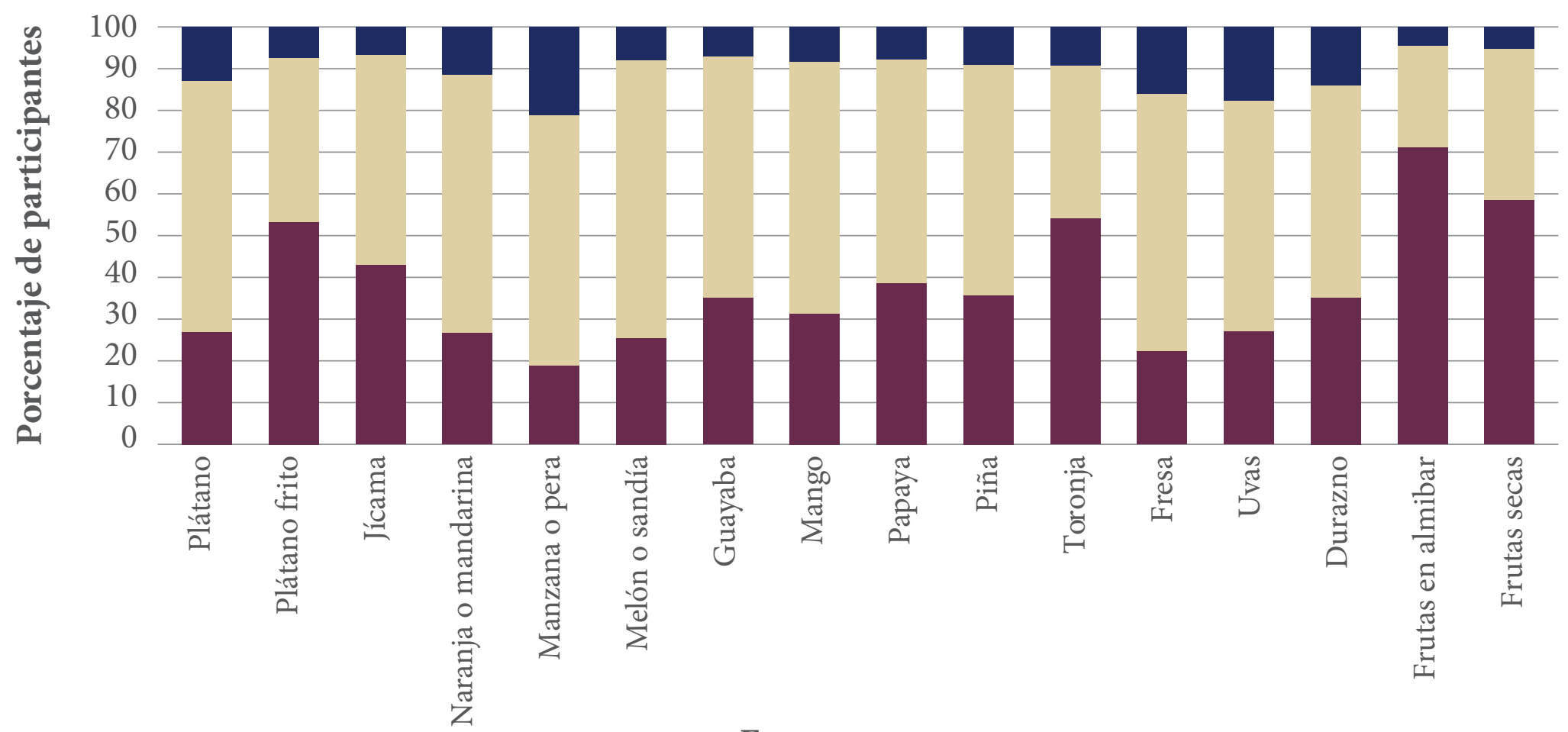

Fruta

De 5 a 7 días

De 1 a 4 días

Nunca 


\section{CAPÍTULO 1}

Respecto a la frecuencia de consumo de verduras, la mayoría de los hombres las consumen una vez a la semana, con excepción del jitomate (47.5\%), la lechuga (52.7\%) y la cebolla (65.5\%) que la consumen terciado. Las mujeres consumen con mayor frecuencia verduras, aunque va de 2 a 4 días a la semana, siendo el jitomate (57\%), la cebolla (63.1\%), las hojas verdes (52.4\%), la zanahoria (56.3\%), la calabacita (55.3\%), el brócoli (57\%), el elote (62.1\%), la lechuga (62.8\%), el pepino (55.8\%) y el aguacate (61.9\%).

La frecuencia de consumo de comida rápida fue mayor en los hombres. El 52\% consumía terciado una torta o sándwich, el 39.2\% consumía al menos una vez a la semana hamburguesa, el $35.3 \%$ pizza y el $37.7 \%$ hot dog de dos a tres días a la semana. En el caso de las mujeres, el $68.4 \%$ consumía entre dos y tres días a la semana torta o sándwich, el $50.6 \%$ al menos un día a la semana hamburguesa, el 65.5\% al menos un día a la semana pizza y $44 \%$ al menos un día a la semana hot dog.

De acuerdo con el consumo de proteína, del total de varones, el $44.4 \%$ consume al menos un día a la semana carne de puerco y el $24.1 \%$ de dos a cuatro días. Del total de hombres, el $35.8 \%$ consume de dos a cuatro días pierna, muslo o pechuga de pollo y el $32.1 \%$ un día a la semana. Igualmente, el 31.4\% consumen huevos tibios o cocidos terciado y el $27.5 \%$ lo hace una vez a la semana. De los varones participantes, el $49.1 \%$ come una vez a la semana salchicha y jamón, esta misma proporción también reportó consumir huevo cocinado al menos una vez a la semana.

La frecuencia de consumo de proteínas de las mujeres es menor en comparación con los hombres, ya que las mayores proporciones se ubicaron en el consumo de un día a la semana: carne de puerco (45.2\%), carne de res (44.7\%) y salchicha y jamón (46.5\%). El $32.9 \%$ de las participantes consume pierna, muslo o pechuga de pollo entre 2 y 4 días a la semana.

Los frijoles refritos es la leguminosa consumida con mayor frecuencia, el 59.3\% de los hombres y el $64.7 \%$ de las mujeres lo comen terciado. Lo mismo sucede con el arroz, el $69.2 \%$ de los hombres y el $72.9 \%$ de las mujeres lo comen terciado. El pan integral es más frecuente en las mujeres, el $41.5 \%$ lo consumen una vez a la semana y el $26.8 \%$ terciado, mientras que el $30.9 \%$ de los hombres consumen pan dulce de dos a seis días a la semana, asimismo, el $24.1 \%$ come donas y churros de 2 a 6 días a la semana. La ingesta de papa cocida y papa frita es mayor en las mujeres, el 30.5\% al menos consume la 
primera dos veces a la semana, y dos terceras partes consumen papas fritas al menos un día al a semana. De los varones, el $29.8 \%$ come una vez a la semana papa cocida y el $30.6 \%$ come una vez a la semana papa frita. El $42.6 \%$ de los hombres y el $47 \%$ de las mujeres come terciado cereal de caja de chocolate.

En la tabla 4 se observa la distribución porcentual de los participantes de acuerdo con la frecuencia de consumo de antojitos; se aprecia una mayor proporción de mujeres que consumen antojitos en comparación con los hombres, las cuales, en la mayoría de los casos, al menos los consumen una vez a la semana y es mayor el consumo de antojitos fritos, mientras que en los hombres es mayor el consumo de antojitos con algún tipo de carne.

\section{Tabla 4}

\section{Distribución porcentual de hombres y mujeres de acuerdo con la frecuencia de consumo de antojitos}

\begin{tabular}{|c|c|c|c|c|c|c|}
\hline & $\begin{array}{c}\text { Antojitos con } \\
\text { vegetales como } \\
\text { sopes, quesadillas, } \\
\text { gorditas y } \\
\text { enchiladas sin freír }\end{array}$ & $\begin{array}{c}\text { Antojitos } \\
\text { con vegetales } \\
\text { como sopes, } \\
\text { quesadillas, } \\
\text { gorditas y } \\
\text { enchiladas fritos }\end{array}$ & $\begin{array}{l}\text { Antojitos } \\
\text { con carne } \\
\text { como tacos } \\
\text { y quesadillas } \\
\text { sin freír }\end{array}$ & $\begin{array}{c}\text { Antojitos } \\
\text { con carne } \\
\text { como tacos } \\
\text { y quesadillas } \\
\text { fritos }\end{array}$ & Pozole & Tamales \\
\hline \multicolumn{7}{|c|}{ Hombres } \\
\hline Nunca & 50.9 & 35.7 & 43.1 & 38.2 & 42.6 & 49.1 \\
\hline 1 día & 37.7 & 42.9 & 39.2 & 38.2 & 44.4 & 34.0 \\
\hline 2-4 días & 11.3 & 17.9 & 17.6 & 18.2 & 13.0 & 15.1 \\
\hline 5-6 días & 0.0 & 3.6 & 0.0 & 3.6 & 0.0 & 1.9 \\
\hline 7 días & 0.0 & 0.0 & 0.0 & 1.8 & 0.0 & 0.0 \\
\hline \multicolumn{7}{|l|}{ Mujeres } \\
\hline Nunca & 37.8 & 27.2 & 46.3 & 36.1 & 36.1 & 35.7 \\
\hline 1 día & 43.9 & 58.0 & 35.4 & 48.2 & 53.0 & 53.6 \\
\hline 2-4 días & 14.6 & 12.3 & 15.9 & 12.0 & 4.8 & 7.1 \\
\hline 5-6 días & 1.2 & 2.5 & 1.2 & 1.2 & 4.8 & 2.4 \\
\hline 7 días & 2.4 & 0.0 & 1.2 & 2.4 & 1.2 & 1.2 \\
\hline
\end{tabular}




\section{CAPÍTULO 1}

Respecto a la ingesta de bebidas, observamos que una tercera parte de hombres y mujeres consumen una vez a la semana refresco. El café sin azúcar es más consumido por los hombres, el $43 \%$ lo beben terciado o casi a diario, mientras que las mujeres beben con menos frecuencia café ( 1 a 3 días a la semana), lo hacen con azúcar $54.8 \%$ o con leche 45.8\%. Tanto en hombres como en mujeres el consumo de jugos naturales es de 1 a 3 días a la semana en una tercera parte de la muestra, así como de aguas preparadas con frutas naturales y azúcar agregada. El 48.1\% de los hombres y el $67.3 \%$ de las mujeres consume a diario agua. Respecto a bebidas alcohólicas, una tercera parte reportó consumirlas una vez a la semana.

Dulces, paletas de leche, frituras, dulces de chile y palomitas son golosinas que consumen la tercera parte de los universitarios, tanto hombres como mujeres. Respecto a aderezos y condimentos, la mayonesa y la crema fueron las más consumidas (más de la tercera parte de los participantes), así como la sal en una tercera parte de los universitarios y salsa picante en todos los participantes de la muestra, todos los días de la semana. El platillo más común consumido es el caldo de pollo con verduras y las sopas de pasta caldudas con verduras, así también, la tortilla se come a diario por más del $80 \%$ de los participantes.

\section{Discusión y conclusiones}

La importancia de estudiar la población universitaria radica en el hecho de que existen a la fecha pocas investigaciones al respecto. Además, suponemos que los estudios de nivel superior se caracterizan por actividades de alta demanda en cuanto al tiempo se refiere, por lo que los hábitos alimenticios pueden verse afectados por las exigencias escolares (Duarte et al., 2015).

Entre los hallazgos más destacados del estudio, se encuentran los correspondientes al estado de IMC de los estudiantes, ya que los que asistían a la escuela en el turno matutino obtuvieron valores más altos respecto a los estudiantes del turno vespertino, tal vez porque los universitarios que acuden a la escuela por la mañana tienen que consumir alimentos adquiridos en establecimientos aledaños a la escuela o incluso dentro de ella, que pueden resultar ser de alto contenido en grasas, azúcares y carbohidratos, es decir, comida rápida y de fácil acceso, lo cual se constata con altos porcentajes de jóvenes que 


\section{CAPÍTULO 1}

consumen frecuentemente comida rápida. Es posible que los estudiantes del turno vespertino tengan mayores oportunidades de que durante las primeras horas del día coman alimentos elaborados en su casa y que sean posiblemente más nutritivos, higiénicos y variados. Pese a que no detectamos estudios que respalden o contradigan la importancia del turno escolar en los hábitos alimentarios, según Rosales et al. (2015), entre más tiempo pase un alumno universitario fuera de casa, aumentará el consumo de alimentos poco nutritivos y de fácil acceso.

Un segundo punto de interés en esta investigación son las diferencias por género. Las mujeres reportaron una alimentación más variada, ya que alternan alimentos de todos los grupos; por su parte, en los hombres, su rutina de alimentación suele ser más monótona, ya que predominaba el consumo de proteínas, especialmente el pollo, así como el café, la leche con saborizante y el consumo de huevo preparado de diversas maneras.

Lo anterior, quizás ofrece una posible razón por la que una mayor proporción de varones con IMC se ubicó por arriba de los valores normales y, además, tal como lo señalan Méndez et al. (2008), estos resultados pudieran estar relacionados con las exigencias estéticas y de belleza culturales que recaen sobre todo en las mujeres y que posiblemente son factores que influyen al momento de elegir sus alimentos. Por su parte, en los hombres, se sabe que algunos alimentos pueden ser riesgosos para su masculinidad, tal es el caso de las frutas y de las verduras, ya que se tiene la creencia de que por ser hombres deben de comer cosas que los hagan más fuertes (carne, tortilla, huevo), además, la idea de que deben ingerir grandes cantidades según el estándar de aceptación, ello referido por Méndez et al. (2008).

Aunque pareciera que las mujeres están exentas de problemas de peso, no es así, dado que, aunque su alimentación es variada, también contiene consumos altos de golosinas y de antojitos, lo que puede explicar el incremento paulatino de sobrepeso y obesidad conforme avanzan los semestres, este aspecto es coincidente con otras investigaciones (Becerra et al., 2015; Torres et al., 2016).

Además de estas diferencias por género, nuestra investigación refleja la importancia de los aspectos culturales del contexto mexicano, coincidimos con el punto de vista de Rivera (2006), quien señaló que el tipo de alimentación más recurrente son las preparaciones a base de maíz; lo cual podemos apreciar en el caso del consumo diario de tortilla 


\section{CAPÍTULO 1}

de prácticamente todos los participantes, lo cual nos hace suponer que está presente en todas las comidas del día, pese a que en la actualidad son bien sabidos sus efectos negativos que produce en el control de peso, al ser un alimento derivado del grupo de los cereales y leguminosas, así como alto en calorías. Por su parte, las salsas picantes como acompañamientos pueden producir algunos efectos negativos, principalmente a nivel gastrointestinal, cabe señalar que dichas salsas también forman parte de la dieta diaria del mexicano y, por ende, de los universitarios que participaron en la investigación.

La importancia de los costos de los alimentos tal parece que juega un papel importante, ya que observamos una predominancia en el consumo de caldos de pollo con verduras y de sopas caldudas acompañadas de tortillas, dichos alimentos en el contexto mexicano suelen ser de los más económicos, por lo que tal vez las familias de los estudiantes que participaron optan por cuidar el presupuesto familiar a la hora de elegir qué comer, esto es coincidente con la explicación que ofrecen Contreras et al. (2013) en su investigación.

Resultará importante llevar a cabo futuros estudios que nos permitan indagar acerca de las causas (costos, accesibilidad, preferencias, entre otros) que determinan la selección de alimentos que los estudiantes universitarios hacen y si ellas tienen que ver con las características propias de la escuela o bien, por los propios hábitos que ya traen desde casa, ya que, a pesar de que las Instituciones de Educación Superior (IEs) en los últimos años han promovido entornos saludables, incluyendo buenos hábitos alimenticios, la presente investigación y otras indican aún muchos retos por enfrentar y resolver en cuanto al tema de la alimentación; resulta necesario promover la educación alimentaria desde los primeros años de la carrera y así prevenir daños a la salud. 


\section{CAPÍTULO 1}

\section{Referencias}

Asociación Médica Mundial. (2001). Declaración de Helsinki de la Asociación Médica Mundial. Gaceta Médica Mexicana, 17(4), 387-390. https://www.medigraphic.com/pdfs/ gaceta/gm-2001/gm014n.pdf

Becerra, F., Pinzón, G., Vargas, M., Martínez, E., \& Callejas E. (2015). Cambios en el estado nutricional y hábitos alimentarios de estudiantes universitarios. Revista de la Facultad Medicina, 64(2), 249-256.

Contreras, G., Camacho, E., Ibarra, M., López, R., Escoto, M., Pereira, C., \& Munguía, L. (2013). Los hábitos alimentarios de estudiantes universitarios. Revista Digital Universitaria, 14(11), 1-15. http://www.revista.unam.mx/vol.14/num11/art48/art48.pdf

Duarte, C., Ramos, D., Latorre, A., \& González, P. (2015). Factores relacionados con las prácticas de estudiantes de tres universidades de Bogotá. Revista Salud Pública, 17(6), 925-937. http://www.scielo.org.co/pdf/rsap/v17n6/v17n6a09.pdf

Instituto Nacional de Salud Pública. (2017). Encuesta Nacional de Salud y Nutrición Medio Camino 2016. INSP. https://ensanut.insp.mx/ensanut2016/index.php

Organización de las Naciones Unidas para la Alimentación y la Agricultura. (2003). Educación en Alimentación y Nutrición para la Enseñanza Básica. FAo. http://www.fao.org/3/am401s/ am401s.pdf

Organización Mundial de la Salud. (2016a). Obesidad y sobrepeso. https://www.who.int/es/ news-room/fact-sheets/detail/obesity-and-overweight

Organización Mundial de la Salud. (2016b). La OMS recomienda aplicar medidas en todo el mundo para reducir el consumo de bebidas azucaradas y sus consecuencias para la salud. https://www.who.int/es/news-room/detail/11-10-2016-who-urges-global-action-tocurtail-consumption-and-health-impacts-of-sugary-drinks

Organización Mundial de la Salud. (2016c). Informe mundial sobre la diabetes. https://www. who.int/diabetes/global-report/es/

Méndez, J., Vázquez, V., \& García-García, E. (2008). Los trastornos de la conducta alimentaria. Boletín Médico del Hospital Infantil de México, 65(6), 579-592. http://www.scielo.org.mx/ $\mathrm{pdf} / \mathrm{bmim} / \mathrm{v} 65 \mathrm{n} 6 / \mathrm{v} 65 \mathrm{n} 6 \mathrm{a} 14 . \mathrm{pdf}$

Nieves, Z. I., Satchimo, A., González, Y., \& Jiménez, M. (2013). Algunas consideraciones acerca del estrés académico en los estudiantes universitarios. Revista Virtual de Ciencias Sociales y Humanas, Psicoespacios, 7(11), 91-116. 


\section{CAPÍTULO 1}

Pereira, J., \& Salas, M. (2017). Análisis de los hábitos alimenticios con estudiantes de décimo año de un Colegio Técnico en Pérez Zeledón basados en los temas transversales del programa de tercer ciclo de educación general básica de Costa Rica. Revista Electrónica Educare, 21(3), 229-251. https://doi.org/10.15359/ree.21-3.12

Phinder-Puente, M. E., Sánchez-Cardel, A., Romero-Castellanos, F., Vizcarra-García, J., \& Sánchez-Valdivieso, E. A. (2014). Percepción sobre factores estresantes en estudiantes de Medicina de primer semestre, sus padres y sus maestros. Investigación en Educación Médica, 3(11), 139-146. http://www.scielo.org.mx/pdf/iem/v3n11/v3n11a4.pdf

Reglamento de la Ley General de Salud en Materia de Investigación para la Salud. (2014). Nuevo Reglamento publicado en el Diario Oficial de la Federación el 6 de enero de 1987. Última reforma publicada DOF 02-04-2014. http://www.diputados.gob.mx/LeyesBiblio/ regley/Reg_LGS_MIS.pdf

Rivera, M. (2006). Hábitos alimentarios en estudiantes de la Universidad Juárez Autónoma de Tabasco. Revista Cubana de Salud Pública, 32(3). http://scielo.sld.cu/scielo. php?script=sci_arttext\&pid=S0864-34662006000300005

Rosales, M., Díaz, G., \& Saldaña, G. (2015). Alimentación saludable; ¿Qué comen los estudiantes de primer año de medicina de la UABC Tijuana? Revista Iberoamericana de las Ciencias de la Salud, 4(8). https://dialnet.unirioja.es/descarga/articulo/5279091

Sánchez, V., \& Aguilar, A. (2015). Hábitos alimentarios y conductas relacionadas con la salud en una población universitaria. Nutrición Hospitalaria, 31(1), 449-457. https://scielo.isciii. es/pdf/nh/v31n1/51originalvaloracionnutricional03.pdf

Torres, C., Trujillo, C., Urquiza, A., Salazar, R., \& Taype, A. (2016). Hábitos alimentarios en estudiantes de medicina de primer y sexto año de una universidad privada de Lima, Perú. Revista Chile Nutrición, 43(2), 146-154. https://www.redalyc.org/articulo. oa? id $=46946547006$

Vargas, M., Becerra, F., \& Prieto, E. (2010). Evaluación de la ingesta dietética en estudiantes universitarios. Revista de Salud Pública, 12(1), 116-125. https://www.redalyc.org/ pdf/422/42219010011.pdf 


\title{
CAPÍTULO 2
}

\section{Caracterización de la actividad física de estudiantes universitarios}

\author{
Erik Emmanuel Zúñiga Flores, Isaac Emmanuel Jauregui Rodríguez \\ y Daniel Alejandro López Hidalgo
}

La Organización Mundial de la Salud (oms, 2020) define la actividad física como cualquier movimiento corporal producido por los músculos esqueléticos que exija gasto de energía, abarca actividades que incluyen movimiento corporal y se realizan como parte de los momentos diarios de juego, de trabajo, formas de transporte activas, tareas domésticas y actividades recreativas.

La actividad física es diferente al ejercicio, aunque es considerado como una variación caracterizada por ser planificada, estructurada, repetitiva y con un objetivo relacionado con la mejora o el mantenimiento de uno o más componentes de la condición física y su salud. Además, es moderada y vigorosa, es decir, lleva a las personas a esforzarse, a sudar, respirar rápido y aumentar considerablemente la frecuencia cardíaca, por ejemplo, correr, escalar, montar bicicleta, nadar rápido, cargar o mover cosas que pesen más de 20 kilos y los deportes en general (oms, 2010). La oms (2010) propuso que la población de 18 años o más, acumulen "un mínimo de 150 minutos semanales de actividad física aeróbica moderada, o bien 75 minutos de actividad física aeróbica vigorosa cada semana, o bien una combinación equivalente" (p.8) de estas dos.

Los beneficios del ejercicio se asocian con cambios físicos saludables; entre los cambios fisiológicos se encuentran la estimulación del metabolismo y cardiorrespiratorio y la liberación de hormonas, además, ayuda al sistema inmunológico, mejora la sensibilidad a la insulina y el perfil de lípidos - lo cual regula la glucosa sanguínea previniendo la diabetes y otras enfermedades-, incrementa el fortalecimiento muscular y el deterioro cognitivo, especialmente en etapas avanzadas de la vida (Estévez, 2016; 


\section{CAPÍTULO 2}

Rivera et al., 2016; Rodríguez et al., 2017; Salas et al., 2016). El impacto positivo en la salud mental y emocional se muestra al reducir el estrés y la ansiedad, mejorar la autoimagen y la apariencia del cuerpo, fortalecer la calidad de vida, aumentar la longevidad - debido a que su práctica habitual puede reducir los niveles de morbilidad y mortalidad atribuidos a los padecimientos mencionados en líneas anteriores- (Barberán \& Roa, 2016; Barbosa \& Urrea, 2018; oms, 2020; Reynaga et al., 2016).

En la actualidad, la reducción de actividades físicas programadas y el aumento de actividades sedentarias son consideradas principales factores causantes de obesidad, sobrepeso y diabetes, principalmente en países desarrollados o en vías de desarrollo, debido al estilo de vida, en donde más de la mitad de la población mundial juvenil y adulta tiene una actividad física deficiente, necesaria para obtener beneficios para la salud (oms, 2020). El sedentarismo se presenta cada vez con mayor frecuencia impactando en la salud de la población, ocasionando consecuencias a nivel económico, biológico y social; Soler y Castañeda (2017) señalaron que los hábitos de vida sedentarios están creciendo en la sociedad, sobre todo desde el auge de las tecnologías y el estilo de vida transmitido a futuras generaciones, convirtiéndose en un problema de salud pública.

En México, se estima que el 73\% de los adultos tienen problemas de obesidad o sobrepeso, mientras que el 40\% de los jóvenes, así como un 33\% de los niños presentan el mismo padecimiento, posicionando a México como el país número uno a nivel mundial con mayor incidencia de sobrepeso, de acuerdo con la Organización de las Naciones Unidas para la Alimentación y la Agricultura (Excelsior, 2018). Por su parte, la Encuesta Nacional de Salud y Nutrición (ENSANut, 2016) reportó que cuatro de cada diez adolescentes de 12 a 19 años tienen sobrepeso u obesidad, representando el 36.3\% de la población; en 2012, la cifra era de 34.9\%, lo cual indica un aumento en los índices nacionales. También revela que, en adultos mayores de 20 años, siete de cada diez adultos tienen sobrepeso u obesidad, indicando que el 72.5\% de la población tienen problemas de peso (Instituto Nacional de Salud Pública [INSP], 2016).

Es de gran relevancia destacar a la población joven de entre 18 y 25 años en torno al presente tema, que, aunque es un periodo de la vida en donde suele estar presente un estado de salud óptimo, también resulta ser un momento crítico para consolidar hábitos saludables que postergarán e incluso evitarán la aparición de las enfermedades antes 


\section{CAPÍTULO 2}

descritas. Dentro de este rango de edad están presentes los estudiantes universitarios que es nuestra población de interés, debido a las condiciones recomendables para llevar a cabo actividad física (Quiceno \& Vinaccia, 2014).

Los estudiantes universitarios, definidos como aquellos que cumplen los requisitos de ingreso a las Instituciones de Educación Superior (IES) y que se forman profesionalmente en alguna disciplina representan una población que, debido a las exigencias escolares, suelen permanecer sentados y sin actividad física durante gran parte del día, lo cual representa un factor para el desarrollo del sedentarismo.

Según el Instituto Nacional de Estadística y Geografía (INEGI, 2018), mediante resultados del Módulo de Práctica Deportiva y Ejercicio Físico (MODPRAdef), a mayor nivel educativo se incrementa el porcentaje de población que declaró realizar práctica físico-deportiva, sobresale que entre la población de 18 y más años de edad que no ha concluido su educación básica la proporción de activos físicamente es más baja (27.6\%), dando cuenta de la importancia de promover principalmente entre las personas con menor escolarización los beneficios de la práctica físico-deportiva para la salud, debido a que las personas de 18 y más años abandonan la práctica deportiva o declaran nunca haberlo realizado debido a la falta de tiempo, cansancio por el trabajo y las actividades propias de la licenciatura, problemas de salud, la pereza y otros factores como el uso de vehículos motorizados, además de la falta de intervenciones institucionales enfocadas en la promoción de la salud dirigida a estudiantes (Arteaga et al., 2014; Barberán \& Roa, 2016; Práxedes et al., 2016; Ramírez et al., 2018).

Existe evidencia científica en estudiantes universitarios, que analizan los principales motivos y consecuencias que ocasiona la falta de actividad física y de ejercicio. A nivel nacional, Oropeza et al. (2017) observaron un mejor rendimiento académico y aprovechamiento escolar en universitarios que llevaban a cabo actividad física recurrente. Por su parte, Ramírez et al. (2018), mediante un estudio cualitativo, confirmaron que los estudiantes universitarios activos tenían una mejor salud física y psicológica percibida. Además, Castañeda et al. (2018) afirmaron que los principales motivos de práctica de actividad física están relacionados con la mejora de la salud, la satisfacción y la diversión en los jóvenes universitarios. Por su parte, Pérez et al. (2014) mostraron mediante una investigación que estadísticamente los alumnos que se identificaban con un nivel de 


\section{CAPÍTULO 2}

actividad física alto eran los que cursaban en turno diurno, no consumían tabaco, alcohol ni drogas, no trabajaban, no tenían hijos ni pareja estable y poseían un nivel socioeconómico medio.

Dado que gran parte del tiempo que destinan los estudiantes universitarios a sus estudios implica permanecer sentados y en contacto con medios digitales (actividades propiamente sedentarias) y que a la fecha son pocos los estudios nacionales actualizados que muestran el tipo de actividad física que realiza dicha población, el objetivo de nuestra investigación fue caracterizar la actividad física que llevan a cabo estudiantes de diferentes carreras de una universidad pública.

\section{Método}

\section{Participantes}

Participaron voluntariamente 138 estudiantes de una universidad pública adscritos a una carrera en modalidad presencial (Derecho 21.7\%, Médico Cirujano y Partero 44.9\%, Administración de Negocios 15.9\%, Contaduría Pública 9.4\%, Nutrición 8.0\%), de ambos turnos (61\% vespertino y 39\% matutino) y de ambos sexos (65\% mujeres y $35 \%$ hombres). La edad promedio fue de 19.7 ( DT $=1.7$ ). El 30\% cursaba el primer semestre, el $43 \%$ cursaba el segundo semestre y el 23\% cursaba el tercer semestre. La participación de los estudiantes fue voluntaria.

\section{Equipo e instrumentos}

Para obtener las medidas antropométricas se utilizó una balanza más monitor de la grasa corporal con porcentaje de agua corporal (Tanita Corporation ${ }^{\circledR}$ ) de 150 kilogramos de capacidad de peso, un estadiómetro portátil de alta precisión de hasta una talla de 205 centímetros marca SECA $213^{\circ}$.

Además, se utilizó una ficha de datos para obtener información sociodemográfica y escolar, en la ficha también se registró la información antropométrica. Para identificar y caracterizar el tipo de actividad física de los estudiantes, utilizamos el Cuestionario Mundial de Actividad Física (GPAQ), el cual fue desarrollado por la oms (s.f.), utilizado para obtener datos básicos sobre los factores de riesgo que determinan las enfermedades crónicas más comunes. Cada país tiene la flexibilidad de ampliar las variables básicas y 


\section{CAPÍTULO 2}

los factores de riesgo, e incorporar módulos opcionales relacionados con temas de interés local o regional. Al inicio brindan las instrucciones necesarias de llenado para cada pregunta, considera el tipo de actividad física en rango de baja, moderada o alta y el comportamiento sedentario de la población en tres distintos campos. El cuestionario se divide en cuatro dimensiones: (1) en el trabajo, (2) para desplazarse, (3) en el tiempo libre y (4) comportamiento sedentario. Contiene 16 reactivos, en los que cinco de ellos se responden con "sí" y "no", mientras que en otros cinco deben anotar el número de días semanales y el resto de los reactivos deben registrar horas y minutos de las actividades referidas.

\section{Diseño y procedimiento}

Se desarrolló una investigación cuantitativa, transversal, descriptiva para caracterizar la actividad física que llevan a cabo estudiantes de diferentes carreras de una universidad pública. La recolección de datos se llevó a cabo dentro de los salones de clase, donde se les explicó a los participantes el propósito de la investigación, posteriormente, se les dio a conocer los términos del consentimiento informado, dejándoles claro que participarían si así lo deseaban; los estudiantes que estuvieron de acuerdo firmaron dicho formato. Una vez firmado se les explicaron las instrucciones para responder el Cuestionario Mundial de Actividad Física (GPAQ) y, después de aclarar dudas, se procedió a contestarlo. Conforme concluyeron, se les tomaron las medidas antropométricas de peso, talla y se calculó el índice de masa corporal (IMC), el cual "es un indicador simple de la relación entre el peso y la talla que se utiliza frecuentemente para identificar el sobrepeso y la obesidad en los adultos. Se calcula dividiendo el peso de una persona en kilos por el cuadrado de su talla en metros" (oms, 2021, párr.9).

\section{Consideraciones éticas}

La investigación se ajustó a los principios éticos de Helsinki (Asociación Médica Mundial, 2001), a los criterios del Reglamento de la Ley General de Salud en Materia de Investigación para la Salud (2014). Se tomó como consideración ética, el anonimato y la confidencialidad de los participantes. 


\section{CAPÍTULO 2}

\section{Resultados}

El $65.1 \%$ de los participantes eran mujeres y el 34.9\% hombres. Predominantemente pertenecían a las licenciaturas de Médico Cirujano y Partero (43.1\%) y Derecho (25.0\%), aunque también participaron de la carrera de Administración de Negocios (15.3\%), Contaduría Pública (9.0\%) y Nutrición (7.6\%). El 29.7\% cursaban el primer semestre, el $44.9 \%$ el segundo semestre, el $25.4 \%$ tercer semestre. El 60.9\% asistía a clase en el turno vespertino, solo el $29.0 \%$ trabajaba y estudiaba.

Respecto a los resultados antropométricos, observamos un IMC promedio de 23.91 ( mín $=14.08$, máx $=35.86, \mathrm{DT}=4.04)$, el cual se encuentra dentro de parámetros normales. En la tabla 1 está representada la distribución porcentual de los participantes de acuerdo con cada estado de IMC y sus características personales. La mayoría de los estudiantes, hombres y mujeres se ubicaron dentro de los índices normales de peso (50.9\% y $67.7 \%$, respectivamente). Destaca el hecho de que la mitad de los participantes hombres se ubicaron en un estado de IMC por arriba de lo normal, mientras que una cuarta parte de las mujeres universitarias se ubicaron en un estado de IMC por arriba de lo normal.

Al comparar el estado de IMC por semestre observamos que la mayoría de los participantes se encontró en la normalidad, teniendo una mayor proporción en tercer semestre. Al comparar a los estudiantes de acuerdo con el turno en el que asistían a la escuela, observamos un porcentaje ligeramente mayor de participantes con IMC normal en el turno vespertino en comparación con el matutino, igualmente, los universitarios que reportaron no trabajar presentaron un estado de IMC normal en mayor proporción (64.5\%) en comparación con los que refirieron sí trabajar (55.6\%) (tabla 1).

Al comparar el estado de IMC de acuerdo con la carrera que cursaban los participantes, observamos que la mayor proporción se ubicó en valores de normalidad, aunque el 30.6\% de la Licenciatura en Derecho y el 36.4\% de la Licenciatura en Administración de Negocios obtuvieron un estado de IMC por arriba del normal (tabla 2). 


\section{Tabla 1}

Distribución porcentual de los participantes de acuerdo con su estado de IMC y características personales

\begin{tabular}{lccccc} 
& $\mathbf{n}$ & Bajo peso & Normal & Sobrepeso & Obesidad \\
Mujer & 99 & 7.1 & 67.7 & 16.2 & 9 \\
Hombre & 53 & 0 & 50.9 & 43.4 & 5.7 \\
\hline 1er. semestre & 46 & 8.7 & 52.2 & 30.4 & 8.7 \\
2do. semestre & 65 & 3.1 & 63.1 & 24.6 & 9.3 \\
3er. semestre & 35 & 2.9 & 77.1 & 20 & 0 \\
\hline Matutino & 57 & 5.3 & 59.6 & 28.1 & 7 \\
Vespertino & 95 & 4.2 & 63.2 & 24.2 & 8.4 \\
\hline Sí trabaja & 45 & 4.4 & 55.6 & 37.8 & 2.2 \\
No trabaja & 107 & 4.7 & 64.5 & 20.6 & 10.3 \\
\hline
\end{tabular}

Nota. $\mathrm{n}=138$.

\section{Tabla 2}

Distribución porcentual de los participantes de acuerdo con su estado de IMC y la carrera que cursaban

\begin{tabular}{lccccc} 
& I & II & III & IV & V \\
Bajo peso & 5.6 & 3.2 & 9.1 & 0 & 9.1 \\
Normal & 47.2 & 67.7 & 50 & 84.6 & 72.7 \\
Sobrepeso & 30.6 & 22.6 & 36.4 & 15.4 & 18.2 \\
Obesidad & 16.7 & 6.4 & 4.5 & 0 & 0 \\
\hline
\end{tabular}

Nota. $\mathrm{n}=138$, I = Licenciatura en Derecho $(\mathrm{n}=36)$, II = Licenciatura en Médico, Cirujano y Partero $(\mathrm{n}=62)$, III = Licenciatura en Administración de Negocios $(\mathrm{n}=22), \mathrm{IV}=$ Licenciatura en Contaduría Pública $(\mathrm{n}=13), \mathrm{V}=$ Licenciatura en Nutrición $(\mathrm{n}=11)$. 
En la tabla 3, podemos apreciar que la mayoría de los hombres (75.5\%) y las mujeres (83.8\%) no consideraron que su trabajo les exigía una aceleración importante de la respiración y el ritmo cardiaco durante al menos 10 minutos consecutivos, pero la mayoría de los hombres (83\%) y las mujeres (64.6\%) afirmaron que durante sus desplazamientos de un sitio a otro les requiere llevar a cabo actividad física intensa durante al menos 10 minutos consecutivos.

Aproximadamente, la mitad de las mujeres reportaron practicar actividad física intensa en su tiempo libre un promedio de 1.57 días a la semana $(\mathrm{DT}=1.7)$ y en uno de esos días en los que realizaban actividades físicas, el tiempo promedio dedicado fue de 34 minutos ( $\mathrm{DT}=49.1)$, los hombres promediaron 1.55 días a la semana $(\mathrm{DT}=2.05)$, y en uno de esos días, el tiempo promedio dedicado fue de 36 minutos $(\mathrm{DT}=53.1)$.

\section{Tabla 3}

\section{Distribución porcentual de acuerdo con el sexo y las dimensiones del GPAQ}

\begin{tabular}{lcccc} 
& \multicolumn{2}{c}{ Hombres } & \multicolumn{2}{c}{ Mujeres } \\
& Sí & No & Sí & No \\
\hline En el trabajo (intensa) & $24.5 \%$ & $75.5 \%$ & $16.2 \%$ & $83.8 \%$ \\
En el trabajo (moderada) & $50.9 \%$ & $49.6 \%$ & $42.4 \% \%$ & $57.6 \%$ \\
Para desplazarse (intensa) & $83.0 \%$ & $17.0 \%$ & $64.6 \%$ & $35.4 \%$ \\
En el tiempo libre (intensa) & $50.9 \%$ & $49.1 \%$ & $53.5 \%$ & $46.5 \%$ \\
En el tiempo libre (moderada) & $52.8 \%$ & $47.2 \%$ & $42.4 \%$ & $57.6 \%$ \\
\hline
\end{tabular}

Nota. $\mathrm{n}=138$.

En la tabla 4 observamos que la mayoría de los estudiantes de los distintos semestres no consideran que su trabajo requiera una aceleración importante de la respiración y el ritmo cardiaco durante al menos 10 minutos consecutivos, pero ambos sexos consideraron que durante sus desplazamientos diarios realizaban actividad física intensa durante al menos 10 minutos. Por su parte, los estudiantes de segundo semestre practican deporte intenso y moderado en mayor proporción que los estudiantes del primer y tercer semestre. 
En cuanto al promedio de días en los que practicaban algún deporte intenso, el primer semestre reportó $1.09(\mathrm{DT}=1.9)$ días a la semana, y en uno de eso días el tiempo promedio fue de $25(\mathrm{DT}=49.9)$ minutos. El segundo semestre reportó $2.18(\mathrm{DT}=2.3)$ días a la semana, y en uno de esos días el tiempo promedio fue de $65(\mathrm{DT}=82)$ minutos. En el tercer semestre se reportó $1.17(\mathrm{DT}=1.7)$ días a la semana, y en uno de eso días el tiempo promedio fue de $36.7(\mathrm{DT}=49.9)$ minutos.

\section{Tabla 4}

Distribución porcentual de acuerdo con el semestre cursado y las dimensiones del GPAQ

\begin{tabular}{lcccccc} 
& \multicolumn{2}{c}{ 1er. semestre } & \multicolumn{2}{c}{ 2do. semestre } & \multicolumn{2}{c}{ 3er. semestre } \\
& Sí & No & Sí & No & Sí & No \\
\hline En el trabajo (intensa) & $6.5 \%$ & $93.5 \%$ & $24.6 \%$ & $75.4 \%$ & $20.0 \%$ & $80.0 \%$ \\
En el trabajo (moderada) & $32.6 \%$ & $67.4 \%$ & $50.8 \%$ & $49.2 \%$ & $37.1 \%$ & $62.9 \%$ \\
Para desplazarse (intensa) & $80.4 \%$ & $19.6 \%$ & $67.7 \%$ & $32.3 \%$ & $65.7 \%$ & $34.3 \%$ \\
En el tiempo libre (intensa) & $45.7 \%$ & $54.3 \%$ & $64.6 \%$ & $35.4 \%$ & $42.9 \%$ & $57.1 \%$ \\
En el tiempo libre (moderada) & $32.6 \%$ & $67.4 \%$ & $56.9 \%$ & $43.1 \%$ & $42.9 \%$ & $57.1 \%$ \\
\hline
\end{tabular}

Nota. $\mathrm{n}=138$.

En la tabla 5 se muestra que la mayoría de los universitarios de ambos turnos, caminaban o usaban bicicleta al menos 10 minutos consecutivos en sus desplazamientos de un sitio a otro. Una mayor proporción de estudiantes del turno matutino en comparación con el vespertino reportó practicar deportes intensos y actividades moderadas en su tiempo libre. En cuanto al promedio de días en los que practicaban algún deporte intenso, el turno matutino reportó $2.21(\mathrm{DT}=2.3$ ) días promedio y en uno de esos días dedicó $64(\mathrm{DT}=74.5)$ minutos. Respecto al turno vespertino, el promedio de días en los que practicaban algún deporte intenso fue de $1.27(\mathrm{DT}=2)$ días y en uno de esos días dedicó $34.2(\mathrm{DT}=57.2)$ minutos. 


\section{Tabla 5}

Distribución porcentual de acuerdo con el turno escolar y las dimensiones del GPAQ

\begin{tabular}{lcccc} 
& \multicolumn{2}{c}{ Matutino } & \multicolumn{2}{c}{ Vespertino } \\
& Sí & No & Sí & No \\
\hline En el trabajo (intensa) & $21.1 \%$ & $78.9 \%$ & $15.7 \%$ & $84.3 \%$ \\
En el trabajo (moderada) & $42.2 \%$ & $57.9 \%$ & $42.7 \%$ & $57.3 \%$ \\
Para desplazarse (intensa) & $68.4 \%$ & $31.6 \%$ & $73.0 \%$ & $27.0 \%$ \\
En el tiempo libre (intensa) & $61.4 \%$ & $38.6 \%$ & $48.3 \%$ & $51.7 \%$ \\
En el tiempo libre (moderada) & $59.6 \%$ & $40.4 \%$ & $37.1 \%$ & $62.9 \%$ \\
\hline
\end{tabular}

Nota. $\mathrm{n}=138$.

En la tabla 6 podemos observar que el $60 \%$ de los estudiantes de la Licenciatura en Derecho consideraron que su trabajo les exigía una actividad de intensidad moderada, como caminar de prisa o transportar pesos ligeros al menos 10 minutos. Respecto a la actividad física realizada al desplazarse de un sitio a otro, la mayoría de los estudiantes de todas las carreras consideraron que caminan al menos 10 minutos consecutivos para ello. La práctica de deportes intensos en su tiempo libre fue mayor en los estudiantes de la Licenciatura en Contaduría Pública (61.5\%), seguidos de los de la Licenciatura en Nutrición (54.5\%). Finalmente, la práctica de actividades moderadas realizadas en su tiempo libre fue mayor en los estudiantes de la Licenciatura en Nutrición (72.7\%) seguidos de los estudiantes de Derecho (66.7\%).

Los días promedio en los que practicaron deporte en su tiempo libre fue de 2.9 en la Licenciatura en Nutrición ( $\mathrm{DT}=2.4$ ), y de 2.3 ( $\mathrm{DT}=2.1$ ) días en la Licenciatura en Contaduría Pública. En cuanto al tiempo dedicado a la práctica de deporte intenso en los días libres destacaron los estudiantes de la Licenciatura en Contaduría Pública con 72.31 (DT = 88.4) minutos promedio y los de la Licenciatura en Nutrición con 57.27 (DT $=63.5)$ minutos promedio. 


\section{Tabla 6}

Distribución porcentual de acuerdo con la carrera de adscripción y las dimensiones del GPAQ

\begin{tabular}{lccccccccccc} 
& \multicolumn{1}{c}{ I } & \multicolumn{2}{c}{ II } & \multicolumn{2}{c}{ III } & \multicolumn{2}{c}{ IV } & \multicolumn{2}{c}{ V } \\
& Sí & No & Sí & No & Sí & No & Sí & No & Sí & No \\
\hline $\begin{array}{l}\text { En el trabajo } \\
\text { (intensa) }\end{array}$ & 36.7 & 63.3 & 14.5 & 85.5 & 9.1 & 90.9 & 15.4 & 84.6 & 9.1 & 90.9 \\
$\begin{array}{l}\text { En el trabajo } \\
\text { (moderada) }\end{array}$ & 60.0 & 40.0 & 35.5 & 64.5 & 50.0 & 50.0 & 30.8 & 69.2 & 45.5 & 54.5 \\
$\begin{array}{l}\text { Para desplazarse } \\
\text { (intensa) }\end{array}$ & 76.7 & 23.3 & 64.5 & 35.5 & 81.8 & 18.2 & 61.5 & 38.5 & 72.7 & 27.3 \\
$\begin{array}{l}\text { En el tiempo libre } \\
\text { (intensa) }\end{array}$ & 50.0 & 50.0 & 41.9 & 58.1 & 36.4 & 63.6 & 61.5 & 38.5 & 54.5 & 45.5 \\
$\begin{array}{l}\text { En el tiempo libre } \\
\text { (moderada) }\end{array}$ & 66.7 & 33.3 & 45.2 & 54.8 & 50.0 & 50.0 & 53.8 & 46.2 & 72.7 & 27.3 \\
\hline
\end{tabular}

Nota. $\mathrm{n}=138$, I = Licenciatura en Derecho ( $\mathrm{n}=36)$, II = Licenciatura en Médico, Cirujano y Partero $(n=62)$, III = Licenciatura en Administración de Negocios $(n=22), I V=$ Licenciatura en Contaduría Pública $(\mathrm{n}=13), \mathrm{V}=$ Licenciatura en Nutrición $(\mathrm{n}=11)$.

Al comparar el tipo de actividad física y su intensidad con el IMC de los participantes, observamos que la mayoría no consideró que en el trabajo realizaban esfuerzos físicos, al desplazarse de un lado a otro la mayoría de los estudiantes consideraron que caminan al menos 10 minutos consecutivos, aunque apreciamos ligeramente una menor proporción de los universitarios con obesidad (66.7\%). La práctica de deporte intenso durante el tiempo libre fue nula en los estudiantes de bajo peso y la mayor proporción la observamos en los participantes con sobrepeso (54.3\%), mientras que la práctica de actividad física moderada durante su tiempo libre fue mayor en los estudiantes con obesidad (66.7\%) (tabla 7).

Los días promedio en los que se practica deporte intenso en el tiempo libre fueron de $2.6(\mathrm{DT}=2.4)$ en los participantes con obesidad y en uno de eso días el tiempo promedio dedicado fue de $90(\mathrm{DT}=109.2)$ minutos. En los participantes con IMC normal, los días promedio fueron de $1.82(\mathrm{DT}=2.2)$ y en uno de esos días el tiempo promedio fue de 44.4 
$(\mathrm{DT}=59.5)$ minutos. Con respecto a los participantes con sobrepeso los días promedio fueron de $1.36(\mathrm{DT}=1.8)$ mientras que el tiempo promedio fue de $48.9(\mathrm{DT}=70)$ minutos.

\section{Tabla 7}

Distribución porcentual de acuerdo con el estado por IMC y las dimensiones del GPAQ

\begin{tabular}{lcccccccc} 
& \multicolumn{2}{c}{ Bajo peso } & \multicolumn{2}{c}{ Normal } & \multicolumn{2}{c}{ Sobrepeso } & \multicolumn{2}{c}{ Obesidad } \\
& Sí & No & Sí & No & Sí & No & Sí & No \\
\hline $\begin{array}{l}\text { En el trabajo } \\
\text { (intensa) }\end{array}$ & $14.3 \%$ & $85.7 \%$ & $16.1 \%$ & $83.9 \%$ & $28.6 \%$ & $71.4 \%$ & $0.0 \%$ & $100 \%$ \\
$\begin{array}{l}\text { En el trabajo } \\
\text { (moderada) }\end{array}$ & $42.9 \%$ & $57.1 \%$ & $41.9 \%$ & $58.1 \%$ & $45.7 \%$ & $54.3 \%$ & $55.6 \%$ & $44.4 \%$ \\
$\begin{array}{l}\text { Para desplazarse } \\
\text { (intensa) }\end{array}$ & $71.4 \%$ & $28.6 \%$ & $70.1 \%$ & $29.9 \%$ & $71.4 \%$ & $28.6 \%$ & $66.7 \%$ & $33.3 \%$ \\
$\begin{array}{l}\text { En el tiempo libre } \\
\text { (intensa) }\end{array}$ & $0.0 \%$ & $100 \%$ & $46.0 \%$ & $54.0 \%$ & $54.3 \%$ & $45.7 \%$ & $44.4 \%$ & $55.6 \%$ \\
$\begin{array}{l}\text { En el tiempo libre } \\
\text { (moderada) }\end{array}$ & $57.1 \%$ & $42.9 \%$ & $51.7 \%$ & $48.3 \%$ & $54.3 \%$ & $45.7 \%$ & $66.7 \%$ & $33.3 \%$ \\
\hline
\end{tabular}

Nota. $\mathrm{n}=138$.

En la tabla 8 observamos que los estudiantes con bajo peso obtuvieron un promedio de tiempo diario mayor en el cual permanecen sentados seguido de los universitarios con obesidad.

\section{Tabla 8}

Estado de IMC $y$ tiempo promedio diario (en minutos y horas) que permanecen sentados los participantes

\begin{tabular}{lccc} 
& $\overline{\mathrm{X}}$ (minutos) & $\overline{\mathrm{X}}($ horas) & Desviación estándar (minutos) \\
Bajo peso & 608.57 & 10.14 & 178.08 \\
Normal & 398.83 & 6.64 & 229.05 \\
Sobrepeso & 348.46 & 5.80 & 248.95 \\
Obesidad & 468.33 & 7.80 & 262.74 \\
\hline
\end{tabular}

Nota. $\mathrm{n}=152$. 


\section{CAPÍTULO 2}

Al llevar a cabo una prueba de correlación de Pearson $(\mathrm{p}=<0.05)$ entre el IMC y los minutos que pasan sentados observamos significancia estadística de -0.062 . También al comparar el IMC con los minutos de actividad física moderada en el tiempo libre $(\mathrm{p}=-0.017)$. Respecto a la relación entre IMC y los minutos en los que se practica deporte intenso no encontramos asociación estadísticamente significativa $(\mathrm{p}=0.115)$.

\section{Discusión y conclusiones}

Aunque la mayoría de los participantes en esta investigación se ubicaron en valores normales de IMC, los estudiantes con obesidad reportaron caminar menos para desplazarse, por su parte y contrariamente a lo esperado, los estudiantes con sobrepeso hacían más actividad física intensa en su tiempo libre, aunque no excedieron los dos días a la semana y la hora y media diaria (en al menos uno de esos días), mientras que los participantes que presentaron obesidad realizaban actividad física moderada en su tiempo libre, pero también pasaban mucho tiempo sentados al igual que los de bajo peso.

Estudios como los de Sánchez y De Luna (2015) confirman parte de nuestros hallazgos al evidenciar que los jóvenes universitarios en general no tienen una adecuada práctica de ejercicio físico, ya que a pesar de que nuestros datos nos indican intentos por parte de los jóvenes para llevar a cabo estas prácticas saludables, el tiempo destinado y el tipo de actividad no se acerca al mínimo requerido, ello de acuerdo a lo que señala la oms (2010), en el que las personas mayores de 18 a 64 años deberían dedicar como mínimo 150 minutos semanales a la práctica de actividad física aeróbica, de intensidad moderada, "o bien 75 minutos de actividad física aeróbica vigorosa cada semana, o bien una combinación equivalente de actividades moderadas y vigorosas" (p.6). Asimismo, estudios como el de Rizo et al. (2014), también coinciden en que los estudiantes universitarios pasan mucho tiempo sentados, sobre todo frente a la computadora.

Al comparar la actividad física entre hombres y mujeres, no encontramos diferencias entre el número de días y el tiempo promedio que dedicaban a ellas. Nuestros hallazgos coinciden con los datos reportados por el INEGI (2018), a través del MOPRADEF, en donde se hace una comparativa entre hombres y mujeres señalando que el $49.8 \%$ de los varones declararon hacer alguna actividad física en su tiempo libre, proporción mayor a la declarada por las mujeres de $36 \%$. Ello puede entenderse, ya que desde pequeños los 


\section{CAPÍTULO 2}

niños varones mexicanos suelen realizar más actividades recreativas que les impliquen esfuerzo físico.

El turno escolar puede resultar ser una variable importante para el control de peso, ya que observamos que los del turno vespertino presentaron valores de IMC mayores. Y esto concuerda también con el hecho de que los del turno matutino realizan actividad física intensa y moderada con mayor frecuencia, ello quizá porque disponen de un mayor tiempo durante la tarde para llevarla a cabo, en este sentido, Pérez et al. (2014) y Oropeza et al. (2017) identificaron que los estudiantes con un nivel de actividad física alto eran los que cursaban en turno diurno, no consumían tabaco, alcohol ni drogas, no trabajaban, no tenían hijos ni pareja estable y poseían un nivel socio-económico medio.

El contar con un empleo remunerado, resulta ser un factor de riesgo para la presencia de sobrepeso y obesidad, ello derivado de la carga horaria propia de la universidad y del trabajo, que no les permiten realizar la actividad física adecuada. Para futuros estudios, resultará importante indagar el tipo de actividad laboral a la que se dedican los jóvenes universitarios y determinar si los propios contextos laborales cuentan con ambientes saludables en donde se promueve la actividad física y la correcta ergonomía corporal como un proceso de mejora continua para proteger y promover tanto la salud física como psicosocial, la seguridad, el bienestar de todos los trabajadores y la sostenibilidad del lugar de trabajo oms (2010a).

$\mathrm{Al}$ analizar los datos de acuerdo con el semestre, observamos que la proporción de participantes con IMC normal va en aumento conforme avanzan en sus estudios, sin embargo, al revisar la actividad física, solo en el segundo semestre practican deporte o ejercicio intenso durante dos días a la semana y una hora (en uno de esos días), pero después dejan de hacerlo. Suponemos que se debe a la poca flexibilidad de horario para llevar una vida más activa y a la carga de trabajo escolar, ya reportada por otros investigadores (Arteaga et al., 2014; Barberán \& Roa, 2016; Práxedes et al., 2016; Ramírez et al., 2018).

Es muy importante resaltar que los estudiantes de la Licenciatura en Médico Cirujano y Partero reportaron bajos niveles de actividad física, lo cual es de llamar la atención, ya que es de esperar que en carreras enfocadas a las ciencias de la salud, los alumnos sean más sensibles al tema de los hábitos saludables, ya que tal como lo señala el INEGI (2018), la población con mayor nivel de estudios tiende a adoptar comportamientos saludables, aunque quizás también la sobrecarga de trabajo les impida llevar a cabo actividad física. 


\section{CAPÍTULO 2}

Rizo, González y Cortés (2014) encontraron que estudiantes de nutrición y enfermería no aplican en sus hábitos cotidianos los conocimientos que están adquiriendo en sus estudios universitarios. En nuestra investigación, destacan los jóvenes de la Licenciatura en Nutrición quienes sí hacen actividad física, más días y más tiempo en comparación con el resto, lo cual pueda deberse a los conocimientos de su carrera y a ser congruentes con ella. Finalmente, sorprende el hecho de que los estudiantes de la Licenciatura en Contaduría Pública hacían actividad física intensa y los estudiantes de Derecho hacían actividad física moderada en comparación con el resto de las carreras; en el contexto universitario en el que se llevó a cabo la investigación, la organización de actividades deportivas principalmente es gestionada por comités de alumnos de estas carreras, los cuales son llevados a cabo en horarios libres de sus clases y realizados en los espacios deportivos con los que cuenta la institución.

Aunque en nuestro estudio se caracterizó la actividad física que llevan a cabo estudiantes de diferentes carreras, concluimos que, de acuerdo a los parámetros nacionales e internacionales acerca de las recomendaciones mínimas de actividad física para jóvenes, los participantes de esta investigación no llevan a cabo el suficiente movimiento para proteger su salud y prevenir enfermedades a corto y largo plazo, por lo que resulta apremiante proponer programas de activación física en el entorno universitario. 


\section{CAPÍTULO 2}

\section{Referencias}

Arteaga, M., Campoverde, J., \& Duran, M. (2014). Grado de sedentarismo y sus causas en los estudiantes de la Facultad de Ciencias Médicas de la Universidad de Cuenca 2014 (Tesis de Licenciatura de Tecnología Médica Terapia Física). Universidad de Cuenca, Ecuador. http://dspace.ucuenca.edu.ec/bitstream/123456789/21054/1/Tesis.pdf.pdf Asociación Médica Mundial. (2001). Declaración de Helsinki de la AMM - Principios éticos para las investigaciones médicas en seres humanos. https://www.wma.net/ es/policies-post/declaracion-de-helsinki-de-la-amm-principios-eticos-para-lasinvestigaciones-medicas-en-seres-humanos/

Barberán, J., \& Roa, J. (2016). Actividad física en universitarios y su relación con autoeficacia y percepción de riesgo (Tesis de Licenciatura en Psicología). Pontificia Universidad Javeriana Cali: Colombia. http://vitela.javerianacali.edu.co/bitstream/ handle/11522/4471/Actividad_fisica_universitarios_relacion.pdf?sequence=1

Barbosa, S., \& Urrea. Á. (2018). Influencia del deporte y la actividad física en el estado de salud físico y mental: una revisión bibliográfica. Revista KATHARSIS, 25, 141-159. https://dialnet.unirioja.es/descarga/articulo/6369972.pdf

Castañeda, C., Zagalez, L., Aruje, V., \& Campos, C. (2018). Motivos hacia la práctica de actividad física de los estudiantes universitarios sevillanos. Revista Iberoamericana de Psicología del Ejercicio y el Deporte, 13(1), 79-89. http://www.redalyc.org/articulo. oa? id=311153534008

Estévez, R. (2016). Beneficios de un programa de ejercicios físicos municipal para el bienestar del mayor. International Journal of Developmental and Educational Psychology, 1(2), 329-335. http://www.redalyc.org/articulo.oa?id=349851778036

Excelsior. (2018). Obesidad en México, problema de gravedad mayor: FAO. https://www. excelsior.com.mx/global/2018/03/11/1225688\#view-1

Instituto Nacional de Estadística y Geografía. (2018). Menos de la mitad de la población realiza en su tiempo libre la práctica de algún deporte o ejercicio físico. https://www.inegi. org.mx/contenidos/saladeprensa/boletines/2018/mopradef/mopradef2018_01.pdf

Instituto Nacional de Salud Pública. (2016). Encuesta Nacional de Salud y Nutrición de Medio Camino 2016. INSP. https://ensanut.insp.mx/encuestas/ensanut2016/doctos/ informes/ENSANUT2016ResultadosNacionales.pdf 


\section{CAPÍTULO 2}

Organización Mundial de la Salud. (s.f). Cuestionario Mundial sobre Actividad Física (GPAQ). https://www.who.int/ncds/surveillance/steps/GPAQ_ES.pdf

Organización Mundial de la Salud. (2010). Recomendaciones mundiales sobre la actividad física para la salud. oms. https://apps.who.int/iris/bitstream/ handle/10665/44441/9789243599977_spa.pdf

Organización Mundial de la Salud. (2010a). Ambientes de trabajo saludables: un modelo para la acción para empleadores, trabajadores, autoridades normativas y profesionales. https://apps.who.int/iris/bitstream/handle/10665/44317/9789243599311_spa. pdf? sequence $=1$

Organización Mundial de la Salud. (2020). Actividad física. https://www.who.int/es/ news-room/fact-sheets/detail/physical-activity

Organización Mundial de la Salud. (2021). Datos y cifras. https://www.who.int/es/ news-room/fact-sheets/detail/obesity-and-overweight

Oropeza, R., Ávalos, M., \& Ferreyra, D. (2017). Comparación entre rendimiento académico, autoeficacia y práctica deportiva en universitarios. Revista Actualidades Investigativas en Educación, 17(1), 1-21. https://revistas.ucr.ac.cr/index.php/aie/ article/view/27271

Práxades, A., Moreno, J., del Villar, F., \& García, L. (2016). Niveles de actividad física en estudiantes universitarios: diferencias en función del género, la edad y los estados de cambios. Revista Iberoamericana del Ejercicio y el Deporte, 11(1), 123-132. http:// www.redalyc.org/articulo.oa?id=311143051014

Pérez, G., Laiño, F., Zelarayán, J., \& Márquez, S. (2014). Actividad física y hábitos de salud en estudiantes universitarios argentinos. Revista Nutrición Hospitalaria, 30(4), 896-904. http://scielo.isciii.es/pdf/nh/v30n4/26originaldeporteyejercicio01.pdf

Quiceno, J., \& Vinaccia, S. (2014). Calidad de vida en adolescentes: Análisis desde las fortalezas personales y las emociones negativas. Revista Terapia Psicológica, 32(3), 185200. https://scielo.conicyt.cl/pdf/terpsicol/v32n3/art02.pdf

Ramírez, M., Raya, M., \& Ruíz, M. (2018). Sedentarismo y salud: efectos beneficiosos de la actividad física en estudiantes universitarios. Reidocrea, 7(7). https://www.ugr. es/ reidocrea/7-7.pdf 


\section{CAPÍTULO 2}

Reglamento de la Ley General de Salud en Materia de Investigación para la Salud. (2014).

Nuevo Reglamento publicado en el Diario Oficial de la Federación el 6 de enero de 1987. Última reforma publicada DOF 02-04-2014. http://www.diputados.gob.mx/ LeyesBiblio/regley/Reg_LGS_MIS.pdf

Reynaga, P., Arévalo, E., Verdesoto, A., Jiménez, I., Preciado M., \& Morales, J. (2016). Beneficios psicológicos de la actividad física en el trabajo de un centro educativo. Revista Federación Española de Asociaciones de Docentes de Educación Física, 30, 203-206. https://dialnet.unirioja.es/servlet/articulo?codigo=5529626

Rivera, A., Macías, J., Ochoa, P., \& Castellanos, A. (2016). Respuesta de la glucosa sanguínea en el ejercicio físico máximo. Revista Latinoamericana de Patología Clínica Medicina de Laboratorio, 63(2), 79-81. https://www.medigraphic.com/pdfs/patol/pt2016/pt162d.pdf

Rizo, M., González, N., \& Cortés, E. (2014). Calidad de la dieta y estilos de vida en estudiantes de Ciencias de la Salud. Nutrición Hospitalaria, 29(1), 153-157. http:// scielo.isciii.es/scielo.php?script=sci_arttext\&pid=S0212-16112014000100020

Rodríguez, C., González, M., Aguilar, C., \& Nájera, O. (2017). Mecanismos inmunológicos involucrados en la obesidad. Revista Investigación Clínica, 58(2), 175-196. http:// ve.scielo.org/pdf/ic/v58n2/art08.pdf

Salas, A., Loreto, I., Pérez, A., Buela, L., Canelón, E., \& Cortés, K. (2016). Hábito deportivo: efecto en la aptitud físico-motora y cardiorrespiratoria en escolares. Revista Venezolana de Endocrinología y Metabolismo, 14(2), 128-136. http://www. redalyc.org/articulo.oa?id=375546666005

Sánchez, M., \& De Luna, E. (2015). Hábitos de vida saludable en la población universitaria. Nutrición Hospitalaria, 31(5), 1910-1919. http://www.aulamedica.es/nh/pdf/8608.pdf Soler, A., \& Castañeda, C. (2017). Estilo de vida sedentario y consecuencias en la salud de los niños. Una revisión sobre el estado de la cuestión. Journal of Sport and Health Research, 9(2), 187-198. http://www.journalshr.com/papers/Vol\%209_N\%202/ JSHR\%20V09_2_1.pdf 


\title{
CAPÍTULO 3
}

\section{Conducta prosocial y rendimiento académico en estudiantes universitarios}

\author{
María Luisa Avalos Latorre, Roberto Oropeza Tena, \\ José Carlos Ramírez Cruz y Nancy Patricia Valencia Silva
}

\begin{abstract}
Altruismo, conducta prosocial, servicio comunitario o conducta de ayuda es entendido como las conductas dirigidas a procurar el bien ajeno aun a costa del propio; tiene una naturaleza desinteresada, puede ser un motivador extrínseco o intrínseco que lleva al individuo a obrar sobre el otro. Por ello, ser prosocial implica necesariamente acciones y es propio de la conducta humana (Osorio, 2010). Inglés et al. (2009) afirmaron que dicha conducta fortalece las relaciones con otras personas y asegura el bienestar personal y social. Se puede manifestar de diferentes maneras, como habilidad social, empatía, cooperación y complacencia (Redondo et al., 2014).

El origen de la conducta prosocial de una persona tiene lugar en la familia, parte de la transmisión oral de normas y valores por parte de los adultos a los niños, con la intención de aumentar sus disposiciones prosociales.
\end{abstract}

Los padres enseñan a los hijos, verbalmente, que determinadas conductas son buenas, y que otras son malas. Este conocimiento adquirido por los hijos es necesario para el desarrollo moral, y, por tanto, su adecuada transmisión es un factor determinante en la educación. (Osorio, 2010, p.129)

Además de este componente cognitivo, existen aspectos emocionales que permiten apreciar de determinada manera los eventos y realidades. Por ello, aunque la persona no reciba explícitamente ningún premio por su conducta prosocial hay algo que, de hecho, mejora la situación de este, ello es, su estado emocional (Garaigordobil \& Peña, 2014). 


\section{CAPÍTULO 3}

En este sentido, desde una perspectiva ética, Schwartz (1992) consideró que el comportamiento prosocial hace referencia a los valores de autotrascendencia que se asocian al interés y preocupación por otros, que dan cuenta de la empatía y de la motivación interna orientada a proporcionar bienestar a otros. Afirma que este tipo de conductas siempre son positivas para ambas partes, tanto para quien las emite como para quien las recibe.

La conducta prosocial también es fomentada en los contextos educativos. La escuela es un espacio en donde las personas no solo adquieren conocimientos disciplinares, sino que también adquieren competencias relacionadas con las habilidades sociales asociadas a la sana convivencia, la tolerancia y demás valores que favorecen la integración social de los alumnos (Santana, 2015). Algunas veces estas habilidades se incluyen en los criterios de evaluación del desempeño, otras veces son considerados indicadores cualitativos de la formación integral de los educandos. El rendimiento académico se concibe como la medida de las capacidades que manifiestan, en forma estimativa, lo que una persona ha aprendido como consecuencia de un proceso de instrucción o formación (Pizarro, 1985).

Tourón (1984) señaló que el rendimiento académico es el resultado del proceso de enseñanza-aprendizaje, mientras que Cruz y Quiñonez (2012) afirmaron que indica "en qué medida el proceso educativo logra sus objetivos fundamentales y confronta los fijados con los realmente alcanzados" (p.98). Al igual que otros autores (Ávalos et al., 2018), consideramos que el rendimiento académico puede reflejarse a partir de la calificación obtenida por los estudiantes.

La evidencia científica reporta un efecto positivo del ejercicio de conductas prosociales en el rendimiento académico (Inglés et al., 2009; Meza, 2012; Santana, 2015; Vieira \& Puigdellívol, 2013). En menor medida, otros reportan un efecto negativo, ello en donde se comparan estudiantes becados y no becados (Guigui, 2017). A nivel universitario, algunas investigaciones se han centrado en indagar la importancia de las instituciones universitarias para promover la responsabilidad social, a través del servicio social para integrar a los futuros profesionistas a los contextos reales (Ávila \& Cortés, 2016; Brunstein \& Romero, 2012; Corredor, 2017). Ellos muestran que los escenarios en donde los estudiantes sienten mayor empatía ofrecen un apoyo de mejor calidad de su servicio.

En dichas investigaciones se aprecia que la conducta prosocial fomenta repertorios de cooperación, generan sentido de pertenencia, empatía, de compromiso y de esfuerzo 
hacia lo que hacemos día con día. Suponemos que la conducta prosocial es un rasgo de la moralidad de una persona ya que, de acuerdo con Bandura (1999), está impregnada de hábitos encaminados a la consecución del bien y la felicidad tanto individual como colectiva. Asimismo, la conducta prosocial implica la capacidad de juzgar las acciones, las de otros, así como las nuestras, a través de reglas interiorizadas aprendidas desde los primeros años de vida. En general, se trata de comportamientos virtuosos que promueven las pautas de convivencia replicables por otros.

La mayoría de los estudios antes referidos, en los que se analiza la relación entre el desempeño académico y la conducta prosocial, fueron llevados a cabo en población adolescente de educación básica, mientras que los estudios realizados con estudiantes universitarios analizan particularmente el desempeño de estos en el servicio social profesional. Por ello, resulta relevante llevar a cabo una investigación en donde se analicen las diferencias y la relación entre la conducta prosocial y el rendimiento académico en universitarios.

\section{Método}

\section{Participantes}

A través de un muestreo no probabilístico aleatorio, participaron voluntariamente 328 estudiantes de ambos sexos, adscritos a la Facultad de Psicología de una Universidad pública en la ciudad de Morelia, Michoacán, que cursaban tercero, quinto, séptimo y noveno semestre, con una edad promedio de 21.32 años con un rango de 19 a 26 años y una desviación típica de 1.63 años.

El presente trabajo se ajustó a los principios éticos de Helsinki (Asociación Médica Mundial, 2001), a los criterios del Reglamento de la Ley General de Salud en materia de investigación para la salud en México (2014). Se tomó como consideración ética, el anonimato y la confidencialidad de los participantes.

\section{Instrumentos}

Se empleó una ficha de identificación, en la cual se solicitó información sociodemográfica de los estudiantes, como edad, género y semestre al que pertenecían. Asimismo, utilizamos el Inventario sobre Actividades Académicas y Extra Académicas (IAAEA, diseñado 


\section{CAPÍTULO 3}

específicamente para esta investigación), elaborado con 55 reactivos con respuestas de opción múltiple. Es de autoaplicación y obtiene información de cuatro áreas: (a) actividades cotidianas, clima escolar, logros e interés académicos; (b) involucramiento personal y nivel de motivación en las artes; (c) involucramiento personal en práctica deportiva; (d) involucramiento personal (horas semanales, años dedicados), nivel de participación (bajo, medio, alto y muy alto) y nivel de motivación (bajo, medio, alto, muy alto) en algún servicio comunitario o conducta prosocial. Para fines de esta investigación, solo se analizó el área (d).

Otro recurso fue la Boleta de Calificaciones Escolares de las materias cursadas hasta el momento de la recolección de la información, estas evaluadas en una escala de 0 a 10. Los participantes descargaron e imprimieron las boletas desde el servidor escolar de la universidad en la que estaban adscritos. En todos los casos, el rendimiento académico se entendió como la calificación de cada materia cursada y el promedio total de calificaciones.

\section{Diseño y procedimiento}

La investigación fue cuantitativa, transversal y analítica de evaluación única. La recolección de la información se llevó a cabo en los salones de la universidad, con la autorización previa del profesor de utilizar el tiempo de esa clase para fines del estudio. Se informó el objetivo de la investigación a los participantes, solicitando su participación. Los estudiantes que estuvieron de acuerdo en colaborar firmaron el consentimiento informado, mediante el cual autorizaron el uso de sus datos para fines de divulgación científica y en la cual se garantizó el anonimato y confidencialidad de su identidad. De manera grupal, recibieron las indicaciones pertinentes sobre el llenado del instrumento. Para el llenado del inventario y los demás formatos, los participantes emplearon en promedio noventa minutos.

Los datos recolectados se capturaron en el programa SPSS Versión 23.0, llevamos a cabo estadísticos descriptivos tales como frecuencia, porcentaje y desviación típica, así como pruebas $t$ de diferencias para grupos independientes entre el promedio global de calificaciones y la práctica de actividades prosociales. Finalmente, realizamos pruebas de correlación de Spearman entre el promedio global de calificaciones, entre la calificación promedio en cada asignatura y entre el nivel de involucramiento en actividades prosociales. 


\section{Resultados}

De los 328 estudiantes, 85 realizaban alguna actividad prosocial; 11 fueron hombres (12.9\%) y 74 mujeres (87.1\%). En la tabla 1 se observa la distribución de los participantes de acuerdo con el semestre que cursaban y a la participación en actividades prosociales.

\section{Tabla 1}

\section{Estudiantes que realizan actividades prosociales por semestre}

\begin{tabular}{lcc}
\multicolumn{1}{c}{ Semestre } & Sí hacen & No hacen \\
\hline Tercero & 13 & 45 \\
Quinto & 6 & 9 \\
Sexto & 25 & 48 \\
Séptimo & 20 & 82 \\
Noveno & 21 & 59 \\
Total & 85 & 243 \\
\hline
\end{tabular}

En la tabla 2 observamos que, de los 85 estudiantes que afirmaron llevar a cabo actividades prosociales, el 57.7\% eran actividades religiosas, seguidas de actividades relacionadas con la protección del medio ambiente (23.6\%) y con la participación en organizaciones altruistas o prosociales (23.6\%).

El tiempo promedio reportado por los participantes llevando a cabo las actividades prosociales fue de 2.97 años (rango 1 a 16 años, DT $=2.4$ ). La participación en grupos de scouts y en grupos religiosos fueron los de mayor tiempo (tabla 3). Por otra parte, respecto a las horas promedio semanales que los jóvenes invertían en las actividades prosociales fue de 3.57 horas a la semana (rango 1 a 4.8 horas, $\mathrm{DT}=2.52$ ) (tabla 4 ). 


\section{Tabla 2}

Porcentaje de estudiantes que realizan algún tipo de actividad prosocial

\begin{tabular}{lc}
\multicolumn{1}{c}{ Actividad prosocial } & $\%$ \\
\hline Religiosa & 57.7 \\
Protección del medio ambiente & 23.6 \\
Organización civil & 23.6 \\
Protección de animales & 13 \\
Ayuda a adultos mayores & 13 \\
Ayuda en orfanatos & 11.8 \\
Scouts & 8.3 \\
Ayuda a indigentes & 2.4 \\
Otros & 4.7 \\
\hline
\end{tabular}

\section{Tabla 3}

Promedio de años dedicados a las actividades prosociales

\begin{tabular}{lcc}
\multicolumn{1}{c}{ Actividad prosocial } & M (años) & DT (años) \\
\hline Scouts & 4.57 & 5.35 \\
Religiosa & 4.04 & 3.02 \\
Protección del medio ambiente & 3.15 & 2.41 \\
Protección de animales & 2.91 & 2.55 \\
Ayuda a adultos mayores & 2.82 & 1.33 \\
Ayuda en orfanatos & 2.10 & 2.08 \\
Ayuda a indigentes & 2 & 1.41 \\
Organización civil & 1.95 & 1.67 \\
Otros & 3.25 & 1.89 \\
\hline
\end{tabular}




\section{Tabla 4}

Horas semanales dedicadas a actividades prosociales

\begin{tabular}{lcc}
\multicolumn{1}{c}{ Actividad prosocial } & M (horas) & DT (horas) \\
Religiosa & 4.6 & 6.8 \\
Scouts & 4.29 & 1.7 \\
Organización civil & 3.50 & 2.43 \\
Ayuda a adultos mayores & 3.00 & 1.61 \\
Protección de animales & 2.64 & 0.80 \\
Protección del medio ambiente & 2.35 & 1.26 \\
Ayuda a indigentes & 2.00 & 0.00 \\
Ayuda en orfanatos & 1.00 & 1.05 \\
Otros & 4.75 & 2.50 \\
\hline
\end{tabular}

De las 103 asignaturas del Plan de Estudios de la Licenciatura en Psicología evaluadas, el 66\% de los estudiantes que realizaban actividad prosocial contaban con un promedio de calificación mayor que aquellos estudiantes que no realizaban este tipo de actividades, solo el 34\% de los estudiantes que no realizaban actividades comunitarias tenían un mayor promedio escolar.

Aunado a ello, llevamos a cabo pruebas t de diferencias para grupos independientes entre el promedio global de calificaciones y la práctica de actividades prosociales. No encontramos diferencias estadísticamente significativas entre ambos grupos $(t=2.345$, $\mathrm{p}>0.05)$. Con la misma prueba, comparamos las calificaciones promedio en cada una de las asignaturas y la práctica de actividades comunitarias y observamos diferencias estadísticamente significativas en algunas de ellas (tabla 5). 


\section{Tabla 5}

Prueba t de diferencia entre asignaturas y práctica de actividades prosociales

\begin{tabular}{lccc}
\multicolumn{1}{c}{ Asignatura } & $\mathbf{t}$ & $\mathbf{g l}$ & $\mathbf{p}$ \\
Estadística inferencial & -3.69 & 185.61 & .0001 \\
Metodología cuantitativa & -2.90 & 147.16 & .004 \\
Bases biológicas del comportamiento & -2.72 & 189.81 & .007 \\
Epistemología de la psicología & -2.46 & 180.51 & .015 \\
Fundamentos de biopsicología & -2.43 & 230 & .016 \\
Estadística descriptiva & -2.08 & 227 & .038 \\
Psicología de la adolescencia & -1.9 & 227 & .05 \\
\hline
\end{tabular}

Además, llevamos a cabo una correlación de Spearman entre el promedio global de calificaciones, entre la calificación promedio en cada asignatura y entre el nivel de involucramiento en actividades prosociales. No observamos correlación entre el promedio global de calificaciones y ni el nivel de involucramiento en actividades prosociales ( $\mathrm{r}_{\mathrm{s}}$ $=0.12, \mathrm{p}>.05)$. De las 103 asignaturas evaluadas, en 13 observamos correlación estadísticamente significativa, once de las cuales tuvieron una correlación positiva y dos presentaron una correlación negativa (tabla 6).

Por último, llevamos a cabo prueba de correlación de Spearman entre el promedio global de calificaciones y las asignaturas cursadas con el nivel de motivación implicado en las actividades prosociales. Tampoco observamos relación estadísticamente significativa entre dichas variables ( $\mathrm{p}>0.05$ ). De las calificaciones de las 103 asignaturas, en 10 observamos relación estadísticamente significativa, nueve de las cuales fueron positivas y una negativa (tabla 7). 


\section{Tabla 6}

Correlación entre calificación por asignatura y nivel de involucramiento en actividades prosociales

\begin{tabular}{lcc}
\multicolumn{1}{c}{ Asignatura } & rs & p \\
\hline Psicometría & .529 & .012 \\
Estructuras clínicas del psicoanálisis & .331 & .009 \\
Fundamentos del enfoque psicoanalítico & .331 & .008 \\
Método psicoanalítico & .314 & .018 \\
Fundamentos del enfoque humanista & .298 & .017 \\
Psicología de la educación & .277 & .028 \\
Laboratorio de procesos perceptivos y motivacionales & .243 & .034 \\
Procesos perceptivos y motivacionales & .241 & .033 \\
Fundamentos del enfoque sistémico & .228 & .05 \\
Laboratorio de bases biológicas del comportamiento & .205 & .05 \\
Sistemas de pensamiento psicológico 2 & -.479 & .014 \\
Antropología & -.345 & .047 \\
\hline
\end{tabular}

\section{Tabla 7}

Correlación entre calificación promedio por asignatura y nivel de motivación en actividades prosociales

\begin{tabular}{lcc}
\multicolumn{1}{c}{ Asignatura } & rs & p \\
\hline Psicometría & .529 & .012 \\
Método psicoanalítico & .443 & .001 \\
Psicología de la educación & .382 & .004 \\
Estudios clínicos psicoanalíticos & .369 & .004 \\
Psicodiagnóstico & .359 & .05 \\
Fundamentos del enfoque psicoanalítico & .357 & .005 \\
Fundamentos del enfoque humanista & .287 & .020 \\
Sexualidad y género & .280 & .024 \\
Laboratorio de Procesos perceptivos y motivacionales & .235 & .039 \\
Sistemas de pensamientos II & -.457 & .019 \\
\hline
\end{tabular}




\section{CAPÍTULO 3}

\section{Discusión y conclusiones}

El objetivo de este trabajo fue analizar las diferencias y la relación entre la conducta prosocial y el rendimiento académico en estudiantes universitarios. Como muestran los resultados obtenidos, es probable que la involucración en actividades prosociales beneficie al rendimiento académico; la mayoría de los estudiantes que se dedicaban a estas acciones mostraron un promedio mayor que los que no participaban en ellas. A pesar de tener mayor rendimiento académico, las pruebas estadísticas no mostraron diferencias significativas entre ambos grupos. Estos resultados hay que tomarlos con cuidado y hacer más investigaciones con estas variables, buscando una muestra más amplia y comparar diferentes licenciaturas.

Entre las asignaturas en las que se identificaron diferencias estadísticamente significativas están cuatro, es probable que dichas asignaturas se asocien con habilidades que ayudan a tener experiencias de aprendizaje significativo. Lorenzo y Matallanes (2013) indicaron que las actividades prosociales promueven el desarrollo de diferentes tipos de competencias, entre ellas las cognitivas, prosociales, éticas y cívicas, además de ayudar al desarrollo integral de los universitarios.

De acuerdo con Inglés et al. (2009), el rendimiento académico es mayor en los estudiantes de secundaria con conductas prosociales. La proporción de los alumnos prosociales que aprobaron todas las asignaturas fue significativamente mayor que el grupo de estudiantes no prosociales $(\mathrm{d}=.10)$. Asimismo, se encontraron dos asignaturas con correlaciones negativas estadísticamente significativas (sistemas del pensamiento psicológico y antropología). Es decir, parece que cursar estas asignaturas hace que los estudiantes les vaya mal en sus calificaciones. Sería necesario indagar el porqué de estos resultados.

Los resultados de esta y otras investigaciones (Anné et al., 2014) nos pueden indicar que realizar un servicio comunitario puede ayudar al rendimiento académico (así como en otras áreas de la vida) tanto en algunas asignaturas específicas como en el promedio general de estudiantes universitarios. Debido a esto, podría ser importante motivar a trabajar en estos espacios desde la infancia y seguir practicándola hasta la adultez. Al respecto, en Estados Unidos, Celio et al. (2011) revisaron 62 programas de aprendizaje-servicio, en los cuales participaron 11837 estudiantes (68\% universitarios) y encontraron efectos positivos en el rendimiento académico, así como en la actitud ha- 


\section{CAPÍTULO 3}

cia uno mismo, actitudes hacia la universidad y el aprendizaje, el compromiso cívico y las competencias sociales. Por su parte, Scales et al. (2006) señalaron que participar en actividades comunitarias influye de manera importante en el rendimiento académico, debido a que los estudiantes se sienten efectivos en sus labores y a que identifican la utilidad que tienen los conocimientos que han adquirido en sus estudios.

En los resultados obtenidos, sobresale el hecho de que únicamente una cuarta parte de los estudiantes practica alguna actividad prosocial; debido a esto, sería deseable motivar este tipo de actividades poco habituales en la población general (y específicamente en universitarios) en México.

Es necesario hacer más investigación en este tema, para poder identificar cómo las herramientas obtenidas en el desarrollo de las actividades comunitarias influyen de alguna manera en nivel de educación superior. En una investigación donde se entrevistaron a 3450 estudiantes de 42 instituciones universitarias, se encontró que las actividades comunitarias tenían efectos positivos en diez dimensiones relacionadas con el rendimiento académico, tales como el promedio general, el aumento de los conocimientos tanto generales como de la disciplina, las aspiraciones académicas, la perseverancia en la carrera, el autoconcepto escolar, el tiempo ofrecido al estudio, el trabajo extra en las materias escolares y la buena relación con los maestros (Astin \& Sax, 1998). Anné et al. (2014) indicaron que la conducta prosocial es relevante en muchas profesiones, creemos que especialmente en profesiones como la psicología, debido a que muchos de sus objetivos están relacionados con ayudar a los demás.

Nuestra investigación hace un primer acercamiento a variables extracurriculares que se han estudiado muy poco respecto al rendimiento académico, es el caso específico de las actividades comunitarias (Mella-Núñez et al., 2015) en estudiantes universitarios, tratando de profundizar en la relación específica con asignaturas de la licenciatura en psicología. Valdría la pena hacer este acercamiento entre licenciaturas del área de la salud, así como entre diferentes áreas de estudio, para identificar si en alguna de ellas se identifican relaciones más fuertes con el rendimiento académico. Además, sería necesario identificar variables mediadoras tales como la motivación o la autoeficacia, entre otras.

Nuestro estudio ofrece un acercamiento a aquellas variables extracurriculares que pudieran estar relacionadas con el rendimiento académico, así como su relación 


\section{CAPÍTULO 3}

específica con asignaturas específicas de la Licenciatura en Psicología. Pese a este acercamiento, resulta indispensable seguir profundizando al respecto. Por último, es necesario desarrollar estrategias dirigidas en las universidades tendientes a impulsar una cultura de responsabilidad social (Ramos, 2010). 


\section{CAPÍTULO 3}

\section{Referencias}

Anné, S. E., Abal, J. P., Lozzia, G. S., \& Horacio, F. A. (2014). La conducta prosocial: estado actual de la investigación. Perspectivas en Psicología, 11(2), 21-33.

Asociación Médica Mundial. (2001). Declaración de Helsinki de la AMM-principios éticos para las investigaciones médicas en seres humanos. https://www.wma.net/ es/policies-post/declaracion-de-helsinki-de-la-amm-principios-eticos-para-lasinvestigaciones-medicas-en-seres-humanos/

Astin, A. W., \& Sax, L. J. (1998). How are undergraduates affected by service participation? Journal of College Student Development, 39(3), 251-263.

Ávalos, M., Oropeza, R., Ramírez, J., \& Palos, U. (2018). Percepción de autoeficacia y rendimiento académico en estudiantes de bachillerato. Caleidoscopio-Revista Semestral de Ciencias Sociales y Humanidades, 39.

Ávila, L., \& Cortés. J. (2016). Comunic@ tu servicio social comunitario: una experiencia en la implementación de una propuesta educativa. Revista Iberoamericana de Educación Superior, 7(20), 60-77.

Bandura, A. (1999). Moral disengagement in the perpetration of inhumanities. Personality and Social Psychology Review, 3(3), 193-209.

Brunstein, S., \& Romero, R. (2012). Servicio comunitario desde la visión del estudiante universitario. Revista Multiciencias, 12, 75-80.

Celio, C. I., Durlak, J., \& Dymnicki, A. (2011). A meta-analysis of the impact of ServiceLearning on students. Journal of Experiential Education, 34(2), 164-181.

Corredor, Z. (2017). Impacto del servicio comunitario en educación universitaria: Perspectivas. Revista Opción, 33(83), 669-693.

Cruz, N., \& Quiñones, A. (2012). Importancia de la evaluación y autoevaluación en el rendimiento académico. Revista Zona Próxima, 16.

Garaigordobil, M., \& Peña, A. (2014). Intervención en las habilidades sociales: Efectos en la inteligencia emocional y la conducta social. Behavioral Psychology, 22(3),551-567. Guigui, L. (2017). Diferencia en las conductas prosociales entre estudiantes becados Loyola y estudiantes no becados de la universidad Rafael Landívar de Guatemala (Tesis de licenciatura). Universidad Rafael Landívar, Guatemala. 


\section{CAPÍTULO 3}

Inglés, C., Benavides, G., Redondo, J., García, J., Ruiz, C., Estévez, C., \& Huescar, E. (2009). Conducta prosocial y rendimiento académico en estudiantes españoles de Educación Secundaria Obligatoria. Revista Anales de Psicología, 25(1), 93-101.

Lorenzo, V., \& Matallanes, B. (2013). Desarrollo y evaluación de competencias psicosociales en estudiantes universitarios a través de un programa de AprendizajeServicio. Revista Internacional de Educación para la Justicia Social, 2(2), 155-176.

Mella, I., Santos, M., \& Malheiro, X. (2015). Aprendizaje-Servicio y rendimiento académico del alumnado universitario. Revista de Estudios e Investigación en Psicología y Educación, 12, 035-039.

Meza, C. (2012). La conducta prosocial y su relación con el rendimiento académico en el área de persona, familia y relaciones humanas en los estudiantes del quinto grado de educación secundaria de la institución educativa "Francisco Irazola" (Tesis de Magister en Educación). Universidad César Vallejo, Perú. http://repositorio.ucv.edu. pe/handle/UCV/10510

Osorio, A. (2010). Insuficiencia de los constructos psicológicos en la educación del altruismo. Revista Educación y Educadores, 13(1), 125-138.

Pizarro, R. (1985). Rasgos y actitudes del profesor efectivo (Tesis de maestría). Universidad de Chile, Chile.

Ramos, C. (2010). Hacia una cultura de responsabilidad social universitaria. CICAG, 7(2), 97-113.

Redondo, J., Inglés, C., \& García, J. (2014). Conducta prosocial y auto atribuciones académicas en Educación Secundaria Obligatoria. Revista Anales de Psicología, 30(2), 482-489.

Santana, M. (2015). Rendimiento escolar, conducta prosocial y conducta antisocial en estudiantes adolescentes del nivel medio superior del Valle de Toluca (Tesis de licenciatura). Universidad Autónoma del Estado de México. http://ri.uaemex.mx/ handle/20.500.11799/66617

Scales, P., Roehlkepartain, E., Neal, M., Kielsmeier, J., \& Benson, P. (2006). Reducing academic achievement gaps: The role of Community Service and Service Learning. Journal of Experiential Education, 29(1), 38-60. 


\section{CAPÍTULO 3}

Schwartz, S. (1992). Universals in the Content and Structure of Values: Theory and Empirical Tests in 20 Countries. Advances in Experimental Social Psychology, 25, 1-65. Reglamento de la Ley General de Salud en Materia de Investigación para la Salud. (2014). Nuevo Reglamento publicado en el Diario Oficial de la Federación el 6 de enero de 1987. Última reforma publicada DOF 02-04-2014. http://www.diputados.gob.mx/ LeyesBiblio/regley/Reg_LGS_MIS.pdf

Tourón, J. (1984). Factores del rendimiento académico en la universidad. Universidad de Navarra.

Vieira, L., \& Puigdellívol, I. (2013). ¿Voluntarios dentro del aula? El rol del voluntariado en "Comunidades de Aprendizaje". Revista de Estudios y Experiencias en Educación, 12(24), 38-55. http://www.rexe.cl/ojournal/index.php/rexe/article/view/66/62 


\title{
CAPÍTULO 4
}

\section{Estrés académico, características sociodemográficas y escolares en estudiantes de medicina}

\author{
Ana Laura Rodríguez Hernández, Brandon Ruiz Espinoza \\ y Daniela Berenice Sandoval Campos
}

En la actualidad, el ritmo de vida es bastante acelerado, esto debido a que las expectativas y las exigencias, en conjunto con la limitación del tiempo, día a día van poniendo a la persona sobre un aumento de presión, trayendo como consecuencia algún tipo de estrés. De acuerdo con Barrio et al. (2006), el estrés es una respuesta fisiológica, originada por el instinto de supervivencia del ser humano, que en un intento por adaptarse a las presiones a las que se ve sometido produce una segregación de hormonas que genera respuestas en diversas partes del organismo, involucrando así diversos órganos y funciones del cuerpo. Asimismo, según Aguilar et al. (2015), el estrés es una relación dinámica entre el sujeto y su entorno, dependiendo de la forma de pensar y razonar que tenga hacia cierta situación, será la magnitud de la respuesta. Esto quiere decir que, el grado de estrés dependerá de la forma en que el individuo afronte la situación y su capacidad para soportarla, produciendo así que los factores que ocasionen estrés en una persona no lo produzcan en otra.

Como ya se mencionó en los párrafos anteriores, el cuerpo utiliza el estrés para activar la supervivencia del individuo, brindando energía y vigor para facilitarle la adaptación a una situación demandante. Sin embargo, cuando el individuo está sometido a una gran presión y estrés durante mucho tiempo, puede resultar perjudicial para la salud. A este tipo de estrés negativo o dañino se le denomina distrés o estrés crónico, y surge cuando una persona no es capaz de ver la salida a una situación (Pérez et al., 2014).

De acuerdo con Lazarus y Folkman (1984), los signos y síntomas físicos presentes en alguien que sufre de estrés pueden ser frecuencia cardiaca acelerada, elevación de la 


\section{CAPÍTULO 4}

presión arterial, náuseas, vómito, tensión o dolor muscular, dificultades respiratorias, desmayo, vértigo, aumento en la sudoración, dolores de cabeza, temblores musculares, sed, languidez, fatiga, dolores en el pecho y problemas en el sueño. En casos extremos, sus manifestaciones pueden ser letales produciendo un ataque al corazón, apoplejía, cáncer e incluso inducir al individuo al suicidio.

El último informe de la Organización Mundial de la Salud (como se citó en Ahued, 2018) reveló que $75 \%$ de los mexicanos padece estrés, sobre todo laboral, y esto nos pone a la cabeza de un listado en el que se encuentran China, con 73\%, y Estados Unidos, con $59 \%$, trayendo consigo pérdidas económicas significativas al disminuir el rendimiento en nuestras actividades diarias, considerándolo como una enfermedad que ataca el bienestar y la salud de las personas. De acuerdo con la Organización para la Cooperación y el Desarrollo Económico (como se citó en Expansión, 2019), existen diversos factores entre la población o habitantes de las ciudades que generan estrés crónico, por ejemplo, el $43 \%$ de los mexicanos padecen estrés laboral, puesto que se trata de la nación que más horas trabaja, pero que tiene menores índices de productividad dentro del grupo de países miembros.

Las responsabilidades, los compromisos, las presiones y las urgencias están presentes en la vida moderna de la sociedad, afectando también a los estudiantes de pregrado, debido a que, por diversos motivos, la universidad representa una etapa desencadenante del estrés académico. Este tipo de estrés no ha sido definido con precisión pese a que el individuo que estudia una carrera universitaria se enfrenta a situaciones de alta demanda, que son generadoras de estrés, y requieren del despliegue de todas sus capacidades de afrontamiento para adaptarse a los estresores, los cuales suelen ocurrir en el espacio cotidiano en el que se desenvuelven. En este sentido, el estrés académico puede ser entendido como la respuesta del organismo a los estresores que se dan dentro del espacio educativo y que afectan directamente el rendimiento de los alumnos (Berrío \& Mazo, 2012; Maturana \& Vargas, 2015).

De acuerdo con Maturana y Vargas (2015), un estudiante puede sentirse estresado al evaluar que las exigencias presentadas en el ámbito escolar sobrepasan sus capacidades y, al no resolver esta sobrecarga, el estrés permanecerá por largos periodos de tiempo, aumentando el riesgo a la salud. 


\section{CAPÍTULO 4}

Se considera que el exceso de responsabilidades, las altas cargas de trabajo dentro o fuera de la escuela, la evaluación de los docentes, la competitividad, el miedo a fracasar, la presión de los padres, la rivalidad con otros compañeros, los constantes cambios en alimentación y horas de sueño, así como el cansancio cognitivo, son algunos de los factores que pueden iniciar o desencadenar el estrés escolar (Maturana \& Vargas, 2015).

Según Aguilar et al. (2015):

los estudiantes deben dominar cada vez más las exigencias y retos que les demanda la gran cantidad de recursos físicos y psicológicos para enfrentar esta problemática. Tal situación les puede hacer experimentar agotamiento, poco in-

terés frente al estudio, nerviosismo e incluso pérdida de control. (pp.163-164)

Además, mencionan que fomenta el consumo de drogas y produce alteraciones en el ciclo de sueño y vigilia. Francisco (2015) afirmó que los elevados niveles de estrés terminan provocando deterioro en el rendimiento académico; por su parte, Phinder et al. (2014) aseguraron que este padecimiento contribuye al fracaso escolar y a la deserción de la carrera; en casos graves, indicó Zeidner (1998), puede llevar al suicidio.

Los síntomas físicos también se hacen presentes, dolores de cabeza, deseo de comer a todas horas, problemas gastrointestinales, explosiones de ira, dolores de cuello e imposibilidad de concentrarse son algunos de ellos (Arita, 1997). Además, el estrés académico se ha asociado a la depresión, agotamiento y ansiedad (Naranjo, 2009), enfermedades cardiacas (Lowe et al., 2000) y fallas en el sistema inmune (Pérez et al., 2014).

Los hallazgos y datos referentes a la presencia de estrés en población universitaria son alarmantes. Aguilar et al. (2015) señalaron que, "En Cuba, la situación es similar a la reportada en otros países; un estudio realizado en el año 2002 en La Habana, para determinar algunas características del estrés" (p.173), reflejó que el 69.2\% de los estudiantes era vulnerable al estrés. En un estudio realizado por Bedoya et al. (2014), se observó que la prevalencia de estrés académico en 184 estudiantes de medicina fue de $77.5 \% \mathrm{y}$, según años de estudios, el 82.5\% de estudiantes de primer año presentaron estrés, el $67.2 \%$ de cuarto año y $80.4 \%$ de séptimo año. 


\section{CAPÍTULO 4}

Maturana y Vargas (2015) llevaron a cabo estudios realizados en Canadá en los que observaron que el 58\% de una muestra de 374 estudiantes presentaron lo que llamaron ansiedad antes del examen, es decir, estrés académico. El segundo estudio realizado con 1091 estudiantes mostró que el 54\% de los alumnos se sentía estresado frente a diversas situaciones escolares, mientras que el 86\% de los alumnos de educación media informó sentirse estresado durante el segundo semestre académico del año en curso y por otro.

Aunque no hay muchos datos referentes al estrés académico, las cifras encontradas son alarmantes, Lemos et al. (2018) mencionaron que en Brasil la prevalencia de estrés y trastornos emocionales es superior al 70\% en estudiantes universitarios. Santos (2017) observó una prevalencia de 87.2\% en estudiantes de la Universidad de Cuenca en Ecuador y una asociación estadísticamente significativa con el estado civil y carreras de Medicina, Odontología, Enfermería y Psicología Clínica. La Encuesta Nacional de Epidemiología Psiquiátrica realizada en el 2015 (Medina et al., 2015) indicó que, en la Ciudad de México, 16\% de la población en edad escolar presenta indicios de algún padecimiento mental. Del total, $19 \%$ sufre inquietud, $17 \%$ irritabilidad, $16 \%$ nerviosismo y $14 \%$ problemas de concentración.

El estrés académico es aquel que padecen los alumnos fundamentalmente de educación media y superior, y que tiene como fuente exclusiva a estresores relacionados con las actividades a desarrollar en el ámbito escolar (Aguilar et al., 2015). Esta definición se circunscribe al estrés que padecen los alumnos a consecuencia de las exigencias endógenas o exógenas que impactan su desempeño en el ámbito escolar, los estudiantes de medicina no están exentos de este.

Se ha encontrado que los estudiantes de medicina presentan estrés por la dificultad para comprender los temas, la proximidad de las evaluaciones, el abuso hacia el estudiante, los conflictos éticos presentes en la toma de decisiones en el internado y la exposición ante la muerte y el sufrimiento humano (Castillo et al., 2016). Por su parte, Toribio y Franco (2016) mencionaron que los factores que influyen para que se presente el estrés son los periodos de exámenes, la sobrecarga y exigencia académica, el inicio de la carrera, una enseñanza y aprendizaje memorístico, las exposiciones en público, deficiencias docentes y la obtención de bajas notas escolares. 


\section{CAPÍTULO 4}

Aunado a ello, Aguilar et al. (2015) identificaron que el hacerle frente a la inserción al mundo laboral a través de las prácticas profesionales, el servicio social y la residencia médica, puede resultar complejo, ya que el estudiante de medicina se inserta en la realidad del paciente, la atención hospitalaria, el constante contacto con la enfermedad, sufrimiento y muerte, así como a la competitividad laboral con sus compañeros, lo que puede causarle altos niveles de estrés al no saber hacer frente a estas nuevas experiencias.

Tal como podemos apreciar, la presencia de estrés en estudiante universitarios, sobre todo de la carrera de Medicina, es una condición cada vez más frecuente que puede acarrear severas alteraciones a la salud y afectar considerablemente su desempeño académico; debido a ello, el objetivo de esta investigación es identificar la presencia de estrés en los estudiantes de la carrera de Medicina de una universidad pública de Guadalajara, México.

\section{Método}

\section{Participantes}

Participaron voluntariamente 300 estudiantes de ambos sexos con una edad promedio de 20 años, adscritos a la Licenciatura de Médico Cirujano y Partero en dos centros universitarios que cursaban el primer, tercer y sexto semestre, de una universidad pública del estado de Jalisco, su edad promedio fue de 20 años ( $\mathrm{DT}=1.9$ años). Se excluyeron a aquellos participantes que trabajaban, estuvieran casados o tuvieran hijos.

\section{Equipo e instrumentos}

Para esta investigación se utilizó una ficha de datos sociodemográficos y escolares. Se empleó el inventario sisco del estrés académico (Barraza, 2007), que tiene como objetivo reconocer las características del estrés que suelen acompañar a los estudiantes de educación media superior, superior y posgrado durante sus estudios, tiene una confiabilidad de alfa de Cronbach de 0.90. Puede ser autoadministrado o solicitar su llenado de manera individual o colectiva, tiene una duración aproximada de 10 a 15 minutos. El inventario cuenta con 31 preguntas; para responderlas se utiliza una escala que va del 1 al 5 en donde el valor de 1 representa nunca, 2 rara vez, 3 algunas veces, 4 casi siempre y 5 siempre. 


\section{CAPÍTULO 4}

El inventario tiene cuatro áreas: en el área 1 se evalúa la preocupación o nerviosismo presentada en cada estudiante y su frecuencia; en el área 2 se analiza el reconocimiento por parte del individuo para identificar momentos de estrés durante su trayecto estudiantil; el área 3 se centra en las reacciones físicas causadas por el estrés; y, por último, el área 4 se centra en las reacciones psicológicas y comportamentales presentes en cada estudiante.

\section{Diseño y procedimiento}

Se llevó a cabo una investigación cuantitativa, transversal y analítica. A cada estudiante se le invitó a participar en el estudio, los que aceptaron firmaron el consentimiento informado y se les explicó el objetivo de la investigación. Enseguida y de manera individual, se les entregó un formato del inventario sisco (Barraza, 2007) y se les pidió que lo respondieran en silencio. La recolección de los datos se llevó a cabo en el periodo comprendido de octubre a noviembre del 2018.

\section{Consideraciones éticas}

La investigación se ajustó a los principios éticos de Helsinki (Asociación Médica Mundial, 2001), a los criterios del Reglamento de la Ley General de Salud de México en Materia de Investigación para la Salud (2014). Se tomó como consideración ética, el anonimato y la confidencialidad de los participantes. Para la autorización de la participación y uso de la información se utilizó un formato a manera de consentimiento informado, el cual firmaron de manera personal.

\section{Resultados}

El 58\% de los participantes eran mujeres y el $42 \%$ hombres con un promedio de edad de 20 años ( $\operatorname{mín}=17$, máx $=31$, DT $=20$ ). El 41\% cursaban el primer semestre, el 31\% el tercer semestre y el 28\% el sexto semestre. En cuanto a su adscripción, el $46.7 \%$ pertenecían a un centro universitario que, en lo sucesivo, nombraremos como C1 y el 53.3\% pertenecía al segundo centro universitario que, en lo sucesivo, nombraremos como C2. El promedio de calificación de la muestra fue de 93.96 en una escala del 0 al 100 y las horas diarias de estudio promedio fueron de 5.59. 
En la tabla 1, se muestran los resultados globales del nivel de estrés, destacan altos niveles de estrés profundo, independientemente de cualquier característica, aunque cabe señalar que son más mujeres las que presentan estrés en comparación con los hombres, así como los que cursan en tercer semestre y los que pertenecen al Centro Universitario C1.

\section{Tabla 1}

\section{Distribución porcentual de los participantes por grado de estrés}

\begin{tabular}{lccc} 
& Leve & Moderado & Profundo \\
Global & $6.0 \%$ & $24.7 \%$ & $69.3 \%$ \\
\hline Sexo & & & \\
Hombre & $8.7 \%$ & $30.7 \%$ & $60.6 \%$ \\
Mujer & $4.0 \%$ & $20.2 \%$ & $75.7 \%$ \\
\hline Semestre & & & \\
Primero & $33 . \%$ & $26.4 \%$ & $70.2 \%$ \\
Tercero & $5.3 \%$ & $17.9 \%$ & $76.8 \%$ \\
Sexto & $10.7 \%$ & $29.8 \%$ & $59.5 \%$ \\
\hline Centro Universitario & & & \\
C1 & $2.9 \%$ & $17.9 \%$ & $79.3 \%$ \\
C2 & $8.8 \%$ & $30.6 \%$ & $60.6 \%$ \\
\hline
\end{tabular}

Nota. $\mathrm{n}=300$.

Respecto a los tipos de estresores y su nivel de frecuencia experimentado, observamos que las evaluaciones de los profesores, la sobrecarga de actividades escolares, la personalidad del profesor son los que reportan mayores niveles (tabla 2).

Por otro lado, los principales síntomas físicos fueron fatiga crónica, somnolencia o mayor necesidad de dormir y dolores de cabeza (tabla 3). Los síntomas psicológicos más recurrentes fueron ansiedad, inquietud y depresión, problemas para concentrarse principalmente (tabla 4 ). 


\section{Tabla 2}

Puntaje promedio obtenido en cada uno de los estresores

\begin{tabular}{lcc} 
& Media & DT \\
Competencia entre compañeros & 2.87 & 1.18 \\
Sobrecarga de trabajo & 3.85 & 0.98 \\
Personalidad del docente & 3.39 & 1.12 \\
Evaluaciones escolares & 4.06 & 0.95 \\
Tipo de actividad escolar & 3.31 & 1.13 \\
Dificultad para comprender & 3.25 & 1.32 \\
Tiempo limitado de los trabajos & 3.61 & 1.22 \\
Participación en clase & 2.98 & 1.19 \\
\hline
\end{tabular}

Nota. $\mathrm{n}=300$.

\section{Tabla 3}

Puntaje promedio obtenido de los síntomas físicos experimentados

\begin{tabular}{lcc} 
& Media & DT \\
Trastornos en el sueño & 2.46 & 1.19 \\
Fatiga crónica & 3.20 & 1.14 \\
Dolores de cabeza o migrañas & 2.70 & 1.17 \\
Problemas de digestión, dolor abdominal o diarrea & 2.48 & 1.22 \\
Somnolencia o mayor necesidad de dormir & 3.56 & 1.10 \\
Rascarse, morderse las uñas, frotarse, etc. & 2.62 & 1.37 \\
\hline
\end{tabular}

Nota. $\mathrm{n}=300$. 


\section{Tabla 4}

Puntaje promedio obtenido de los síntomas psicológicos experimentados

\begin{tabular}{lcc} 
& Media & DT \\
\hline Inquietud (incapacidad de relajarse y estar tranquilo) & 3.05 & 1.16 \\
Sentimientos de depresión y tristeza (decaído) & 3.03 & 1.29 \\
Ansiedad, angustia o desesperación & 3.19 & 1.19 \\
Problemas de concentración & 3.01 & 1.16 \\
Sentimiento de agresividad o aumento de irritabilidad & 2.64 & 1.23 \\
\hline
\end{tabular}

Nota. $\mathrm{n}=300$.

Los síntomas que se presentan con mayor frecuencia en las actitudes y comportamientos de los estudiantes que presentan niveles alto de estrés son el aumento o reducción del consumo promedio de alimentos durante el día, el desgano por continuar con las actividades escolares diarias y el aislamiento de su círculo social (tabla 5). Finalmente, las estrategias de afrontamiento empleadas con mayor frecuencia fueron la habilidad asertiva, la elaboración de un plan y ejecución de sus tareas, así como la verbalización de sus preocupaciones (tabla 6).

\section{Tabla 5}

Puntaje promedio obtenido de los síntomas comportamentales experimentados

\begin{tabular}{lcc} 
& Media & DT \\
Conflictos o tendencia a polemizar o discutir & 2.30 & 1.10 \\
Aislamiento de los demás & 2.43 & 1.21 \\
Desgano para realizar las labores escolares & 2.90 & 1.18 \\
Aumentos o reducción del consumo de alimentos & 3.03 & 1.29 \\
\hline
\end{tabular}

Nota. $\mathrm{n}=300$. 


\section{Tabla 6}

\section{Puntaje promedio obtenido de las estrategias de afrontamiento experimentadas}

\begin{tabular}{lcc} 
& Media & DT \\
Habilidad asertiva & 3.38 & 1.17 \\
Elaboración de un plan y ejecución de sus tareas & 3.38 & 1.14 \\
Elogios a sí mismo & 2.63 & 1.21 \\
La religiosidad (oraciones o asistencia a misa) & 2.17 & 1.30 \\
Búsqueda de información sobre la situación & 2.73 & 1.28 \\
Verbalización de la situación que preocupa & 2.81 & 1.26 \\
Relajarme & 5.00 & 0.0 \\
\hline
\end{tabular}

Nota. $\mathrm{n}=300$.

Para establecer la relación y determinar si existen significancias estadísticas llevamos a cabo pruebas de correlación de Pearson y observamos que, el sexo y el nivel de estrés se correlacionaron significativamente $(\mathrm{rxy}=0.239, \mathrm{p}=.000)$, así como el promedio escolar $\mathrm{y}$ el nivel de estrés ( $\mathrm{rxy}=.131, \mathrm{p}=025)$. También observamos correlación estadísticamente significativa entre el Centro Universitario y el nivel de estrés ( $r x y=-0.206, p=0.000$ ).

Por otra parte, el nivel de estrés se correlacionó negativamente con el semestre cursado ( $\mathrm{rxy}=-0.125, \mathrm{p}=.030$ ), así como con las horas de sueño $(\mathrm{rxy}=-0.210, \mathrm{p}=.000$ ). Asimismo, el promedio escolar se asoció positivamente con la presencia de ansiedad, angustia o desesperación ( $\mathrm{rxy}=0.136, \mathrm{p}=.024)$ y con las habilidades de afrontamiento "habilidad asertiva" ( $r x y=0.169, \mathrm{p}=.005)$ y "elaboración de un plan de ejecución de sus tareas" $(\mathrm{rxy}=0.129, \mathrm{p}=.033)$.

\section{Discusión}

La importancia de llevar a cabo la presente investigación, en primer lugar, radicó en los pocos estudios llevados a cabo en el contexto mexicano, pese a que, en los últimos tiempos, el estrés es un tema de salud de alta prioridad a nivel mundial. Tal como lo han reportado autores de otros países latinos (Lemos et al., 2018; Santos, 2017), se observa una alta presencia de estudiantes con niveles profundos de estrés en la muestra de estudiantes de la carrera de Medicina. 


\section{CAPÍTULO 4}

Coincidimos con los hallazgos reportados por Bedoya et al. (2014), que indican que los primeros años de la carrera pueden resultar más abrumadores para el alumno; en nuestro caso, también apreciamos que una mayor proporción de estudiantes de primer semestre reportaron más altos niveles de estrés, esto nos hace suponer que la incertidumbre hacia la carrera, los nuevos estilos de enseñanza, las exigencias específicas de la carrera, entre otras, causan en el estudiante una sensación de incapacidad para hacerle frente a los nuevos retos escolares.

El hecho de que las mujeres presenten mayores niveles de estrés nos remite necesariamente a una perspectiva de género, en donde los atributos sociales y culturales establecen determinados roles a los hombres y a las mujeres, de tal forma que, como lo señalaron Segura y Pérez (2016), aunque los estresores pueden ser incluso los mismos, existen diferencias en la forma como afectan a un hombre o a una mujer y en la forma para hacerles frente. Resultará importante llevar a cabo investigaciones futuras sobre el estrés desde una aproximación de género.

Tener un desempeño escolar alto está asociado a la presencia de estrés, debido a que podemos suponer que los estudiantes que sobresalen tienden a preocuparse más que el resto por aprender, lograr un promedio mayor, así como cumplir con todas las demandas escolares y de su vida personal; en este sentido, según Chacón (2018), un mejor rendimiento académico se asocia con el reporte de mayor intensidad del estrés. Resultará importante evaluar y fortalecer estrategias de aprendizaje que beneficien el desempeño escolar sin poner en riesgo el estado de salud del alumnado; por su parte, Phinder et al. (2014) afirmaron que el adecuado afrontamiento del estrés académico ocurre cuando se proveen estrategias de organización y manejo del tiempo libre, así como de técnicas de estudio a los estudiantes universitarios.

La presencia de estrés profundo también está relacionada con la falta de adecuadas estrategias de afrontamiento; en la muestra estudiada, observamos que suelen emplear la relajación, la planeación y la asertividad como mecanismos para hacerle frente a los estresores, es recomendable profundizar en la forma como estas son llevadas a cabo, ya que, tal como lo señaló Morales (2018), el empleo de estrategias funcionales o productivas, guarda relación con un mayor bienestar, adaptación y ajuste en el ámbito universitario. Por lo que, si se realizan adecuadamente, es altamente probable que el estrés no se haga 


\section{CAPÍTULO 4}

presente por periodos prolongado, ya que evitarán la acumulación paulatina de tareas y pendientes escolares, sobre todo cuando el estudiante se cree incapaz de realizarlas en $\tan$ poco tiempo.

Nuestra investigación constata que la carrera de Medicina representa un ambiente de estrés para los que deciden formarse como profesionistas de la salud, implica sobrecarga de trabajo y de evaluaciones, lo que facilita la presencia de fatiga, somnolencia, dolores de cabeza, problemas de concentración, ansiedad e inquietud. Lo anterior no solo se experimenta al inicio del semestre, sino que es probable que cuando ingresan a los escenarios hospitalarios y tengan contacto con el sufrimiento y la muerte, perciban un ambiente estresante, sobre todo en aquellos con pocas habilidades positivas de afrontamiento. Existe evidencia que indica que los médicos residentes experimentan estrés, atribuido a la sobrecarga de trabajo, ambiente físico degradado, exceso de responsabilidad, falta de incentivos, burocracia organizativa, evaluaciones, competencia grupal, exigencias de médicos adscritos y compañeros de mayor jerarquía (Arenas, 2006).

Destaca el hecho de que el centro universitario de adscripción muestra diferencias en los niveles de estrés, lo cual puede explicarse a partir de las diferencias en las exigencias de cada centro y la propia competitividad entre compañeros. De acuerdo con Maturana y Vargas (2015), la escuela constituye un lugar de desarrollo diario que puede afectar la estabilidad general del estudiante; además, que para evaluar el significado individual de los estresores es importante considerar el contenido de las situaciones generadoras de estrés y la intensidad o significado subjetivo que cada individuo adjudica a lo vivenciado $\mathrm{y}$ al entorno.

A la luz de nuestros hallazgos, y tal como lo mencionan Condoyque et al. (2016), resulta indispensable que las Instituciones de Educación Superior (IEs) implementen estrategias psicoeducativas para que los estudiantes adquieran habilidades de afrontamiento positivas. Asimismo, la sistematización de procesos diagnósticos de este tipo de problemáticas favorecerá la temprana detección y la adecuada derivación. 


\section{CAPÍTULO 4}

\section{Referencias}

Aguilar, B., Calcines, M., Monteagudo, R., \& Nieves, Z. (2015). Estrés académico. Revista Edumecentro, 7(2), 163-178. http://scielo.sld.cu/scielo. php?script=sci_arttext\&pid=S2077-28742015000200013

Ahued, A. (2018). 75\% de los mexicanos padece estrés, escasa funcionalidad laboral y académica. Excelsior. https://www.excelsior.com.mx/opinion/armando-ahued/75-de-losmexicanos-padece-estres-escasa-funcionalidad-laboral-y-academica

Arenas, O. (2006). Estrés en médicos residentes en una Unidad de Atención Médica de tercer nivel. Revista Medigraphic, 28(2), 103-109. https://www.medigraphic.com/pdfs/cirgen/ cg-2006/cg062h.pdf

Arita, B. (1997). Síntomas de estrés en estudiantes de psicología. Documento Interno. Universidad Autónoma de Sinaloa.

Asociación Médica Mundial. (2001). Declaración de Helsinki de la AmM. Principios éticos para las investigaciones médicas en seres humanos. https://www.wma.net/ es/policies-post/declaracion-de-helsinki-de-la-amm-principios-eticos-para-lasinvestigaciones-medicas-en-seres-humanos/

Barraza, A. (2007). Inventario sisco sv-21. Inventario Sistémico Cognoscitivista para el estudio del estrés académico. Segunda versión de 21 items. ECORfan. http://www.ecorfan.org/ libros/Inventario_SISCO_SV-21/Inventario_sist\%C3\%A9mico_cognoscitivista_para_ el_estudio_del_estr\%C3\%A9s.pdf

Barrio, J., García, M., Ruíz, I., \& Arce, A. (2006). El estrés como respuesta. International Journal of Developmental and Educational Psychology, 1(1), 37-48. https://www.redalyc. org/pdf/3498/349832311003.pdf

Bedoya, F., Matos, L., \& Zelaya, E. (2014). Niveles de estrés académico, manifestaciones psicosomáticas y estrategias de afrontamiento en alumnos de la facultad de medicina de una universidad privada de Lima en el año 2012. Revista Neuropsiquiatría, 77(4), 262270. http://www.scielo.org.pe/pdf/rnp/v77n4/a09v77n4.pdf

Berrío, N., \& Mazo, R. (2011). Estrés académico. Revista de Psicología Universidad de Antioquia, 3(2), 65-82. http://pepsic.bvsalud.org/pdf/rpsua/v3n2/v3n2a6.pdf 


\section{CAPÍTULO 4}

Castillo, C., Chacón, T., \& Díaz, G. (2016). Ansiedad y fuentes de estrés académico en estudiantes de carreras de la salud. Revista Investigación en Educación Médica, 5(20), 230237. http://www.redalyc.org/articulo.oa?id=349747925004

Chacón, C. (2018). Estrés y rendimiento académico en los estudiantes de primer año de la escuela de medicina de la universidad Pablo Guardado Chávez 2017-2018 (Tesis de Licenciatura). Universidad Autónoma de Chiapas, México. https://static.elsevier.es/jano/ estresyrendimiento.pdf

Condoyque, K., Herrera, A., Ramírez, A., Hernández, P., \& Hernández, L. (2016). Nivel de Estrés en los Estudiantes de las Licenciaturas en Enfermería y Nutrición de la Universidad de la Sierra Sur. Revista Salud y Administración, 3(9), 15-24. https://revista.unsis.edu.mx/ index.php/saludyadmon/article/view/36

Expansión. (2019). El 43\% de los mexicanos padecen estrés laboral y estas son las consecuencias. https://expansion.mx/vida-arte/2019/08/20/43-los-mexicanos-padecen-estres-laboralconsecuencias

Francisco, H. (2015). Estrés en adolescentes que estudian y trabajan (Tesis de Licenciatura). Universidad Rafael Landivas, Guatemala. http://recursosbiblio.url.edu.gt/ tesiseortiz/2015/05/22/Mendez-Hugo.pdf

Lazarus, R., \& Folkman, S. (1984). Stress, appraisal and coping. Springer Publishing Company. Lemos, M., Pérez, M., \& López, D. (2018). Estrés y Salud Mental en Estudiantes de Medicina: Relación con Afrontamiento y Actividades Extracurriculares. Archivos de medicina, 14(2), 1-8. https://dialnet.unirioja.es/metricas/documentos/ARTREV/6499267

Lowe, G., Urquhart, J., Greenman, J., \& Lowe, G. (2000). Academic Stress and Secretory Immunoglobulin A. Psychological Reports, 87(3), 721-722. https://doi. org/10.2466\%2Fpr0.2000.87.3.721

Maturana, A., \& Vargas, A. (2015). El estrés escolar. Revista Médica Clínica Las Condes, 26(1), 34-41. https://www.researchgate.net/publication/273791533_El_estres_escolar

Medina, M., Borges, G., \& Benjet, C. (2015). Encuesta Nacional de Epidemiología Psiquiátrica en Adultos-México. http://inprf.gob.mx/psicosociales/archivos/encuestaepidemiologia. pdf 


\section{CAPÍTULO 4}

Morales, F. (2018). Estrategias de afrontamientos en una muestra de estudiantes universitarios. International Journal of Developmental and Educational Psychology, 2(1), 289-293. http:// www.infad.eu/RevistaINFAD/OJS/index.php/IJODAEP/article/view/1228/1061

Naranjo, M. (2009). Una revisión teórica sobre el estrés y algunos aspectos relevantes de este en el ámbito educativo. Revista Educación, 33(2), 171-190.

Pérez, D., García, G., García, T., Ortiz, D., \& Centelles, M. (2014). Conocimientos sobre estrés, salud y creencias de control para la Atención Primaria de Salud. Revista Cubana de Medicina General Integral, 30(3), 354-363. http://scielo.sld.cu/pdf/mgi/v30n3/mgi09314. pdf

Phinder, M., Sánchez, A., Romero, F., Vizcarra, J., \& Sánchez, E. (2014). Percepción sobre factores estresantes en estudiantes de Medicina de primer semestre, sus padres y sus maestros. Revista Investigación en Educación Médica, 3(11), 139-146. http://www.scielo. org.mx/pdf/iem/v3n11/v3n11a4.pdf

Santos, J. (2017). Prevalencia de estrés académico y factores asociados en estudiantes de ciencias de la salud de la Universidad Católica de Cuenca, 2016 (Tesis de maestría). Universidad de Cuenca, Ecuador. http://dspace.ucuenca.edu.ec/bitstream/123456789/26542/1/TESIS. pdf

Reglamento de la Ley General de Salud en Materia de Investigación para la Salud. (2014). Nuevo Reglamento publicado en el Diario Oficial de la Federación el 6 de enero de 1987. Última reforma publicada DOF 02-04-2014. http://www.diputados.gob.mx/LeyesBiblio/ regley/Reg_LGS_MIS.pdf

Segura, R., \& Pérez, I. (2016). Impacto diferencial del estrés entre hombres y mujeres: una aproximación desde el género. Revista Alternativas en Psicología, 36, 105-120. https:// www.alternativas.me/attachments/article/138/Impacto\%20diferencial\%20del\%20 estr\%C3\%A9s\%20entre\%20hombres\%20y\%20mujeres.pdf

Toribio, C., \& Franco, S. (2016). Estrés Académico:El Enemigo Silencioso del Estudiante. Revista Salud y Administración, 3(7), 11-18. http://www.unsis.edu.mx/SaludyAdministracion/07/ A2_ESTRES.pdf

Zeidner, M. (1998). Test anxiety: The state of the art. Plenum Press. 


\title{
CAPÍTULO 5
}

\section{Consumo de alcohol, depresión y ansiedad en jóvenes universitarios}

\author{
Ana Luisa Alejandre Alcantar, Jennifer Daana Ávila Cervantes, \\ Javier González Guzmán, Estefania Ochoa Montañez y Roberto Oropeza Tena
}

La Encuesta Nacional de Consumo de Drogas, Alcohol y Tabaco (Encodat) (ReynalesShigematsu et al., 2017) señala que el uso de alcohol es el principal problema de uso de sustancias en México. Además, indica que el 71\% de toda la población de 12 a 65 años en nuestro país ha consumido alcohol alguna vez en la vida $(80.1 \%$ hombres y $62.6 \%$ mujeres), el $49.1 \%$ (41.8 millones) lo ha usado en el último año (59.8\% hombres y $39 \%$ mujeres) y el $35.9 \%$ en el último mes ( $48.1 \%$ hombres y $24.4 \%$ mujeres). Respecto al consumo en población adulta (de 18 a 65 años), alguna vez en la vida ha consumido alcohol el 77.3\% (88.3\% hombres y 67.3\% mujeres); el 53.3\% consumió durante el último año (37.8 millones), de los cuales, el $66.4 \%$ son hombres y el $41.3 \%$ mujeres. Asimismo, el consumo excesivo de alcohol lo tuvo el $22.1 \%$, siendo el $34.4 \%$ hombres y el $10.8 \%$ mujeres. Por último, la posible dependencia a esta sustancia fue del $2.5 \%$, lo que implica que consumieron aproximadamente 1.7 millones de personas, entre las cuales el $4.6 \%$ fueron hombres y $0.6 \%$ mujeres.

Por su parte, Slade et al. (2016) hicieron una revisión sistemática, identificando las diferencias en el consumo de alcohol entre hombres y mujeres; señalan que los datos de los estudios de todo el siglo xx y lo que va del xxI, desafortunadamente, se ha ido cerrando cada vez más la brecha respecto al consumo de alcohol entre hombres y mujeres.

Hay un alto costo por abusar del consumo de esta sustancia, ya que las consecuencias de su consumo pueden ser muy graves o hasta mortales. Pueden ir desde enfermedades biológicas o psicológicas hasta distanciamiento en las relaciones sociales o familiares (Ahumada-Cortez et al., 2017; Castaño-Pérez \& Calderón-Vallejo, 2014). 


\section{CAPÍTULO 5}

Flórez et al. (2018) señalaron que tiene diferentes efectos (que pueden ser muy complejos) sobre la conducta. Tiene propiedades que pueden ser muy distintas, ya que aparentemente genera un estado estimulante y euforizante, aunque en realidad es sedante. Además, su consumo puede presentar efectos placenteros o muy desagradables. Entre algunos de los problemas fisiológicos o de salud están las alteraciones digestivas (cirrosis, pancreatitis), musculoesqueléticas (osteoporosis, miopatía), endócrinas (hipogonadismo o alteraciones en el ciclo hormonal), cardiovasculares (muerte súbita, accidente cerebro vascular), respiratorias (neumonía, tuberculosis), sobrepeso y otras más, incluyendo el cáncer. Otro tipo de problemáticas son las sociales, que se relacionan sobre todo con el efecto agudo de esta bebida. Encontrándose una fuerte correlación entre la cantidad de alcohol consumida y este tipo de problemas. Algunos de estos son los problemas familiares (maltrato familiar, separación, divorcio), laborales (absentismo, bajo rendimiento, accidentes) y judiciales (accidentes, violencia callejera, delitos) (Gogeascoechea-Trejo et al., 2016). Entre los problemas psicológicos están el alcoholismo, los trastornos de la personalidad, los problemas con la autoridad, la ruptura o separación de relaciones sociales, la deficiencia laboral, así como la depresión y la ansiedad, dos de los trastornos más comunes y graves que enfrenta nuestra sociedad (Bellos et al., 2020). En esta investigación, nos enfocaremos en el consumo de alcohol y su interacción con estos dos últimos problemas.

El National Institute on Drug Abuse (2007) hizo una investigación en la que muestra que en Canadá, México y Estados Unidos existe un considerable abuso de alcohol en estudiantes universitarios. El alcoholismo en alumnos de nivel superior es un tema importante en la salud pública en nuestro país (Gómez-Maqueo et al., 2009). Barradas et al. (2016) hicieron un estudio con 4821 estudiantes de la Universidad Veracruzana para identificar la prevalencia del consumo de alcohol; el 83\% de los participantes señaló haberlo consumido alguna vez en la vida, el 52.8\% indicó tener un consumo moderado, el $17.4 \%$ un consumo abusivo y el $7.8 \%$ un consumo de riesgo.

Castaño-Pérez y Calderón-Vallejo (2014) realizaron una investigación en estudiantes universitarios, donde analizaron el consumo de alcohol y los problemas psicosociales asociados. Observaron que el consumo afecta de manera importante su nivel académico, las relaciones sociales, así como el área sexual y psicológica. 


\section{CAPÍTULO 5}

La depresión y la ansiedad se refieren a aquellos trastornos psicológicos que causan deficiencias comportamentales en los individuos (Arrieta et al., 2014). Ambos trastornos están muy asociados con el consumo de drogas, en ambos géneros. Contreras-Olive et al. (2020), quienes realizaron una investigación en consumidores adictos a sustancias psicoactivas en deshabituación, en un hospital en Cuba, encontraron que había pacientes que presentaban tanto depresión como ansiedad. Además, identificaron que el tiempo de consumo estuvo relacionado con la intensidad de los síntomas y que entre más intensos fueran los síntomas afectivos, había mayor probabilidad de consumo.

La depresión podría definirse como un trastorno del estado de ánimo donde hay una alteración del comportamiento, que lleva a la persona a tener malestar y discapacidad y, en casos graves, se asocia con sufrimiento, dolor, peligro de vida o muerte (GonzálezForteza et al., 2015). Este trastorno se relaciona con ausentismo en la vida social, laboral o escolar, lleva a ideaciones de duda sobre su existencia, de su motivación de vivir y puede llevar a tener pensamientos y actos suicidas.

Vallejo et al. (2019) realizaron un estudio cuyo objetivo fue analizar el consumo de sustancias y la sintomatología depresiva en estudiantes universitarios, en el cual participaron 4543 universitarios. Estos autores identificaron en las mujeres una mayor sintomatología relacionada con la depresión que los hombres; encontraron que las mujeres con síntomas de depresión consumen alcohol en exceso, mientras que los hombres muestran síntomas de dependencia. Además, hallaron que la sintomatología depresiva en ambos géneros aumenta con el policonsumo de drogas. Diferentes estudios, han mostrado una relación importante entre el consumo de alcohol y la depresión en estudiantes adolescentes y adultos jóvenes (Hernández-Cortaza et al., 2018). Por su parte, Emiro et al. (2018) encontraron una correlación baja, pero estadísticamente significativa, entre el consumo de alcohol y la depresión en estudiantes universitarios. Martínez-Martínez et al. (2016) hicieron un estudio sobre síntomas depresivos en estudiantes de medicina e identificaron que el 95.3\% tenía por lo menos un síntoma en las últimas dos semanas y casi el 32\% parecía cumplir con los criterios del síndrome depresivo mayor.

La ansiedad se caracteriza por una sensación de aprensión imprecisa, incómoda y vaga. Es una respuesta emocional a una amenaza futura y se acompaña de un sentimiento desagradable y síntomas somáticos de tensión; puede estar acompañada por síntomas 


\section{CAPÍTULO 5}

vegetativos como cefalea, diaforesis, taquicardia, opresión torácica, malestar epigástrico e inquietud (Cardona-Arias et al., 2015). Es un trastorno que hace que el sujeto no logre estabilizarse en su medio ambiente, es decir, lo mantiene en estados de alerta y exaltación, con constantes ideas particulares sobre situaciones estresantes o preocupantes que le causan alteraciones emocionales (Arrieta et al., 2014).

Los universitarios están expuestos a toda una serie de requerimientos psicológicos, sociales y académicos, por lo que son un grupo de riesgo alto para la ansiedad. Castaño-Pérez y Calderón-Vallejo (2014) hicieron una investigación en universitarios para analizar el consumo de alcohol y los problemas psicosociales asociados; encontraron que la ansiedad se presentaba con una frecuencia muy alta en los consumidores de bebidas alcohólicas, de los cuales el $37.3 \%$ eran casos de abuso y el 50\% eran casos de dependencia.

Por su parte, Arrieta et al. (2014), en una investigación con 973 universitarios, identificaron que 634 padecían ansiedad y, de ellos, el $80.1 \%$ eran consumidores habituales de alcohol; de estos últimos, el 27.6\% tenían un consumo riesgoso, perjudicial o estaban en riesgo de dependencia. Asimismo, encontraron una asociación muy alta entre la ansiedad y el consumo de alcohol con las dificultades económicas.

Beneton et al. (2021) llevaron a cabo un estudio para identificar si algunos síntomas emocionales (estrés, ansiedad y depresión) se asociaban con el uso de drogas (alcohol, tabaco y marihuana) entre estudiantes universitarios que cursaban alguna área de la salud. Identificaron que las sustancias más consumidas eran alcohol, tabaco y marihuana, en ese orden. Al correlacionar el uso de sustancias con los síntomas emocionales se encontraron asociaciones entre las tres emociones; sin embargo, las correlaciones significativas fueron con el estrés y la ansiedad, no con la depresión.

Comprender esta asociación entre el consumo de alcohol con la depresión y la ansiedad es crucial para la implementación de intervenciones en salud mental con esta población tan vulnerable; por lo tanto, el objetivo de esta investigación fue identificar la relación que hay entre el consumo de alcohol con la depresión y ansiedad en los estudiantes universitarios. Adicionalmente, se analizó si hay algún efecto con el género (hombres y mujeres) o con la edad. 


\section{Método}

\section{Tipo de estudio}

Se trató de un estudio de corte cuantitativo, de tipo correlacional descriptivo, con un diseño no experimental.

\section{Participantes}

Se entrevistaron a 200 estudiantes de diferentes carreras, entre ellas, Psicología, Químico-fármaco-biólogo y Arquitectura, en la Universidad Michoacana de San Nicolás de Hidalgo y en el Instituto Tecnológico de Morelia. Se utilizó un muestreo no probabilístico por conveniencia.

\section{Instrumentos}

Entre los instrumentos utilizados se encuentran:

- Ficha de datos generales. Para recabar información respecto a la edad, género e institución de pertenencia.

- Cuestionario CAge para el consumo de alcohol (Ewin, 1984). Es quizás el instrumento más usado para identificar el consumo abusivo de esta sustancia. El objetivo de este instrumento es identificar posibles casos de consumo problemático (abuso o dependencia). Tiene cuatro reactivos con dos opciones de respuesta (sí o no). Campos-Arias et al. (2009) identificaron que, en Colombia, el instrumento tenía una consistencia interna aceptable en población general, cuyo alfa de Cronbach variaba entre 0.75 y 0.83 .

- Escala de Depresión de Zung (EDz) (Zung, 1965). Su objetivo es identificar síntomas depresivos durante las últimas dos semanas. Es un instrumento autoaplicado que incluye 20 reactivos relacionados con la depresión, la mitad en términos positivos y la otra mitad en términos negativos. Utiliza una escala de respuesta de tipo ordinal con cuatro opciones de respuestas que son nunca, a veces, casi siempre y siempre. Por lo tanto, el puntaje total puede variar de 20 a 80 puntos. Fue probablemente una de las primeras en validarse en México (Conde et al., 1970). En un estudio sobre su validación hecho en una muestra que habla castellano se encontró que tiene un $\alpha=.689$ (Cogollo et al., 2006). También encontraron que había un 


\section{CAPÍTULO 5}

primer factor principal, denominado estado de ánimo deprimido, que explicaba el $15.8 \%$ de la varianza; mientras que también había un segundo factor, denominado síntomas cognoscitivos y somáticos, que exponía el 9.1\% de la varianza.

- Escala de Ansiedad de Hamilton (EAH) (Hamilton, 1959). El objetivo de este instrumento es valorar el grado de ansiedad en pacientes previamente diagnosticados. Incluye 14 reactivos con cinco opciones de respuesta, que van de ausente (0) a muy grave (4). Lobo et al. (2002) hicieron un estudio para evaluar las propiedades psicométricas de la versión en español de esta escala. Encontraron que tenía una buena consistencia interna $(\alpha=0.89)$, así como alta confiabilidad test-retest y entre observadores (coeficiente de correlación intraclase 0.92 y .092, respectivamente); en cuanto a su validez discriminante, se obtuvo una $\mathrm{p}<.001$, validez convergente $\mathrm{p}<.01$, y finalmente, por lo que se refiere a la sensibilidad al cambio, el tamaño del efecto fue de 1.36 .

\section{Procedimiento}

Se solicitó la autorización a las instancias pertinentes de las diferentes licenciaturas de ambas universidades (Universidad Michoacana de San Nicolás de Hidalgo e Instituto Tecnológico de Morelia, ambas ubicadas en Morelia, Michoacán). Las autoridades de dichas instituciones no tuvieron problema de otorgar los permisos correspondientes a la aplicación. Una vez en el salón de clase, a los participantes se les indicó el objetivo del estudio. A quienes aceptaban colaborar se les pidió firmar un consentimiento informado. Una vez firmado, procedían a contestar la batería de pruebas. La participación fue voluntaria y anónima. Los datos fueron recolectados por los integrantes del equipo investigador mediante procedimientos estandarizados de instrucciones en las dos instituciones participantes. El equipo investigador estuvo conformado por cuatro estudiantes de la Licenciatura en Psicología, debidamente capacitados en la aplicación de los instrumentos. Una vez terminada la aplicación, se dio las gracias a todos los estudiantes que participaron. Asimismo, se les dieron los datos del investigador principal, por si algún participante quería conocer sus resultados. 


\section{CAPÍTULO 5}

\section{Análisis de datos}

El análisis de datos se llevó a cabo con el paquete informático SPSS Statistics, versión 24. Se hizo un análisis descriptivo de los datos sociodemográficos y de las variables evaluadas (consumo de alcohol, depresión y ansiedad) usando frecuencias, porcentajes, promedios y desviación estándar. Asimismo, se hicieron comparaciones por género con la prueba $t$ para el consumo de alcohol, los niveles de depresión y de ansiedad. Se realizó una correlación de Pearson para evaluar la relación entre el consumo de alcohol, con el nivel de depresión y ansiedad. Por último, se llevaron a cabo análisis de regresión múltiple por pasos sucesivos entre el consumo de alcohol y depresión, ansiedad, género y edad.

\section{Consideraciones éticas}

Esta investigación se adhiere a las normas que establece el Código Ético del Psicólogo (Sociedad Mexicana de Psicología, 2010), la Norma Oficial Mexicana Nom-012-sSA3-2012 (Secretaría de Salud, 2013), que señala los criterios para la ejecución de proyectos de investigación para la salud en seres humanos y el Código Helsinki de la Asociación Médica Mundial (AMM, 2013). Para proteger la privacidad de los participantes, se les informó que los datos obtenidos serían manejados de forma confidencial y anónima, de manera que no se podía identificar quién contestó los instrumentos. También se especificó que todo era con fines académicos. La participación de los sujetos para esta investigación fue voluntaria y siempre con su consentimiento.

\section{Resultados}

Participaron 200 estudiantes, de los cuales $47.5 \%$ fueron hombres y $52.5 \%$ mujeres. El promedio de edad fue de 18.5 años ( $\mathrm{DE}=.64$ ), con un rango que iba de los 18 a los 20 años. El 54\% estaba matriculado en un programa de psicología, el 11\% en químico farmacobiología, el 15.5\% en arquitectura (los tres de la Universidad Michoacana de San Nicolás de Hidalgo) y el 19.5\% en el Instituto Tecnológico de Morelia. 


\section{Tabla 1}

Frecuencias de los niveles de alcoholismo, depresión y ansiedad total y diferenciado en hombres y mujeres

\begin{tabular}{|c|c|c|c|c|c|c|}
\hline & $\begin{array}{c}\text { Nivel de } \\
\text { alcoholismo }\end{array}$ & $\begin{array}{c}\text { Alcoholismo } \\
\% \text { (n) }\end{array}$ & $\begin{array}{c}\text { Nivel } \\
\text { depresión }\end{array}$ & $\begin{array}{c}\text { Depresión } \\
\%(\mathbf{n})\end{array}$ & $\begin{array}{c}\text { Nivel } \\
\text { ansiedad }\end{array}$ & $\begin{array}{c}\text { Ansiedad } \\
\%(\mathbf{n})\end{array}$ \\
\hline \multicolumn{7}{|l|}{ Total } \\
\hline & Sin riesgo & $45.5(91)$ & Sin & 79.5 (159) & Sin & $21.5(43)$ \\
\hline & Bajo riesgo & $26.5(53)$ & Leve & $18(36)$ & Leve & $32(64)$ \\
\hline & Riesgoso & $14(28)$ & Moderada & $2(4)$ & Moderada & $53(70)$ \\
\hline & Excesivo & 9.5 (19) & Severa & $0.5(1)$ & Grave & $11.5(23)$ \\
\hline & Dependencia & $4.5(9)$ & & & & \\
\hline \multirow[t]{5}{*}{$\begin{array}{c}\text { Hombres } \\
(\mathrm{n}=95)\end{array}$} & Sin riesgo & $33.7(32)$ & Sin & $74.7(71)$ & Sin & $18.9(18)$ \\
\hline & Bajo riesgo & $30.5(29)$ & Leve & $21.1(20)$ & Leve & $28.4(27)$ \\
\hline & Riesgoso & $15.8(15)$ & Moderada & $3.2(3)$ & Moderada & $38.9(37)$ \\
\hline & Excesivo & $12.6(12)$ & Severa & $1(1)$ & Grave & $13.7(13)$ \\
\hline & Dependencia & $7.4(7)$ & & & & \\
\hline \multirow[t]{5}{*}{$\begin{array}{c}\text { Mujeres } \\
(n=105)\end{array}$} & Sin riesgo & $56.2(59)$ & $\operatorname{Sin}$ & $83.8(88)$ & $\operatorname{Sin}$ & $23.8(25)$ \\
\hline & Bajo riesgo & $22.9(24)$ & Leve & $15.2(16)$ & Leve & $35.2(37)$ \\
\hline & Riesgoso & $12.4(13)$ & Moderada & $1(1)$ & Moderada & $31.4(33)$ \\
\hline & Excesivo & $6.7(7)$ & Severa & 0 & Grave & $9.5(10)$ \\
\hline & Dependencia & $1.9(2)$ & & & & \\
\hline
\end{tabular}

Nota. $\mathrm{n}=300$.

En la tabla 1 podemos observar las frecuencias sobre el consumo de alcohol, depresión y ansiedad. Al revisar los niveles de consumo de alcohol, medidos con la escala CAGE, vemos que el $28 \%$ presentan un consumo de riesgo, excesivo o dependencia de alcohol, de los cuales, el 35.8\% de los hombres y el 21\% de las mujeres presentan este nivel de consumo. Respecto a la depresión (medida con la EDz), solo el 2.5\% del total de los 


\section{CAPÍTULO 5}

estudiantes presentan sintomatología depresiva moderada o severa, de los cuales el $4.3 \%$ de los hombres y el 1\% de las mujeres la presentan. En cuanto a la ansiedad (evaluado con la $\mathrm{EAH}$ ), el $64.5 \%$ de todos los estudiantes presentan ansiedad moderada o grave, de los cuales el $52.6 \%$ eran hombres y el $40.9 \%$ mujeres.

En la tabla 2 se muestran los resultados de los análisis de las pruebas t para comparar el promedio de las variables en función del sexo (hombres y mujeres). Se encontraron diferencias estadísticamente significativas en la prueba CAGE de dependencia al alcohol, donde los hombres tienen un consumo mayor $(\bar{x}=1.294)$ que las mujeres $(\bar{x}=0.752)$. De acuerdo con la frecuencia de consumo de esta sustancia observada en la tabla 1, el $15.8 \%$ de los hombres y el $12.4 \%$ de las mujeres tienen un consumo riesgoso, mientras que el $12.6 \%$ de los hombres y el $6.7 \%$ de las mujeres tienen un consumo excesivo. El $7.4 \%$ de los hombres y el $1.9 \%$ de las mujeres presentan una dependencia. Estos dos últimos niveles de consumo requerirían una derivación con terapeutas expertos para iniciar un tratamiento.

No se encontraron diferencias estadísticamente significativas entre hombres y mujeres respecto al nivel de depresión observada con la EDZ. Afortunadamente, entre los hombres hay muy pocos casos moderados o severos (4.2\%); en el caso de las mujeres, solo el $1 \%$ presenta una depresión moderada.

Respecto a los niveles de ansiedad (medidos con la $\mathrm{EAH}$ ), tampoco se encontraron diferencias estadísticamente significativas entre los géneros. Sin embargo, el 13.7\% de los hombres y el 9.5\% de las mujeres, presenta una ansiedad grave; a estos estudiantes valdría la pena derivarlos con algún especialista en el tema. 


\section{Tabla 2}

Comparación del consumo de alcohol, niveles de depresión y ansiedad en función del sexo

\begin{tabular}{lccc} 
& CAGE (alcohol) & EDZ (depresión) & EAH (ansiedad) \\
\hline Prueba t & $3.302^{\star}$ & $1.134^{* *}$ & 4293 \\
$\bar{x}$ hombres & 1.294 & 45.43 & 16.71 \\
$\bar{x}$ mujeres & 0.752 & 44,41 & 14.01 \\
P (unilateral) & .001 & .258 & .075 \\
\hline
\end{tabular}

Nota. ${ }^{\star} \mathrm{gl}=182.27 ;{ }^{*} \mathrm{gl}=198$.

Se hizo un análisis de regresión múltiple por pasos sucesivos en el programa spss versión 21. Se incluyó como variable dependiente al consumo de alcohol y como variables predictoras a la depresión, ansiedad, género y edad.

\section{Tabla 3}

Correlaciones de Pearson entre la depresión, ansiedad, edad y género que arroja el modelo de regresión múltiple

\begin{tabular}{lcccc} 
& Alcohol & Depresión & Ansiedad & Género \\
Alcohol & & & \\
Depresión & .110 & & \\
Ansiedad & $.275^{\star *}$ & $.301^{\star *}$ & \\
Género & $-.231^{\star *}$ & -.080 & $-.126^{\star}$ & \\
Edad & $.173^{\star *}$ & .011 & -.001 & $-.235^{\star *}$ \\
\hline
\end{tabular}

Nota. ${ }^{\star} \mathrm{p}>.05 ;{ }^{* *} \mathrm{p}<.01$.

En la tabla 3 se muestran las correlaciones bivariadas de Pearson arrojadas por la regresión múltiple entre las variables de alcohol, depresión, ansiedad, edad y género. Se encontraron tres correlaciones positivas estadísticamente significativas con una $\mathrm{p}<.01$. La más alta fue entre la ansiedad y la depresión (.301), seguida de la de consumo de alcohol 
y ansiedad (.275), y, en último lugar, consumo de alcohol y edad (.173). Se identificaron dos correlaciones estadísticamente significativas negativas, una con una $\mathrm{p}<.01$, que fueron entre el consumo de alcohol y género (-.231), y otra con una $\mathrm{p}<.05$ que fue entre ansiedad y género.

El análisis de regresión múltiple por pasos arrojó dos modelos. El primero solo tomó como variable predictora a la ansiedad y excluyó a la depresión, edad y género. El segundo modelo tomó como variable predictora a la ansiedad y al género, excluyendo a la depresión y a la edad. De ambos modelos, el segundo tiene un poder predictivo mayor. Los resultados del segundo modelo se muestran en la tabla 4. Según el ANova que arroja el análisis, el resultado es estadísticamente significativo $(\mathrm{p}<.01)$. Este segundo modelo explicó el 10.6\% de la varianza.

\section{Tabla 4}

\section{Modelo de regresión lineal múltiple por pasos entre la depresión, ansiedad, edad y género que arroja el modelo de regresión múltiple}

$\begin{array}{llllllll}\text { Variable dependiente } & \text { Variable independiente } & \text { B } & \text { ET B } & \beta & \text { P } & \mathbf{r}^{2} \text { corregida }\end{array}$

Consumo de alcohol

.106

$\begin{array}{ccccc}\text { Ansiedad } & .027 & .007 & .250 & .0002 \\ \text { Género } & -.468 & .159 & .199 & .004\end{array}$

\section{Discusión}

Los resultados de nuestra investigación ayudaron a conocer la asociación que hay entre el consumo de alcohol y la depresión, la ansiedad, el género y la edad, en estudiantes universitarios. Poco más de una tercera parte de los estudiantes de esta muestra tiene un consumo peligroso del alcohol. Este nivel de consumo es menor al reportado en otros países, como Irlanda o el Reino Unido, donde esos estudiantes presentan un consumo mayor (Davorent et al., 2016). Respecto a las diferencias entre sexo de nuestro estudio, hay más hombres (35.4\%) con un consumo riesgoso de alcohol que mujeres (21\%), habiendo una diferencia estadísticamente significativa. Este resultado concuerda con otros estudios, donde también las mujeres tienen menor consumo que los hombres. 


\section{CAPÍTULO 5}

En cuanto a la depresión, muy pocos estudiantes salieron con niveles moderados o severos (2.5\%). Tampoco identificamos diferencias estadísticamente significativas entre hombres y mujeres. Este resultado es completamente diferente al obtenido por Wahed y Hassan (2017), quienes encontraron que el 60.8\% de estudiantes universitarios de una universidad en Egipto presentaba algún grado de ansiedad. Estos autores también observaron que había diferencias estadísticamente significativas entre hombres y mujeres. En otro estudio realizado también con universitarios en Perú (Valle et al., 2013), se encontró una prevalencia de sintomatología depresiva de $23.3 \%$, que no es tan alta como la de los estudiantes egipcios, pero tampoco tan baja como los estudiantes mexicanos.

Respecto a la ansiedad, casi dos terceras partes de la muestra presentan niveles moderados o severos (64.5\%) de este trastorno, de los cuales, los hombres presentan mayor presencia de sintomatología ansiosa que las mujeres. Estos resultados concuerdan con los de Wahed y Hassan (2017), quienes encontraron en su estudio que el 64.3\% de los estudiantes universitarios tenían alguna sintomatología ansiosa. Respecto al género, identificaron diferencias estadísticamente significativas entre hombres y mujeres, donde las mujeres presentaban más síntomas ansiosos que los hombres, en todos los niveles.

En este estudio, encontramos que el consumo de alcohol tiene una correlación baja, pero estadísticamente significativa con la ansiedad, con el género y con la edad; donde no se encontró correlación fue con la depresión. Nuestros resultados son similares a los encontrados en un estudio que se hizo con universitarios españoles y canadienses, donde Mezquita-Guillamón et al. (2016) también encontraron más motivos de consumo de alcohol asociados con la ansiedad que con la depresión.

Respecto al resultado de la correlación múltiple por pasos, se encontró que el consumo de alcohol puede ser explicado tanto por la ansiedad como por el género, teniendo mayor fuerza explicativa esta segunda variable. Ni la depresión ni la edad tuvieron algún peso en el consumo de alcohol.

Una limitación importante de este estudio es que no se analizan otros elementos relacionados con el consumo de alcohol, tal como la frecuencia o cantidad consumida. También podría ser importante identificar los patrones de consumo de alcohol o identificar los días de la semana que hay consumo (entre semana o los fines de semana), ya que 


\section{CAPÍTULO 5}

hay estudios que muestran que estas variables se relacionan con la depresión o ansiedad (Mezquita-Guillamón et al., 2014).

Se sugiere implementar estrategias institucionales para aminorar estos síntomas y fortalecer tanto el apoyo pedagógico como psicológico para evitar problemas importantes durante los estudios (Caro et al., 2019). Al respecto, Valle et al. (2013) recomendaron actuar en la prevención y detección de estas problemáticas desde el inicio de la formación académica de los estudiantes. A su vez, Vallejo et al. (2019) indicaron que es necesario que las universidades incluyan, en sus planes de estudio y módulos psicopedagógicos, un programa de corte multidisciplinario que busque la atención oportuna en la salud mental.

En conclusión, los resultados de este estudio muestran que el consumo de alcohol se relaciona con situaciones emocionales, tales como las revisadas en esta investigación (depresión y ansiedad), aunque sería interesante conocer la interacción con otras variables (como estrés). Además, es necesario conocer, en otras regiones del país, cómo se comportan las variables asociadas al consumo de sustancias (alcohol, depresión y ansiedad) en estudiantes universitarios. Quizás valdría la pena incluir, en una siguiente investigación, el consumo de metanfetaminas que, desafortunadamente, está aumentando en México (Reynales-Shigematsu et al., 2017). 


\section{CAPÍTULO 5}

\section{Referencias}

Ahumada-Cortez, J., Gámez-Medina, M., \& Valdez-Montero, C. (2017). El consumo de alcohol como problema de salud pública. Ra Ximhai, 13(2), 13-24.

Arrieta, K., Díaz, S., \& González, F. (2014). Síntomas de depresión y ansiedad en jóvenes universitarios: prevalencia y factores relacionados. Revista Clínica Médica Familiar, 7(1), 14-22.

Asociación Médica Mundial. (2013). Declaración de Helsinki de la AMM - Principios éticos para las investigaciones médicas en seres humanos. https://www.wma.net/ es/policies-post/declaracion-de-helsinki-de-la-amm-principios-eticos-para-lasinvestigaciones-medicas-en-seres-humanos/

Barradas, M. E., Fernández, N., \& Gutiérrez, L. (2016). Prevalencia de consumo de alcohol en estudiantes universitarios. Revista Iberoamericana para la Investigación y el Desarrollo Educativo, 6(12), 1-14. https://www.ride.org.mx/index.php/RIDE/article/view/213

Bellos, S., Petrikis, P., Malliori, M., Mavreas, V., \& Skapinakis, P. (2020). Prevalence of alcohol use disorders and their association with sociodemographic determinants and depression/ anxiety disorders in a representative sample of the Greek general population. Psychiatry Journal, 1-11. https://doi.org/10.1155/2020/4841050

Beneton, E. R., Schmitt, M., \& Andretta, I. (2021). Sintomas de depressão, ansiedade e estresse e uso de drogas em universitários da área da saúde. Revista da SPAGESP, 22(1), 145-159. http://pepsic.bvsalud.org/scielo.php?script=sci_arttext\&pid=S1677$29702021000100011 \& \operatorname{lng}=\mathrm{pt} \& t \operatorname{lng}=$

Campos-Arias, A., Barros-Bermúdez, J. A., \& Rueda-Jaimes, G. E. (2009). Propiedades psicométricas del cuestionario CAGE para consumo abusivo de alcohol: resultados de tres análisis. Revista Colombiana de Psiquiatría, 38(2), 294-303.

Cardona-Arias, J. A., Pérez-Restrepo, D., Rivera-Ocampo, S., Gómez-Martínez, J., \& Reyes, Á. (2015). Prevalencia de ansiedad en estudiantes universitarios. Diversitas: Perspectivas en Psicología, 11(1), 79-89.

Caro, Y., Trujillo, S., \& Trujillo, N. (2019). Prevalencia y factores asociados a sintomatología depresiva y ansiedad rasgo en estudiantes universitarios del área de la salud. Psychologia, 13(1), 41-52. https://doi.org/10.21500/19002386.3726 


\section{CAPÍTULO 5}

Castaño-Pérez, G., \& Calderón-Vallejo, G. (2014). Problemas asociados al consumo de alcohol en estudiantes universitarios. Revista Latino-Americana de Enfermagem, 22(5), 39-46. https://doi.org/10.1590/0104-1169.3579.2475

Cogollo, Z., Díaz, C. E., \& Campo, A. (2006). Exploración de la validez de constructo de la escala de Zung para depresión en adolescentes escolarizados. Colombia Médica, 37(2), 102-106.

Conde, V., Escribá, J. A., \& Izquierdo, J. (1970). Evaluación estadística y adaptación castellana de la escala autoaplicada para la depresión de Zung. Archivos de Neurobiología, 33, 185-206.

Contreras-Olive, Y., Miranda-Gómez, O., \& Torres Lio-Coo, V. (2020). Ansiedad y depresión en pacientes adictos a sustancias psicoactivas. Revista Cubana de Medicina Militar, 49(1), 71-85.

Davorent, M. P., Dermant, J., Shiely, F., \& Perry, I. J. (2016). Alcohol consumption among university students in Ireland and the United Kingdom from 2002 to 2014: a systematic Review. BMC Public Health, 16, 173-186. https://doi.org/10.1186/s12889-016-2843-1

Emiro, J., Amador, O., Calderón, G., Castañeda, T., Osorio, Y., \& Diez, P. (2018). Depresión y su relación con el consumo de sustancias psicoactivas, el estrés académico y la ideación suicida en estudiantes universitarios colombianos. Health and Addictions, 18(2), 227-239. https://doi.org/10.21134/haaj.v18i2.359

Ewin, J. A. (1984). Detecting alcoholism: the CAGE questionnaire. Journal of the American Medical Association, 252(14), 1905-1907.

Flórez, G., Balcells, M., Uzal, C., Domínguez, I., \& Balseiro, E. (2018). Alcohol. En C. Pereiro, \& J. J. Fernández (Coords.), Guía de adicciones para especialistas en formación. Socidrogalcohol.

Gogeascoechea-Trejo, M.C., Méndez-Maín, M. S., Natera-Rey, G., Blázquez-Morales, M. S. L., De San Jorge-Cárdenas, X., \& Treviño-Siller, S. (2016). Consumo de alcohol y lesiones: estudio en población atendida en servicios de urgencias de la ciudad de Xalapa, Veracruz, México. Salud Mental, 39(2), 61-68. https://doi.org/10.17711/SM.0185-3325.2016.002

Gómez-Maqueo, E. L., Gómez, H. L., Morales, B., \& Pérez, M. (2009). Uso del audit y el DasT10 para la identificación de abuso de sustancias psicoactivas y alcohol en adolescentes. Revista Colombiana de Psicología, 18(1), 9-17. 2344-8644. 


\section{CAPÍTULO 5}

González-Forteza, C., Hermosillo, A., Vacio-Muro, M. A., Peralta, R., \& Wagner, F. A. (2015). Depresión en adolescentes. Un problema oculto para la salud pública y la práctica clínica. Boletín Médico del Hospital Infantil de México, 72(2), 149-155. https://doi.org/10.1016/j. bmhimx.2015.05.006

Hamilton, M. (1959). The assessment of anxiety states by rating. British Journal of Medical Psychology, 32, 50-55.

Hernández-Cortaza, B. A., Cortaza-Ramírez, L., \& Blanco-Enríquez, F. E. (2018). Depresión y consumo de alcohol en estudiantes de una zona rural del Sur de Veracruz. Revista de Investigaciones Sociales, 4(14), 1-8.

Lobo, A., Chamorro, L., Luque, A., Dal-Ré, R., Badía, X., \& Baró, E. (2002). Validación de las versiones en español de la Montgomery-Asberg Depression Rating Scale y la Hamilton Anxiety Rating Scale para la evaluación de la depresión y de la ansiedad. Medicina Clínica, 118(13), 493-499.

Martínez-Martínez, M. C., Muñoz-Zurita, G., Rojas-Valderrama, K., \& Sánchez-Hernández, J. A. (2016). Prevalencia de síntomas depresivos en estudiantes de la licenciatura en Medicina de Puebla, México. Atención Familiar, 23(4), 145-149. https://doi.org/10.1016/j. af.2016.10.004

Mezquita-Guillamón, L., Ibáñez, M. I., Moya, J., Villa, H., \& Ortet, G. (2014). A longitudinal examination of different etiological pathways to alcohol use and misuse. Alcoholism, Clinical and Experimental Research, 38, 1770-1779. https://doi.org/10.1111/acer.12419

Mezquita-Guillamón, L., Stewart, S. H., Kuntsche, E., \& Grant, V.V.(2016). Estudiotranscultural del modelo de cinco factores de motivos de consumo de alcohol en universitarios españoles y canadienses. Adicciones, 28(4), 215-220.

National Institute of Drug Abuse. (2007). Monitoring the Future. NIDA.

Reynales-Shigematsu, L. M., Zavala-Arciniega, L., Paz-Ballesteros, W. C., Gutiérrez-Torres, D. S., García-Buendía, J. C., Rodríguez-Andrade, M. A., Gutiérrez-Reyes, J., FrancoNúñez, A., Romero-Martínez, M., \& Mendoza-Alvarado, L. (2017). Encuesta Nacional de Consumo de Drogas, Alcohol y Tabaco 2016-2017: Reporte de Drogas. Instituto Nacional de Psiquiatría Ramón de la Fuente Muñiz. 


\section{CAPÍTULO 5}

Secretaría de Salud. (2013). Norma Oficial Mexicana Nom-012-ssa3-2012, Que establece los criterios para la ejecución de proyectos de investigación para la salud en seres humanos. Diario Oficial de la Federación, DOF 04-01-2013. http://dof.gob.mx/nota_detalle. php? codigo $=5284148 \&$ fecha $=04 / 01 / 2013$

Slade, T., Chapman, C., Swift, W., Keyes, K., Tonks, Z., \& Teeson, M. (2016). Birth cohort trends in the global epidemiology of alcohol use and alcohol-related harms in men and women: systematic review and metaregression. Journal Behavioral and Medicine, 6, 1-12. https://doi.org/10.1136/bmjopen-2016-011827

Sociedad Mexicana de Psicología. (2010). Código Ético del Psicólogo. Trillas.

Valle, R., Sánchez, E., \& Perales, A. (2013). Sintomatología depresiva y problemas relacionados al consumo de alcohol durante la formación académica de estudiantes de medicina. Revista Peruana de Medicina Experimental y Salud Pública, 30(1), 54-7.

Vallejo, A. G., Díaz, K., Méndez, M. M., \& López, P. (2019). Sintomatología depresiva y consumo de sustancias en universitarios de Veracruz, México. Revista Electrónica de Psicología Iztacala, 22(4), 3255-3272.

Wahed, W. Y., \& Hassan, S. K. (2017). Prevalence and associated factors of stress, anxiety and depression among medical Fayoum University students. Alexandria Journal of Medicine, $53,77-84$.

Zung, W. W. (1965). A self rating depression scale. Archives of General Psychiatry, 12, 63-70. 


\title{
CAPÍTULO 6
}

\section{Identificación de hábitos de consumo y su relación con la autoestima en estudiantes universitarios}

\author{
Arlet Estephani Hernandez Mendez, Nataly Consuelo Pérez Valdovinos, \\ Mariana Paulina Alcantar Zavala, Yuri Guadalupe Zenteno Rios, \\ Michelle Yelena González Sánchez y Roberto Oropeza Tena
}

La Comisión Nacional para la Protección y Defensa de los Usuarios de Servicios Financieros (CONDUSEF, 2018) estima que los mexicanos gastan el 58.5\% de sus ingresos anuales en productos de necesidad alimenticia, seguida de gastos en transporte y comunicación. Por su parte, la Encuesta Nacional de Ingresos y Gastos de los Hogares 2018 (Instituto Nacional de Estadística y Geografía [INEGI], 2019) mostró que, en los hogares mexicanos, alrededor del 35\% del gasto cotidiano se destina a alimentos y bebidas, y el $20 \%$ a transportes y comunicaciones. En esta encuesta se encontraron diferencias importantes en los ingresos, así como en el gasto entre comunidades urbanas y rurales en nuestro país, entre el nivel de estudios de los padres o tutores de la zona del país donde habita, entre otros. Por otro lado, Michoacán ocupa el lugar 24 en ingreso corriente promedio trimestral del país.

El comportamiento de consumo se puede definir como el conjunto de actividades que hacen las personas al usar bienes y servicios, como seleccionar, comprar y evaluar, que satisfacen sus deseos y necesidades (Mollá et al., 2014). Un consumidor puede ser cualquier persona que consuma algo, tal como un niño, un estudiante, una ama de casa o un profesionista. Por esta razón, los bienes y servicios que se compran o consumen son de gran diversidad.

La Real Academia Española (RAE, 2020) define al hábito como la forma en que una persona se conduce en su vida cotidiana, adquirido por la repetición de actos similares en un contexto específico. Wood y Neal (2009) señalaron que los hábitos son funda- 


\section{CAPÍTULO 6}

mentales en la psicología del consumidor, debido a que aproximadamente el $45 \%$ de las conductas cotidianas se repiten diariamente en situaciones similares. Respecto a los hábitos de compra, Parrado y Mendivelso (2015) indicaron que el automatismo y la repetición de acciones en un contexto explican los patrones de selección, compra, uso y desecho de productos, bienes o servicios (Solomon, 2008).

El consumo se ha explicado desde diferentes disciplinas (psicología, economía, antropología, sociología, entre otras) y con diversas aproximaciones. Sin embargo, la teoría económica ha tratado de abordar la conducta de consumo asociándose a la producción y a la deuda. Según Liquitaya et al. (2014), hay tres teorías económicas fundamentales que ayudan a explicar el consumo:

a. La Teoría del Ingreso Relativo de Duesenberry indica que el consumo lo establece la posición relativa del consumidor en la distribución del ingreso. Debido a esto, el gasto, la deuda y el ahorro están supeditados al ingreso.

b. La Teoría del Ciclo Vital de Ando y Modigliani muestra que dependiendo del momento de vida del consumidor y del ingreso de ese momento, será el consumo que presenten. Por lo tanto, la experiencia que haya con el dinero será lo que determine el comportamiento de ahorro, gasto y deuda.

c. La Teoría del Ingreso Permanente de Friedman señala que el consumidor usará su gasto dependiendo de qué espera obtener a largo plazo. Por lo tanto, dependiendo del grupo social al que pertenece, la persona ajustará su ahorro, gasto y consumo. Los científicos sociales no ven las decisiones de consumo solo como expresiones de gusto personal, sino que las vinculan a los recursos y a las posiciones sociales de la gente en una sociedad (Schieferdecker, 2017).

La población estudiantil en México es bastante nutrida, el INEGI (2020) señala que en el ciclo 2018-2019, hubo 3943544 estudiantes universitarios en México, de los cuales Michoacán tiene 113 262. Actualmente, la Universidad Michoacana de San Nicolás de Hidalgo cuenta con poco más de 55000 estudiantes. Una cantidad importante de potenciales consumidores, como lo son los alumnos universitarios. Esta población es muy atractiva para los comercios de cualquier tipo, ya sea para el consumo de productos como para el uso de servicios, por lo tanto, tiene gran relevancia estudiar los hábitos de consumo de esta población. 


\section{CAPÍTULO 6}

A partir de la investigación de los hábitos de consumo es posible conocer las necesidades que tienen los estudiantes y, a través de esta información, se podrían crear estrategias que aumenten los niveles de satisfacción de los consumidores (Rodríguez, 2018).

Tomando en cuenta lo anterior, se reconoce que los hábitos de consumo de los estudiantes universitarios están determinados por diferentes factores, entre los cuales destaca el ingreso, el cual se puede obtener por dos vías: (a) la transferencia monetaria, que normalmente les hacen sus padres y (b) los ingresos económicos propios (Gil \& Ríos, 2016). Estos hábitos de consumo también son el resultado de su interacción con distintos miembros de la sociedad, así como por las diferentes normas sociales que guían los patrones de comportamiento económico (Acikalin et al., 2009). El ingreso de esta población normalmente es limitado, aunque tiene la ventaja de tener pocos compromisos económicos, tal como podría ser tener hijos o cónyuge.

López et al. (2014) realizaron una investigación sobre hábitos de consumo en estudiantes universitarios en uno de los campus de la Universidad de Guadalajara (Centro Universitario del Sur, en Ciudad Guzmán). Encontraron que los alumnos tienen una gran diversidad de gastos a lo largo de sus estudios; entre los rubros más importantes están la alimentación, el transporte y los materiales de estudio.

Cabe mencionar que se han encontrado diferencias entre el género y los hábitos de compra (Naim \& Khan, 2012). Por ejemplo, Han (1988) y Ranjbarian, Barari y Zabihzade (2011) hallaron que, para comprar normalmente las mujeres son más conservadoras, colectivistas y conformistas que los hombres. También ellas tienen más interés respecto al conocimiento de las características del producto a adquirir (Kolyesnikova et al., 2009). Según Cleaver (2004), el 80\% de todas las decisiones de compra las toman las mujeres, al buscar las mejores opciones, mientras que los hombres hacen compras sin buscar información adicional. Martínez et al. (2018) hicieron una investigación con estudiantes universitarios de Monterrey y encontraron diferencias entre el tipo de compra de textiles que hacen los hombres y las mujeres, donde estas últimas se interesan más por la calidad y por la responsabilidad social que tengan las empresas.

Se ha encontrado que la autoestima puede influir en las respuestas conductuales, cognitivas y emocionales de diversas situaciones (Yang et al., 2010), específicamente sobre los hábitos de compra. La autoestima se define como la evaluación que hace una 


\section{CAPÍTULO 6}

persona sobre su propia valía (Crocker \& Park, 2004). De acuerdo con Jiuhua et al. (2013), las personas con autoestima promedio son las que más riesgos financieros toman. Se ha encontrado que quienes tienen problemas de compra compulsiva, tienen un menor nivel de autoestima (Roberts et al., 2014). Por su parte, Cavallo et al. (2012) hallaron que personas con baja autoestima son más conservadoras financieramente que las personas con alta autoestima, debido a que son más temerosos sobre el futuro. Sin embargo, Çamlıbel (2017) realizó una investigación con estudiantes universitarios turcos sobre la asociación entre la autoestima y la toma de riesgos financieros; sin embargo, no se encontró ninguna relación entre ambas variables. Por lo tanto, debido a que se han encontrado resultados contradictorios respecto a los hábitos de compra y la autoestima, nos interesó comparar estas variables.

Con base en estos antecedentes, esta investigación tiene el objetivo de identificar los hábitos de consumo y su relación con la autoestima en estudiantes universitarios. Como objetivo secundario, se busca conocer si existen diferencias estadísticamente significativas de hábitos de consumo y autoestima respecto al género.

\section{Método}

\section{Tipo de estudio}

Se realizó un estudio transversal, de tipo descriptivo y correlacional.

\section{Participantes}

Se utilizó un muestreo no probabilístico por conveniencia. Se reclutó a 200 estudiantes de la licenciatura en Psicología, de la Universidad Michoacana de San Nicolás de Hidalgo (Morelia, Michoacán). La edad promedio fue de 20.78 años con un rango entre 18 y

$25(\mathrm{DE}=1.99)$. El 50\% de los participantes eran hombres y el 50\% mujeres. Respecto al semestre que cursaban, el $27 \%$ estaba en segundo semestre, el $43 \%$ en cuarto, $15.5 \%$ en sexto y $14.5 \%$ en octavo.

Los criterios de inclusión fueron: (a) estudiar en la facultad de psicología, (b) ser mayores de edad y (c) que en el momento de la aplicación estuvieran activos como estudiantes. 


\section{CAPÍTULO 6}

\section{Instrumentos}

Los instrumentos utilizados en el estudio fueron los siguientes:

- Ficha de datos generales. Este instrumento se elaboró para el presente estudio con el fin de recabar la información sobre género, edad y nivel de estudios de los participantes.

- Escala de Hábitos y Conductas de Consumo (EHCC) (Denegri et al., 1999). Su objetivo es identificar conductas reflexivas de consumo (que delinean hábitos de compra eficientes y eficaces) y diferenciarlas de las conductas impulsivas de adquisición (incluye la compra poco eficaz y el uso del crédito para adquirir bienes). Esta escala incluye 19 ítems con cuatro opciones de respuesta que van de "nunca" (1) a "siempre" (4). Para esta investigación se usó la versión de Casasola y Clavo (2019), cuyo estudio hecho en Perú señala que el instrumento tiene buenas propiedades psicométricas. Mediante un análisis factorial exploratorio, Ortega y Rodríguez-Vargas (2004) identificaron cinco factores: (1) calidad del producto ( $\alpha=0.81)$; (2) planificación de la compra $(\alpha=0.80)$; (3) precio $(\alpha=0.50)$; (4) uso responsable del crédito $(\alpha=0.85)$; y (5) uso impulsivo del crédito $(\alpha=0.35)$. Cada factor identifica cuatro niveles de evaluación: bajo, medio, medio alto y alto.

- Escala de Autoestima de Rosenberg (1965). Es un cuestionario que explora la autoestima personal entendida como los sentimientos de valía propia y de respeto a sí mismo. La escala consta de 10 ítems, de los cuales cinco están enunciados de forma positiva y cinco de forma negativa. Incluye cuatro opciones de respuesta que van de "muy en desacuerdo" (1) a "muy de acuerdo" (4). Ceballos-Ospino et al. (2017) lo tradujeron y validaron en castellano, encontrando un alfa de Cronbach de 0.72 , un omega de McDonald de 0.65 y un coeficiente de Mosier de 0.75.

\section{Procedimiento}

Antes de aplicar los instrumentos, se informó a los participantes sobre el objetivo del estudio. La participación fue voluntaria y anónima. En la primera hoja de la batería de pruebas aparecía el consentimiento informado, el cual se pidió a los estudiantes que leyeran. En caso de que estuvieran de acuerdo, lo tenían que firmar. Se aplicó la EHCC y la Escala de Autoestima. Los participantes tardaron en contestar un tiempo aproximado 


\section{CAPÍTULO 6}

de 10 minutos. Al final, se agradeció su participación. También se dio la información de contacto para quienes quisieran tener retroalimentación sobre sus resultados.

\section{Análisis de datos}

El análisis de datos se llevó a cabo con el paquete informático Iвм SPSs Statistics, versión 24. Se hicieron análisis descriptivos para las variables sociodemográficas y para describir los resultados obtenidos en cada instrumento, especialmente del EHCC. Para evaluar la asociación entre los hábitos de consumo y la autoestima se utilizó la prueba de correlación de Pearson. Para conocer la diferencia entre géneros, respecto a los hábitos de consumo y la autoestima, se utilizó la prueba t de Student.

\section{Consideraciones éticas}

La investigación se ajustó a los Principios Éticos de Helsinki (Asociación Médica Mundial, 2013) y a los criterios del Código Ético del Psicólogo (Sociedad Mexicana de Psicología, 2010). Con el fin de proteger la información proporcionada por los estudiantes, los datos personales fueron tratados con carácter anónimo y confidencial. Antes de aplicar el instrumento se les indicó el objetivo de la investigación y sus derechos, de manera que estos elementos fueran claros para que los participantes decidieran si querían participar en dicha investigación. Se usó un formato de consentimiento informado, donde se señalaba la finalidad de la investigación y se formalizaba su participación voluntaria, a través de la firma. Asimismo, se les informó que los datos se utilizarían únicamente con fines de investigación y que tenían el derecho de conocer los resultados.

\section{Resultados}

Respecto a sus hábitos de consumo, los resultados generales de la EHCC mostraron que el $18.5 \%$ de los estudiantes se pueden considerar como malos compradores, el 71.1\% como compradores regulares y solo el $10 \%$ como buenos compradores.

Se hizo un análisis descriptivo en todos los reactivos de la EHCC para conocer los hábitos de compra. Para ello, se realizó un análisis de $\mathrm{x}^{2}$, para identificar si había diferencias estadísticamente significativas entre las cuatro opciones de respuesta de cada ítem o si había igualdad entre las opciones. Se utilizó la prueba $\mathrm{x}^{2}(3, \mathrm{n}=200)$ y se usó como 


\section{CAPÍTULO 6}

criterio de significación una $\mathrm{p}<.01$. Se encontró que, en todos los ítems, la frecuencia de respuesta (nunca, pocas veces, frecuentemente y siempre) era estadísticamente diferente (tabla 1). Ninguna opción de respuesta $(0.0 \%)$ obtuvo una frecuencia esperada menor a 5.

En cuanto a los resultados por reactivo de la EHCC, estos muestran que los estudiantes frecuentemente comparan precios entre distintas marcas (44.5\%), leen las etiquetas de los productos y comparan precios entre distintos locales de ventas (42\%), pocas veces gastan más de lo que deberían, seleccionan los productos según su precio y seleccionan los productos según su calidad (41\%), preguntan por el tiempo de garantía de los productos (40\%), examinan detalladamente los productos que compran (38\%), preguntan sus dudas al vendedor antes de comprar (37\%), hacen una lista de los productos y servicios que necesitan (36.5\%), planifican sus compras con antelación (36.5\%), leen la etiqueta de la ropa para ver sus características (36\%) y compran a crédito (33\%).

Sin embargo, pocas veces miran el peso neto (35\% - reactivo 8$)$, para distribuir su dinero, ordenan los productos según su importancia (34.5\% - reactivo 3), compran en el comercio ambulante ( $47 \%$ - reactivo 12$)$ o preguntan por la tasa de interés $(31.5 \%$ - reactivo 18). Y nunca checan si los electrodomésticos cuentan con servicio ( $34 \%$ - reactivo 9) o comparan las tasas de interés en distintos locales (34.5\% - reactivo 19).

$\mathrm{Al}$ revisar la tendencia de las respuestas, se puede señalar que los estudiantes presentan una adecuada planeación de sus compras y hábitos de consumo. A pesar de esto, resaltan los reactivos $3,8,12,18$, pero sobre todo el reactivo 9 y 19 tienen una tendencia diferente al resto de los reactivos, ya que una buena parte de esta población no ordena los productos según su importancia para distribuir su dinero, no mira el peso neto, compra en el comercio ambulante o no pregunta por las tasas de interés; pero, sobre todo, no revisa que los electrodomésticos tengan servicio o nunca compara las tasas de interés de distintos locales. 


\section{Tabla 1}

\section{Hábitos de consumo identificados en la EHCC en estudiantes universitarios}

\begin{tabular}{|c|c|c|c|c|c|c|}
\hline Factores y reactivos & Nunca & $\begin{array}{l}\text { Pocas } \\
\text { veces }\end{array}$ & $\begin{array}{l}\text { Frecuen- } \\
\text { temente }\end{array}$ & Siempre & $\mathbf{x}^{2}$ & Sig. \\
\hline \multicolumn{7}{|l|}{ I. Calidad del producto } \\
\hline $\begin{array}{l}\text { 2. Selecciona los productos según } \\
\text { su calidad }\end{array}$ & 12.5 & 29.5 & 41 & 17 & 39.72 & .000 \\
\hline 7. Lee las etiquetas de los productos & 9.5 & 26.5 & 42 & 22 & 36.36 & .000 \\
\hline $\begin{array}{l}\text { 9. Checa que los electrodomésticos } \\
\text { tengan servicio }\end{array}$ & 34.0 & 30.5 & 24.5 & 11 & 24.60 & .000 \\
\hline $\begin{array}{l}\text { 10. Pregunta por el tiempo de } \\
\text { garantía de los productos }\end{array}$ & 21.5 & 18.5 & 40 & 20 & 24.36 & .000 \\
\hline $\begin{array}{l}\text { 11. Pregunta sus dudas al vendedor } \\
\text { antes de comprar }\end{array}$ & 15.5 & 26.5 & 37 & 21 & 20.20 & .000 \\
\hline $\begin{array}{l}\text { 16. Examina detalladamente los } \\
\text { productos que compran }\end{array}$ & 16.5 & 29.5 & 38 & 16 & 27.40 & .000 \\
\hline \multicolumn{7}{|l|}{ II. Planificación de la compra } \\
\hline $\begin{array}{l}\text { 1. Hace una lista de los productos y } \\
\text { servicios que necesita }\end{array}$ & 24.5 & 30 & 36.5 & 9 & 33.08 & .000 \\
\hline $\begin{array}{l}\text { 3. Para distribuir su dinero, ordena } \\
\text { los productos según su importancia } \\
\text { antes de comprar }\end{array}$ & 21.0 & 34.5 & 31.5 & 13 & 23.40 & .000 \\
\hline 8. Mira el peso neto & 26.5 & 35 & 26 & 12.5 & 20.76 & .000 \\
\hline $\begin{array}{l}\text { 13. Planifica sus compras con } \\
\text { antelación }\end{array}$ & 19.5 & 33 & 36.5 & 11 & 33.80 & .000 \\
\hline $\begin{array}{l}\text { 14. Lee la etiqueta de la ropa para } \\
\text { ver sus características }\end{array}$ & 21.0 & 28 & 36 & 15 & 19.68 & .000 \\
\hline \multicolumn{7}{|l|}{ III. Precio del producto } \\
\hline $\begin{array}{l}\text { 4. Selecciona los productos según } \\
\text { su precio }\end{array}$ & 13.5 & 27.5 & 41 & 18 & 35.48 & .000 \\
\hline $\begin{array}{l}\text { 5. Compara precios entre distintas } \\
\text { marcas }\end{array}$ & 13.0 & 19.5 & 44.5 & 23 & 44.68 & .000 \\
\hline $\begin{array}{l}\text { 6. Compara precios entre distintos } \\
\text { locales de ventas }\end{array}$ & 9.5 & 26.5 & 42 & 22 & 43.24 & .000 \\
\hline $\begin{array}{l}\text { 12. Compra en el comercio } \\
\text { ambulante }\end{array}$ & 13.5 & 47 & 27 & 12.5 & 62.12 & .000 \\
\hline
\end{tabular}




\section{Factores y reactivos}

Nunca

Pocas veces

Frecuen-

temente

Siempre

$\mathbf{X}^{2}$

Sig.

IV. Uso responsable del crédito

\begin{tabular}{lcccccc}
\hline $\begin{array}{l}\text { 18. Pregunta por las tasas de interés } \\
\text { y el precio final }\end{array}$ & 29.0 & 31.5 & 28 & 11.5 & 19.96 & .000 \\
$\begin{array}{l}\text { 19. Compara las tasas de interés en } \\
\text { distintos locales }\end{array}$ & 34.5 & 30.5 & 24 & 11 & 25.40 & .000 \\
\hline $\begin{array}{l}\text { V. Uso impulsivo del crédito } \\
\text { 15. Gasta más de lo que debería }\end{array}$ & 20.5 & 41 & 24 & 14.5 & 31.00 & .000 \\
\begin{tabular}{l} 
17. Compra a crédito \\
\hline
\end{tabular} & 7.5 & 27 & 33 & 32.5 & 34.44 & .000 \\
\hline
\end{tabular}

Asimismo, se identificó por nivel, el porcentaje de la muestra evaluada en cada uno de los cinco factores de la EHCC (tabla 2). Estos resultados resumen la tendencia mostrada por los reactivos individuales. Se puede observar que cuatro de los cinco factores manifiestan una tendencia de buenos compradores. Solamente en el factor IV. Uso responsable del crédito, no tienen tan buenos hábitos.

\section{Tabla 2}

\section{Hábitos de compra identificados por cada factor de la EHCC}

\begin{tabular}{lcccc}
\multicolumn{1}{c}{ Factores } & \multicolumn{3}{c}{ Nivel } \\
& Bajo & Medio & Alto & Muy alto \\
\hline I. Calidad del producto & $1.5 \%$ & $26.5 \%$ & $49 \%$ & $23 \%$ \\
II. Planificación de la compra & $3.5 \%$ & $29.5 \%$ & $52 \%$ & $15 \%$ \\
III. Precio del producto & $0 \%$ & $18 \%$ & $66 \%$ & $16 \%$ \\
IV. Uso responsable del crédito & $28 \%$ & $29 \%$ & $31 \%$ & $12 \%$ \\
V. Uso impulsivo del crédito & $2 \%$ & $32.5 \%$ & $45.5 \%$ & $20 \%$ \\
\hline
\end{tabular}

Por otro lado, se identificó el tipo de autoestima general que tenían los participantes. Se encontró que el 5.5\% tenía un nivel de autoestima baja, el 43.5\% presentaba autoestima media y el $51 \%$ autoestima alta. 
Se realizó una correlación de Pearson entre el puntaje de cada uno de los cinco factores de la EHCC y la autoestima general, la autoestima positiva y la autoestima negativa (tabla 3). Solamente hubo tres correlaciones estadísticamente significativas, pero fueron muy bajas y negativas, entre la autoestima positiva con la calidad del producto y con la planificación de la compra, así como la autoestima general con la calidad del producto.

\section{Tabla 3}

Correlación de Pearson entre la autoestima general, positiva, negativa y los puntajes promedio de los cinco factores de la EHCC

\begin{tabular}{lccc} 
& $\begin{array}{c}\text { Autoestima } \\
\text { general }\end{array}$ & $\begin{array}{c}\text { Autoestima } \\
\text { positiva }\end{array}$ & $\begin{array}{c}\text { Autoestima } \\
\text { negativa }\end{array}$ \\
\hline Calidad del producto & $-.146^{*}$ & $-.123^{*}$ & -.093 \\
Planificación de la compra & -.094 & -.105 & -.033 \\
Precio & .006 & -.048 & .087 \\
Uso responsable del crédito & .071 & .016 & .049 \\
Uso impulsivo del crédito & .017 & $.142^{*}$ & -.088 \\
\hline
\end{tabular}

Nota. ${ }^{*}>.05$

Adicionalmente, para identificar si había diferencias estadísticamente significativas entre hombres y mujeres, con cada uno de los cinco factores de la EHCC, así como en la autoestima (general, positiva y negativa), se utilizó la prueba t de Student para grupos independientes (tabla 4). Solo se encontraron diferencias estadísticamente significativas en la autoestima positiva entre hombres y mujeres, donde los hombres tienen mayor autoestima que las mujeres, aunque es una diferencia muy pequeña. En ninguna de las otras comparaciones se encontraron diferencias estadísticamente significativas. 


\section{Tabla 4}

Resultados de la prueba $t$ de los puntajes promedio entre hombres y mujeres en cada uno de los cinco factores de la EHCC y en la autoestima

\begin{tabular}{|c|c|c|c|c|c|c|c|c|c|c|c|c|c|c|c|c|}
\hline & \multicolumn{2}{|c|}{ CDP } & \multicolumn{2}{|c|}{ PC } & \multicolumn{2}{|c|}{ PP } & \multicolumn{2}{|c|}{ URC } & \multicolumn{2}{|c|}{ UIC } & \multicolumn{2}{|c|}{ AE general } & \multicolumn{2}{|c|}{ AE positiva } & \multicolumn{2}{|c|}{ AE negativa } \\
\hline & $\underline{x}$ & $\mathbf{t}$ & $\underline{x}$ & $\mathbf{t}$ & $\underline{x}$ & $\mathbf{t}$ & $\underline{x}$ & $\mathbf{t}$ & $\underline{x}$ & $\mathbf{t}$ & $\underline{x}$ & $\mathbf{t}$ & $\underline{x}$ & $\mathbf{t}$ & $\underline{x}$ & $\mathbf{t}$ \\
\hline $\mathrm{H}$ & 2.57 & 1.20 & 2.41 & .39 & 2.65 & .34 & 2.15 & -.261 & 2.65 & .76 & 25.39 & 1.2 & 12.75 & $2.13^{\star}$ & 12.52 & -.58 \\
\hline M & 2.45 & & 2.37 & & 2.62 & & 2.18 & & 2.57 & & 24.92 & & 12.27 & & 12.70 & \\
\hline
\end{tabular}

Nota. $\mathrm{p}<.05 ; \mathrm{H}=$ Hombre; $\mathrm{M}=$ Mujer; $\mathrm{CDP}=$ calidad del producto; $\mathrm{PC}=$ planificación de la compra; $\mathrm{PP}=$ precio; $\mathrm{URC}=$ uso responsable del crédito; $\mathrm{UIC}=$ uso impulsivo del crédito; $\mathrm{AE}=$ autoestima.

\section{Discusión}

Respecto a los hábitos de consumo identificados con la EHCC en estudiantes universitarios, los resultados nos dan un panorama general sobre el tipo de decisiones que toman en cuanto a su consumo y sus hábitos de compra. De las tres teorías económicas descritas por Liquitaya et al. (2014), la teoría del ciclo de vida es la más adecuada para explicar los hábitos de compra de los estudiantes universitarios. Esta teoría incorpora una dimensión sociodemográfica, debido a que señala que los gastos asociados con el consumo se van modificando, dependiendo del periodo de vida en que estén los consumidores.

En nuestros resultados, se puede observar que la mayoría de los universitarios encuestados muestran hábitos concretos para planificar sus compras. Por ejemplo, la mayoría de ellos comparan precios entre distintas marcas, seleccionan los productos según su calidad, pocas veces gastan más de lo que deberían o hacen una lista de los productos que necesitan, entre otros. Estos estudiantes, especialmente los que provienen de alguna comunidad rural, tienen que ir aprendiendo a tener actitudes de previsión, cálculo y disciplina para un buen uso de los recursos económicos (Moreno, 2004).

A pesar de esos buenos hábitos, algunos estudiantes todavía tienen hábitos de consumo poco adecuados, tal como no ordenar los productos según su importancia o comprar en el comercio ambulante (que generalmente es más barato, pero no con la calidad apropiada). Comprar en la economía subterránea es algo muy común en la so- 


\section{CAPÍTULO 6}

ciedad mexicana, en la cual una gran parte de la población es de escasos recursos. Y los estudiantes de las universidades públicas no son ajenos a esto. A pesar de que muchas de las compras se hacen en lugares informales, esto no implica que los consumidores no se fijen en la calidad de los productos, en el precio y en la marca que consumen, como atributos fundamentales para elegir lo que van a comprar (Parrado \& Mendivelso, 2015).

Este resultado es similar a lo encontrado por Ranjbarian et al. (2011), quienes señalaron que los estudiantes universitarios iraníes, al hacer sus compras, se enfocan en los aspectos utilitarios de un producto, en lugar de poner atención en sus aspectos superficiales; además, indican que ellos tratan de maximizar la relación entre el precio y calidad de los productos que adquieren. Por otro lado, Acikalin et al. (2009) hicieron una investigación comparando estudiantes universitarios de clase alta y de clase baja respecto al tipo de artículos que usualmente utilizaban, que podían ser funcionales o de prestigio. Encontraron que los estudiantes de bajos ingresos, le daban más importancia al aspecto funcional de los bienes en comparación de los estudiantes de ingresos altos. Por otro lado, podemos ver que el mexicano destina la mayoría de sus gastos a compras alimenticias, tabaco y alcohol, destinando el 35.2\% de sus recursos a estos y solo el $4.6 \%$ a ropa y calzado (Zavala, 2019) o cualquier otro tipo de objetos que no son de primera necesidad.

Respecto al uso del crédito de los estudiantes universitarios, llama la atención que en los reactivos "comparan las tasas de interés en distintos locales" (el 64\% nunca o pocas veces lo hace) y "preguntan por las tasas de interés" (el 60\% nunca o pocas veces lo hace), hayan salido tan altas. Esto se debe a que quizás pocos de ellos usan una tarjeta de crédito o a que sus ingresos sean demasiado bajos, lo cual provoque que no hagan este tipo de compras. En la presente investigación no se indagó si los estudiantes utilizan tarjeta de crédito, por lo que sería importante hacerlo para futuras investigaciones. Así se obtendrían más datos para dar respuesta a estas interrogantes. Liquitaya et al. (2014) señalaron que, en México, muchas familias no pueden tener ahorros por sus bajos sueldos y no tienen la posibilidad de endeudarse, debido a que sus perspectivas de ingreso son modestas; por lo tanto, al tener restricciones de liquidez, únicamente dependen de sus ingresos corrientes.

Los resultados obtenidos en la presente investigación llevan a considerar la necesidad de ejecutar acciones sobre educación económica con los estudiantes universitarios, 


\section{CAPÍTULO 6}

que aborden aspectos tales como las alternativas que hay para el mejor uso del crédito y la identificación de sus necesidades reales de consumo, buscando evitar las conductas impulsivas que lleven a tener gastos innecesarios, de modo que se pueda aumentar su bienestar (Herrera et al., 2011). Frisancho (2017) hizo una intervención financiera con estudiantes y profesores de secundaria en Perú; esta intervención llevó a mejoras importantes en las habilidades de autocontrol y en los hábitos de compra, así como en la reducción de las compras superfluas de los estudiantes; además, los profesores aumentaron sus hábitos de ahorro.

Por otro lado, en la presente investigación se realizaron algunos análisis adicionales, uno de ellos, sobre la asociación entre los hábitos de compra y la autoestima. Se contaba con la hipótesis de que habría una correlación media entre los buenos hábitos de compra y la autoestima; sin embargo, no se encontró ninguna correlación entre los diferentes hábitos de compra con la autoestima general, positiva o negativa. Estos resultados son consistentes con lo encontrado por Yang et al. (2010), quienes tampoco encontraron ninguna relación entre la situación financiera y la autoestima (alta o baja) de estudiantes universitarios. El resultado obtenido en la presente investigación quizás se deba al limitado tamaño de la muestra, ya que se hizo solamente en una facultad de una universidad pública.

Finalmente, al comparar si había diferencias de género tanto entre los hábitos de compra como con la autoestima, no se encontró ninguna.

Los resultados de la presente investigación no pueden generalizarse a todos los estudiantes universitarios mexicanos. La muestra usada se limitó a una pequeña porción de estudiantes de una universidad pública del centro del país. Los resultados presentados pueden dar una idea de cómo son los hábitos de consumo de los estudiantes de las universidades públicas en México; sin embargo, sería necesario indagar más respecto a cómo es que esta población adquiere este tipo de hábitos y a qué se deben las diferencias entre unos y otros; se podría trabajar con variables como el estrés, las prácticas de crianza, los grupos de pares y los estilos de comunicación (Roberts et al., 2014).

Entre las limitaciones de la investigación, podemos mencionar que no se abordaron los siguientes aspectos: (a) ingreso mensual de los estudiantes y de sus familias, y la forma como lo obtiene (Checa-Artasu, 2011); (b) el uso de tarjetas de crédito; (c) la percepción de su situación financiera; (d) el uso cotidiano del dinero y las deudas con- 


\section{CAPÍTULO 6}

traídas, en aspectos específicos; (e) la diferenciación entre los estudiantes pertenecientes a familias de una zona rural o de una zona urbana; (f) el nivel de estudios de los padres o tutores, así como la cantidad de hijos en el hogar. Por lo que sería relevante inquirir sobre todos estos aspectos (Ferreira et al., 2013).

Por último, sería importante ampliar el espectro de la muestra, encuestando a la población general o a una muestra más amplia de estudiantes universitarios, así como comparar los hábitos de consumo entre estudiantes de universidades públicas y universidades privadas. 


\section{CAPÍTULO 6}

\section{Referencias}

Acikalin, S., Gul, E., \& Develioglu, K. (2009). Conspicuous consumption patterns of Turkish youth: case of cellular phones. Young Consumers, 10(3), 199-209. https://doi. org/10.1108/17473610910986017

Asociación Médica Mundial. (2013). Declaración de Helsinki de la AMM - Principios éticos para las investigaciones médicas en seres humanos. https://www.wma.net/ es/policies-post/declaracion-de-helsinki-de-la-amm-principios-eticos-para-lasinvestigaciones-medicas-en-seres-humanos/

Çamlıbel, A. (2017). Self-Esteem and financial risk taking. Koc University Undergradute Psychology Journal, 1(1), 19-24.

Casasola, D. K., \& Clavo, P. A. (2019). Propiedades psicométricas de la escala de hábitos y conductas de consumo en los docentes de las Instituciones públicas de Chimbote (Tesis de licenciatura). Universidad Cesar Vallejo, Perú.

Cavallo, J. V., Holmes, J. G., Fitzsimons, G. M., Murray, S. L., \& Wood, J. V. (2012). Managing motivational conflict: How self-esteem and executive resources influence sel-fregulatory responses to risk. Journal of Personality and Social Psychology, 103(3), 430-451.

Ceballos-Ospino, G. A., Paba-Barbosa, C., Suescún, J., Oviedo, H. C., Herazo, E., \& CamposArias, A. (2017). Validez y dimensionalidad de la escala de autoestima de Rosenberg en estudiantes universitarios. Pensamiento Psicológico, 15(2), 29-39. https://doi.org/10.11144/ Javerianacali.PPSI15-2.vdea

Checa-Artasu, M. M. (2011). Hábitos y aptitudes de los estudiantes universitarios en una ciudad pequeña mexicana. El caso de la Piedad de Cavadas, Michoacán. Ide@s CONCYTEG, 6(69), 412-435.

Cleaver, J. (2004). What women want: the growing economic power of women consumers consumer behavior. The Journal of Consumer Marketing, 29(3), 200-213.

Comisión Nacional para la Protección y Defensa de los Usuarios de Servicios Financieros. (2018). Y tu familia ¿En qué gasta? https://www.condusef.gob.mx/Revista/index.php/ presupuesto-familiar/gastos/377-y-tu-familia-en-que-gasta

Crocker, J., \& Park, L. E. (2004). The costly pursuit of self-esteem. Psychological Bulletin, 130(3), 392-414. 


\section{CAPÍTULO 6}

Denegri, M., Palavecinos, M., Ripoll, M., \& Yáñez, V. (1999). Caracterización Psicológica del Consumidor de la IX Región. En M. Denegri, F. Fernández, R. Iturra, M. Palavecinos, \& M. Ripio (Eds.), Consumir para Vivir y no Vivir para Consumir (pp. 7-31). Universidad de la Frontera.

Ferreira, F. H. G., Messina, J., Rigolini, J., López-Calva, L. F., Lugo, M. A., \& Vakis, R. (2013). La movilidad económica y el crecimiento de la clase media en América Latina: Panorama General. Banco Mundial.

Frisancho, V. (2017). Evaluación experimental del piloto "Finanzas en mi colegio". Banco Interamericano de Desarrollo.

Gil, E. O., \& Ríos, H. F. (2016). Hábitos y preferencias de consumo. Consumo en estudiantes universitarios. Dimensión Empresarial, 14(2), 55-72.

Han, C. M. (1988). The role of consumer patriotism in the choice of domestic versus foreign products. Journal of Advertising Research, 28, 25-32. https://www.sid.ir/En/Journal/ ViewPaper.aspx? ID=296702

Herrera, M., Estrada G, C., \& Denegri, M. (2011). La alfabetización económica, hábitos de consumo, actitud hacia el endeudamiento y su relación con el bienestar psicológico en funcionarios públicos de la ciudad de Punta Arenas. Magallania, 39, 83-92. https://doi. org/10.4067/S0718-22442011000100005

Instituto Nacional de Estadística y Geografía. (2020). Matrícula escolar por entidad federativa según nivel educativo. https://www.inegi.org.mx/app/tabulados/ interactivos/?px=Educacion_06\&bd=Educacion\#variables

Instituto Nacional de Estadística y Geografía. (2019). Encuesta Nacional de Ingresos y Gastos de los Hogares 2018. INEGI.

Jiuhua, Z., Yilu, Z., \& Yongfang, L. (2013). Effects of self-esteem level on risk preference in different tasks. Social Behavior \& Personality: An International Journal, 41(5), 815-818. https://doi.org/10.2224/sbp.2013.41.5.815

Kolyesnikova, N., Dodd, T. H., \& Wilcox, J. B. (2009). Gender as a moderator of reciprocal INEGI is transforming today's marketplace. Entrepreneur, 2, 3-4.

Liquitaya, J. D., Gutiérrez, G., \& Ramírez, M. A. (2014). Teorías que resuelven el enigma del consumo. Denarius, 28, 73-111. 


\section{CAPÍTULO 6}

López, M. C., Espinoza de los Monteros, A., Rojo, D., Flores, K., \& Rojas, A. (2014). Hábitos de consumo del estudiante universitario. Revista Electrónica Nova Scientia, 13(7), 352-373.

Martínez, I. M. Casillas, M. F., Núñez, C. M., González, A. D., Aguilera, A. E., \& Portales, L. (2018). Influencia del marketing social y prácticas de RSE en la intención de compra de los millennials. Revista Universidad y Empresa, 20(35), 251-280.

Mollá, A., Berenguer, G., Gómez, M. A., \& Quintanilla, I. (2014). Comportamiento del consumidor. UOC.

Moreno, M. (2004). Experiencias de vida económica y desarrollo humano de estudiantes universitarios de otras localidades en Barranquilla (Colombia). Psicología desde el Caribe, 13, 48-72. http://www.redalyc.org/pdf/213/21301305.pdf

Naim, N., \& Khan, G. (2012). Gender differences in fashion consciousness among malaysian youth. 2012 Global Marketing Conference at Seoul, 1220-1235. https://www. researchgate.net/publication/328353302_GENDER_DIFFERENCES_IN_FASHION_ CONSCIOUSNESS_AMONG_MALAYSIAN_YOUTH

Ortega, V., \& Rodríguez-Vargas, J. C. (2004). Escala de hábitos y conductas de consumo: evidencias sobre dimensionalidad. International Journal of Clinical and Health Psychology, 4(1), 121-136.

Parrado, F., \& Mendivelso, M. (2015). Descripción de hábitos compra y endeudamiento de una muestra de consumidores del área metropolitana de Pereira. Revista Científica Guillermo de Ockham, 13(2), 107-115.

Ranjbarian, B., Barari, B., \& Zabihzade, K. (2011). Ethnocentrism among Iranian Consumer with Different Consumption Habits. International Journal of Marketing Studies, 3(3), 3041. https://doi.org/10.5539/ijms.v3n3p30

Real Academia Española. (2020). Diccionario de la lengua española. https://dle.rae.es/ hábito?m=form

Roberts, J. A., Manolis, C., \& Pullig, C. (2014). Contingent self-esteem, self-presentational concerns, and compulsive buying. Psychology \& Marketing, 31(2), 147-160.

Rodríguez, M. (2018). Redes sociales y hábitos de consumo en estudiantes universitarios, caso universidad pedagógica y tecnológica de Colombia. Redes, Revista Espacios, 39(09), 1-14. Rosenberg, M. (1965). Society and the adolescent self-image. Princeton University Press. 


\section{CAPÍTULO 6}

Schieferdecker, D. (2017). When audience segmentation is twofold: differences in media consumption along race and socio-economic background at a South African. African Journalism Studies, 38(1), 129-151. https://doi.org/10.1080/23743670.2017.1291442

Sociedad Mexicana de Psicología. (2010). Código Ético del Psicólogo. Trillas.

Solomon, M. R. (2008). Comportamiento del consumidor. Prentice Hall.

Wood, W., \& Neal, D. T. (2009). The habitual consumer. Journal of Consumer Psychology, 19(4), 579-592. http://dx.doi.org/10.1016/j.jcps.2009.08.003

Yang, J., Dedovic, K., \& Zhang, Q. (2010). Self-esteem and risky decision-making: An ERP study. Neurocase, 16(6), 512-519.

Zavala, L. (2019). ¿En qué gastan más su dinero los mexicanos? Quinto Poder. 


\title{
CAPÍTULO 7
}

\section{Conocimientos y actitudes hacia el autoexamen de mama de mujeres universitarias}

\author{
Alexa Fernanda Leal Fregoso, Sergio Antonio Vázquez Claro, \\ Martin Ricardo Gutiérrez Jiménez y Diana Carolina Ramírez Ruvalcaba
}

La mama es la glándula encargada de producir y secretar leche con el objeto de nutrir a las crías, sin embargo, si esta fuera la única función en el caso del ser humano (mujeres), las enfermedades en ellas no representarían una gran consecuencia, es decir, no serían de relevancia; este órgano tiene múltiples funciones, las cuales han sido fuente de discusión entre si son primarias o secundarias, pero, más que nada, la mama ha sido vista como un órgano estético, relacionándola a lo erótico y la belleza (Sardiñas, 2019).

Por otra parte, el cáncer, en términos generales, incluye un gran grupo de enfermedades con la posibilidad de afectar cualquier parte del cuerpo. Una característica del cáncer es la metástasis, esto es que existe una proliferación de células anormales, las cuales llegan a invadir el cuerpo y a extenderse hacia otros órganos (Organización Mundial de la Salud [OMs], 2021a). Las metástasis son la causa principal de muerte por cáncer, casi 10 millones de muertes ocurridas en 2020 se atribuyeron a esto. Casi una de cada seis defunciones en el mundo está asociada a algún tipo de cáncer. Los cánceres que causaron un mayor número de muertes en 2020 fueron los de pulmón (1.8 millones de defunciones), colon (935 000), hígado (830 000), estómago (769 000) y mama (685 000) (oms, 2021a).

Anualmente, se estiman 1.67 millones de casos nuevos por cáncer de mama, lo que lo convierte a nivel mundial en el segundo tipo de tumor más frecuente, con una cuarta parte del total de los casos por cáncer en las mujeres (Secretaría de Salud [ssa], 2015). El cáncer de mama en América Latina y el Caribe se establece como la primera causa de muerte por tumores malignos en las mujeres de edad reproductiva, desplazando en 


\section{CAPÍTULO 7}

diversos países al cáncer cervicouterino. El cáncer en las mamas en el continente americano muestra una incidencia mayor a la que tenía anteriormente, además, es considerado el más agresivo en la mujer. En países latinos, el cáncer de mama es considerado la primera enfermedad neoplásica mortal, teniendo 30000 muertes femeninas anualmente (Sánchez et al., 2016). La oms (2021b) señala que, aunque se ha reducido hasta en un $40 \%$ la tasa de mortalidad por cáncer de mama en países con altos ingresos, su incidencia sigue dándose en su mayoría en países en desarrollo, exceptuando a Japón; en África Central varía desde 27 por 100000 mujeres y en Europa occidental hasta 96 (ssA, 2015).

A partir del año 2006, en México, el carcinoma mamario se convirtió en la primera causa de muerte por cáncer (ssA, 2015). En 2009, se registraron 4964 decesos a causa del cáncer de mama, esto representó un $2 \%$ del total de muertes en mujeres, es decir, en ese año ocurrieron 14 muertes por día debido a esta problemática (Instituto Nacional de Estadística y Geografía [INEGI], 2009). La tasa de mortalidad se ha ido elevando con la edad, no solo en el país, sino a nivel mundial, donde, por ejemplo, en 2009 la tasa de mortalidad en mujeres de $40-49$ años fue de " 14.9 por 100 mil, en las de 50 a 59 años de 29.1, en las mujeres de 60 a 69 de 37.0 y en las de 70 y más años la mortalidad fue de 53.1 por 100 mil” (ssa, 2011, párr.4).

Es importante señalar que esta neoplasia puede curarse si se realiza un diagnóstico oportuno, para esto es necesario educar tanto a las mujeres como al personal de salud, y en especial a los estudiantes de esta área, ya que estos últimos son clave en el rol de la prevención del cáncer de mama (Torres et al., 2017).

La mayoría de los casos de cáncer de mama no presentan síntomas al inicio y puede detectarse; existen distintos tipos de diagnóstico precoz para el cáncer de mama, como la mamografía, el tamizaje mamográfico y la autoexploración. Este último se basa en un método sencillo que implica palpar los senos para identificar alguna anomalía; esta técnica aumenta la posibilidad de detectar a tiempo algún signo de enfermedad en las mamas. En el caso de las mujeres menores de 40 años, pueden realizarse ecografías y, a partir de esa edad, mamografías (Abugattas et al., 2015).

Profundizaremos en la autoexploración al ser esta el tema investigado en el presente trabajo. Según Castro y Rizo (2009), para realizar una correcta autoexploración: 


\section{CAPÍTULO 7}

La mujer se debe colocar frente a un espejo. [...] Ha de buscar cambios o enrojecimiento de los pezones, alteraciones en la piel como retracciones o aspecto de piel de naranja; con las manos en las caderas, tiene que ir moviendo la pelvis y estirar los hombros hacia atrás y mirar las irregularidades de las mamas. Esta observación se debe repetir con las manos detrás de la cabeza y moviendo el brazo y el hombro hacia atrás. (pp.123-124)

Para ayudarse en el proceso, la mujer pude hacer uso de alguna loción o aceite sobre sus mamas e ir estirando la piel, a la vez que palpa con la yema de sus dedos y hace movimientos circulares ejerciendo un poco de presión, iniciando en el cuello y bajando al pecho y viceversa; es necesario examinar toda la zona, asegurándose de revisar también el área debajo del pecho y de la mitad de este hacia las axilas, para detectar cualquier bulto, el cual se define como "cualquier punto que se mueva o quede fijo y puede resultar algo anodino, tejido fibroso, o una lesión sospechosa" (Castro \& Rizo, 2009, p.124). Todas las mujeres poseen algunos nódulos, por lo que deben familiarizarse con su cuerpo y su tejido mamario al momento de presentar el ciclo menstrual (Castro \& Rizo, 2009).

La autoexploración de mama resulta ser una técnica muy importante, ya que la mayoría de los casos en México se detectan a través de este mecanismo (Brandan \& Villaseñor, 2006). En los últimos años, gracias a la aplicación de este método preventivo, se ha logrado detectar un número mayor de casos nuevos diagnosticados en estados iniciales, permitiendo una mayor supervivencia, calidad de vida y tratamientos con menor invasión (Gálvez, 2013). Por tal motivo, la importancia de realizar el autoexamen y acudir al médico lo antes posible cuando se detecta alguna anomalía.

Una mala detección y un tratamiento no oportuno pueden llevar a grandes y aterradoras consecuencias, como sería la mastectomía, la cual implica la extirpación de la mama y parte del tejido cutáneo, conllevando problemas psicológicos; además, puede influir emocionalmente siendo una respuesta negativa en el problema, ya que las mamas son uno de los elementos más importantes de la belleza femenina, la pérdida de una o ambas mamas trae para la mujer sufrimientos de todo tipo, los cuales pueden ser variables en cada caso (Fernández, 2020). 


\section{CAPÍTULO 7}

En el contexto de la mujer universitaria de entre 18 y 25 años, es necesario saber sobre todas estas medidas de prevención oportunas, ya que se cree que el cáncer de mama solo afecta a mujeres mayores, pero se ha observado que la presencia de tumores comienza desde una edad más temprana. La cantidad de defunciones a partir del 2010 en mujeres de entre 20 y 29 años en Jalisco ha sido de 34 en todo este periodo, en todo el país en el mismo periodo y en el mismo rango de edad se ha alcanzado el valor de 423 muertes en mujeres por cáncer de seno, siendo las mujeres de 25 a 29 años las que más fallecen por esta causa (INEGI, 2017).

En un estudio hecho en México se demostró que, de 23 mil mujeres con cáncer de mama, casi 3 mil de ellas tenían una edad menor a los 40 años, esto representa casi el doble de casos que los que se tienen registrados en Estados Unidos y Canadá. En el mismo estudio se expuso que este tipo de cáncer afectaba de una manera más agresiva a las mujeres jóvenes y que desafortunadamente se detectaban en una etapa más avanzada, ya que las mujeres desconocían que podían padecer esta enfermedad, por lo tanto, no acudían con el médico regularmente para hacer una detección temprana (American Cancer Society, 2017).

La detección de alguna anormalidad se facilita cuando las mujeres ya presentan una cierta intimidad con la autoexploración, es muy importante que estas tengan un alto grado de conocimiento sobre la técnica correcta en autoexploración para la detección precoz y, así, reducir los índices de mortalidad por este cáncer.

Respecto a la autoexploración, Sardiñas (2009) menciona que:

deben realizárselo todas las mujeres a partir de los 20 años, entre el quinto y séptimo día, posterior al ciclo menstrual, ya que es cuando los senos están más blandos; las mujeres que ya no presentan su menstruación habrán de realizarlo un día específico de cada mes, esto es para crear hábito e intentar mejorar la técnica de detección. (s.p.)

La mayor parte del conocimiento que tienen las mujeres sobre esta técnica resulta de los medios de comunicación masiva y de la instrucción recibida por los equipos básicos de salud en los primeros niveles de atención. Castillo et al. (2016) afirmaron que las mujeres de las grandes ciudades se realizan la autoexploración con mayor frecuencia, así 
como aquellas con mayor nivel educativo y socioeconómico. Por ello, estudiar los conocimientos, las actitudes y las prácticas sobre el autoexamen de mama es importante, no solo debido a las cifras de la enfermedad, sino porque la detección oportuna, mediante la autoexploración mamaria, es un procedimiento de mucho valor.

\section{Método}

\section{Participantes}

Participaron voluntariamente 130 mujeres universitarias de 18 a 25 años, que cursaban alguna de las siguientes carreras: Licenciatura en Derecho, Licenciatura en Ciencias Forenses, Licenciatura en Estudios Liberales, Ingeniería en Nanotecnología, Licenciatura en Administración de Negocios, Licenciatura en Contaduría Pública, Licenciatura en Radiología e Imagen, Licenciatura en Médico Cirujano Dentista, Licenciatura en Artesanías y Licenciatura en Ciencias Computacionales. Sus edades oscilaron entre los 18 y 25 años $(\bar{x}=19.5$, DT $=1.4)$. Se excluyeron a las mujeres que reportaron alguna enfermedad cancerígena o que tuvieran algún trastorno mental o psicológico que les impidiera responder el cuestionario. Se eliminaron aquellas participaciones en las que quedaron incompletos parcialmente los cuestionarios.

\section{Escenario y materiales}

Las encuestas se llevaron a cabo de forma grupal en las aulas donde las participantes tomaban clase, las cuales contaban con ventilación e iluminación tanto artificial como natural, sillas y mesas individuales. A cada una de las participantes se les entregó un lápiz y un borrador para contestar los cuestionarios. También se utilizó una infografía elaborada por los propios investigadores en la que se presentó información general sobre los pasos correctos de la técnica de autoexploración de mamas.

\section{Instrumentos}

Inicialmente se utilizó una carta de consentimiento informado en la cual se describió el objetivo y las actividades a realizar si aceptaban participar en la investigación, asimismo, se explicaron los criterios de anonimato y confidencialidad en el uso de la información. Cada una de las participantes firmó dicho formato. También se utilizó el Cuestionario de 


\section{CAPÍTULO 7}

Conocimiento sobre Autoexploración Mamaria (Jara \& Peña, 2011), con el objetivo de identificar los conocimientos y actitudes acerca del cáncer, las técnicas diagnósticas y la autoexploración de mama. Este cuestionario considera cuatro apartados:

1. Datos personales, tales como la edad, ocupación, estado civil, nivel de estudios.

2. Conocimiento general de cáncer de mama, se evalúan los conceptos básicos, síntomas, factores de riesgo y técnicas de detección.

3. Conocimiento y dominio de la técnica de autoexploración, evalúa los pasos a seguir, el conocimiento del concepto, la influencia del personal de salud, los motivos, los momentos y las personas para realizarlo, así como las razones y beneficios para realizarla o no realizarla.

4. Actitudes ante el autoexamen de mama, evalúa las creencias en torno a dicha técnica.

Cada reactivo del apartado dos y tres, cuenta con opciones de respuesta dicotómicas de "sí" y "no", mientras que el cuarto apartado, se interpreta mediante una escala tipo Likert que va de "totalmente de acuerdo" a "totalmente en desacuerdo". El nivel de conocimiento y de actitud se determina a través de sumatorias y tomando en cuenta una escala de valoración con las categorías: bueno, regular o malo. El cuestionario tiene un alfa de Cronbach de 0.917.

\section{Diseño y procedimiento}

El estudio fue de tipo cuantitativo, transversal y descriptivo. A través de un muestreo aleatorio por conveniencia se invitó a mujeres universitarias a participar en el estudio, todas las que cumplieron con los criterios de inclusión y que aceptaron participar voluntariamente, firmaron el consentimiento informado y, enseguida, de manera grupal y en las aulas, se les entregó un cuestionario y se dieron las instrucciones verbalmente de la forma en que debía ser llenado, una vez que se resolvieron las preguntas se les solicitó lo respondieran, conforme fueron terminando y se les obsequió una infografía acerca de la técnica de autoexploración de mamas. 


\section{Consideraciones éticas}

La investigación se ajustó a los principios éticos de Helsinki (Asociación Médica Mundial, 2001), a los criterios del Reglamento de la Ley General de Salud de México en Materia de Investigación para la Salud (2014). Se tomó como consideración ética, el anonimato y la confidencialidad de los participantes.

\section{Resultados}

De manera general, en la tabla 1 podemos apreciar los puntajes globales obtenidos en cada una de las dimensiones indagadas. El 96.9\% de las participantes se ubicaron en un nivel de conocimiento regular acerca del cáncer. El 86.9\% de las participantes se ubicaron en un nivel regular en cuanto al conocimiento y dominio de la técnica de autoexploración. Finalmente, el 91.5\% de las participantes se ubicó en un nivel malo respecto a las actitudes ante el autoexamen de mama.

\section{Tabla 1}

Frecuencias y porcentajes de los niveles de conocimiento en cada una de las dimensiones

Conocimiento sobre el cáncer de mama

\begin{tabular}{lcc}
\hline Bueno & 0 & 0 \\
Regular & 126 & 96.9 \\
Malo & 4 & 3.1 \\
\hline Conocimiento y dominio de la técnica de autoexploración & & \\
\hline Bueno & 0 & 0 \\
Regular & 113 & 86.9 \\
Malo & 17 & 13.1 \\
\hline Actitudes ante el autoexamen de mama & & \\
\hline Bueno & 0 & 0 \\
Regular & 11 & 8.5 \\
Malo & 119 & 91.5 \\
\hline
\end{tabular}

Nota. $\mathrm{n}=130$. 


\section{CAPÍTULO 7}

De manera específica describiremos las creencias, conocimientos y actitudes más relevantes obtenidas en cada uno de los apartados. Destacan las creencias en torno a tres condiciones, el 20\% consideraron que una mujer gestante no puede sufrir cáncer de mama, el 30\% cree que los tumores de la mamá no pueden invadir otros órganos y el $30 \%$ cree que los tumores benignos son característicos del cáncer de mama.

En referencia al conocimiento de los síntomas visibles o palpables del cáncer de mamá, el $44 \%$ de las participantes no considera que las mamas y pezón con heridas indiquen la presencia de esta enfermedad, así también, el 26\% no considera como un síntoma la secreción de sangre o pus en el pezón.

Sobre aquellas situaciones que resultan riesgosas para el cáncer de mama, pero que no fueron reconocidos por las participantes como tales, destaca que el $61 \%$ de las universitarias considera que el beber alcohol o fumar de forma habitual no es un riesgo para la presencia de esta enfermedad, el $62 \%$ cree que el ser obesa y ser sedentaria no resulta ser un factor de riesgo, mientras que el $27 \%$ de las participantes cree que no es un riesgo utilizar hormonas frecuentemente.

Con respecto al conocimiento acerca de las técnicas para detectar el cáncer de mama, se aprecia una alta proporción de participantes que las desconocen, en la tabla 2 se presenta el porcentaje de participantes que respondieron correcta e incorrectamente a cada oración. 


\section{Tabla 2}

\section{Distribución porcentual de respuestas correctas e incorrectas sobre el conocimiento de las técnicas para detectar el cáncer de mama}

$\begin{array}{ccl}\text { Correcto } & \text { Incorrecto } & \\ 95 \% & 5 \% & \begin{array}{l}\text { El autoexamen de mamas es el examen realizado } \\ \text { por la misma mujer. }\end{array} \\ 73 \% & 27 \% & \begin{array}{l}\text { La ecografía es útil para el estudio de las mamas } \\ \text { de mujeres menores de } 35 \text { años. }\end{array} \\ 41 \% & 59 \% & \begin{array}{l}\text { El autoexamen de mamas se realiza mensualmente } \\ \text { a partir de la aparición de la primera menstruación. }\end{array} \\ 91 \% & 87 \% & \begin{array}{l}\text { La mamografía debe realizarse anualmente } \\ \text { en toda mujer mayor a } 40 \text { años. }\end{array} \\ 13 \% & \begin{array}{l}\text { El autoexamen de mamas debe realizarse } \\ \text { en cualquier momento que la mujer lo desee. }\end{array} \\ 9 \% & 91 \% & \begin{array}{l}\text { La mujer mayor de } 30 \text { años debe acudir al ginecólogo } \\ \text { para su examen de mamas anualmente. }\end{array} \\ 31 \% & 69 \% & \begin{array}{l}\text { La tomografía es un método para detectar } \\ \text { el cáncer de mama. }\end{array} \\ 79 \% & 21 \% & \begin{array}{l}\text { Las mujeres que usan hormonas deben realizarse } \\ \text { la mamografía. }\end{array}\end{array}$

Nota. $\mathrm{n}=130$.

$\mathrm{Al}$ analizar específicamente los conocimientos y dominios que las participantes tienen acerca de la técnica de autoexploración, podemos apreciar en la tabla 3 que una alta proporción conoce algunos de los pasos, sin embargo, existen pasos que consideran que no son necesarios o que no son parte de la correcta ejecución de la técnica. 


\section{Tabla 3}

\section{Distribución porcentual de respuestas correctas e incorrectas sobre la técnica de autoexploración de mamas}

\begin{tabular}{|c|c|c|}
\hline Correcto & Incorrecto & Técnicas \\
\hline $100 \%$ & $0 \%$ & $\begin{array}{l}\text { Observar frente al espejo las características } \\
\text { de la mama y el pezón. }\end{array}$ \\
\hline $59 \%$ & $41 \%$ & $\begin{array}{l}\text { Las mamas se pueden observar con los brazos caídos, } \\
\text { manos en la cintura o detrás de la cabeza. }\end{array}$ \\
\hline $100 \%$ & $0 \%$ & $\begin{array}{l}\text { Palpar sus mamas con la yema de los dedos en forma } \\
\text { circular, para buscar la presencia de bultos. }\end{array}$ \\
\hline $87 \%$ & $13 \%$ & $\begin{array}{l}\text { Examinar y palpar las mamas por encima } \\
\text { de la ropa interior. }\end{array}$ \\
\hline $97 \%$ & $3 \%$ & $\begin{array}{l}\text { Colocar un brazo detrás de la nuca y con el otro revisar la } \\
\text { mama opuesta, axila y luego el cuello. }\end{array}$ \\
\hline $85 \%$ & $15 \%$ & $\begin{array}{l}\text { Presionar el pezón para comprobar } \\
\text { si sale alguna secreción. }\end{array}$ \\
\hline $92 \%$ & $8 \%$ & Examen que se debe realizar toda mujer periódicamente. \\
\hline $90 \%$ & $10 \%$ & $\begin{array}{l}\text { Examen para detectar masas (tumores) } \\
\text { o algo anormal. }\end{array}$ \\
\hline $59 \%$ & $41 \%$ & Solo se lo deben realizar mujeres en edad fértil. \\
\hline $43 \%$ & $57 \%$ & Se realiza mensualmente. \\
\hline $75 \%$ & $25 \%$ & Se realiza ocho días después de la menstruación. \\
\hline $93 \%$ & $7 \%$ & Es un examen necesario. \\
\hline $92 \%$ & $8 \%$ & Es bueno para evitar el cáncer. \\
\hline $89 \%$ & $11 \%$ & $\begin{array}{l}\text { Se lo hace la mujer con las manos para tratar } \\
\text { de encontrar bolitas. }\end{array}$ \\
\hline
\end{tabular}

Nota. $\mathrm{n}=130$. 


\section{CAPÍTULO 7}

Respecto a la influencia del personal de salud acerca de la autoexploración de mama, el $80 \%$ considera que influye positivamente, el $89 \%$ lo recomienda, el $74 \%$ afirma que el personal de salud ofrece charlas al respecto, mientras que el $26 \%$ considera que no orientan por falta de tiempo; finalmente, el $91 \%$ considera que deberían de difundir información.

Los motivos que las participantes consideraron para realizarse en autoexamen de mama fueron: para buscar alguna patología (72\%), para detectar nódulos, secreciones por el pezón y retracción de la piel (79\%), para detectar cáncer $(87 \%)$, para detectar tempranamente patologías (77\%), para estar seguras de estar sanas (92\%), para prevenir muertes por cáncer de mama (95\%).

Respecto a quiénes deben realizarse el autoexamen de mama, el 89\% señaló que todas las mujeres, el $79 \%$ solo mujeres en edad fértil, el $68 \%$ mujeres y hombres, $48 \%$ todas las mujeres a partir de los 20 años, 29\% mujeres mayores de 35 años, $84 \%$ mujeres con vida sexualmente activa, $46 \%$ toda mujer premenopáusica, $89 \%$ solo las madres después de tener un hijo.

En referencia al momento en que debe realizarse la autoexploración, el 33\% indicó que una vez al mes después de la menstruación, el $31 \%$ cada tres meses, el $45 \%$ en cualquier momento cada 6 meses, el 36\% una vez al año, el 15\% diario, el 29\% ocho días después de la menstruación, el 50\% en el baño, el 31\% acostada en la cama, el 75\% cuando siento molestias en la mama, el 78\% cuando sienta dolor.

Respecto a los factores para la autoexploración, el 94\% consideran que lo hacen para detectar cáncer tempranamente, el 82\% para conocer tu cuerpo, el 95\% para saber si están bien, el $91 \%$ para saber si se tiene la enfermedad. Por su parte, en la tabla 4 se aprecia la distribución porcentual de los participantes de acuerdo con los motivos que consideran que obstaculizan la autoexploración; destacan principalmente el pensar que la autoexploración se realiza por morbo, porque el personal de salud no orienta lo suficiente, también por tener bajo nivel educativo o recursos económicos. 


\section{Tabla 4}

\section{Distribución porcentual de los participantes de acuerdo con los factores que obstaculizan la autoexploración}

\section{Porcentaje Indicadores de los motivos}

$62 \% \quad$ Porque piensa que es morboso.

62\% Porque el personal de salud no orienta.

$62 \% \quad$ Por bajos recursos y educación.

55\% Factor cultural.

54\% Por falta de tiempo.

45\% Por pereza.

$42 \% \quad$ Por miedo y vergüenza.

36\% Despreocupación.

33\% No le toma importancia.

28\% Por temor a tener algo anormal.

27\% Falta de costumbre y actitud.

27\% Por olvido.

23\% Porque no sabe cómo realizarlo.

19\% $\quad$ Por miedo a que la pareja la abandone.

Por otra parte, al valorar las actitudes hacia el autoexamen (tabla 5), observamos que todas las participantes consideraron que realizarlo es bueno. Asimismo, el 47\% afirmó que su madre influye en la decisión de realizar la autoexploración y el 44\% consideró que el personal de salud influye en tomar esta decisión. El olvido es una razón por la cual no se realizan la autoexploración (40\% de las participantes). 


\section{Tabla 5}

\section{Porcentaje de participantes de acuerdo con cada actitud ante la autoexploración}

\section{Actitudes}

$100 \%$ Es bueno realizarlo.

$71 \%$ El grado de escolaridad influye en la realización del examen.

47\% Mi madre influye en la realización del examen.

$44 \%$ El personal de salud influye en la realización del examen.

$40 \%$ Se me olvida.

$32 \%$ Yo me realizo el autoexamen de mama para protegerme de enfermedades.

$32 \%$ Mi pareja influye en la realización del examen.

$27 \%$ Me da miedo realizarme el examen por lo que puedo encontrar.

$24 \%$ Mis amigas influyen en la realización del examen.

$24 \%$ El personal de salud no me ha explicado sobre esto.

19\% No tengo tiempo para realizarlo.

19\% Me da pereza.

$12 \%$ La religión influye en la realización del examen.

$12 \%$ El examen me ayuda a detectar enfermedades malignas y benignas.

$10 \%$ No me lo realizo porque no tengo nada, no va a salir nada.

$10 \%$ No creo que sea importante.

$10 \% \mathrm{El}$ autoexamen me da muchos beneficios.

9\% Me da vergüenza realizarlo.

9\% Debo acudir al médico cuando encuentre algo anormal.

9\% Puedo acudir a un curandero para masajes y remedios para curarme.

9\% A mi pareja no le gusta que me toque mis senos.

9\% No tengo dinero para realizarlo.

8\% Es un pecado realizarlo.

$5 \%$ Me preocupa la aparición de tumores (bultos).

4\% Me duele al realizarlo. 


\section{CAPÍTULO 7}

\section{Discusión y conclusiones}

Tal como podemos apreciar, las participantes estudiantes universitarias de la presente investigación cuentan con un conocimiento parcial del cáncer de mama y la técnica de autoexploración; al igual que otras poblaciones, también se evidencian actitudes que obstaculizan la búsqueda y aceptación de estos términos o conceptos. Nuestros resultados coinciden con otros estudios, como el de Álvarez et al. (2017), quienes encontraron en mujeres hondureñas conocimientos incompletos del cáncer de mama y de la autoexploración, asimismo, reportaron que sus participantes consideraron que el personal de salud proporcionaba poca información al respecto.

El tener poca o parcial información conlleva prácticamente el mismo riesgo que cuando se tiene nula información, por ello, resulta importante crear estrategias de promoción de la salud que, por un lado, ofrezcan alternativas educativas y pedagógicas para que las mujeres jóvenes adquieran los conocimientos suficientes y adecuados para su propio autocuidado y realicen adecuadamente las acciones preventivas del cáncer de mama, principalmente lo concerniente a la autoexploración. Al respecto, Meneses et al. (2018) afirmaron que para lograr la reducción y diagnóstico oportuno del cáncer de mama, se puede emplear tanto la educación como la información. Los expertos afirman que es importante que las mujeres estén familiarizadas con su propio tejido mamario desde la etapa adolescente, ya que así les será más sencillo detectar cualquier anomalía (Prats \& Font, 2001).

Además de lo anterior, es importante resaltar los aspectos actitudinales que se ven presentes en este estudio, ya que dan cuenta de la importancia de los conocimientos y experiencias que se aprenden y transmiten por generaciones (Giraldo et al., 2010), de tal forma que las actitudes influyen determinantemente en las creencias sobre el cáncer de mama y la autoexploración. En este sentido, podemos observar que las universitarias entrevistadas, a pesar de que consideran buena la autoexploración - sobre todo, para detectar alguna enfermedad-, también tienen la idea de que son conductas morbosas, de que su madre influye en su actitud ante esta técnica y adjudican la mayor parte de su poco dominio al personal de salud.

Estas actitudes se conjugan como estados de disposición que van a influir en las conductas de las universitarias (Allport, 1935), por ello, resultó importante indagarlas en la 


\section{CAPÍTULO 7}

presente investigación, ya que no se pueden observar a simple vista; además, también involucran emociones que, al organizarse, establecen los juicios que las jóvenes hacen de la enfermedad y la técnica de exploración. Para impactar positivamente en las actitudes es necesario contextualizar a las participantes en la cultura que forman parte, ya que a través de esta se modulan las actitudes y ayuda a la toma de conciencia de ellas y el papel que juegan en sus comportamientos de autocuidado.

Esta investigación permite identificar las necesidades en torno a los conocimientos que deben ser entrenados en las mujeres universitarias, ya que el adecuado dominio de la información y de la técnica de autoexploración fungirá como una adecuada medida temprana preventiva ante el cáncer de mama, el cual es considerado el más agresivo y el que más muertes ocasiona en la población femenina (Zaharia \& Gómez, 2013). Aunado a ello, la mayor parte de los diagnósticos tempranos se deben a las palpitaciones que las propias mujeres se realizan (Cárdenas et al., 2013), lo cual garantiza un control de la enfermedad y, por lo tanto, un mejor pronóstico de vida.

El hecho de que reconozcan que el personal de salud es quien debe de ofrecer información y capacitación indica que el trabajo multidisciplinario debe organizarse para ofrecer un adecuado abordaje para garantizar la obtención de un alto grado de conocimiento, principalmente de la técnica de autoexploración, de la toma de conciencia de las actitudes y emociones que experimentan y que pueden ser obstáculos para adquirir conductas de autocuidado adecuadas.

La adopción de procedimientos parar detectar a tiempo posibles anomalías ayudará a prevenir diagnósticos tardíos y complicaciones que conllevan consecuencias a largo plazo tanto físicas como psicológicas, resulta importante que las jóvenes estén conscientes de que no es una enfermedad propia de las mujeres adultas o mayores, sino que, con el paso de los años, se ha vuelto una enfermedad que ocurre cada vez más a edades más tempranas (Asociación Española Contra el Cáncer, 2020). 


\section{CAPÍTULO 7}

\section{Referencias}

Abugattas, J., Manrique, J., \& Vidaurre, T. (2015). Mamografía como instrumento de tamizaje en cáncer de mama. Revista Peruana de Ginecología y Obstetricia, 61(3), 311-319.

Allport, G. (1935). Attitudes. En C. Murchison (Ed.), Handbook of social psychology. Clark University Press.

Álvarez, L., Marily, I., Durón, R., Medina, F., Gómez, S., Henríquez, O., Castro, C. E., Salgado, A. M., Fernández, D. M., Velásquez, L. E., Vásquez, P. I, Murillo, O. A., \& Cabrera, S. (2017). Conocimientos, actitudes y prácticas en cáncer de mama y el autoexamen para detección temprana. Revista Médica de Honduras, 85(3-4), 81-86. https://pesquisa.bvsalud.org/ portal/resource/pt/biblio-970037

American Cancer Society. (2017). Tasas de supervivencia del cáncer de seno. https://www. cancer.org/es/cancer/cancer-de-seno/comprension-de-un-diagnostico-de-cancer-deseno/tasas-de-supervivencia-del-cancer-de-seno.html

Asociación Española Contra el Cáncer. (2020). Pronóstico del Cáncer de Mama: Mortalidad y Esperanzadevida.https://www.aecc.es/es/todo-sobre-cancer/tipos-cancer/cancer-mama/ mas-informacion/evolucion-cancer-mama

Asociación Médica Mundial. (2001). Declaración de Helsinki de la AMM - Principios éticos para las investigaciones médicas en seres humanos. https://www.wma.net/ es/policies-post/declaracion-de-helsinki-de-la-amm-principios-eticos-para-lasinvestigaciones-medicas-en-seres-humanos/

Brandan, M. E., \& Villaseñor, Y. (2006). Detección del cáncer de mama: estado de la mamografía en México. Cancerología 1, 147-162. http://incan-mexico.org/revistainvestiga/elementos/ documentosPortada/1172289111.pdf

Cárdenas, J., Bargalló, E., Erazo, A., Maafs, E., \& Poitevin, A. (2013). Consenso mexicano sobre diagnóstico y tratamiento del cáncer mamario. Secretaría de Salud. http:// consensocancermamario.com/

Castillo, I., Bohórquez, C., Palomino, J., Elles, L., \& Montero, L. (2016). Conocimientos, actitudes y prácticas sobre el autoexamen de mama en mujeres del área rural de Cartagena. Revista U. D. C. A. Actualidad \& Divulgación Científica, 19(1). https://revistas.udca.edu. co/index.php/ruadc/article/view/105 


\section{CAPÍTULO 7}

Castro, I., \& Rizo, Y. (2009). Nivel de conocimiento de la población femenina del consultorio 6 sobre autoexamen de mama. Revista Habanera De Ciencias Médicas, 8(5), 121-130. https://www.redalyc.org/articulo.oa?id=180414046017

Fernández, L. (2020). Representaciones sociales de las mamas, mujeres mastectomizadas, feminidad y cuidado (Tesis de Licenciatura). Universidad de Ciencias Aplicadas y Ambientales, Bogotá, Colombia. https://repository.udca.edu.co/handle/11158/3719

Gálvez, E. M. (2013). Relación entre el conocimiento del autoexamen de mama y la prevención del cáncer de mama. Mediciego, 19(2). https://www.medigraphic.com/cgi-bin/new/ resumen.cgi?IDARTICULO $=46469$

Giraldo, A., Toro, M., Macías, A., Valencia, C., \& Palacio, S. (2010). La promoción de la salud como estrategia para el fomento de estilos de vida saludables. Revista hacia la Promoción de la Salud, 13(1), 128-143. https://www.redalyc.org/articulo.oa?id=309126693010

Instituto Nacional de Estadística y Geografía. (2017). Defunciones de mujeres por tumor maligno de la mama por entidad federativa de residencia habitual de la persona fallecida y grupo quinquenal de edad, 2010 a 2017. https://www.inegi.org.mx/app/tabulados/ interactivos/?px=Mortalidad_05\&bd=Mortalidad

Jara, A. L., \& Peña, S. K. (2011). Nivel de conocimientos sobre factores de riesgo y prevención del cáncer de mama en usuarias de 19 a 49 años del Centro de Salud San Sebastián; enero- febrero 2011 (Tesis de Licenciatura). Universidad Nacional Mayor de San Marcos, Lima, Perú. https://cybertesis.unmsm.edu.pe/bitstream/handle/20.500.12672/3021/ Jara_ra.pdf? sequence $=1$ \&isAllowed $=y$

Meneses, J., Martínez, J., Chavarriga, M., González, K., Vinaccia, S., Rincón, A., Rincón, G., Muñoz, B., \& Ramírez, R. (2018). Creencias y conocimientos relacionados a la práctica del autoexamen de mama en mujeres universitarias de Colombia: un estudio descriptivo. Revista Chilena de Obstetricia y Ginecología, 83(2), 120-129. https://scielo.conicyt.cl/ scielo.php?script=sci_arttext\&pid=S0717-75262018000200120

Organización Mundial de la Salud. (2021a). Cáncer. https://www.who.int/es/news-room/ fact-sheets/detail/cancer

Organización Mundial de la Salud. (2021b). Cáncer de mama: prevención y control. https:// www.who.int/es/news-room/fact-sheets/detail/breast-cancer 


\section{CAPÍTULO 7}

Prats, M., \& Font, V. (2001). La paciente sintomática: motivos de consulta en atención primaria. Medicina Integral, 28(10), 437-253. https://www.elsevier.es/en-revista-medicina-integral63-articulo-la-paciente-sintomatica-motivos-consulta-13024496

Reglamento de la Ley General de Salud en Materia de Investigación para la Salud. (2014). Nuevo Reglamento publicado en el Diario Oficial de la Federación el 6 de enero de 1987. Última reforma publicada DOF 02-04-2014. http://www.diputados.gob.mx/LeyesBiblio/ regley/Reg_LGS_MIS.pdf

Sánchez, U., Urdaneta, J., Villalobos, N., Contreras, A., Garcia, J., Baabel, N., Villalobos, S., \& Cepeda, M. (2016). Conocimiento sobre cáncer de mamas y práctica del autoexamen de mama en mujeres de edad mediana. Revista Venezolana de Oncología, 28(1) 37-51. https://www.redalyc.org/pdf/3756/375643222006.pdf

Sardiñas, R. (2009). Autoexamen de mama: un importante instrumento de prevención del cáncer de mama en atención primaria de la salud. Revista Habanera de Ciencias Médicas, 8(3). https://www.redalyc.org/articulo.oa?id=180414043005

Secretaría de Salud. (2011). Norma Oficial Mexicana Nom-041-ssa2-2011, Para la prevención, diagnóstico, tratamiento, control y vigilancia epidemiológica del cáncer de mama. Diario Oficial de la Federación, DOF 09-06-2011. http://dof.gob.mx/nota_detalle. php? codigo $=5194157 \&$ fecha $=09 / 06 / 2011$

Secretaría de Salud. (2015). Estadísticas de Cáncer de Mama y Cáncer Cérvico Uterino. https:// www.gob.mx/salud/acciones-y-programas/informacion-estadistica

Torres, J., Arce, M., Ruiz, E., \& Mejía, C. (2017). Actitudes frente a la autoexploración de mama en dos facultades de ciencias de la salud de Ica, Perú: un estudio piloto. Salud Pública de México, 59(2), 117-118. https://www.redalyc.org/articulo.oa?id=10650931001

Zaharia, M., \& Gómez, H. (2013). Cáncer de mama triple negativo: una enfermedad de difícil diagnóstico y tratamiento. Revista Peruana de Medicina Experimental y Salud Pública, 30(4), 649-656. http://www.scielo.org.pe/scielo. php?script=sci_arttext\&pid=S1726-46342013000400018 


\title{
CAPÍTULO 8
}

\section{Estilo de vida en estudiantes universitarios}

\author{
Alicia Abundis Gutiérrez, Joel Omar González Cantero \\ y Víctor Hugo González Becerra
}

El estilo de vida (EV) "es una forma utilizada por personas, grupos y naciones y se forma en un contexto geográfico, económico, político, cultural y religioso específico” (Farhud, 2015, p.1443). Desde el enfoque de la psicología de la salud, genéricamente el estilo de vida es definido como un "conjunto de hábitos de comportamiento que constituyen factores de protección para la salud, o factores de riesgo de enfermedad" (Flórez, 2007, p.5).

Particularmente, en el cuestionario fantastic, el estilo de vida es entendido como un conjunto de decisiones personales que afectan la salud y sobre las cuales el individuo tiene cierto control, implicando que pobres decisiones y hábitos puedan generar riesgos autoimpuestos que resulten en enfermedad, e incluso la muerte (Wilson \& Ciliska, 1948). Estas decisiones y hábitos impactan en el bienestar físico, emocional y social del individuo, por lo que el cuestionario incluye factores interpersonales y de contexto.

Cuando el estilo de vida es saludable influye en el aumento del bienestar psicológico y social, preservando y optimizando las capacidades cognitivas y las funciones neuronales; en contraste, cuando no es saludable, contribuye al desarrollo de múltiples psicopatologías (Walsh, 2011).

Por otro lado, lograr la modificación del estilo de vida no es fácil, pues a pesar de que hay una actitud favorable hacia un estilo de vida saludable, no siempre esto conlleva la adopción o mantenimiento de este. Arrivillaga y Salazar (2005) encontraron que estudiantes universitarios colombianos tienen creencias favorables hacia la condición, actividad física y deporte, la recreación y manejo del tiempo libre, autocuidado y cuidado médico, hábitos alimenticios, consumo de alcohol, tabaco y otras drogas; no obstante, señalan que, exceptuando la recreación y el manejo del tiempo libre, los demás 


\section{CAPÍTULO 8}

factores en que los jóvenes reportan creencias favorables no coinciden con las prácticas realizadas.

La expectativa social es que los estudiantes universitarios tengan un estilo de vida saludable. No obstante, González-Cantero et al. (2017) señalaron que, en un estudio realizado con 320 universitarios mexicanos de una universidad del occidente de México, solo el $28.4 \%$ obtuvo un nivel alto en el estilo de vida saludable. En el mismo sentido, en un estudio de revisión bibliográfica, Sánchez-Ojeda y Luna-Bertos (2015) concluyeron que los jóvenes universitarios no tienen buenos hábitos alimentarios, la práctica del ejercicio físico es nula y tienen un consumo elevado de alcohol, tabaco y marihuana.

Dado lo anterior, se considera necesario que desde la perspectiva de la psicología de la salud se realicen contribuciones importantes para mejorar el estilo de vida saludable con base en el estudio del comportamiento saludable y no saludable (Conner \& Norman, 2017).

\section{Método}

\section{Participantes}

En el estudio participaron de forma voluntaria e informada 169 estudiantes de primer y segundo semestre de distintas licenciaturas del Centro Universitario de Los Valles, de la Universidad de Guadalajara (rango de edad de 18 a 43 años, $\mathrm{M}=20.9, \mathrm{DE}=4.3 ; 71$ mujeres).

\section{Instrumento}

El cuestionario FANTASTiC (Wilson \& Ciliska, 1984) fue diseñado por el Departamento de Medicina Familiar de la Universidad McMaster de Canadá para evaluar el estilo de vida. Contiene 25 ítems con una escala tipo Likert con opciones de respuesta de 0 a 2 , donde 2 hace referencia a mayor frecuencia u ocurrencia de las conductas consideradas. Los ítems se agrupan en nueve dominios físicos, psicológicos y sociales asociados al estilo de vida: (1) familia y amigos, (2) actividad, (3) nutrición, (4) tabaco y toxinas, (5) alcohol, (6) sueño, cinturón de seguridad y estrés, (7) tipo de personalidad, (8) introspección y (9) carrera. La puntuación para cada dominio es el promedio de los ítems de los cuales se compone. La puntuación total corresponde a la sumatoria de los 25 ítems, se multiplica por 2 para obtener un máximo de 100 puntos. El FANTASTIC considera cinco niveles de estilo de vida a partir de la puntuación total: excelente (85-100), bueno (70- 


\section{CAPÍTULO 8}

85), regular (60-69), malo (40-59) y peligroso (<39). En este estudio, la confiabilidad de la prueba FANTASTIC fue de 0.78 según la a de Cronbrach. En el cuestionario se pidió también información de peso y estatura de los participantes para obtener su índice de masa corporal (IMC).

\section{Procedimiento}

La aplicación del cuestionario se realizó en un aula durante el tiempo libre de una clase, previa autorización del profesor en turno. Al inicio de la aplicación se dieron las instrucciones para dar respuesta a las preguntas, se resolvieron dudas y se especificó que la información recibida sería confidencial. El dato del peso y estatura de los participantes fue auto-reportado. Cuando el último cuestionario contestado fue entregado, se agradeció la participación a los alumnos y al profesor por el tiempo de su clase. En cada una de las aulas de los participantes considerados en esta investigación, se realizó el mismo procedimiento para la aplicación del cuestionario.

\section{Resultados}

Los descriptivos de sexo, edad, IMC, estilo de vida y los nueve dominios del cuestionario fANTASTIC se muestran en la tabla 1. Según el IMC, la mayoría de los participantes mostraron una composición corporal normal (40.2\%), sobrepeso (42\%), obesidad tipo I (14.2\%), delgadez aceptable (2.4\%) y obesidad tipo II y III (1.2\%, solo un caso para cada categoría). A pesar de que los hombres mostraron mayor IMC que las mujeres (tabla 1), no se encontraron diferencias en composición corporal entre hombres $(\mathrm{Mdn}=3) \mathrm{y} \mathrm{mu}$ jeres $(\mathrm{Mdn}=3): \mathrm{U}=3,061, \mathrm{z}=-1.44, \mathrm{p}>.05, \mathrm{r}=-.21$. 


\section{Tabla 1}

Descriptivos de edad, IMC, puntuación total y los nueve dominios del cuestionario FANTASTIC (comparaciones por sexo)

\begin{tabular}{lccccccccc} 
& \multicolumn{1}{c}{ Total } & \multicolumn{7}{c}{ Hombres } & \multicolumn{2}{c}{ Mujeres } \\
$\mathbf{n}=\mathbf{1 6 9}$ & $\mathbf{n}=\mathbf{9 8}$ & $\mathbf{n}=\mathbf{7 1}$ & & & \\
& $\mathbf{M}$ & $\mathbf{D E}$ & $\mathbf{M}$ & $\mathbf{D E}$ & $\mathbf{M}$ & $\mathbf{D E}$ & $\mathbf{U}$ & $\mathbf{p}$ & $\mathbf{~}$ \\
\hline Edad & 20.9 & 4.4 & 21.2 & 4.5 & 20.5 & 4.1 & 3172.5 & 0.319 & -0.08 \\
Índice de masa corporal & 26.1 & 4.5 & 26.5 & 4.3 & 25.5 & 4.7 & 2819.0 & 0.036 & -0.16 \\
Estilo de vida $^{\mathbf{a}}$ & 72.7 & 12.2 & 73.2 & 12.4 & 72.1 & 12.0 & 3269.0 & 0.503 & -0.05 \\
Familia y amigos & 1.6 & 0.4 & 1.6 & 0.4 & 1.6 & 0.3 & 3829.0 & 0.242 & 0.09 \\
Actividad & 1.2 & 0.6 & 1.2 & 0.6 & 1.1 & 0.6 & 2934.0 & 0.073 & -0.14 \\
Nutrición & 1.3 & 0.4 & 1.3 & 0.4 & 1.3 & 0.4 & 3706.5 & 0.462 & 0.06 \\
Tabaco y toxinas & 1.7 & 0.4 & 1.7 & 0.4 & 1.7 & 0.3 & 3529.0 & 0.859 & 0.01 \\
Alcohol & 1.8 & 0.3 & 1.7 & 0.4 & 1.9 & 0.3 & 4411.5 & 0.000 & 0.28 \\
Sueño, cinturón y estrés & 1.0 & 0.5 & 1.1 & 0.5 & 0.9 & 0.5 & 2709.0 & 0.013 & -0.19 \\
Tipo de personalidad & 1.4 & 0.5 & 1.4 & 0.5 & 1.4 & 0.5 & 3344.0 & 0.659 & -0.03 \\
Introspección & 1.5 & 0.4 & 1.5 & 0.4 & 1.4 & 0.4 & 3043.0 & 0.150 & -0.11 \\
Carrera & 1.7 & 0.4 & 1.7 & 0.4 & 1.7 & 0.3 & 3187.0 & 0.302 & -0.08 \\
\hline
\end{tabular}

Nota. $\mathrm{M}=$ media, $\mathrm{DE}=$ desviación estándar, $\mathrm{U}=\mathrm{U}$ de Mann-Whitney, $\mathrm{r}=$ tamaño del efecto. En negritas comparaciones significativas según la prueba de Mann-Whitney $(\mathrm{p}<0.05)$. a Puntuación total en el cuestionario FANTASTIC.

De acuerdo con la puntuación total en el cuestionario FANTASTIC, encontramos que, en estilo de vida, el $14.2 \%$ de los participantes obtuvo la categoría de excelente y el $50.3 \%$ bueno, mientras que el $22 \%$ regular y el $13.6 \%$ malo. Si observamos la composición corporal y el estilo de vida, encontramos las cuatro composiciones corporales en todas las categorías de estilo de vida, sin embargo, vemos que prácticamente el $90 \%$ de los participantes con un estilo de vida bueno, tienen una composición normal (43.5\%) y de sobrepeso (45.9\%), mientras que el 7.4\% de participantes con composición normal, $13 \%$ en categoría sobrepeso y $33 \%$ con Obesidad tipo I, obtuvieron estilo de vida malo. 
La figura 1 muestra la distribución de las categorías de estilo de vida de acuerdo con la composición corporal.

\section{Figura 1}

\section{Porcentaje de composición corporal según tipos de estilo de vida}

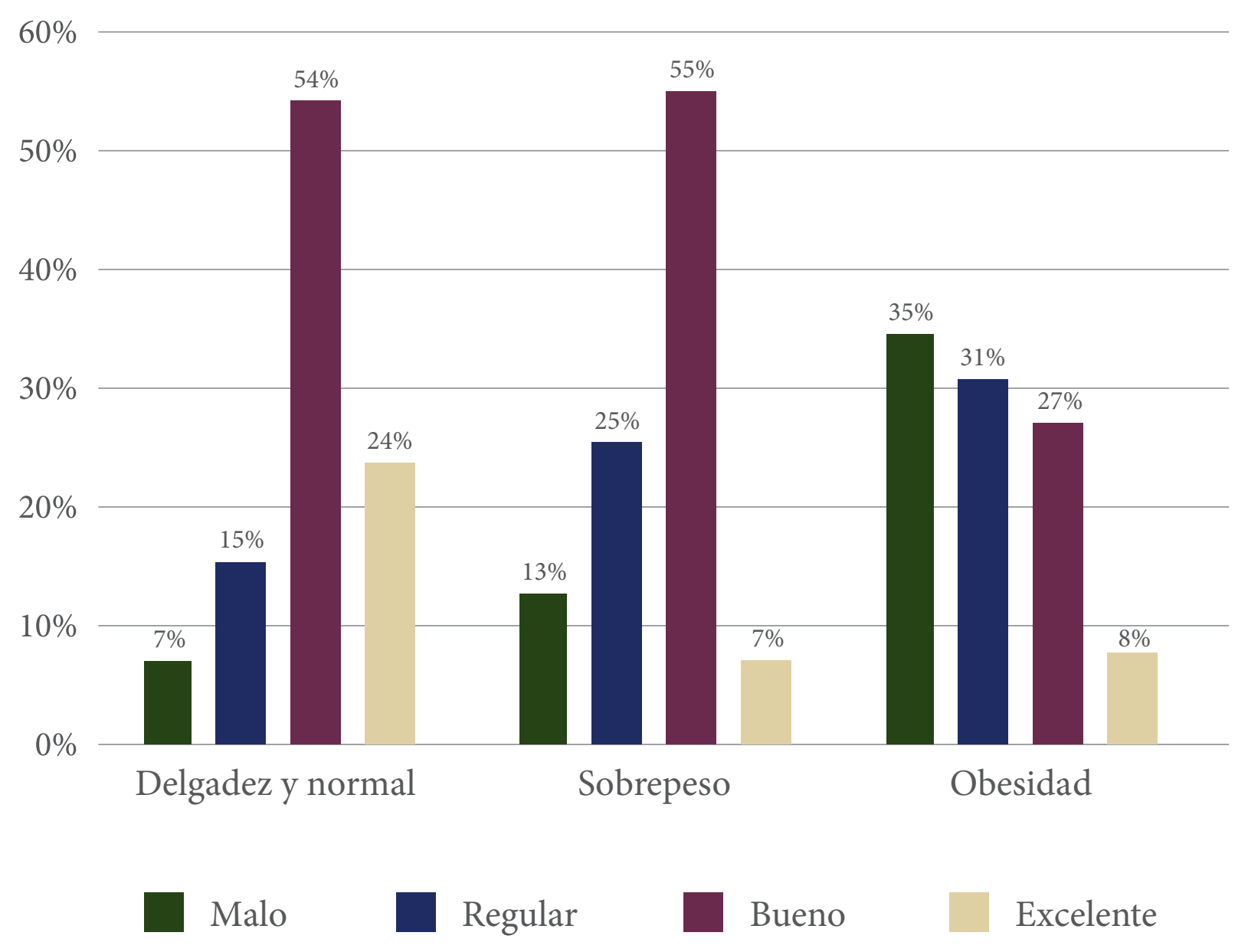

Nota. Delgadez se refiere a delgadez aceptable; la etiqueta Obesidad incluye tipo I, II y III.

En la tabla 2 se muestran los resultados de correlación. El sexo correlacionó positivamente con el dominio alcohol $(\mathrm{r}=.25)$ y negativamente con el dominio sueño, cinturón de seguridad y estrés $(r=-.19)$, mostrando relación entre ser mujer y mayor consumo de alcohol, menos episodios de estrés y más hora de sueño. La edad se relacionó positivamente con el IMC $(\mathrm{r}=.20)$ y negativamente con el dominio actividad $(\mathrm{r}=-.23)$; a mayor edad, mayor IMC y menor actividad física. El IMC correlacionó negativamente con el estilo de vida $(\mathrm{r}=-.37)$ ylos dominios actividad $(\mathrm{r}=-.24)$, nutrición $(\mathrm{r}=-.59)$, introspección $(\mathrm{r}=-.17)$ y carrera $(\mathrm{r}=-.23)$, indicando que valores menores de IMC se asocian a 


\section{Tabla 2}

Correlaciones entre los dominios de estilo de vida, sexo, edad e IMC

\begin{tabular}{|c|c|c|c|c|c|c|c|c|c|c|c|c|}
\hline & 1 & 2 & 3 & 4 & 5 & 6 & 7 & 8 & 9 & 10 & 11 & 12 \\
\hline \multicolumn{13}{|l|}{ 1. Sexo } \\
\hline 2. Edad & -.09 & & & & & & & & & & & \\
\hline 3. Índice de masa corporal & -.11 & $.20^{\star *}$ & & & & & & & & & & \\
\hline 4. Estilo de vida & -.04 & -.01 & $-.37^{\star *}$ & & & & & & & & & \\
\hline 5. Familia y amigos & .12 & .02 & -.14 & $.52^{\star *}$ & & & & & & & & \\
\hline 6. Actividad & -.14 & $-.23^{* *}$ & $-.24^{\star \star}$ & $.53^{\star *}$ & $.16^{\star}$ & & & & & & & \\
\hline 7. Nutrición & .04 & -.11 & $-.58^{\star \star}$ & $.59^{* *}$ & .15 & $.36^{* *}$ & & & & & & \\
\hline 8. Tabaco y toxinas & .03 & -.05 & -.15 & $.41^{\star *}$ & .05 & .11 & $.22^{\star *}$ & & & & & \\
\hline 9. Alcohol & $.25^{\star *}$ & -.06 & -.03 & $.16^{\star}$ & -.01 & -.05 & .06 & $.17^{\star}$ & & & & \\
\hline 10. Sueño, cinturón y estrés & $-.19^{\star}$ & .11 & -.07 & $.68^{\star *}$ & $.28^{\star *}$ & $.35^{\star *}$ & $.18^{\star}$ & .13 & .06 & & & \\
\hline 11. Tipo de personalidad & -.03 & .10 & -.13 & $.65^{\star *}$ & $.22^{\star *}$ & $.16^{\star}$ & $.17^{\star}$ & $.22^{\star *}$ & .09 & $.41^{\star *}$ & & \\
\hline 12. Introspección & -.09 & .11 & $-.17^{\star}$ & $.71^{\star *}$ & $.35^{\star *}$ & $.25^{* *}$ & $.28^{* *}$ & .11 & -.10 & $.45^{\star *}$ & $.51^{\star *}$ & \\
\hline 13. Carrera & -.05 & .02 & $-.23^{* *}$ & $.63^{\star *}$ & $.49^{* *}$ & $.19^{*}$ & $.34^{\star *}$ & $.18^{\star}$ & -.01 & $.31^{\star *}$ & $.32^{\star \star}$ & $.51^{\star x}$ \\
\hline
\end{tabular}

Nota. Estilo de vida (4) se refiere a la puntuación total obtenida en el cuestionario. ${ }^{\star} \mathrm{p}<.05,{ }^{*} \mathrm{p}<.01$.

conductas más saludables en los dominios mencionados. El estilo de vida, por su parte, se relacionó positivamente con los nueve dominios de la prueba FANTASTIC, aunque la correlación con el dominio alcohol fue muy baja $(r=.16)$. En cuanto a las relaciones observadas entre los dominios de estilo de vida, encontramos que el dominio familia y amigos (comunicación, afecto y apoyo emocional) mostró correlaciones positivas con actividad $(\mathrm{r}=.17)$, sueño, cinturón de seguridad y estrés $(\mathrm{r}=.28)$, tipo de personalidad $(\mathrm{r}=.22)$, introspección $(\mathrm{r}=.36)$ y carrera $(\mathrm{r}=.49)$. El dominio actividad (ejercicio y relajación) se relacionó con nutrición $(\mathrm{r}=.36)$, sueño, cinturón de seguridad y estrés $(\mathrm{r}=.35)$, tipo de personalidad $(\mathrm{r}=.16)$, introspección $(\mathrm{r}=.25)$ y carrera $(\mathrm{r}=.19)$. Nutrición (elementos de una alimentación balanceada y peso ideal) se correlacionó positivamente con tabaco y toxinas $(\mathrm{r}=.22)$, sueño, cinturón de seguridad y estrés $(\mathrm{r}=.18)$, tipo de personalidad $(\mathrm{r}=.17)$, introspección $(\mathrm{r}=.28)$ y carrera $(\mathrm{r}=.34)$. El dominio tabaco y 


\section{CAPÍTULO 8}

toxinas (tabaco, drogas, café y cola) se relacionó con alcohol $(\mathrm{r}=.17)$, tipo de personalidad $(\mathrm{r}=.22)$ y carrera $(\mathrm{r}=.18)$. Sueño, cinturón de seguridad y estrés (horas de sueño, uso de cinturón y episodios de estrés) se correlacionó con tipo de personalidad $(\mathrm{r}=.41)$, introspección $(\mathrm{r}=.45)$ y carrera $(\mathrm{r}=.31)$. Por su parte, tipo de personalidad (impaciencia, competitividad y hostilidad) se relacionó con introspección $(\mathrm{r}=.51)$ y carrera $(\mathrm{r}=.32)$. Finalmente, encontramos correlación $(\mathrm{r}=.51)$ entre introspección (pensamiento positivo, preocupación y depresión) y carrera (satisfacción con actividades y buenas relaciones).

Dada la naturaleza ordinal de los datos y la falta de normalidad ( $\mathrm{p}>.01 \mathrm{en}$ la prueba de Kolmogorov-Smirnov), se realizaron análisis estadísticos no paramétricos para hacer comparaciones entre grupos. De acuerdo con la prueba de U de Mann-Whitney para muestras independientes (tabla 1), el IMC $(\mathrm{U}=2819, \mathrm{p}=.036, \mathrm{r}=-.16)$, y los dominios alcohol ( $\mathrm{U}=4411.5, \mathrm{p}=.000, \mathrm{r}=.28)$ y sueños, cinturón de seguridad y estrés $(\mathrm{U}=2709$, $\mathrm{p}=.013, \mathrm{r}=-.19)$ resultaron ser diferentes entre hombres $(\mathrm{n}=98)$ y mujeres $(\mathrm{n}=71)$.

Agrupando con base en la composición corporal (delgado y normal [DN] $n=72$, Sobrepeso [Sp] $n=71$ y Obesidad [Ob] $n=26$ ), se realizó la prueba de Kruskal-Wallis para muestras independientes y se encontraron diferencias significativas en estilo de vida $(\mathrm{H}(2)=18.77, \mathrm{p}=.000)$, actividad $(\mathrm{H}(2)=7.77, \mathrm{p}=.021)$, nutrición $(\mathrm{H}(2)=58.36$, $\mathrm{p}=.000)$, y carrera $(\mathrm{H}(2)=6.11, \mathrm{p}=.047)$. Comparaciones Post-hoc por pares con $\mathrm{p}$ ajustada por corrección de Bonferroni, mostraron que la puntuación total de estilo de vida de DN fue mayor al estilo de vida de $\mathrm{Sp}(\mathrm{p}=032, \mathrm{r}=-.22)$ y Ob $(\mathrm{p}=.000, \mathrm{r}=-.40)$, las puntuaciones de estilo de vida fueron estadísticamente iguales entre $\mathrm{Sp}$ y $\mathrm{Ob}(\mathrm{p}=.120$, $\mathrm{r}=-.26)$. El dominio actividad fue mayor en el grupo $\mathrm{DN}$, respecto al grupo $\mathrm{Sp}(\mathrm{p}=.047$, $\mathrm{r}=-.21)$, la diferencia entre $\mathrm{DN}$ y Ob fue marginal $(\mathrm{p}=.089, \mathrm{r}=-.20)$, los grupos Sp y Ob mostraron frecuencias similares en realización de ejercicio activo y disfrute del tiempo libre. Las diferencias en nutrición se encontraron en los tres pares de comparación, indicando que los hábitos saludables de alimentación fueron más frecuentes en el grupo DN respecto a $\mathrm{Sp}(\mathrm{p}=.000, \mathrm{r}=-.46)$ y $\mathrm{Ob}(\mathrm{p}=.000, \mathrm{r}=-.67)$, a su vez, $\mathrm{Sp}$ fue significativamente mayor que el grupo $\mathrm{Ob}(\mathrm{p}=.003, \mathrm{r}=-.39)$. Por último, se encontraron diferencias en Carrera entre DN y Ob $(\mathrm{p}=.041, \mathrm{r}=-.25)$, indicando que el grupo DN tuvo mayor satisfacción con las labores que desempeña y mejores relaciones con quienes los rodean, que las personas con Obesidad $(\mathrm{Ob})$. 


\section{CAPÍTULO 8}

Agrupando por la frecuencia de realización de 30 minutos de ejercicio activo (correr, andar en bicicleta, caminar rápido), tres o más veces a la semana (E3), dos veces a la semana (E2) y rara vez o nunca (E0) se observó, según la prueba de Kruskal-Wallis para muestras independientes, que el IMC $(\mathrm{H}(2)=9.72, \mathrm{p}=.008)$, estilo de vida $(\mathrm{H}(2)=$ 23.01, $\mathrm{p}=.000)$, nutrición $(\mathrm{H}(2)=20.24, \mathrm{p}=.000)$ e introspección $(\mathrm{H}(2)=6.73, \mathrm{p}=.035)$ fueron diferentes entre los tres grupos. Según las comparaciones Post-hoc, el IMC del grupo E3 fue significativamente menor al IMC del grupo E0 ( $\mathrm{p}=.006, \mathrm{r}=-.28$ ), las puntuaciones de estilo de vida del grupo que no realizó ejercicio fueron significativamente menores que los estudiantes que realizaron ejercicio dos veces a la semana ( $p=.018$, $\mathrm{r}=-.27)$ y tres o más veces $(\mathrm{p}=.000, \mathrm{r}=-.45)$. En el dominio nutrición, encontramos que el grupo que realizó ejercicio activo tres o más veces por semana, tuvo mayor frecuencia de alimentación balanceada y desayuno diario, menor uso de azúcar, sal, grasas animales o comida basura, así como menos kilos de sobrepeso, que quienes realizaron ejercicio dos veces $(\mathrm{p}=.015, \mathrm{r}=-.28)$ y rara vez o nunca $(\mathrm{p}=.000, \mathrm{r}=-.41)$ por semana.

También se analizaron diferencias según la frecuencia de los episodios de estrés importantes el año pasado a la aplicación: ninguno (Ep0), de 1 a 2 (Ep1) y tres o más (Ep3). La prueba de Kruskal-Wallis, mostró diferencias en estilo de vida $(\mathrm{H}(2)=53.34$, $\mathrm{p}=.000)$, actividad $(\mathrm{H}(2)=6.56, \mathrm{p}=.038)$, tabaco y toxinas $(\mathrm{H}(2)=10.84, \mathrm{p}=.004)$, tipo de personalidad $(\mathrm{H}(2)=34.24, \mathrm{p}=.000)$, introspección $(\mathrm{H}(2)=35.77, \mathrm{p}=.000), \mathrm{y}$ carrera $(\mathrm{H}(2)=15.61, \mathrm{p}=.000)$. Acorde a las comparaciones Post-hoc, el estilo de vida de Ep0 fue significativamente mayor al estilo de vida de Ep1 $(\mathrm{p}=.002, \mathrm{r}=-.37)$ y Ep3 $(\mathrm{p}=.000, \mathrm{r}=-.67)$, y el estilo de vida de Ep1 fue también mayor que el de Ep3 ( $\mathrm{p}=.000$, $r=-.46)$. En cuanto a actividad, solo se encontró que Ep0 fue significativamente mayor que Ep3 ( $\mathrm{p}=.035, \mathrm{r}=-.26$ ), lo que sugiere que el ejercicio activo y el disfrute del tiempo libre es menor en estudiantes que han tenido tres o más episodios importantes de estrés, quienes también parecen haber consumido con mayor frecuencia tabaco y toxinas en relación con el grupo con uno o dos episodios de estrés (Ep $1, \mathrm{p}=.004, \mathrm{r}=-.27$ ).

Puntajes en el dominio tipo de personalidad variaron en función de los episodios de estrés. De acuerdo con las comparaciones, el grupo Ep0 tuvo puntuaciones más altas en tipo de personalidad que Ep1 $(\mathrm{p}=.006, \mathrm{r}=-.31)$ y Ep3 $(\mathrm{p}=.000, \mathrm{r}=-.58)$, además, Ep1 fue superior a Ep3 ( $\mathrm{p}=.001, \mathrm{r}=-.32$ ), lo que sugiere que los participantes con mayor 


\section{CAPÍTULO 8}

frecuencia de episodios de estrés puntuaron más alto en el complejo compuesto por impaciencia, competitividad y hostilidad. Se encontró este mismo patrón para el dominio introspección: el grupo Ep0 tuvo puntuaciones más altas que Ep1 $(\mathrm{p}=.016, \mathrm{r}=-.29)$ y Ep3 $(\mathrm{p}=.000, \mathrm{r}=-.58)$, además, Ep1 fue superior a Ep3 $(\mathrm{p}=.000, \mathrm{r}=-.36)$. En este sentido, el promedio obtenido de la frecuencia de pensamiento positivo, ansiedad y depresión fue menor (menos deseable) para quienes sufrieron más episodios importantes de estrés, y viceversa. En cuanto al dominio carrera, las puntuaciones de Ep3 fueron significativamente menores que Ep $1(\mathrm{p}=.001, \mathrm{r}=-.31)$ y Ep $0(\mathrm{p}=.003, \mathrm{r}=-.33)$, indicando menor satisfacción con las actividades y menor frecuencia de buenas relaciones en el grupo que sufrió tres o más episodios importantes de estrés. Encontramos, además, que la frecuencia de dormir de 7 a 9 horas varió de acuerdo con los episodios de estrés; específicamente, se observó que el grupo con más episodios de estrés (Ep3) reportó dormir menos horas que los grupos Ep1 $(\mathrm{p}=.019, \mathrm{r}=-.25)$ y Ep0 $(\mathrm{p}=.004, \mathrm{r}=-.32)$.

\section{Discusión}

En las últimas décadas, el estudio del estilo de vida en estudiantes universitarios ha incrementado, pues se han convertido en población vulnerable por las modificaciones de estilo de vida a las que se ven obligados muchos jóvenes al iniciar sus estudios, adoptando prácticas asociadas a hábitos no saludables, especialmente en lo que concierne a alimentación, sedentarismo y estrés (Greaney et al., 2009; Nelson et al., 2008). El objetivo del presente estudio fue evaluar el estilo de vida de universitarios de una zona rural de Jalisco, México.

Los resultados muestran que el $60 \%$ de los participantes tenían un IMC por arriba de los parámetros de una composición corporal normal, con prevalencia de sobrepeso (42\%). Estudios previos en población universitaria mexicana han encontrado también altos porcentajes de sobrepeso y obesidad, fluctuando entre 34\% (de León-Vázquez et al., 2017), 40\% (Gómez-Miranda et al., 2015), y 49\% (Lorenzini, et al., 2015), por mencionar algunos. De hecho, García-Alcala et al. (2010) reportaron un incremento progresivo y significativo en la prevalencia de sobrepeso y obesidad en esta población, reflejada en aumento de peso, IMC y circunferencia de cintura en universitarios en contexto urbano $(\mathrm{n}=4606)$ de 1994 a 2008. La obesidad no solo impacta la salud física de las personas, 


\section{CAPÍTULO 8}

también se ha encontrado una correlación negativa con el bienestar emocional, psicológico, social (Rand et al., 2017) y económico (Sassi, 2010), así como con la satisfacción con la vida (Baumann et al., 2017). Al respecto, en este estudio se encontró que los estudiantes con algún tipo de obesidad reportaron menor satisfacción con sus actividades y menor calidad de sus relaciones interpersonales, en comparación a los participantes con IMC tipo normopeso.

El sobrepeso y la obesidad es un problema de salud pública importante en México, más del 70\% de la población lo padece (ENSANUT, 2018), situación que reflejan los participantes del estudio con relación a la prevalencia de esta condición en adultos jóvenes en nuestro país. Sin embargo, a pesar de que se ha socializado y difundido el impacto negativo del sobrepeso en la salud, algunos estudios señalan que muchos estudiantes universitarios carecen del conocimiento necesario para hacer las elecciones adecuadas para mantener una alimentación sana y cubrir los requerimientos nutricionales necesarios (Kolodinsky et al., 2007; Zuercher \& Kranz, 2012).

Además, es muy probable que, durante la etapa universitaria, muchos jóvenes estén viviendo procesos de transición hacia una mayor independencia y autonomía personal y económica, lo cual determina las posibilidades que tienen para mantener una alimentación balanceada. Este periodo de emergencia de la adultez es crucial en la toma de decisiones para la formación y consolidación de hábitos y conductas saludables que conforman el estilo de vida (Nelson et al., 2008). En la presente muestra, 35\% de los participantes obtuvieron un estilo de vida regular y malo. El IMC y el estilo de vida mostraron una relación negativa, indicando que los estilos de vida saludables de los participantes se asociaron con mantener un peso adecuado. A pesar de que un poco más de los estudiantes con sobrepeso obtuvieron un estilo de vida bueno, los estudiantes con composición delgada aceptable y normal, se diferenciaron del resto en estilo de vida, actividad y nutrición. En esta misma línea, los estudiantes que realizaron media hora de ejercicio activo tres o más veces por semana hicieron más elecciones de nutrición sana que el resto. Por el contrario, quienes hicieron ejercicio activo rara vez en la semana o nunca mostraron los puntajes de estilo de vida más bajos.

En el presente estudio no se identificaron diferencias significativas por sexo respecto a la actividad física, lo cual contrasta con lo que reportan Fagaras et al. (2015), en cuyo 


\section{CAPÍTULO 8}

estudio los estudiantes universitarios refirieron tener un mayor nivel de actividad física que las mujeres en las cuatro categorías en las que segmentaron la actividad física (caminata, moderada, vigorosa y total; contabilizadas en minutos por semana).

Hasta aquí, pareciera que los resultados muestran un patrón claro de relación del estilo de vida con la composición corporal, el ejercicio activo y la nutrición, factores importantes en la salud y el bienestar. Sin embargo, encontramos otro elemento clave en la salud que se asoció principalmente con aspectos socioemocionales: el estrés. En este estudio, el estrés se refiere a haber sufrido episodios importantes de estrés en el año previo a la participación, considerando la frecuencia de tres o más, 1 o 2, o ninguno. Se observó que los estudiantes que tuvieron tres o más episodios importantes de estrés se diferenciaron con conductas poco saludables en algunos dominios: puntuaron menos que quienes no tuvieron episodios en el dominio actividad y más en tabaco que quienes tuvieron 1 o 2 episodios; también se distinguieron del resto por dormir con menor frecuencia 7 a 9 horas diarias.

Se encontró que el estilo de vida fue sensible a los episodios de estrés, de manera que los estudiantes sin episodios importantes de estrés tuvieron puntajes más altos en estilo de vida que el resto, y a su vez, los puntajes de quieres reportaron 1 o 2 episodios fueron significativamente más altos que los que tuvieron 3 o más episodios. Los datos obtenidos no permiten obtener conclusiones sobre el rol del estrés en el estilo de vida en esta muestra. Sin embargo, existe amplia evidencia de los efectos del estrés en la salud y el bienestar. Varios estudios con estudiantes universitarios han encontrado relación entre el estrés y conductas alimenticias asociadas a sobrepeso (Hudd et al., 2000; Lyzwinski et al., 2018), y correlación negativa con ejercicio (Largo-Wight et al., 2005), salud física y salud psicológica (Dinzeo et al., 2014). También se ha reportado que el estrés en el periodo universitario incrementa la susceptibilidad a problemas de salud mental (Cavazos et al., 2010) y disminuye la satisfacción con la escuela y la vida (Chao, 2013; Jenkins et al., 2013; Lardier et al., 2020).

En la misma línea, nuestros resultados muestran diferencias asociadas al estrés en impaciencia, competitividad, hostilidad (tipo de personalidad), pensamiento positivo, preocupación, depresión (introspección), satisfacción con las actividades y calidad de las relaciones con quienes les rodean (carrera). Es común que los estudiantes universita- 


\section{CAPÍTULO 8}

rios describan esta etapa como altamente estresante. El estrés mal manejado está detrás de muchos problemas de salud y es también una señal de alarma de fracaso académico (Amirkhan \& Kofman, 2018). Los datos presentados se obtuvieron de estudiantes que cursaban primer y segundo semestre de licenciatura; en estas etapas, se espera que los nuevos universitarios manejen exitosamente trabajo académico de mayor complejidad, que sean independientes, que se desenvuelvan adecuadamente en un contexto social nuevo y generen relaciones sociales sanas y productivas (Hicks \& Heastie, 2008). Estas expectativas aunadas a la emergencia de la adultez y la mayor autonomía que se espera de ellos generan niveles altos de estrés (Dyson \& Renk, 2006).

El desarrollo de un estilo de vida saludable debe ser prioritario en los sistemas sanitarios por su utilidad para el desarrollo de una adecuada salud mental, médica y pública (Walsh, 2011). La salud es un concepto multidimensional que implica distintos dominios del estilo de vida y la etapa universitaria es un periodo sensible en el establecimiento y consolidación de hábitos y conductas que tendrán un impacto en la salud del individuo durante su vida adulta; por tal motivo, es de gran relevancia promover un estilo de vida saludable en esta población, que aumente las posibilidades de un estado de salud óptimo.

Varias investigaciones señalan la importancia y necesidad de ofrecer espacios en el contexto universitario que provean a los estudiantes con información, orientación y apoyo en temas de salud física y mental, encaminados a que los estudiantes tomen responsabilidad sobre sus hábitos y acciones y entiendan el impacto que estas tienen en su salud a corto y largo plazo (Lardier et al., 2020). A pesar de que los resultados de nuestra investigación sugieren alta incidencia de sobrepeso y factores de riesgo como estrés y sedentarismo, es importante considerar que estas son conductas moldeables. Habilidades susceptibles de entrenamiento, como la autoeficacia académica, la tolerancia al estrés y el optimismo se asocian a un adecuado desempeño académico, buena salud y un adecuado manejo del estrés (Chemers et al., 2001). El contexto universitario puede ser un escenario propicio para promover y consolidad hábitos y conductas que establezcan un estilo de vida saludable sólido que se mantenga en el tiempo, más allá de la etapa universitaria.

Los resultados presentados sugieren que un amplio número de universitarios mantienen estilos de vida poco saludables. Sin embargo, muestran una gran ventana de oportunidad y la necesidad de implementar intervenciones puntuales. Estos hallazgos 


\section{CAPÍTULO 8}

deben considerarse tomando en cuenta las limitaciones de esta investigación: (a) la versión utilizada del cuestionario FANTASTIC tiene un rango muy discreto de respuesta que ajusta a los universitarios a un limitado rango de opciones; (b) se encontraron relaciones significativas entre distintos factores del estilo de vida, el sexo y el IMC, que coinciden con los hallazgos de otras investigaciones, sin embargo, es necesario recalcar que los participantes autorreportaron su peso y altura, lo que supone un sesgo. Tomando esto en consideración, un siguiente estudio en el que el IMC se obtenga de datos antropométricos medidos por expertos en nutrición puede ser útil para corroborar si este correlaciona con el estilo de vida y el sexo de manera similar al dato obtenido del autorreporte. 


\section{CAPÍTULO 8}

\section{Referencias}

Amirkhan, J. H., \& Kofman, Y. B. (2018). Stress overload as a red flag for freshman failure and attrition. Contemporary Educational Psychology, 54, 297-308. https://doi.org/10.1016/j. cedpsych.2018.07.004

Arrivillaga, M., \& Salazar, I. C. (2005). Creencias relacionadas con el estilo de vida de jóvenes latinoamericanos. Psicología Conductual, 13(1), 19-36.

Baumann, M., Tchicaya, A., Lorentz, N., \& Le Bihan, E. (2017). Life satisfaction and longitudinal changes in physical activity, diabetes, and obesity among patients with cardiovascular diseases. BMC Public Health, 17(1), 925. https://doi.org/10.1186/s12889-017-4925-0

Cavazos, J., Johnson, M. B., \& Sparrow, G. S. (2010). Overcoming personal and academic challenges: Perspectives from Latina/o college students. Journal of Hispanic Higher Education, 9(4), 304-316. https://doi.org/10.1177/1538192710380744

Chao, R. C. L. (2012). Managing perceived stress among college students: The roles of social support and dysfunctional coping. Journal of College Counseling, 15(1), 5-21. https://doi. org/10.1002/j.2161-1882.2012.00002.x

Chemers, M. M., Hu, L., \& García, B. F. (2001). Academic self-efficacy and first year college student performance and adjustment. Journal of Educational Psychology, 93(1), 55-64. https://doi.org/10.1037/0022-0663.93.1.55

Conner, M., \& Norman, P. (2017). Health behaviour: Current issues and challenges. Psychology \& Health, 32(8), 895-906. https://doi.org/10.1080/08870446.2017.1336240

de León-Vázquez, C. D., Rivera-Márquez, J. A., Bojorquez-Chapela, I., \& Unikel-Santoncini, C. (2017). Variables associated with disordered eating behaviors among freshman students from Mexico City. Salud Pública de México, 59(3), 258-265. https://doi.org/10.21149/8000

Dinzeo, T. J., Thayasivam, U., \& Sledjeski, E. M. (2014). The development of the lifestyle and habits questionnaire-brief version: Relationship to quality of life and stress in college students. Prevention Science, 15(1), 103-114. https://doi.org/10.1007/s11121-013-0370-1

Dyson, R., \& Renk, K. (2006). Freshmen adaptation to university life: Depressive symptoms, stress, and coping. Journal of clinical psychology, 62(10), 1231-1244.https://doi.org/10.1002/ jclp.20295

Instituto Nacional de Salud Pública. (2018). Encuesta Nacional de Salud y Nutrición 2018. Presentación de resultados. INSP. 


\section{CAPÍTULO 8}

Fagaraş, S., Radu, L., \& Vanvu, G. (2015). The Level of Physical Activity of University Students. Procedia - Social and Behavioral Sciences, 197, 1454-1457. https://doi: 10.1016/j. sbspro.2015.07.094

Farhud, D. (2015). Impact of Lifestyle on Health. Iran Public Health, 44(11), 1442-1444. https:// www.ncbi.nlm.nih.gov/pmc/articles/PMC4703222/pdf/IJPH-44-1442.pdf

Flórez, L. (2007). Psicología Social de la Salud. Promoción y prevención. Manual Moderno.

García-Alcala, H., Cuevas-Ramos, D., Genestier-Tamborero, Ch., Hirales-Tamez, O., AlmedaValdés, P., Mehta, R., \& Aguilar-Salinas, C. A. (2010). Significant increment in the prevalence of overweight and obesity documented between 1994 and 2008 in Mexican college students. Diabetes, Metabolic Syndrome and Obesity: Targets and Therapy, 3, 7985. https://www.ncbi.nlm.nih.gov/pmc/articles/PMC3047981/

Gómez-Miranda, L. M., Bacardí-Gascón, M., Caravalí-Meza, N. Y., \& Jiménez-Cruz, A. (2015). Consumo de bebidas energéticas, alcohólicas y azucaradas en jóvenes universitarios de la frontera México-UsA. Nutrición hospitalaria, 31(1), 191-195. http://doi.org/10.3305/ nh.2015.31.5.8729

González-Cantero, J. O., Oropeza-Tena, R., Padrós-Blázquez, F., Colunga-Rodríguez, C., Montes-Delgado, R., \& González-Becerra, V. H. (2017). Capital psicológico y su relación con el estilo de vida de universitarios mexicanos. Nutrición Hospitalaria, 34(2), 439-443. https://dx.doi.org/10.20960/nh.172

Greaney, M. L., Less, F. D., White, A. A., Dayton, S. F., Riebe, D., Blissmer, B., ... \& Greene, G. W. (2009). College students' barriers and enablers for healthful weight management: a qualitative study. Journal of nutrition education and behavior, 41(4), 281-286. https://doi. org/10.1016/j.jneb.2008.04.354

Hicks, T., \& Heastlie, S. (2008). High school to college transition: a profile of the stressors, physical and psychological health issues that affect the first year on-campus college student. Journal of Cultural Diversity, 15,143-146.

Hudd, S., Dumlao, J., Erdmann-Sager, D., Murray, D., Phan, E., Soukas, N., \& Yokozuku, N. (2000). Stress at college: Effects on health habits, health status and self-esteem. Yale University College Journal, 34, 217-228. 


\section{CAPÍTULO 8}

Jenkins, S. R., Belanger, A., Connally, M. L., Boals, A., \& Durón, K. M. (2013). First-generation undergraduate students' social support, depression, and life satisfaction. Journal of College Counseling, 16(2), 129-142. https://doi.org/10.1002/j.2161-1882.2013.00032.x

Kolodinsky J., Harvey-Berino J. R, Berlin L., Johnson R. K., \& Reynolds T. W. (2007). Knowledge of current dietary guidelines and food choice by college students: better eaters have higher knowledge of dietary guidance. Journal of American Diet Association,107(8), 1409-13. https://doi.org/10.1016/j.jada.2007.05.016

Lardier, D. T., Lee, C.-Y. S., Rodas, J. M., Garcia-Reid, P., \& Reid, R. J. (2020). The Effect of Perceived College-Related Stress on Depression, Life Satisfaction, and School Satisfaction: The Coping Strategies of Hispanic College Students from a Hispanic Serving Institution. EducationandUrbanSociety,52(8),1204-1222.https://doi.org/10.1177/0013124519896845

Lorenzini, R., Betancur-Ancona, D. A., Chel-Guerrero, L. A., Segura-Campos, M. R., \& Castellanos-Ruelas, A. F. (2015). Estado nutricional en relación con el estilo de vida de estudiantes universitarios mexicanos. Nutrición Hospitalaria, 32(1), 94-100. https:// dx.doi.org/10.3305/nh.2015.32.1.8872

Lyzwinski, L. N., Caffery, L., Bambling, M., \& Edirippulige, S. (2018). The relationship between stress and maladaptive weight-related behaviors in college students: a review of the literature. American Journal of Health Education, 49(3), 166-178. https://doi.org/10.1 080/19325037.2018.1449683

Nelson, M. C., Story, M., Larson, N. I., Neumark-Sztainer, D., \& Lytle, L. A. (2008). Emerging adulthood and college-aged youth: an overlooked age for weight-related behavior change. Obesity, 16(10), 2205-2211. https://doi.org/10.1038/oby.2008.365

Rand, K., Vallis, M., Aston, M., Price, S., Piccinini-Vallis, H., Rehman, L., \& Kirk, S. F. (2017). "It is not the diet; it is the mental part we need help with." A multilevel analysis of psychological, emotional, and social well-being in obesity. International Journal of Qualitative Studies on Health and Well-being, 12(1). https://doi.org/10.1080/17482631.20 17.1306421

Sánchez-Ojeda, M. A., \& Luna-Bertos, E. (2015). Hábitos de vida saludable en la población universitaria. Nutrición Hospitalaria, 31(5), 1910-1919. https://doi.org/10.3305/ nh.2015.31.5.8608 


\section{CAPÍTULO 8}

Sassi, F. (2010). Obesity and the Economics of Prevention: Fit not Fat. OECD. https://www.oecd. org/els/health-systems/46044572.pdf

Walsh, R. (2011). Lifestyle and mental health. American Psychologist, 66(7), 579-592. https:// doi.org/10.1037/a0021769

Wilson, D. M., \& Ciliska, D. (1984). Lifestyle Assessment. Canadian Family Physician, 30, 1527.

Zuercher, J., \& Kranz, S. (2012). College eating 101: Factors influencing students food decisions. International Journal of Child and Adolescent Health, 5(1), 3-6. 


\section{CAPÍTULO 9}

\section{Evaluación de la práctica profesional en psicología de la salud en San Luis Potosí, desde la experiencia de psicólogos en formación}

Karina Guadalupe Noyola Luna, Alejandro Chávez Rodríguez, Dulce María Galarza Tejada y Silvia Larisa Méndez Martínez

Los estudiantes de psicología experimentan importantes transiciones en el transcurso de la carrera universitaria que les forman académicamente para su desempeño profesional. Las prácticas profesionales funcionan como una aproximación al contexto laboral real que aporta un aprendizaje relevante para los estudiantes. Dentro de las diferentes áreas de profesionalización de la psicología, actualmente se destaca la psicología de la salud por su importante producción científica, metodológica y de intervención a favor de la salud integral del ser humano.

Algunos estudios denotan el crecimiento y potencial apoyo que la psicología otorga al campo de la salud. Desde los años sesenta la psicología comenzó a tratar temas del proceso salud-enfermedad, sobre todo en Latinoamérica, con aportes a un campo médico tradicional (García et al., 2015). En 1970, la psicología de la salud emergió como un campo que puede aportar a la solución de muchos problemas de salud pública contemporánea y generar procesos de atención integral de primer nivel. Resulta de interés puesto que traza la superación de los planteamientos del modelo biomédico, el cual es criticado por su concepción restrictiva y descontextualizadora de la salud (Grau \& Hernández, 2005), asimismo, apoya en la comprensión de la multiplicidad de variables psicosociales que actúan como mediadores, desencadenantes o facilitadores del proceso salud-enfermedad (Marks et al., 2008).

En América Latina, Cuba fue uno de los primeros países en interesarse y generar investigación y práctica en psicología de la salud, García et al. (2015) mencionaron que 


\section{CAPÍTULO 9}

incluso la psicología de la salud como disciplina, ya existía antes de que Stone publicara Health Psychology en 1974.

Dentro de algunas de las formas de acción del psicólogo en salud se encuentran la intervención psicosocial a pacientes crónicos, en la cual se favorece su adaptación y mayor calidad de vida, a través del desarrollo de habilidades de afrontamiento emocional e instrumental (Álvarez et al., 2010). También se han desarrollado programas cognitivo conductual para reducir los niveles de presión arterial, disminuir los niveles de estrés percibido e incrementar la adherencia al tratamiento (Arrivillaga et al., 2007). De igual forma, se ha trabajado con pacientes que presentan enfermedad crónica como el cáncer, para mejorar su autorregulación emocional y el apego al tratamiento (Garduño et al., 2010).

Las intervenciones grupales se han usado para mejorar el afrontamiento de situaciones que provocan estrés y la búsqueda de apoyo social (Mensorio \& Costa-Junior, 2016). En el caso de pacientes con fibromialgia, se han llevado a cabo estrategias formativas entre iguales, obteniendo mejoría en el estrés emocional y el automanejo de la enfermedad (Danet et al., 2016).

Las intervenciones individuales pre-cirugía son otra modalidad en la que la psicología ha incursionado, se utilizan técnicas de relajación pasiva y psicoeducación para reducir la ansiedad (Lugo et al., 2013). Asimismo, se ha mostrado el importante trabajo que realiza la psicología para favorecer el desempeño y bienestar de los profesionales de la salud que experimentan estrés o burnout (Libertad, 2003) puesto que, por ejemplo, se ha propuesto la adopción de estrategias de la psicología positiva en la enseñanza y aprendizaje a lo largo del plan de estudio de las escuelas de medicina, para disminuir el riesgo de burnout, estrés y depresión (Pedrals et al., 2011).

Ante ello, se esperaría que la psicología en la atención de la salud pública en México tuviera un papel establecido, sin embargo, se demuestra lo contrario por la poca presencia del psicólogo en este sector y la falta de formación del psicólogo en el área, dentro de los planes de licenciatura. De acuerdo con Redondo (2013), la psicología pasa a ser un "plato de segunda mesa", haciendo que esta sobreviva en la salud pública con una visión medicalizada.

Algunos estudios, como el de Zenteno, Munguía y Aranda (2007), exploraron la percepción que tienen los estudiantes de psicología de la Universidad de Guadalajara respecto a su carrera y su desarrollo profesional. Estos autores encontraron que los 


\section{CAPÍTULO 9}

estudiantes avanzados tenían una postura más crítica y una mayor demanda, exigían más y mejores conocimientos, y resaltaron la importancia de un proceso psicoterapéutico para otorgar una mejor calidad en la atención. Aunado a esto, es el área clínica a la que se le sigue otorgando una mayor importancia por encima de las demás áreas.

Por su parte, un estudio que explora el rol autopercibido del psicólogo y sus implicaciones en los procesos de formación de pregrado, identifica que al momento de realizar práctica profesional se otorga un papel importante a las dificultades y limitaciones originadas en el contexto o entorno donde se desempeñan, como las condiciones del marco normativo y contractual, la precariedad de recursos y la poca participación en el diseño de las actividades (González et al., 2014).

El presente estudio parte de la premisa de que los actores sociales más indicados para exponer las situaciones que favorecen y limitan la labor del psicólogo, dentro de los servicios de salud, son los psicólogos en formación, quienes aún no son trabajadores y no se verían presionados a dar una visión determinada sobre su experiencia, pero que forman parte del sistema de salud durante el tiempo que realizan su práctica profesional y, además, lo vinculan con la formación académica universitaria.

La práctica profesional ocurre como una actividad formativa que tiene sus orígenes después de la Segunda Guerra Mundial, bajo el modelo científico, profesional o modelo Boulder, donde se recomienda una doble formación con entrenamiento práctico e instrucción, en un marco compresivo de las diferencias individuales y culturales (De-Loera, et al., 2016). En la formación profesional del psicólogo, el estudiante debe ser capaz de definir cuál es su objeto (la subjetividad) y cómo existe (origen, funcionamiento, manifestaciones, etc.) a fin de transformarlo (Gross et al., 2017), de ahí la relevancia de la práctica profesional.

El sistema de salud en México es sumamente complejo, ya que se caracteriza por tener diversos elementos, relaciones, propiedades y jerarquías. Para empezar, al ser México una república federal, se cuenta con 32 Secretarías de Salud, una por cada entidad federativa del país (Gómez, 2017). Además, en el sector de salud público existen varias instituciones: Instituto Mexicano de Seguro Social (IMSs), Instituto de Seguridad y Servicios Sociales de los Trabajadores del Estado (Issste), Petróleos Mexicanos (PEMEX), Secretaría de la Defensa Nacional (SEDENA), Secretaría de Marina (SEMAR) y las instituciones y programas que atienden a la población sin seguridad social (Gómez et al., 2011). 


\section{CAPÍTULO 9}

Ante la complejidad del sector y las evidentes diferencias que deben existir, se busca plasmar las similitudes de psicólogos en formación que realizan práctica profesional en diversas instituciones de atención a la salud del sector público. Por lo cual, el presente estudio brinda información valiosa sobre los espacios de oportunidad en los que se puede incidir para una mejor formación del futuro profesional del psicólogo, así como los desafíos que se deben sortear y acciones a gestionar para que se obtenga un espacio digno para el ejercicio profesional de la psicología de la salud, lo cual, sin duda, repercutirá positivamente en la calidad de atención integral a la salud de los usuarios y de los mismos profesionales que ahí laboran. El objetivo de esta investigación fue evaluar la práctica profesional de la psicología de la salud, desde la experiencia de psicólogos en formación que se incorporan al sistema de salud pública del Estado de San Luis Potosí.

\section{Método}

El estudio se realizó bajo un enfoque metodológico cualitativo descriptivo con referente teórico-metodológico en la sociología interpretativa de Schütz y Prieto (1993) y sus supuestos; la conciencia del yo y la relación intersubjetiva de los actores en la vida cotidiana (Jesús et al., 2013), particularmente en la formación del psicólogo en el sector salud como dimensión principal para este estudio.

\section{Participantes}

La investigación se llevó a cabo entre los años 2016 y 2018 con la participación de 19 psicólogos en formación de la Facultad de Psicología de la Universidad Autónoma de San Luis Potosí. Se integraron siete mujeres y dos hombres egresados de la Licenciatura en Psicología de la generación 2012-2017, cuatro mujeres egresadas de la generación 20112016 y seis mujeres de la generación 2013-2018. Los psicólogos realizaron sus prácticas profesionales dentro de diversos centros de salud pública, un hospital general ubicado en la capital del estado, un hospital dedicado a la atención de mujeres y niños, un centro de salud ubicado en la zona centro de la capital, un centro dedicado a la atención en adicciones, un hospital psiquiátrico de la capital, un centro encargado de la atención integral a la salud mental, tres centros de salud ubicados en distas áreas de la capital y de la zona conurbada de San Luis Potosí, así como en una clínica de medicina familiar y centro de cirugía simplificada y de especialidades 


\section{CAPÍTULO 9}

La muestra fue de variación máxima y con apoyo de la estrategia bola de nieve, ya que se incluyeron los casos a los que se tenían acceso y cada participante recomendaba a otra persona que consideraba podía aportar a los fines del estudio.

\section{Procedimiento y recolección de datos}

Para la recolección de los datos se realizó una entrevista semiestructurada que se fue focalizando conforme avanzaron las entrevistas (Mella, 2003). En total se realizaron dos entrevistas y cinco grupos focales, con duración aproximada de 50 a 90 minutos. Las entrevistas más focalizadas se dividieron en dos segmentos: (1) experiencia en los servicios de salud (observada, presenciada, escuchada); y (2) la experiencia propia en la institución en la cual se realizó prácticas profesionales, teniendo en cuenta aquellos aspectos que limitan la labor del psicólogo en los servicios de salud, los aspectos que le favorecen sus funciones, entre otros.

Las entrevistas y grupos focales fueron audiograbados para conservar la literalidad de la información y se transcribieron para su posterior análisis. Se emplearon códigos para referir a cada participante. El procesamiento y organización de los datos se realizó con el apoyo del programa ATLAS ti versión 7.5.4.

Se realizó un análisis de contenido temático inductivo del proceso de comunicación entre el texto y el contexto (Andreú, 2000). Dentro del modelo inductivo, la idea fundamental del procedimiento fue formular criterios de definición e identificación de las experiencias sobre la formación del psicólogo. Para la presentación de resultados, se integran algunos inter-textos y fragmentos de narrativas como ejemplo de la dimensión descrita.

\section{Consideraciones éticas}

Se solicitó la aprobación del proyecto a las autoridades de la Facultad de Psicología de la Universidad Autónoma de San Luis Potosí y se obtuvo un registro. Al ser parte de un estudio más amplio que incluye a otros actores sociales, se solicitó también la revisión y autorización por los Comités del Issste, Centro Médico Familiar, de Especialidades y Cirugía Simplificada. Dr. Pedro Bárcena Hiriart. En el campo, antes de iniciar las entrevistas/grupos focales y una vez explicado el proceso general, se les presentó el consentimiento informado, uno de manera verbal y otro por escrito, garantizando: con- 


\section{CAPÍTULO 9}

fidencialidad, anonimato, riesgo mínimo, descripción de objetivos, retribución social del estudio y libertad de participar o suspender la participación. Una vez finiquitado el proyecto, se hizo entrega de los resultados y del informe a las instituciones involucradas.

\section{Resultados}

En este apartado se describen cuatro dimensiones principales de la experiencia de psicólogos en formación que permiten evaluar la práctica profesional: (1) actividades que realizaron dentro del sector salud, (2) acompañamiento que recibieron, (3) necesidades de formación en el aula sobre psicología de la salud, (4) limitaciones que desafiaron en su trabajo en el campo. Dentro de cada dimensión se pueden apreciar sus críticas y sugerencias para mejorar la experiencia de futuros practicantes que se forman en el campo de la psicología de la salud.

\section{Actividades realizadas por psicólogos en formación dentro del sector salud.} ¡Ay no! tengo que llenar la encuesta

La mayoría de las actividades que realiza el psicólogo en formación no se encontraban en su expectativa de trabajo dentro de los servicios de salud, al inicio pensaban que principalmente realizarían intervención clínica en el contexto de la consulta privada. En algunas actividades requeridas por la institución, lograron dar respuesta rápidamente, en otras experimentaron sentimientos de incapacidad para resolver y llevar a buen término y con calidad lo encomendado.

Las actividades que mayormente realizaron en su práctica fueron: (1) actividades de detección, diagnóstico o valoración psicológica, mediante tamizajes, aplicación de pruebas proyectivas, psicométricas, neuropsicológicas y de desarrollo infantil, a población diversa; (2) de promoción de la salud y prevención de riesgos a la salud, mediante talleres o pláticas de orientación y psicoeducación, dirigido a grupos establecidos en las instituciones, por ejemplo, un grupo de mujeres embarazadas, escuelas y población en general; (3) intervención psicológica a usuarios que presentaban problemáticas relacionadas enfermedades crónicas o bien, que requerían de terapia psicológica particular, para ello conformaron grupos de apoyo, grupos terapéuticos y consulta individual o familiar; (4) actividades de promoción a nivel masivo mediante su participación en campañas o ferias de salud; y (5) seguimiento a pacientes. 


\section{CAPÍTULO 9}

Pues lo que llegué a hacer fue, consulta, orientación psicológica, forme un grupo de señoras de apoyo mutuo y pues realicé detecciones de las que pedían ahí: de alcoholismo, depresión [...] Y ahí mismo hacia campañas para lo del cáncer de mama y todo eso [...] En una ocasión también nos mandaron a una escuela... nos llegaban de pronto correos de que teníamos que dar algún taller en alguna escuela o pláticas, a gestionar tu entrada y luego ya hacías tu feria de la salud, tus talleres o pláticas. (GB, comunicación personal)

En algunas de las instituciones, los psicólogos en formación reportan actividades como investigación o reuniones académicas para discutir casos o lecturas, las cuales no fueron tan frecuentes y que tradicionalmente se consideraban propias de la educación teórica. Lo interesante es que en el contexto de la práctica profesional cobran sentido estas actividades e incluso se reconoce el valor científico de la psicología.

nuestra formación era mitad académica y mitad clínica, es decir, teníamos la experiencia de aplicar pruebas psicométricas y por parte del servicio de psicología y de psiquiatría teníamos clases. La actualización científica es bien importante porque por eso precisamente luego nos echan tierra o nos hacen de lado como de "ah sí está bien si" - LG indicó: de que no es una ciencia, de no tiene nada que aportarexacto $[\ldots]$ (FC, comunicación personal)

Como se mencionó previamente, las actividades de promoción de la salud y prevención de riesgos fueron realizadas de forma constante, sin embargo, eran poco valoradas por los psicólogos en formación al iniciar su práctica profesional y refieren no contar con la preparación.

a lo mejor tú vas con una idea de no "pues yo voy a ser psicólogo clínico, pues mi enfoque va a ser en psicología clínica", pero ya... por ejemplo en lugares en donde te piden promoción de la salud o cosas así, es como "esa preparación no la tengo"o en sí pues a veces no te gusta tanto. (NA, comunicación personal) 


\section{CAPÍTULO 9}

Dentro de la institución de salud, los psicólogos en formación se sensibilizaron sobre la importancia de la promoción de la salud y el apoyo a grupos de pacientes que viven con alguna enfermedad crónica, les hizo reflexionar sobre la importancia de la atención integral de los pacientes.

por ejemplo, en el ISSSTE había mucho como de diabetes... si como de diabetes e hipertensión, se buscaban hacer programas que involucrara al psicólogo. (NV, comunicación personal)

Además de la promoción de la salud, otra actividad que les involucraba en el trabajo multidisciplinar era el diagnóstico psicológico focalizado en casos, esas experiencias eran muy valoradas por la implicación de su trabajo en los procesos de atención y para la toma de decisiones en el tratamiento de los usuarios.

De hecho, de que a veces me han llegado pacientes, en donde la psiquiatra no quiere empezar a medicar al niño hasta no saber cómo sale su resultado en la evaluación neuropsicológica para ver si realmente es necesario darle ese apoyo farmacológico, o si... con pura intervención psicológica-cognitiva podría salir adelante. (NS, comunicación personal)

Su colaboración con otras disciplinas se vio reflejado también en actividades de orientación a los mismos profesionales de la salud, quienes se interesaban en una atención psicológica para su desarrollo personal:

Particularmente en los talleres que realizábamos nosotros iban las mismas enfermeras por asuntos personales. (MM, comunicación personal)

Una experiencia desagradable fue en las actividades de aplicación de pruebas o tamizajes relacionados con la salud mental. Señalan haber tenido la preparación, se sentían capaces para realizarlas, pero se convirtieron en una práctica indeseable, debido al ex- 


\section{CAPÍTULO 9}

ceso de aplicaciones que les solicitaban y sin contar con los recursos materiales y del contexto apropiado para su aplicación.

Por ejemplo, era aplicar encuestas a los pacientes, a las personas que estuvieran esperando consulta, ya sea de depresión de violencia o de alcoholismo y drogas. Si nos pedían cierta cantidad o sea creo que eran -GF: 900 al semestre- jeran demasiadas! entonces uno como practicante era como de "ah, tengo que salir a la sala de espera y aplicarlas", entonces a lo mejor solo aplicabas dos porque al momento de aplicar una de violencia, la persona en ese momento decía otras situaciones, entonces en ese momento tampoco decía "ay no, tengo que llenar la encuesta", entonces se le daba el espacio para escucharlo. (SS, comunicación personal)

Algo similar experimentaron con la consulta clínica, mencionan haberse sentido presionados por los funcionarios de los sistemas de salud para prestar atención a una mayor cantidad de pacientes y de forma rápida, por tanto, la atención clínica - que era la mayormente esperada y trabajada en sus clases teóricas- se convirtió en una actividad frustrante dentro de su práctica profesional.

nos pedían cierta cantidad de números, y también como que de alguna o de otra forma "atiendan a tantos pacientes" - GF: Ah sí- entonces tenías que tener un registro de cuántos pacientes atendías, pero en realidad era de "pásele... ah bueno, la veo dentro de tres semanas, dentro de un mes" porque ya tenías una agenda llena de puro pacientes. (SS, comunicación personal)

Es importante mencionar que los psicólogos en formación no esperaban llevar a cabo algunas actividades de tipo administrativo como el llenado fichas técnicas, documentos de referencia de pacientes, derivaciones, conformación del expediente clínico, entre otras. Señalan que se realizaban diariamente y que en un inicio fue difícil por no contar con la capacitación adecuada para ello, pero que poco a poco lo fueron dominando. 


\section{CAPÍTULO 9}

algunas cosas administrativas que a lo mejor no todos estamos preparados para eso [...] y si era un poco desconcertante al principio [...] (FU, comunicación personal)

Otras actividades inesperadas fueron aquellas en las que se les solicitaba apoyo y se partía del supuesto de que no formaban parte de sus funciones. Estas no fueron apreciadas y tampoco consideradas como espacios de oportunidad para la labor del psicólogo.

una vez nos tocó ir a apoyar a poner vacunas de la influenza, o sea yo solo iba como a llenar datos. (GF, comunicación personal)

Él [director del centro] fue el que me asignó lo de hacer las detecciones [...] era sobre la diabetes. (GB, comunicación personal)

Por otro lado, se refieren actividades que pocas veces se realizan en el sistema de salud y que los psicólogos en formación consideran funciones importantes que requieren de mayor aprecio, entre ellas se destaca la atención a los familiares de los pacientes, principalmente, con enfoque psicoeducativo sobre las enfermedades crónicas para un mejor apego al tratamiento y comprensión de la situación vivida. Otra es el acompañamiento y la aplicación de estrategias de contención hacia el paciente y su familia, cuando se realizan algunos procedimientos médicos invasivos o bien, se les notifique algún padecimiento que implique un sufrimiento anímico difícil de sobrellevar.

la parte de psicoeducación, porque a mí, o sea ahorita como que lo traigo muy reciente, porque el viernes me tocó ver a un paciente que salió de cirugía y ahorita está en delirio, entonces ahorita a mí me toca estar con la familia y explicarles, qué es un delirio, las causas [...] (MV, comunicación personal)

Finalmente, es apremiante precisar que no todas las actividades que desempeña un psicólogo en el sector salud eran realizadas por los psicólogos en formación, particularmente con población vulnerable o bien que se consideraba en riesgo importante. Por ejemplo, la atención de casos en los que era evidente el comportamiento agresivo, 


\section{CAPÍTULO 9}

consumo de drogas o bien víctimas de violencia. Sin embargo, tampoco se les permitía ver la forma en que se abordaban los casos.

las psicólogas operativas y la directora eran las que se encargaban de dar atención a los pacientes con adicciones: a la cocaína, a la mariguana, al alcohol, al tabaco, etc., que eran intervenciones pues un poquito más densas porque había pacientes pues que llegaban a lo mejor muy agresivos o que había que tratarlo [...] con cierta reserva. (FU, comunicación personal)

servicios de salud contrata a psicólogas expertas en violencia y hay módulos en diferentes centros de salud [...], cuando había casos de violencia se los mandaba “oye ¿qué hago con este?”... “no pues mándamelo", pero no me explicaba [...] (GF, comunicación personal)

Las prácticas profesionales son enriquecidas con la multiplicidad de actividades a las que los psicólogos en formación están expuestos, amplía la visión de los estudiantes sobre la capacidad de acción que tiene un psicólogo en el campo de la salud y les forma en la vida real, es así como ellos mismos lo reconocen.

\section{Acompañamiento de los psicólogos en formación en la práctica. El asesor también es parte vital} El acompañamiento académico y profesional se reconoce con mucho valor para implementar una práctica profesional de calidad y que a su vez sea una grata experiencia de aprendizaje. Sin embargo, en el presente estudio se resaltan los desafíos y espacios de oportunidad para mejorar este acompañamiento, porque son las experiencias que quedan marcadas de forma profunda en los practicantes.

La mayoría de los psicólogos en formación coinciden en que la preparación de los asesores o el acompañamiento es insuficiente, lo cual afecta su práctica en el campo de la salud al grado de transgredir normas o principios éticos por desconocimiento, además de desencadenar ansiedades y sentimientos de incapacidad en los psicólogos en formación que, en ocasiones, se ven forzados a intervenir. A continuación, se describen tres 


\section{CAPÍTULO 9}

elementos que conforman dicho acompañamiento: (1) capacitaciones institucionales, (2) asesoría interna de profesionales capacitados en la institución determinada durante la práctica profesional y (3) asesoría externa, primordialmente académica, de un profesor con el perfil para intervenir en el campo de la salud.

el asesor también es parte vital [...] de que se haga bien esa actividad dentro del centro. (FC, comunicación personal)

Respecto a las capacitaciones, cabe destacar que no en todas las instituciones se realizan formalmente. La mayoría implementa capacitaciones al inicio de forma periódica, sin embargo, los psicólogos en formación refieren que no recibieron suficiente información para atender situaciones que escapaban de su formación previa y, por tanto, experimentaban sensaciones de agobio y confusión. En ocasiones, las capacitaciones eran recibidas a destiempo, por lo cual no se podía otorgar el servicio requerido, especialmente cuando se les requería intervenir en actividades que no consideraban propias de la función del psicólogo.

No nos dieron una capacitación para aplicar el... ¿qué era para los bebés, ¿cómo se llama? —SS: El... Ah se me olvidó- hay una prueba que ni siquiera la tenemos que hacer nosotros, la tiene que hacer una enfermera o un médico, que es para... -SS: para ver la motricidad fina-ajá, para detectar si hay un retraso en el bebé; entonces tú debes de recibir al bebé en tu, en tu... ese... y medir la circunferencia de su cabecita, darle un juguete y si aprieta si... ver como esas cuestiones para ver si hay un deterioro cognitivo o no -SS: El EDI- el EDI, [...] entonces a ti te mandan desde el día uno para evaluar bebés, entonces dices "me llegó un bebé, ¿qué voy a hacer con ese bebé?, yo ni siquiera sé qué onda", cuando eso me lo explicaron tres meses después [...] (GF, comunicación personal)

Los coordinadores de las capacitaciones son referentes para los psicólogos en formación, sin embargo, es difícil contactarse con ellos y, en ocasiones, prefieren buscar orientación con sus mismos compañeros practicantes. 


\section{CAPÍTULO 9}

la psicóloga no estaba, entonces me era muy difícil también comunicarme [...] la situación de que traen un relajo es hasta esas cosas tan sencillas que no los puedes encontrar, te dicen "pasa algo enseguida márquenos o sea... es grave". (GB, comunicación personal)

yo siento que a mí las capacitaciones no me sirvieron, yo ... yo lo que hacía era acercarme a mis compañeros "a ver tú estás entendiendo qué hay que hacer, cómo hay que...” (SS, comunicación personal)

En la asesoría se contaba con profesores de la Facultad de Psicología de la UASLP, que, si bien son elegidos por ellos mismos al momento de inscribir sus prácticas profesionales, en su mayoría, la expectativa de asesoría supera la realidad; para compensar la carencia, algunos psicólogos en formación buscan profesionales no asignados inicialmente e incluso algunos pagaron por ello. Por su parte, algunos que sí recibieron la asesoría esperada, mencionan sentirse afortunados en comparación del resto de sus compañeros.

yo corrí con la suerte de que en los dos años de prácticas tuve excelentes asesores, el primero me enseñó prácticamente todo lo que se tiene que saber sobre ser un psicólogo. (PD, comunicación personal)

desafortunadamente, yo no tuve el apoyo que hubiera deseado de mi asesor porque no se dieron las cosas... afortunadamente también encontré personas que estaban con toda la disposición de apoyarme y de asesorarme en el momento en que no... no sabía hacia dónde ir. (FU, comunicación personal)

veía como otros compañeros no podían... iqué necesidad había de que mis compañeras tuvieran que ir a pagarle \$100, \$200 pesos a cierta profesora [...], para que ella les asesorara un caso, ¡cuando tenías a tu asesor! (PD, comunicación personal)

Respecto a la asesoría interna, los psicólogos en formación exponen que es sumamente importante su participación y la mayoría se sintieron acompañados, lo cual les 


\section{CAPÍTULO 9}

facilitó reducir el tiempo de adaptación y les favoreció a su práctica para dar respuesta en procesos de atención que desconocían. No fue así en todos los casos, hubo quienes se sentían sin saber qué hacer porque tampoco recibían asesoría externa. De forma interesante, en el caso de quienes no recibían mucho acompañamiento de su asesor académico, tampoco exigían que se les otorgara de parte de los asesores de la institución, una de las razones era porque se daban cuenta de la saturación en el trabajo, sobre todo de los que eran psicólogos trabajando en un centro donde solo había uno o dos para atender las necesidades de atención de todo un centro de salud.

incluso me dijeron "si en el momento en que estas tú en consulta tienes una duda, vienes y preguntas no tienes ningún problema, nosotros aquí te decimos, te apoyamos en lo que podamos" son la verdad muy comprensivas, muy accesibles, muy buenas gentes. (KG, comunicación personal)

Las experiencias de los psicólogos en formación denotan que requieren un mayor acompañamiento, especialmente por los asesores académicos.

\section{Necesidades sentidas en la formación académica para un mejor desempeño} en la práctica. ¡Llegas con esa parte romántica, “yo voy a hacer todo lo posible”! Los psicólogos consideran que se requiere integrar en el plan de estudios, algunos objetivos formativos sobre el desarrollo de habilidades para el trabajo multidisciplinario, especialmente con profesionales que tradicionalmente se encuentran vinculados en el sector salud, pero en ocasiones esto no es valorado por los mismos profesores universitarios en el campo de la psicología.

tampoco aquí en la facultad... nos enseñan [...], yo no he escuchado que trabajes con un abogado y esa parte también es importante, o con un médico o con una trabajadora social, o sea esa parte yo no lo sabía tampoco, cómo nosotros podemos trabajar con ellos porque ellos también ven los casos, entonces yo creo que el que tenga diferentes tipos de profesiones ayuda a que tú aprendas. (GF, comunicación personal) 


\section{CAPÍTULO 9}

muchos maestros si he escuchado que dicen "no pues si, también es un campo muy importante, pero no se necesitan medicinas", "todo lo podemos nosotros", pues sí, en unos casos sí, pero en otros casos se necesita la medicina, es ayuda, entonces, un trabajo multidisciplinario, no te puedes quedar nada más con el psicólogo o nada más con el psiquiatra, son los dos. ( $\mathrm{PD}$, comunicación personal)

Un campo poco explorado, pero igual importante en la formación profesional del psicólogo es proveer herramientas para la gestión, se valora que en las materias curriculares se impulse a realizar actividades que les forman para ello.

Afortunadamente yo tuve muchos profes muy dinámicos y ... que nos ponían mucho a prueba y en situaciones reales... que nos mandaban también a escuelas y a gestionar; entonces ya cuando estas en ese nivel ya no te asusta mucho hasta dices “ay qué padre!” (PD, comunicación personal)

En el mismo sentido, refieren la necesidad de recibir formación en psicología jurídica, que les ayude a conocer sobre las normas oficiales en materia de salud, de salud mental, sobre derechos humanos, protocolos de acción en salud mental, profundizar en el código ético, procesos de referencia y transferencia, entre otros. Además, demandan mayor conocimiento sobre el funcionamiento del sistema de salud, a través de la revisión de sus normativas, consideran que es indispensable para una mejor actuación del psicólogo.

creo que [...] debería de ser parte de nuestra formación, [...] revisar normas, revisar... manuales o cosas que ya estén establecidas para saber qué es lo que se espera de un psicólogo, que a veces ya está un poquito más definido, pero pues, todavía queda también este pulir esas normas, porque todavía le falta, tan solo el código ético todavía tiene muchas lagunas que tú te quedas "ah si, ¿qué significa esto? O ¿por qué esto? O cosas así”. (GF, comunicación personal)

El desconocimiento sobre la normatividad genera incertidumbre sobre lo que es correcto hacer y lo que contraviene a los derechos de los usuarios en los sistemas de salud $\mathrm{y}$, a su vez, poner en riesgo legal al mismo psicólogo en formación. 


\section{CAPÍTULO 9}

nosotros te lo aseguro que muchas veces, interrumpimos o violamos las cuestiones legales de un paciente y eso nadie nos los dijo [...] (GF, comunicación personal)

La forma en que los psicólogos en formación dirigen su acción es gran parte basada en los códigos de conducta establecidos en las instituciones donde realizan sus prácticas, sin embargo, desconocen algunas consideraciones fundamentales respecto a las normas de atención en materia de salud y de salud mental.

No recuerdo que nos mencionaran "ah tienen que conocer tal norma, o tienen que..." el reglamento también era eso, usar la filipina, usar el gafete que no nos dieron (risas), cosas, así como más de conducta, cosas de cómo te debes de comportar, que no debes dejar [...] (NA, comunicación personal)

En las instituciones que se dedican a prestar una atención a la salud mental integral, se percibe una mejor aplicación y conocimiento de los protocolos que se deben de seguir. Sin embargo, eso no ocurre en todas las instituciones y tampoco en la formación universitaria. La falta de estos conocimientos se atribuye a una mayor valoración de la atención clínica no institucionalizada y donde solo se enfatiza en el manejo de técnicas o procedimientos de intervención psicoterapéutica.

en la Facultad, nunca nos dicen que... en las clases al menos que yo tomé, ni en las prácticas, primero que yo tuve que también fueron clínicas, nunca supe qué procedimientos se tenía que hacer con determinados pacientes, [...] entonces acá nos forman muy bien creo yo, pero falta la parte más pública en el sentido de dónde vamos a hacer prácticas [...] (ZM, comunicación personal)

La idea de una atención clínica como es percibida dentro de las aulas, en ocasiones, puede parecer idílica frente a la realidad y, particularmente, a la organización del sistema de salud. Algunas explicaciones sobre ello se relacionan a la falta de experiencia de los profesores o al desinterés por compartir su experiencia. 


\section{CAPÍTULO 9}

Si, a lo mejor ahí intervendría mucho la experiencia del psicólogo que... o bueno del maestro. Porque creo que haciendo como recuento, la mayoría de los profesores son... tienen sus propio consultorio o... si tuvieron a lo mejor experiencia en esta parte de los centros de salud... pero no lo expresan mucho, entonces tú te vas con la idea "ah sí, una hora para atender un paciente" o cosas así, entonces ya cuando... ya cuando llegas a ese punto como decía FC ves que no tienes esas facilidades para hacer como te dicen que tienes que hacerlo, pues ya te desmotivas, te estresas, te preguntas si en realidad estás en el lugar correcto, si lo vas a hacer bien, ¿qué es lo que tienes que hacer? ¿ ¿hasta qué punto tú puedes llegar como psicólogo o como pasante? es decir, pues es que tú llegas con esa parte romántica, que dices: "yo voy a hacer todo lo posible, voy a poner todo mi esfuerzo, veo que está mal esto, tengo que hablarlo, tengo que decir que no se debe de hacer así," pero pues el sistema ya está así y es difícil ya cambiarlo. (NA, comunicación personal)

tenemos maestros en psicoterapia, pero los maestros que están, que te dan las materias clínicas, son maestros que tiene consultorios privados y no es lo mismo que te llegue a consulta privada a que te lleguen a consulta pública -SS: „Pública!, o sea, ¿cuántos pacientes no te llegan diariamente? - (GF, comunicación personal)

Los psicólogos en formación consideran que se requiere de un mayor conocimiento y entendimiento de la psicofarmacología, para mejorar la atención.

yo siento que dentro de la formación de un psicólogo que está decidido a irse al área clínica, tiene que estar la cuestión farmacológica, entonces tiene que venir dentro de las clases de base. (MM, comunicación personal)

La falta de conocimiento clínico relacionado al uso de medicamentos se atribuye a la falta de formación acerca de la intervención psicológica en casos reales y no atenuados. Se percibe que en las clases no se discuten casos como los que reciben en la práctica, casos que de primera mano son impactantes y se sienten sin herramientas para atenderlos. 


\section{CAPÍTULO 9}

acá (refiriéndose a la Universidad) regularmente, bueno te digo desde mi experiencia, te enseñan casos por decir sencillos, menos graves... no quería usar esa palabra... que los que te encuentras allá (refiriéndose al centro de prácticas que es una institución de salud); allá te encuentras con psicosis... bueno, esquizofrenia, intentos suicidas, abusos sexuales, violencia intrafamiliar cosas un poco más graves que... si de por si nos dan miedo ver pacientes, cuando nada más te va a contar que le va mal en la escuela o cosas así, [...] "sabían que existían, pero no que me iba a tocar a mi atenderlas". (ZM, comunicación personal)

Finalmente se considera que es de suma relevancia mejorar la preparación del psicólogo el campo de la salud y procurar un comportamiento ético.

Como les dije, si el producto que tú estás ofreciendo desde el principio está mal, eventualmente nadie lo va a querer, entonces para mí, lo más fundamental como psicólogo es que te prepares bien, es que intentes hacerlo lo mejor posible, que seas lo más ético posible en tu trabajo y que le des toda la importancia al paciente, no tanto a los números, no tanto a cumplir con la cuota, no tanto a lo que hay alrededor, piensa en tu paciente. (PD, comunicación personal)

\section{Limitantes del sistema de salud para el psicólogo. Serpiente pisándose la cola}

La mayoría de los participantes coinciden en que las principales limitantes para los servicios de psicología en sistema de salud se relacionan a dos aspectos generales: (1) desconocimiento sobre las funciones y alcance de la psicología en el campo de la salud y (2) la falta de presupuesto que lleva a la falta de personal y de un espacio digno de trabajo para el psicólogo.

Las limitantes, primero el presupuesto ese si es una de las más grandes, el presupuesto. Segundo también el espacio físico, el espacio físico es una gran limitante en ese punto. Y ya como tercera volvemos a lo mismo, el desconocimiento. (AA, comunicación personal) 


\section{CAPÍTULO 9}

En lo que respecta al desconocimiento de la profesión por parte de algunos profesionales de la salud como médicos y enfermeras, algunos psicólogos en formación refieren haber recibido peticiones que consideraban fuera de sus funciones e incluso algunas que iban en contra de su ética profesional; algunas experiencias en el área de maternidad refieren haberles pedido que convencieran a las mujeres para que amamanten a los hijos recién nacidos, para que utilicen métodos anticonceptivos, entre otras.

yo también creo que es muy conveniente que [...] toda el área de salud: médicos, enfermeras, que estamos de este lado, conozca también la labor del psicólogo o sea porque... lo seguimos mencionando... pero piensan que hacemos todo y no, qué somos magos incluso llegan a pensar y pues tampoco, pues no usamos la magia ni nada de ese estilo, entonces [...], que el personal de salud conozca la labor que realmente se hace, porque acá de este lado si era muy notorio que te voceaban y vas tu pensando que a lo mejor es algo de importancia y te encuentras con que "es que la paciente no se quiere bañar" y dices pues "y luego" "hágala que se bañe". O es [...] que en el hospital va gente de todos lados y si era como "dejé una paciente allá arriba porque me hablan por a lo mejor era una emergencia muy fuerte y me salen con que "evalue si se va a bañar cuando lleve a su hijo a su casa" y tampoco se trata de eso... (KT, comunicación personal)

Un ejemplo claro es la patologización de algunas condiciones, etapas de vida, o sucesos que provocan evidentemente una crisis y que no necesariamente requiere de una medicación o de una atención psiquiátrica, pero que la atención psicológica puede ser muy útil para sobrellevar la situación y encontrar recursos personales para afrontarlo.

En una ocasión a una señora que acababa de morir su hijo, la mandaron al psiquiatra que porque tenía depresión "itu hijo acaba de morir hace dos semanas!, ¡cómo no vas a estar triste!" y todo ese tipo de cosas lo único que genera es que la gente diga "sabes que ya no voy a volver... ya no quiero volver". (PD, comunicación personal) 


\section{CAPÍTULO 9}

Otra de las limitantes que observan los psicólogos en formación es la prevalencia del modelo biomédico en el sistema de salud, que puede desdibujar a otras formas de atención psicológica.

más que fungir como un psicólogo, funge como una extensión del médico, [...] o sea como modelo médico, pues en los formatos... las guías... (FU, comunicación personal)

En el mismo sentido, los psicólogos en formación experimentaron demandas institucionales que les forzaban a atender pacientes que no lo requerían, esto en el afán de justificar el servicio por medio de la captación de la mayor población posible. Tal situación puede provocar rechazo de las personas y evitar la atención psicológica en el futuro.

Más bien lo que yo pienso es que una de las razones por las que no se pueden cumplir tan fácilmente los objetivos son porque el mismo hecho de querer cumplir los objetivos es como una serpiente pisándose la cola, tú lo que estás haciendo es en lugar de dar un espacio para que la gente venga y se desahoga, estas obligando a una persona a sacar cosas que no quiere sacar, eso eventualmente generarás un rechazo más grande. (PD, comunicación personal)

El desconocimiento no solo esta manifestado en los procedimientos estandarizados para la atención de la salud o en las actitudes o solicitudes de los demás profesionales de la salud, como se mencionó previamente, también hay desconocimiento por parte de los usuarios, por ejemplo, algunos pacientes buscan una solución rápida con el uso del medicamento.

quiere una cura rápida, entonces por eso a veces prefieren psiquiatra, "si una pastilla me lo va a quitar, venir aquí cada mes, sacar la cita..." (LG, comunicación personal)

Respecto a la segunda importante limitación que experimentan los psicólogos en formación se ubica la falta de recursos, principalmente, falta de recurso humano capacitado 


\section{CAPÍTULO 9}

en el campo de la psicología de la salud, falta tiempo para atender en relación con la exigencia institucional que busca lograr objetivos cuantitativos, falta de instrumentos o pruebas psicológicas, falta de un espacio en donde ellos pudieran efectuar sus actividades y para que los usuarios puedan expresarse libremente.

a la par después te lo quiere..... bueno, forzar (en la atención a los pacientes) como a tomarlo a pie, pue es tienes que hacerlos rápido, tienes que hacerlo bien, pero tu como psicólogo en formación ¿cómo vas a hacerlo rápido y bien?, a lo mejor un psicólogo ya más avanzado. (NA, comunicación personal)

El exceso de pacientes y la falta de psicólogos contratados es una importante limitante para realizar una práctica psicológica de calidad y además resulta un estresor para el psicólogo en formación, quien no tiene un asesor capacitado.

nada más esta ella como practicante, eso yo creo que no sea muy beneficioso para la institución y menos para ver a todos los pacientes que están hospitalizados [...] (NS, comunicación personal)

Dentro de sistema de salud se percibe una carencia para acceder a recursos materiales con los que el psicólogo se apoya para realizar su trabajo, como algunas pruebas o test psicológicos.

la limitada posibilidad de obtener materiales propios, o que el centro tuviera materiales propios; nosotros debíamos llevar todo nuestro material, el centro no nos daba suficiente material. (FC, comunicación personal)

La falta del espacio físico, para ellos representa de manera alegórica la manera en que se concibe al psicólogo en los servicios de salud. Esto es, sin un espacio, sin un reconocimiento sobre su labor, aun cuando existe la demanda poblacional por su servicio. 


\section{CAPÍTULO 9}

Está la necesidad de la población y no se le da el lugar, por lo menos a los psicólogos a los que... a las enfermeras y a los médicos pues ahí hay un lugar reservado, su propio... incluso estructuralmente en el diseño [...] del lugar, están destinados los lugares [...] para el enfermero, para el dentista y para el médico, pero para el psicólogo, por lo menos a mí me tocó estar en una caseta de policías [...] simbólicamente no hay un lugar para el psicólogo, estructuralmente tampoco hay lugar para el psicólogo [...] (GF, comunicación personal)

bueno para mí las limitantes si fueron, bueno yo no tenía un espacio como tal... bueno si tenía mi espacio, pero era la sala de usos múltiples (FU, comunicación personal)

por ejemplo, sí hay pacientes que dicen "pues yo no puedo hablar porque siento que me van a escuchar al lado" (NA, comunicación personal)

A pesar de las limitaciones experimentadas, los psicólogos en formación refieren que se motivaban cuando la población les reconocía su trabajo y eran solicitados. Todos los entrevistados refirieron aprender mucho de la experiencia y, además, se gratificaron al ver su aportación pese a los desafíos mencionados.

de repente si había pacientes [...], que preguntaban “'hay psicólogo?” ¿podría decirle que venga?" y nos voceaba el mismo personal [...] (KT, comunicación personal)

\section{Discusión}

El estudio permitió identificar algunos espacios de oportunidad que se pueden mejorar en el contexto educativo y formativo dentro de la Universidad y del contexto institucional de la salud pública, para que el psicólogo interesado en la práctica de la psicología de la salud cuente con mejores oportunidades y un mejor aprovechamiento en el aprendizaje de la psicología, la cual aporta valioso apoyo a la salud pública. Principalmente, se infiere que existe poca comunicación entre ambos contextos institucionales (educativo y de 


\section{CAPÍTULO 9}

salud), no se establecen lineamientos de trabajo, funciones a realizar dentro de la práctica profesional y capacidades de los psicólogos en formación, esto ayudaría a plantear un programa de trabajo que fuera introduciendo gradualmente al psicólogo a las actividades.

Respecto a las actividades que se realizan en el contexto institucional, cabe destacar que se requiere regular e informar con claridad sobre la aplicación de tamizajes psicológicos, que realmente se realicen con un objetivo, bajo un proyecto establecido y no por destajo para cumplir con una meta cuantitativa, lo mismo aplica para la atención clínica psicoterapéutica, en la cual se ha forzado a que los psicólogos en formación atiendan a un mayor número de personas, sin que se reconozca que la consulta psicológica no responde a la misma dinámica que la consulta médica, requiere de una estructura que por lo regular es más extensa y con mayor regularidad. Ambas situaciones se pueden solventar si los profesionales de la salud y principalmente los responsables de la institución son informados y sensibilizados sobre la labor del psicólogo de la salud.

Por su parte, los psicólogos en formación requieren mayor formación sobre los alcances e implicaciones de la psicología de la salud, principalmente, en la organización y participación dentro de campañas masivas y ferias de la salud, particularmente al respecto de las actividades de apoyo al resto de los profesionales de la salud, para que encuentren el sentido de su colaboración en estas actividades. Son espacios de máximo aprovechamiento para la promoción de la salud y prevención de riesgos psicosociales en lo que la disciplina psicológica puede contribuir ampliamente.

Los psicólogos en formación refieren realizar múltiples actividades que son muy valiosas para su aprendizaje y para involucrarse en el sector de la salud, sin embargo, reconocen que hay algunas prácticas que debieran fortalecerse y ampliar en el sector, pues representan un indicador de apego al tratamiento y soporte en el mantenimiento de la calidad de vida y bienestar de las personas con una enfermedad crónica. Particularmente, remiten al trabajo psicoeducativo con los familiares y personas que viven algún padecimiento y al trabajo de contención y orientación psicológica, cuando los pacientes reciben una noticia difícil de afrontar.

Lo que refiere al acompañamiento de los psicólogos en formación, se requiere de una cuidadosa selección de los profesores que fungirán como asesores académicos para acreditar que están capacitados para otorgar la asesoría en la institución de salud, 


\section{CAPÍTULO 9}

asimismo, se deben establecer sus funciones para que los practicantes eviten expectativas poco reales sobre su asesoramiento y se comprenda el alcance que este tiene al respecto del acompañamiento. Lo mismo corresponde al asesor interno, quien debiera estar sin excepción en la institución en la cual se incorporará el psicólogo en formación y que de preferencia tenga una formación académica afín a la psicología; además, se debe asegurar que el asesor interno realmente cuente con el tiempo para dar seguimiento a las acciones del practicante. En lo que respecta a las capacitaciones, se requiere que todos los psicólogos en formación reciban casi de inmediato un curso de inducción, en el cual se capacite sobre las funciones que realizarán y se explore el nivel de conocimientos al respecto, además se sugiere fortalecer el trabajo multidisciplinario que es invaluable por su impacto en la salud integral.

Finalmente, se requiere que las universidades mejoren y actualicen los planes de estudio para que se pueda preparar a los psicólogos en formación para una intervención acorde a las realidades que se viven en el sector de la salud pública y concretamente en el contexto sociocultural del país. Los psicólogos deben aprender en las aulas no solamente las teorías o conceptos, sino aprender de las experiencias reales de sus profesores, de sus éxitos y fracasos en la intervención, de la ética profesional a partir del ejemplo, se debe favorecer el trabajo colaborativo multidisciplinario y la autogestión del conocimiento. Si bien, los contenidos dentro de una materia nunca son suficientes frente a lo que las realidades cambiantes demandan, es posible propiciar que los psicólogos en formación se comprometan con su propio aprendizaje y utilicen herramientas para obtener información confiable que les ayude a afrontar un caso emergente en la práctica profesional. 


\section{CAPÍTULO 9}

\section{Referencias}

Álvarez, L., Rueda, Z., González, L., \& Acevedo, L. (2010). Promoción e actitudes y estrategias para el afrontamiento de la Diabetes Mellitus y la Hipertensión arterial en un grupo de enfermos crónicos de la cuidad de Bucarama. Psicoperspectivas: Individuo y Sociedad, 9(2), 279-290.

Andreú, J. (2000). Las técnicas de análisis de contenido: una revisión actualizada. Fundación Centro Estudios Andaluces, Universidad de Granada, 10(2), 1-34.

Arrivillaga, M., Valera, M., Cáceres, D., Correa, D., \& Holguín, L. (2007). Eficacia de un programa cognitivo conductual para la disminución de los niveles de presión arterial. Pensamiento Psicológico, 3(7), 33-49.

Danet, A., Prieto-Rodríguez, M., Varlcárcel-Cabrera, M., \& March-Cerda, J. (2016). Evaluación de una estrategia formativa entre iguales en fibromialgia. Un análisis de género. Aquichan, 16(3), 296-312.

De-Loera Chávez, J. M., Martínez Martínez, K. I., Martínez-Soto, J., \& Padrós Blázquez, F. (2016). Las competencias del psicólogo profesional: análisis de perfiles de egreso. Investigación y Práctica en Psicología del Desarrollo, 2, 170-185. https://doi.org/10.33064/ ippd2687

García, I., Louro, I., \& De la Cruz, G. (2015). Bosquejo del desarrollo de la psicología y su relación con la salud en Cuba 1900- 1958. Revista Cubana de Salud Pública, 41(2), 666-676.

Garduño, C., Riveros, Á., \& Sánchez-Sosa, J. (2010). Calidad de vida y cáncer de mama: efectos de una intervención cognitivo-conductual. Revista Latinoamericana de Medicina Conductual, 1(1), 69-80.

Gómez, C. (2017). El sistema de salud en México. Revista Conamed, 22(3), 129-135.

Gómez, O., Sesma, S., Becerril, V., Knaul, F., Arreola, H., \& Frenk, J. (2011). Sistema de Salud en México. Salud Pública de México, 53(2), 220-232.

González, M., González, I., \& Vicencio, K. (2014). Descripción del rol autopercibido del psicólogo y sus implicancias en los procesos de formación de pregrado. Psicoperspectivas: Individuo y Sociedad, 30(1), 108-120. 


\section{CAPÍTULO 9}

Grau, J., \& Hernández, E. (2005). Psicología de la salud: aspectos teóricos y conceptuales. En E. Hernández, \& J. Grau (Eds.), Psicología de la salud: fundamentos y aplicaciones. Editorial del Centro Universitario de Ciencias de la Salud.

Gross, R., Montoya, J., \& Deroncele, A. (2017). El proceso de formación científico-profesional del psicólogo. Revista Dilemas Contemporáneos: Educación, Política y Valores, 3, 1-17.

Jesús, M. C., Capalbo, C., Merighi, M. A., Oliveira, D. M., Tocantins, F. R., Rodrigues, B. M., \& Ciuffo, L. L. (2013). The social phenomenology of Alfred Schütz and its contribution for the nursing. Revista da Escola de Enfermagem da USP, 47(3), 728-733. https://doi. org/10.1590/S0080-623420130000300030

Libertad, M. (2003). Aplicaciones de la psicología en el proceso salud enfermedad. Revista Cubana de Salud Pública, 29(3), 275-81.

Lugo, I., Becerra, A., \& Reynoso, L. (2013). Intervención psicológica para la intervención de ansiedad ante la colocación de un catéter puerto en mujeres con cáncer. Psiconcología, 10(1), 177-184.

Marks, D., Murray, M., Evans, B., Willig, C., Woodall, C., \& Sykes, C. (2008). Psicología de la salud. Teoría, investigación y práctica. Manual Moderno.

Mella, O. (2003). Metodología cualitativa en ciencias sociales y educación: orientaciones teóricometodológicas y técnicas de investigación. Primus.

Mensorio, M., \& Costa-Junior, Á. (2016). Intervención psicológica a candidatos de cirugía bariátrica en un hospital público de Brasil. Revista Peruana de Medicina Experimental y Salud Pública, 33(1), 120-127.

Pedrals, N., Rigotti, A., \& Bitran, M. (2011). Aplicando psicología positiva en educación médica. Revista Médica de Chile, 941-949.

Redondo, C. (2013). El rol del profesional de psicología en atención primaria en salud. Wímb lu, Revista electrónica de estudiantes de la Escuela de psicología, 1(8), 61-80.

Schutz, A., \& Prieto, E. J. (1993). La construcción significativa del mundo social: introducción a la sociología comprensiva. En La construcción de la vivencia significativa en la corriente de la conciencia de quien la constituye (pp.127-167). Paidós Básica.

Zenteno, H., Munguía, J., \& Aranda, C. (2007). Formación de la identidad profesional en estudiantes de la carrera de psicología. En M. Torres, Imágenes y realidades sobre los profesionales en Ciencias de la Salud (pp. 115-135). Amate Editorial. 


\title{
CAPÍTULO 10
}

\section{Disponibilidad tecnológica, proceso de enseñanza e impacto psicológico en universitarios durante el confinamiento por Covid-19}

\author{
María Luisa Avalos Latorre, Nayeli Amairani Mendoza Ramírez, \\ Miguel Ángel Sosa Ibarra, Alejandro Chávez Rodríguez \\ y Neyda Ma. Mendoza Ruvalcaba
}

A finales del año 2019, la Comisión Municipal de Salud de Wuhan (provincia de Hubei, China) notificó un conglomerado de casos de neumonía. Posteriormente, la Organización Mundial de la Salud (oms, 2020a) determinó que estaban causados por un nuevo coronavirus, que más adelante nombraran Covid-19. Para el 11 de marzo de 2020 la OMs, ante los alarmantes niveles de propagación de la enfermedad, por su gravedad, así como por los altos niveles de inacción, declaró a la CoviD-19 como pandemia; en ese momento, el número de casos a nivel mundial era de 102470 distribuidos en 101 países y 3491 personas habían fallecido a consecuencia de esta (De la Serna, 2020). El 9 de abril se alcanzó el millón y medio de contagios por coronavirus y se superaron las 90000 muertes (oms, 2020b).

El 28 de febrero de 2020, el Gobierno de la ciudad de México confirmó al primer contagiado por COVID-19 en todo el país; el 16 de marzo, la Secretaría de Salud implementó la Jornada Nacional de Sana Distancia como medida preventiva, suspendiendo temporalmente las actividades no esenciales (Secretaría de la Función Pública, 2020). El 20 de marzo de 2020 se cerraron más de 243480 escuelas de educación básica, media superior y superior que atendían a más de 30 millones de estudiantes, de acuerdo con el Instituto Nacional para la Evaluación de la Educación (INEE, 2019).

Encerrados en casa, niños, jóvenes y docentes debían seguir/impartir cursos en línea, preparar clases, hacer tareas, presentar exámenes y elaborar reportes (Hernández, 2020), 


\section{CAPÍTULO 10}

y aunque inicialmente se consideró que esto sería por poco tiempo, la realidad es que al menos, hasta el primer semestre del 2021, la educación continuó en línea. Mientras el periodo de confinamiento o distanciamiento social siga, la apuesta de los servicios educativos es la educación a distancia, lo cual para el sistema educativo y la población mexicana implica un gran desafío, ya que México ocupa el sitio 76 de 140 países, en el índice de adopción de tecnologías de la información favorables al desarrollo económico (Morales, 2019).

El Instituto Nacional de Estadística y Geografía (INEgI, 2019) señaló que, en el 2019, la proporción total de hogares mexicanos que contaba con computadora fue de $44.3 \%$, así también, únicamente el 56.4\% de hogares contaban con conexión a Internet y el 75.1\% de la población de seis años en adelante eran usuarios de teléfono móvil, finalmente, señaló que solo el $44.6 \%$ de las familias usaban la computadora como herramienta de apoyo escolar. Aunado a ello, según Fernández et al. (2020), “dos de cada tres hogares en México no cuentan con una conexión de calidad a internet (velocidad suficiente) y sólo en uno de cada tres, la conexión se logra mediante una red fija de alta velocidad" (s.p.).

A partir del confinamiento, la actividad escolar se transformó, se plantearon cambios en la organización pedagógica y en los modos de interactuar con los contenidos, así como en las formas de obtener los conocimientos. Para llevar a cabo la educación a distancia, no solo basta con tener acceso a internet, sino que se requiere mínimamente un ancho de banda para la trasmisión, en gran medida, simétrica (descarga y subida de información) de audio y video (Fernández et al., 2020), sumado a que los docentes deben de contar con habilidades didácticas propias de la modalidad en línea.

En el contexto de la educación superior, los estudiantes universitarios se han visto afectados por la sobrecarga académica, por no contar con un espacio acondicionado para el estudio, por compartir dicho espacio con varios familiares o porque se realizan varias actividades en el espacio en donde este debe realizar sus tareas escolares (La Jornada, 2020). La incertidumbre al proceso de evaluación también ha sido reportada como una constante en esta población (La Vanguardia, 2020). Aunado a ello, se han cancelado las experiencias educativas prácticas tales como asistir a laboratorios, comunidades, entre otras, así como realizar el servicio social o el trabajo de investigación recepcional, lo cual es fundamental en la formación universitaria al ser claves para que el alumno entre en contacto con la realidad del mundo laboral y adquiriera experiencia real (García, 2018). 


\section{CAPÍTULO 10}

Los estudiantes universitarios, en su mayoría, son nativos digitales, utilizan la tecnología como parte de su vida diaria e incluso participan en la evolución de ella (Hayes, 2017), pueden tornarse exigentes al momento de la virtualización de la educación y esperar un óptimo aprovechamiento de las tecnologías en el proceso de enseñanza (individualidad e interactividad), por dar algunos ejemplos. Herrera (2019) observó una proporción alta de estudiantes que utilizaban el teléfono móvil para actividades escolares tales como tomar fotografías de exposiciones, grabar conferencias, así como enviar, recibir y elaborar documentos. Por su parte, Cervantes et al. (2020) observaron que el uso de las tecnologías de la información y la comunicación (TIC) es de gran apoyo para los estudiantes de medicina, ya que les facilita la búsqueda e intercambio de información científica.

Tal como se puede apreciar, las condiciones que el confinamiento impone en el proceso de enseñanza pueden conllevar efectos negativos en el rendimiento académico del estudiante universitario, debido a una serie de obstáculos que le impiden dar lo mejor de sí, lo que, a su vez, puede hacerlo más propenso a alteraciones de la salud. González et al. (2020) evaluaron a 644 estudiantes universitarios y observaron que una tercera parte presentó estrés, alteraciones de sueño y ansiedad. Por su parte, Jeff (2020) señaló que estudiantes de medicina al inicio de la pandemia mostraron síntomas ansiosos, lo cual coincide con el estudio de González et al. (2020), en el que refieren estrés, alteraciones del sueño, disfunción social y depresión especialmente en mujeres y en los estudiantes universitarios más jóvenes. Por su parte, Ozamiz et al. (2020) señalaron que, en España, la población más joven ha mostrado mayores niveles de estrés, depresión y ansiedad.

La incertidumbre hacia lo que ocurrirá a nivel mundial por la pandemia exige un mayor conocimiento de las consecuencias que va dejando y los factores involucrados en ello. Dado las pocas investigaciones que a la fecha han sido reportadas, el objetivo del presente estudio fue analizar la disponibilidad tecnológica, en el proceso de enseñanza y el impacto psicológico en universitarios durante el confinamiento por Covid-19. 


\section{Método}

\section{Participantes}

La técnica de muestreo fue por conveniencia y no aleatoria. A través de los docentes y de distintos directorios universitarios, se localizaron a los participantes y se les invitó a colaborar, enviándoles electrónicamente el enlace de un formulario de Google Forms. Participaron voluntariamente 636 estudiantes universitarios de distintas carreras, de diferentes estados de la república mexicana, $77 \%$ mujeres y $23 \%$ hombres, con una edad promedio de 21 años ( $\mathrm{DT}=0.904$ ), acudían al turno matutino $57 \%$ de los encuestados, el $24 \%$ al turno vespertino y $19 \%$ al turno mixto, el $92 \%$ eran solteros al momento de la recolección de la información, en promedio los encuestados cursaban el cuarto semestre $(\mathrm{DT}=2.3$ ), el promedio escolar de los participantes en una escala de 0 a 100 fue de 91.46 (DT $=4.8)$. El único criterio para participar en el estudio fue que, al momento de recibir el formulario, estuvieran activos en alguna carrera universitaria y que aceptaran el consentimiento informado.

\section{Instrumentos}

Se empleó una ficha de datos elaborada previamente por los investigadores, en ella se recolectó información sociodemográfica (edad, sexo, estado civil, etc.), escolar (turno escolar, semestre cursado, promedio, etc.) y disponibilidad tecnológica (acceso a internet, computadora, celular, tableta, etc.). También se utilizó la lista de cotejo sobre impactos emocionales de la Covid-19, diseñado por el investigador responsable, la cual tiene por objetivo identificar la presencia de síntomas psicológicos relacionados con el entorno educativo. Constó de cinco dimensiones: cognitiva, emocional, conductual, somática e interpersonal. El instrumento tiene 49 reactivos con opciones de respuesta dicotómicas de "Sî" y "No", su interpretación permitió identificar el nivel de afectación psicológica (bajo, medio y alto) global y por dimensión. Para estimar la confiabilidad de la lista de cotejo empleada se llevó a cabo la prueba Kuder-Richarson en una muestra piloto de 100 estudiantes, se obtuvo un índice de 0.93 . 


\section{Diseño y procedimiento}

La presente investigación fue de tipo cuantitativa, transversal y analítica. Los datos se obtuvieron mediante un formulario distribuido y aplicado en línea, utilizando la aplicación Google Forms. Una vez que se localizaron los potenciales participantes a través de los docentes y de los directorios universitarios de cinco instituciones de educación superior (IES), se difundió el enlace a través de Messenger, WhatsApp o e-mail. La encuesta estuvo disponible del 1 de junio al 25 de julio de 2020, dos meses y medio después de la suspensión de actividades escolares presenciales. Los datos se analizaron y procesaron en el paquete estadístico para ciencias sociales (sPss, por sus siglas en inglés: Statistical Package for the Social Sciences versión 23.0).

\section{Consideraciones éticas}

La presente investigación se sujetó a lo establecido en el Código Ético del Psicólogo (Sociedad Mexicana de Psicología, 2007), la Norma Oficial Mexicana Nom-012-ssA3-2012 (Secretaría de Salud, 2013), que establece los criterios para la ejecución de proyectos de investigación para la salud en seres humanos y el Código Helsinki (Asociación Médica Mundial [AMM], 2013), ello a través de un breve consentimiento informado presentado al inicio del formulario y el cual debía ser aceptado obligadamente para poder responder la encuesta, en él se les informó el objetivo de la investigación y la participación voluntaria, así como la garantía del anonimato y confidencialidad de su información.

\section{Resultados}

Respecto a la disponibilidad tecnológica, se observó que el 92\% contaba con internet en casa, en promedio reportaron contar con tres equipos electrónicos en el hogar $(\mathrm{DT}=1.4)$, en la tabla 1 se aprecia que prácticamente todos los estudiantes contaban con al menos computadora y celular. El 62.6\% señaló que compartía los equipos con otros integrantes de la familia. 


\section{Tabla 1}

Porcentaje de participantes y equipo electrónico con el que cuenta

\begin{tabular}{lcc}
\multicolumn{1}{c}{ Tipo de equipo } & Frecuencia & Porcentaje \\
\hline Computadora escritorio/portátil & 55 & $8.6 \%$ \\
Computadora y celular & 279 & $43.9 \%$ \\
Teléfono celular & 63 & $9.9 \%$ \\
Tableta & 2 & $0.3 \%$ \\
Computadora y otro(s) equipo(s) que no son celular & 3 & $0.5 \%$ \\
Computadora, celular y otro(s) equipo(s) & 170 & $26.7 \%$ \\
Celular y tableta & 19 & $3.0 \%$ \\
Computadora, celular, tableta, impresora, escáner, etc. & 45 & $7.1 \%$ \\
\hline
\end{tabular}

Nota. $\mathrm{n}=636$.

Acerca dela percepción que tenían del proceso de enseñanza a partir del confinamiento por Covid-19, el 40.3\% refirió que no logró los objetivos de aprendizaje de las asignaturas que cursó, el $34 \%$ no sabía si logró o no los objetivos y solo el 24.8\% afirmó haber alcanzado los objetivos académicos. En la tabla 2, se describen los aspectos positivos y los negativos percibidos por los universitarios la educación remota emergente por CoviD-19.

Los materiales o recursos complementarios que los estudiantes emplearon para adquirir los aprendizajes fueron textos digitales y páginas web (33.3\%), videos, textos, páginas web, redes sociales y aplicaciones de mensajería instantánea (23.6\%) y, otros, videos y textos digitales (21.1\%), el resto mencionó únicamente alguna de las antes referidas. 


\section{Tabla 2}

\section{Distribución porcentual de las ventajas y desventajas educativas percibidas en la transición por COVID-19}

\section{Ventajas}

Comodidad y/o ahorro económico

$\begin{array}{cc}143 & 22.5 \% \\ 257 & 40.4 \% \\ 137 & 21.5 \% \\ 42 & 6.6 \% \\ 57 & 9.0 \%\end{array}$

Ninguna

\section{Desventajas}

Mala conexión y/o falta de tecnología

Falta de comunicación y retroalimentación del docente y/o exceso de actividades escolares

Muchos distractores

Sensación de soledad 29

Dificultad para aprender

Falta de prácticas escolares

Nota. $\mathrm{n}=636$.

En la tabla 3, se describen las actividades académicas que los estudiantes realizaron con mayor frecuencia, como se puede apreciar, los ensayos y resúmenes fueron las que más se llevaron a cabo. Aunado a lo anterior, el 71.3\% de los participantes afirmó que la dificultad de las actividades escolares aumentó cuando se cambió a la modalidad a distancia. 


\section{Tabla 3}

Frecuencia y porcentaje de las actividades académicas realizadas por los estudiantes universitarios

\section{Actividad escolar}

Ensayos y resúmenes

Lecturas

Mapas

Exposiciones

Reuniones virtuales

Proyectos y/o investigaciones

Ver videos

Cuestionarios y/o exámenes

\section{Frecuencia}

257

88

66

29

67

90

23

16
Porcentaje

40.4

13.8

10.4

4.6

10.5

14.2

3.6

2.5

Nota. $\mathrm{n}=636$.

Respecto a los aspectos psicológicos evaluados, en la tabla 4 se observa que una tercera parte de los participantes presentó alta sintomatología cognitiva, mientras que la mitad de los participantes mostró un nivel medio de síntomas emocionales e interpersonales. Globalmente, se evidencia que la mitad de los estudiantes presentaron un nivel medio de impacto psicológico. Respecto a los síntomas cognitivos más frecuentes reportados fueron pérdida y concentración de la atención, vacíos de memoria, dificultad para organizarse o seguir pasos de actividades cotidianas, disminución de la capacidad de aprendizaje y preocupación sobre la situación familiar. Los síntomas emocionales presentes con mayor frecuencia fueron insatisfacción con el desempeño escolar, ansiedad, tristeza, expresión de frustración por la duración de la situación e incapacidad para relajarse. Por su parte, los síntomas conductuales más frecuentes fueron dificultad para cumplir rutinas de la escuela, quejas sobre la exigencia de los profesores y trastornos del sueño. Los síntomas somáticos presentes con mayor frecuencia fueron dolores de cabeza, así como cansancio físico y debilidad. Finalmente, de la sintomatología del área interpersonal, la más frecuente fue impaciencia con otras personas. 


\section{Tabla 4}

Distribución porcentual de los participantes de acuerdo con su nivel de impacto en cada una de las dimensiones psicológicas

\begin{tabular}{|c|c|c|}
\hline Dimensiones & Nivel & Porcentaje \\
\hline \multirow{3}{*}{ Cognitiva } & Bajo & 19.7 \\
\hline & Medio & 49.2 \\
\hline & Alto & 31.1 \\
\hline \multirow[t]{3}{*}{ Afectiva } & Bajo & 34.0 \\
\hline & Medio & 49.5 \\
\hline & Alto & 16.5 \\
\hline \multirow[t]{3}{*}{ Conductual } & Bajo & 56.6 \\
\hline & Medio & 30.8 \\
\hline & Alto & 12.6 \\
\hline \multirow[t]{3}{*}{ Somática } & Bajo & 57.7 \\
\hline & Medio & 34.1 \\
\hline & Alto & 8.2 \\
\hline \multirow[t]{3}{*}{ Interpersonal } & Bajo & 29.4 \\
\hline & Medio & 50.3 \\
\hline & Alto & 20.3 \\
\hline \multirow[t]{3}{*}{ GLOBAL } & Bajo & 36.0 \\
\hline & Medio & 50.5 \\
\hline & Alto & 13.5 \\
\hline
\end{tabular}

Nota. $\mathrm{n}=636$.

Al llevar a cabo pruebas de diferencia entre grupos, no se observó significancia estadística (prueba t para muestras independientes) al comparar a los participantes que contaban y no contaban con internet con cada una de las dimensiones y el puntaje global de impacto psicológico. Tampoco se observan diferencias de acuerdo con la prueba de análisis de variación (ANOvA, por sus siglas en inglés: Analysis of Variance) entre la cantidad de equipos con los que contaban y las dimensiones y el puntaje global de 
impacto psicológico (tabla 5). Asimismo, el compartir o no el equipo con otros integrantes de la familia mostró diferencias estadísticamente significativas (prueba $t$ para muestras independientes) únicamente con la dimensión somática. La percepción para lograr los objetivos académicos mostró diferencias significativas (prueba t para muestras independientes) con la dimensión interpersonal.

Se encontraron diferencias estadísticamente significativas (prueba ANOvA) respecto al semestre escolar y la dimensión cognitiva, emocional, conductual e impacto psicológico global. Se registran diferencias estadísticamente significativas entre el número de actividades académicas y todas las dimensiones psicológicas consideradas. El tiempo (en días) para recibir retroalimentación por el docente mostró diferencias significativas (prueba ANOva) con el impacto psicológico. Asimismo, la percepción de ser más complejas las actividades mostró diferencias significativas (prueba ANOvA) con todas las dimensiones psicológicas evaluadas.

\section{Tabla 5}

Comparación de la disponibilidad tecnológica, el proceso de enseñanza, el impacto psicológico y sus dimensiones

Variables

\begin{tabular}{|c|c|c|c|c|c|c|}
\hline & $\begin{array}{c}\text { Dimensión } \\
\text { Cognitiva }\end{array}$ & $\begin{array}{l}\text { Dimensión } \\
\text { Emocional }\end{array}$ & $\begin{array}{l}\text { Dimensión } \\
\text { Conductual }\end{array}$ & $\begin{array}{c}\text { Dimensión } \\
\text { Interpersonal }\end{array}$ & $\begin{array}{l}\text { Dimensión } \\
\text { Somática }\end{array}$ & Global \\
\hline \multirow{3}{*}{$\begin{array}{l}\text { Semestre escolar } \\
\text { (prueba ANOva) }\end{array}$} & $\mathrm{F}=7.328$ & $F=6.235$ & $F=5.050$ & $F=.395$ & $F=3.257$ & $F=5.517$ \\
\hline & $\mathrm{gl}=2$ & $\mathrm{gl}=2$ & $\mathrm{gl}=2$ & $\mathrm{gl}=2$ & $\mathrm{gl}=2$ & $\mathrm{gl}=2$ \\
\hline & $\mathrm{p}=0.001$ & $\mathrm{p}=0.002$ & $\mathrm{p}=0.007$ & $\mathrm{p}=0.674$ & $\mathrm{p}=.039$ & $\mathrm{p}=.004$ \\
\hline \multirow{3}{*}{$\begin{array}{l}\text { Cantidad de equipos } \\
\text { disponibles en casa } \\
\text { (prueba ANOvA) }\end{array}$} & $F=.941$ & $\mathrm{~F}=.459$ & $\mathrm{~F}=.365$ & $\mathrm{~F}=.514$ & $F=0.444$ & $\mathrm{~F}=.413$ \\
\hline & $\mathrm{gl}=5$ & $\mathrm{gl}=5$ & $\mathrm{gl}=5$ & $\mathrm{gl}=5$ & $\mathrm{gl}=5$ & $\mathrm{gl}=5$ \\
\hline & $\mathrm{p}=0.454$ & $\mathrm{p}=0.806$ & $\mathrm{p}=0.873$ & $\mathrm{p}=0.766$ & $\mathrm{p}=0.818$ & $\mathrm{p}=0.840$ \\
\hline \multirow{3}{*}{$\begin{array}{l}\text { Número de } \\
\text { actividades } \\
\text { académicas } \\
\text { (prueba ANOVA) }\end{array}$} & $F=2.585$ & $\mathrm{~F}=3.461$ & $F=4.143$ & $F=3.761$ & $F=2.652$ & $\mathrm{~F}=4.238$ \\
\hline & $\mathrm{gl}=14$ & $\mathrm{gl}=14$ & $\mathrm{gl}=14$ & $\mathrm{gl}=14$ & $\mathrm{gl}=14$ & $\mathrm{gl}=14$ \\
\hline & $\mathrm{p}=0.001$ & $\mathrm{p}=.000$ & $\mathrm{p}=.000$ & $\mathrm{p}=.000$ & $\mathrm{p}=.001$ & $\mathrm{p}=.000$ \\
\hline
\end{tabular}




\section{Variables}

\section{Resultados de las pruebas de comparación}

\begin{tabular}{|c|c|c|c|c|c|c|}
\hline & $\begin{array}{c}\text { Dimensión } \\
\text { Cognitiva }\end{array}$ & $\begin{array}{l}\text { Dimensión } \\
\text { Emocional }\end{array}$ & $\begin{array}{l}\text { Dimensión } \\
\text { Conductual }\end{array}$ & $\begin{array}{l}\text { Dimensión } \\
\text { Interpersonal }\end{array}$ & $\begin{array}{l}\text { Dimensión } \\
\text { Somática }\end{array}$ & Global \\
\hline \multirow{3}{*}{$\begin{array}{l}\text { Tiempo (en } \\
\text { días) en recibir } \\
\text { retroalimentación por } \\
\text { el docente } \\
\text { (prueba ANOVA) }\end{array}$} & & & & & $\mathrm{F}=1.462$ & $\mathrm{~F}=1.770$ \\
\hline & $\mathrm{gl}=12$ & $\mathrm{gl}=12$ & $\mathrm{gl}=12$ & $\mathrm{gl}=12$ & $\mathrm{gl}=12$ & $\mathrm{gl}=12$ \\
\hline & $p=0.166$ & $\mathrm{p}=0.288$ & $\mathrm{p}=0.062$ & $\mathrm{p}=0.056$ & $\mathrm{p}=0.134$ & $\mathrm{p}=.050$ \\
\hline \multirow{3}{*}{$\begin{array}{l}\text { Percepción de la } \\
\text { complejidad de las } \\
\text { actividades escolares } \\
\text { (prueba ANOVA) }\end{array}$} & $F=10.086$ & $\mathrm{~F}=4.407$ & $F=6.136$ & $\mathrm{~F}=2.528$ & $\mathrm{~F}=2.541$ & $\mathrm{~F}=6.611$ \\
\hline & $\mathrm{gl}=4$ & $\mathrm{gl}=4$ & $\mathrm{gl}=4$ & $\mathrm{gl}=4$ & $\mathrm{gl}=4$ & $\mathrm{gl}=4$ \\
\hline & $\mathrm{p}=.000$ & $\mathrm{p}=.002$ & $\mathrm{p}=.000$ & $\mathrm{p}=.040$ & $\mathrm{p}=.039$ & $\mathrm{p}=.000$ \\
\hline \multirow{3}{*}{$\begin{array}{l}\text { Disponibilidad de } \\
\text { internet en casa } \\
\text { (prueba t para muestras } \\
\text { independientes) }\end{array}$} & $\mathrm{t}=-.210$ & $\mathrm{t}=.839$ & $\mathrm{t}=.891$ & $t=1.585$ & $t=-.315$ & $t=.621$ \\
\hline & $\mathrm{gl}=634$ & $\mathrm{gl}=634$ & $\mathrm{gl}=634$ & $\mathrm{gl}=634$ & $\mathrm{gl}=634$ & $\mathrm{gl}=634$ \\
\hline & $\mathrm{p}=.833$ & $\mathrm{p}=.402$ & $\mathrm{p}=.373$ & $\mathrm{p}=.113$ & $\mathrm{p}=.753$ & $\mathrm{p}=.535$ \\
\hline \multirow{3}{*}{$\begin{array}{l}\text { Percepción de } \\
\text { lograr los objetivos } \\
\text { académicos } \\
\text { (prueba t para muestras } \\
\text { independientes) }\end{array}$} & $\mathrm{t}=-.075$ & $\mathrm{t}=-.053$ & $t=.961$ & $\mathrm{t}=2.291$ & $t=-0.276$ & $\mathrm{t}=.499$ \\
\hline & $\mathrm{gl}=254$ & $\mathrm{gl}=254$ & $\mathrm{gl}=254$ & $\mathrm{gl}=254$ & $\mathrm{gl}=254$ & $\mathrm{gl}=254$ \\
\hline & $\mathrm{p}=.940$ & $\mathrm{p}=.958$ & $\mathrm{p}=.338$ & $\mathrm{p}=0.023$ & $\mathrm{p}=0.783$ & $\mathrm{p}=.618$ \\
\hline \multirow{3}{*}{$\begin{array}{l}\text { Compartir el equipo } \\
\text { con otros integrantes } \\
\text { de la familia } \\
\text { (prueba t para muestras } \\
\text { independientes) }\end{array}$} & $\mathrm{t}=.151$ & $\mathrm{t}=.905$ & $\mathrm{t}=1.492$ & $\mathrm{t}=1.257$ & $\mathrm{t}=2.717$ & $\mathrm{t}=1.577$ \\
\hline & $\mathrm{gl}=634$ & $\mathrm{gl}=634$ & $\mathrm{gl}=634$ & $\mathrm{gl}=634$ & $\mathrm{gl}=634$ & $\mathrm{gl}=634$ \\
\hline & $\mathrm{p}=.880$ & $\mathrm{p}=.366$ & $\mathrm{p}=.136$ & $\mathrm{p}=.209$ & $\mathrm{p}=.007$ & $\mathrm{p}=.115$ \\
\hline
\end{tabular}

Nota. $\mathrm{n}=636 ; \mathrm{p}=>0.005$.

\section{Discusión}

En la muestra estudiada se encontró que prácticamente todos los participantes tenían disponibilidad tecnológica, al menos de acceso a internet y un teléfono móvil o computadora, tal parece que la disponibilidad tecnológica no impacta en la dimensión psicológica, aunque el hecho de compartir el equipo con sus integrantes de la familia puede favorecer la presencia de malestares somáticos, en este sentido Sanz et al. (1998) afirmaron que en el entorno familiar en donde se hace presente la somatización, los sistemas de afrontamiento a situaciones de estrés o de dificultades suelen ser deficientes, reduciéndose a conductas anómalas de enfermedad ante las demandas del entorno.

Respecto a las ventajas percibidas por los estudiantes ante la educación a distancia se observó la economía de tiempo y de dinero como la más importante, estos aspectos 


\section{CAPÍTULO 10}

referidos por los estudiantes universitarios coinciden con lo que diversos autores afirman como ventaja de la educación a distancia, por ejemplo, Roldán y Atehortúa (2016) señalaron que el modelo educativo a distancia satisface necesidades de aquellos que tienen inconvenientes para acceder a la educación presencial, que en estos momentos resulta ser la pandemia, pero también ofrece el servicio educativo a aquellos con dificultades económicas, de distancia y de tiempo.

Pese a estas ventajas, para que este sistema educativo a distancia funcione es necesario modificar los papeles de los actores educativos, ya que los elementos tradicionales (aula y docente) pasan a un segundo plano. A la luz de los resultados esto no sucedió, ya que las actividades escolares se redujeron a la realización de lecturas, resúmenes o mapas mentales, desaprovechando la diversidad de maneras que la virtualidad ofrece tales como imágenes, videos, sonidos y realidad virtual.

La falta de comunicación, retroalimentación y evaluación docente percibida por los estudiantes como la principal desventaja, también se contrapone con los requerimientos de calidad de la educación a distancia, ya que en dicha modalidad se deben establecer criterios de valoración específicos, exhaustivos y sistemáticos, en donde la evaluación debe ser permanente y orientada a mejorar cada una de las acciones involucradas. Hernández y Buitrón (2017) afirmaron que el docente debe de garantizar la comunicación y la interacción con los estudiantes y el entorno tecnológico. Esta falta de comunicación y de claridad en la evaluación genera incertidumbre y, por consecuencia, malestares físicos y psicológicos (La Vanguardia, 2020).

La sobrecarga de actividades escolares, reportada por buena parte de los estudiantes, y la dificultad para realizarlas fueron las variables que se relacionaron en mayor medida con la presencia de síntomas psicológicos. El primer aspecto se considera, puede ser entendido a partir de la falta de planeación de las actividades educativas con la poca orientación al logro de competencias y a la ausencia de actividades participativas y reflexivas (Lechuga et al., 2014), ello claro, por la educación a distancia emergente que se tuvo que implementar.

Respecto a la percepción de que las actividades escolares se tornaron más complejas en la modalidad a distancia y la poca certeza de los aprendizajes obtenidos deja entrever la dificultad de los estudiantes de pensar su proceso de aprendizaje como posible ante la separación física con el profesor. Según Gottardi (2015), en la educación a distancia 
los estudiantes tienen que ser disciplinados, establecer un horario fijo de estudio y estar motivados, deben ser capaces de acceder a los recursos materiales, tecnológicos y pedagógicos con los que apoyen sus estudios, asimismo, deben tener una adecuada capacidad comunicativa y de colaboración. Todo ello, les permitirá lograr la autonomía que necesitan para aprender, de tal forma que asuman el compromiso y la responsabilidad de su propia educación. Los resultados de la presente investigación parecen indicar todo lo contrario, ello debido posiblemente a una historia muy arraigada de exposición de enfoques lineales al aprendizaje o también llamados tradicionales, caracterizados por una estructura rígida que se contrapone con los accesos interactivos y sin secuencias determinadas que los medios digitales permiten (Barragán et al., 2009).

La presencia de sintomatología psicológica coincide con otras investigaciones (González et al., 2020; Jeff, 2020; Ozamiz et al., 2020), las cuales destacan la presencia de ansiedad, estrés y trastornos de sueño. En este estudio, encontramos mayor alteración en la dimensión cognitiva, reflejada principalmente en la pérdida de concentración, olvidos y dificultad para organizarse, los participantes informaron sentirse sobrepasados, aunado a los distractores del propio hogar que les dificultaba realizar sus actividades escolares. Granados et al. (2016) consideraron que la atención favorece el desempeño académico de los alumnos y disminuye la ansiedad en el proceso de aprendizaje, de tal forma que cuando esta se ve afectada es de esperar que se vuelva la antesala de problemas o alteraciones psíquicos más complejos.

Tal como en otras investigaciones, la dimensión emocional también indicó alteraciones en la mayoría de los participantes, sobre todo, con la presencia de síntomas de ansiedad, depresión y estrés. En torno a estos aspectos, hay diversidad de estudios llevados a cabo (Arrieta et al., 2013; Caballero et al., 2015; Cardona et al., 2015), por ello, la oportunidad de identificar los factores o variables derivados de la pandemia y de la educación a distancia emergente suscitada en esta época, permite entender las situaciones de riesgo que afectan el bienestar psicológico de los estudiantes universitarios, que en este caso están centrados en la sobrecarga de actividades escolares, la falta de comunicación, retroalimentación y evaluación por parte del docente, así como la incertidumbre de los objetivos alcanzados y la percepción de una mayor exigencia escolar, lo cual nos aproxima a la comprensión de este nuevo fenómeno, de tal forma que el siguiente paso es profundizar en las variables que resultaron relevantes. 


\section{CAPÍTULO 10}

Así también, el diseño e implementación de propuestas de intervenciones psicoeducativas centradas en el fortalecimiento de habilidades de solución de problemas, de comunicación asertiva, de manejo emocional y de planeación del tiempo dirigidas a los estudiantes resultará relevante para hacerle frente a las exigencias académicas que "la nueva normalidad" conlleva, con el fin de vigilar y cuidar la salud mental de los alumnos y prevenir un agravamiento de los síntomas identificados en la presente investigación. Por último, es importante señalar que la calidad educativa y su óptima adaptabilidad a situaciones de crisis mundial no solo es responsabilidad del docente o del alumno, sino que, como lo señala Arriagada (2020), los liderazgos pedagógicos serán capaces de establecer políticas educacionales que se apliquen en el corto y mediano plazo.

\section{Conclusiones}

En general, apreciamos que la educación a distancia implementada emergentemente en los tiempos de pandemia consistió en trasladar los métodos educativos tradicionales a medios virtuales, los cuales afectaron significativamente el bienestar psicológico de los estudiantes universitarios. Nuestros resultados también evidenciaron que la educación en México, sea presencial o en línea, enfatiza la mera transmisión de contenidos y no la reflexión creativa. El problema de la educación a distancia va más allá de la disponibilidad tecnológica, es decir, la interacción docente-alumno y la adecuada planeación didáctica centrada en el aprendizaje autónomo son prioritarios para el logro de los objetivos académicos, la motivación y el bienestar escolar. Se hace evidente la necesidad de capacitación docente para el adecuado manejo de entornos virtuales de aprendizaje, pero también resulta relevante llevar a cabo estudios sobre el impacto psicológico que esta exigencia educativa ha tenido en los docentes y la percepción que tienen acerca de esta transición educativa, ya que como lo señala Martínez (2020), el docente se ha enfrentado a desconciertos y decepciones producto de las exigencias administrativas, la falta de capacitación y actualización, así como la apatía, la despreocupación y las quejas constantes por parte de los estudiantes y sus padres, asimismo, su entorno privado se ha expuesto a un sinfín de personas, es decir, el docente se ha visto obligado a combinar su espacio privado y su espacio laboral e incluso ha tenido que utilizar sus recursos personales para cumplir con las exigencias laborales. Finalmente, es importante destacar 


\section{CAPÍTULO 10}

que esta investigación se realizó virtualmente y a través de un método de muestreo por conveniencia no aleatorio, lo que podría suponer que quedaron fuera los estudiantes con poca disponibilidad tecnológica, por lo que ampliar la técnica muestral para un siguiente estudio resultará relevante. 


\section{CAPÍTULO 10}

\section{Referencias}

Arriagada, P. (2020). Pandemia Covid-19: educación a distancia o las distancias en la educación. Revista Internacional de Educación para la Justicia Social, 9(3).

Arrieta, K., Díaz, S., \& González, F. (2015). Síntomas de depresión, ansiedad y estrés en estudiantes de odontología: prevalencia y factores relacionados. Revista Colombiana de Psiquiatría, 42(2), 173-181.

Asociación Médica Mundial. (2013). Declaración de Helsinki de la AMM - Principios éticos para las investigaciones médicas en seres humanos. https://www.wma.net/ es/policies-post/declaracion-de-helsinki-de-la-amm-principios-eticos-para-lasinvestigaciones-medicas-en-seres-humanos/

Barragán, A., Aguiar, M., Cerpa, G., \& Núñez, H. (2009). Relaciones docente-alumno y rendimiento académico: Un caso de Centro Universitario de Ciencias Exactas e ingenierías de la Universidad de Guadalajara. Sinéctica, 33, 1-15.

Caballero, C., González, G., \& Palacio, J. (2015). Relación del burnout y el engagement con depresión, ansiedad y rendimiento académico en estudiantes universitarios. Revista Cientifica Salud Uninorte, 31(1), 59-69.

Cardona, A., Pérez, D., Rivera, O., Gómez, M., \& Reyes, A. (2015). Prevalencia de ansiedad en estudiantes universitarios. Diversitas: Perspectivas en Psicología, 11(1), 79-89.

Cervantes, M., Peña, A., \& Ramos, A. (2020). Uso de las tecnologías de la información y comunicación como herramienta de apoyo en el aprendizaje de los estudiantes de medicina. Revista CienciaUAT, 15(1), 162-171.

De la Serna, J. (2020). Aspectos psicológicos del Covid. Editorial Tektime. https://www. researchgate.net/publication/340536973_Aspectos_Psicologicos_del_COVID-19

Fernández, M., Hernández, D., Nolasco, R., de-la-Rosa, R., \& Herrera, L. N. (2020). Lecciones del Covid-19 para el sistema educativo mexicano. http://paulfmm.com/ieec/covid.html

García, C. (2018). Modelo de estrategia para las prácticas profesionales en ingeniería (MEPPI) en la Universidad Nuevo León, México. Revista Cubana de Educación Superior, 37(3).

González, N., Tejeda, A., Espinosa, C., \& Ontiveros, Z. (2020). Impacto psicológico en estudiantes universitarios mexicanos por confinamiento durante la pandemia por Covid-19. Preprints. https://doi.org/10.1590/SciELOPreprints.756 


\section{CAPÍTULO 10}

Gottardi, L. (2015). Autonomía en el aprendizaje en la educación a distancia: competencias a desarrollar por estudiantes. Revista Brasileira de Aprendizagem Aberta e a Distância, 14(5).

Granados, D., Figueroa, S., \& Velásquez, A. (2016). Dificultades de atención y competencias de investigación en estudiantes universitarios de psicología. Enseñanza e Investigación en Psicología, 21(2), 31-140.

Hayes, H. (2017). Curriculum XXI: Lo esencial de la Educación para un mundoen cambio. Narcea Ediciones. http://reined.webs.uvigo.es/index.php/reined/article/download/248/291/

Hernández, R. (2020). Coronavirus y educación. https://www.lahaine.org/mm_ss_mundo. $\mathrm{php} /$ coronavirus-y-educacion

Hernández, J., \& Buitrón, H. (2017). Evaluación de los entornos virtuales de aprendizaje y enseñanza. Boletín Científico de la Escuela Superior Atotonilco de Tula, 4(7). https://www. uaeh.edu.mx/scige/boletin/atotonilco/n7/r2.html

Herrera, B. (2019). Disponibilidad, uso y apropiación de las tecnologías por estudiantes universitarios en México: perspectivas para una incorporación innovadora. Revista Iberoamericana de Educación, 48(6), 1-9.

Instituto Nacional de Estadística y Geografía. (2019). Disponibilidad y uso de TIC. https:// www.inegi.org.mx/temas/ticshogares/

Instituto Nacional para la Evaluación de la Educación. (2019). Principales cifras nacionales. Educación básica y media superior inicio del ciclo escolar 2016-2017. INEE. https://www. inee.edu.mx/wp-content/uploads/2019/01/P2M110.pdf

Jeff, V. (2020). Consideraciones sobre la salud mental en la pandemia de Covid-19. Revista Peruana de Medicina Experimental y Salud Pública, 37.

La Jornada. (2020). Sobrecarga académica, foco de tensión de universitarios en confinamiento. https://www.jornada.com.mx/ultimas/sociedad/2020/05/18/sobrecarga-academicaprincipal-estresor-de-universitarios-en-confinamiento-5561.html

La Vanguardia. (2020). Estudio confirma la preocupación de docentes ante el desigual fin de curso. https://www.lavanguardia.com/vida/20200506/481003377891/estudio-confirmala-preocupacion-de-docentes-ante-el-desigual-fin-de-curso.html

Lechuga, M., Fernández, A., Ríos, F., \& Fernández, M. (2014). Utilización de entornos virtuales educativos y recursos educativos abiertos (OpenCourseWare) en cursos de ingeniería química de la Universidad de Granada, España. Formación Universitaria, 7(4), 3-14. 


\section{CAPÍTULO 10}

Martínez, G. I. (2020). Los docentes de educación básica en México ante el COVID-19 ¿La emergencia como principio de innovación docente? http://www.comie.org.mx/v5/ sitio/2020/05/26/los-docentes-de-educacion-basica-en-mexico-ante-el-covid-19-laemergencia-como-principio-de-innovacion-docente/

Morales, Y. (2019). México, a media tabla global en adopción de TIC: WEF. ElEconomista. https:// www.eleconomista.com.mx/empresas/Mexico-a-media-tabla-global-en-adopcion-deTIC-WEF-20190106-0065.html

Organización Mundial de la Salud. (2020a). Cronología de la respuesta de la oms a la Covid-19. https://www.who.int/es/news-room/detail/29-06-2020-covidtimeline

Organización Mundial de la Salud. (2020b). Declaración de la oms tras superarse los 100,00 casos de COVID-19. https://www.who.int/es/news-room/ detail/07-03-2020-who-statement-on-cases-of-covid-19-surpassing-100-000

Ozamiz, N., Dosil, M., Picaza, M., \& Idoiaga, N. (2020). Niveles de estrés, ansiedad y depresión en la primera fase del brote del Covid-19 en una muestra recogida en el norte de España. Prepints.

Roldán, J., \& Atehortúa, R. (2016). La educación virtual un campo para el análisis: ventajas $y$ desventajas. http://aprendeenlinea.udea.edu.co/lms/moodle/pluginfile.php/277433/ mod_forum/attachment/235049/Trabajo\%20final.pdf

Sanz, C., Arévalo de Miguel, J., \& García, C. (1998). Somatización y familia: intervención del médico de atención primaria. Atención Primaria, 21(8), 545-552.

Secretaría de la Función Pública. (2020). Acuerdo por el que se suspenden plazos y términos legales, así como actividades en la Secretaría de la Función Pública, con las exclusiones que en el mismo se indican, como medida de prevención y combate de la propagación de la enfermedad generada por el coronavirus SARs-Cov2 (COvid-19). Diario Oficial de la Federación, DOF 17-04-2020. http://dof.gob.mx/nota_detalle. php? codigo $=5591876 \&$ fecha $=17 / 04 / 2020$

Secretaría de Salud. (2013). Norma Oficial Mexicana Nom-012-ssA3-2012, Que establece los criterios para la ejecución de proyectos de investigación para la salud en seres humanos. Diario Oficial de la Federación, DOF 04-01-2013. http://dof.gob.mx/nota_detalle. php? codigo $=5284148 \&$ fecha $=04 / 01 / 2013$

Sociedad Mexicana de Psicología. (2007). Código Ético del psicólogo. Editorial Trillas. 
Qartuppi, S. de R.L. de C.V. está inscrita de forma definitiva

en el Registro Nacional de Instituciones y Empresas Científicas y Tecnológicas (RENIECYT) con el número 1600052.

Qartuppi, S. de R.L. de C.V. es miembro activo

de la Cámara Nacional de la Industria Editorial Mexicana (CANIEM)

con número de registro 3751 .

\section{INVESTIGACIONES EN EDUCACIÓN SUPERIOR}

Implicaciones y desafíos del estudiante universitario

Esta obra se terminó de producir en octubre de 2021

Su edición y diseño estuvieron a cargo de:

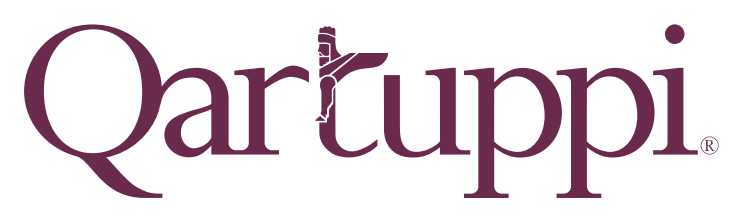

Qartuppi, S. de R.L. de C.V.

http://www.qartuppi.com 


\section{INVESTIGACIONES EN EDUCACIÓN SUPERIOR}

\section{Implicaciones y desafíos del estudiante universitario}

Este libro presenta hallazgos en torno a los retos de los contextos universitarios y al impacto que estos tienen en el alumno. A lo largo de los capítulos se describen estudios científicos desde distintos enfoques y distintas metodologías que nos aproximan a la complejidad universitaria desde la perspectiva del estudiante universitario. Se conforma de una serie de colaboraciones de investigadores y estudiantes adscritos a distintas Instituciones de Educación Superior de México que tiene un interés en común: el contexto universitario y sus implicaciones educativas y de salud. 